


\section{Navajo Generating Station \& Federal Resource Planning \\ Volume 1: Sectoral, Technical, and Economic Trends}

David Hurlbut, Scott Haase, Clayton Barrows, Lori Bird, Greg Brinkman, Jeff Cook, Megan Day, Victor Diakov, Elaine Hale, David Keyser, Anthony Lopez, Trieu Mai, Joyce McLaren, Emerson Reiter, Brady Stoll, and Tian Tian

National Renewable Energy Laboratory

Harvey Cutler

Colorado State University

Dominique Bain and Tom Acker

Northern Arizona University 


\section{NOTICE}

This report was prepared as an account of work sponsored by an agency of the United States government. Neither the United States government nor any agency thereof, nor any of their employees, makes any warranty, express or implied, or assumes any legal liability or responsibility for the accuracy, completeness, or usefulness of any information, apparatus, product, or process disclosed, or represents that its use would not infringe privately owned rights. Reference herein to any specific commercial product, process, or service by trade name, trademark, manufacturer, or otherwise does not necessarily constitute or imply its endorsement, recommendation, or favoring by the United States government or any agency thereof. The views and opinions of authors expressed herein do not necessarily state or reflect those of the United States government or any agency thereof.

This report is available at no cost from the National Renewable Energy Laboratory (NREL) at www.nrel.gov/publications.

Available electronically at SciTech Connect http:/www.osti.gov/scitech Available for a processing fee to U.S. Department of Energy and its contractors, in paper, from:

\section{U.S. Department of Energy}

Office of Scientific and Technical Information

P.O. Box 62

Oak Ridge, TN 37831-0062

OSTI http://www.osti.gov

Phone: 865.576 .8401

Fax: 865.576 .5728

Email: reports@osti.gov

Available for sale to the public, in paper, from:

\section{U.S. Department of Commerce}

National Technical Information Service

5301 Shawnee Road

Alexandria, VA 22312

NTIS http://www.ntis.gov

Phone: 800.553 .6847 or 703.605 .6000

Fax: 703.605 .6900

Email: orders@ntis.gov 


\section{Acknowledgments}

The authors would like to thank the following external reviewers for their valuable comments on this report: Dan Bunk, Russ Callejo, Chau Nguyen, Ron Smith, and Matt Stemmer (U.S. Bureau of Reclamation); Tyler Hodge (U.S. Energy Information Administration); and energy consultant Doug Larson. We also thank NREL reviewers Elizabeth Doris, Jeffrey Logan, Michael Milligan, Robin Newmark, and Gian Porro. This report was edited by Karin Haas and Karen Peterson. Support on graphics design was provided by Joshua Bauer and Alfred Hicks of NREL, and Ignacio Losada Carreno and Roberto Puente Aranda of Northern Arizona University. This report was produced under direction of the U.S. Bureau of Reclamation by the National Renewable Energy Laboratory (NREL) under Interagency Agreement R14PG00077 with the U.S. Department of the Interior. 


\section{Foreword}

The Navajo Generating Station \& Federal Resource Planning report is part of a special collaboration between the U.S. Bureau of Reclamation and the National Renewable Energy Laboratory (NREL) on issues affecting the Navajo Generating Station (NGS). On January 4, 2013, the Department of the Interior, Department of Energy, and the Environmental Protection Agency formed a working group and released a Joint Federal Agency Statement that committed to a broad set of long-term goals for "producing clean, affordable, and reliable power, affordable and sustainable water supplies, and sustainable economic development, while minimizing negative impacts on those who currently obtain significant benefits from NGS, including tribal nations." A key action item was to

[w]ork with stakeholders to develop a Navajo Generating Station roadmap. The NGS Working Group intends to work with stakeholders, including NGS plant owners, Navajo Nation, Hopi Tribe, CAP, Gila River Indian Community and other Arizona Indian tribes who receive water from CAP, non-Indian CAP water users, and environmental and community groups, to develop a roadmap for accomplishing the goals described above. The roadmap should include action recommendations and initial steps to begin implementing key recommendations. It should be consistent with Federal trust responsibilities to federally recognized Indian tribes in the region. ${ }^{1}$

On July 25, 2013, an agreement was reached among a Technical Working Group (TWG) that comprised key stakeholders organized to address various issues associated with continued operations of NGS. The TWG Agreement contained a number of federal commitments including the completion of a comprehensive study by NREL to identify low-emitting energy alternatives to replace the federal shares in NGS.

The Department of Interior delegated Reclamation the responsibility to implement the TWG Agreement commitments. Reclamation initiated a stakeholder process to scope the NREL study, develop funding agreements to provide clean energy development technical assistance with several Arizona NGS affected tribes, and contract the services of NREL.

Volume One: Sectoral, Technical, and Economic Trends is the first of two volumes of the NREL Study. Reclamation acknowledges the invaluable contribution of the authors and co-authors assembled to complete this volume. The NGS roadmap and associated federal decisions will be substantially informed by this effort.

Kevin Black, Sr.

Energy Development Program Manager

Navajo Generating Station Post-2019 Operations Project

U.S. Bureau of Reclamation

\footnotetext{
${ }^{1}$ Department of the Interior, Department of Energy, and Environmental Protection Agency, "Joint Federal Agency Statement Regarding Navajo Generating Station,” January 4, 2013, 2.
} 


\section{Acronyms and Abbreviations}

$\mathrm{AC}$

ACS-PUMS

APS

ATB

AWSA

BA

BEA

BSER

Btu

CAISO

CAP

CEC

CGE

$\mathrm{CO}_{2}$

$\mathrm{CPP}$

CPUC

CRSS

CSP

DC

DOE

DOI

EIA

EIM

EIS

EPA

EPE

FIP

GHG

GW

GWh

IOU

IRP

ITC

$\mathrm{kV}$

$\mathrm{kW}$

kWh

LADWP

LBNL

LCOE

LMP

maf

mmBtu

MW

MWh alternating current

U.S. Census Bureau's American Community Survey Public Use

Microdata Sample

Arizona Public Service Company

Annual Technology Baseline

Arizona Water Settlements Act

balancing authority

U.S. Bureau of Economic Analysis

best system of emission reduction

British thermal unit

California Independent System Operator

Central Arizona Project

California Energy Commission

computable general equilibrium (model)

carbon dioxide

Clean Power Plan

California Public Utilities Commission

Colorado River Simulation System

concentrating solar power

direct current

U.S. Department of Energy

U.S. Department of the Interior

U.S. Energy Information Administration

energy imbalance market

environmental impact statement

U.S. Environmental Protection Agency

El Paso Electric

federal implementation plan

greenhouse gas

gigawatt

gigawatt-hour

investor-owned utility

integrated resource plan

investment tax credit

kilovolt

kilowatt

kilowatt-hour

Los Angeles Department of Water and Power

Lawrence Berkeley National Laboratory

levelized cost of energy

locational marginal price

million acre-feet

million British thermal units

megawatt

megawatt-hour 
NEMS

NEPA

NERC

NGCC

NGCT

NGS

$\mathrm{NO}_{\mathrm{x}}$

NREL

O\&M

PG\&E

PNM

PPA

PTC

PV

REC

RPM

RPS

RTO

SAM

SCE

SCED

SCR

SDG\&E

SMUD

SRP

TEP

TEPPC

TRG

TW

TWG

TWh

WAPA

WECC

WGA

WWSIS
National Energy Modeling System

National Environmental Policy Act

North American Electric Reliability Corporation

natural gas combined cycle

natural gas combustion turbine

Navajo Generating Station

nitrogen oxide

National Renewable Energy Laboratory

operations and maintenance

Pacific Gas \& Electric

Public Service Company of New Mexico

power purchase agreement

production tax credit

photovoltaic

renewable energy credit

Resource Planning Model

renewable portfolio standard

regional transmission organization

System Advisor Model

Southern California Edison

security-constrained economic dispatch

selective catalytic reduction

San Diego Gas \& Electric

Sacramento Municipal Utility District

Salt River Project

Tucson Electric Power

Transmission Expansions Planning and Policy Committee (Western

Electricity Coordinating Council)

Techno-Resource Group

terawatt

Technical Working Group

terawatt-hour

Western Area Power Administration

Western Electricity Coordinating Council

Western Governors' Association

Western Wind and Solar Integration Study 


\section{Executive Summary}

This study for the U.S. Bureau of Reclamation examines conditions in the electricity sector that are likely to affect federal decisions with respect to Navajo Generating Station (NGS), the largest coal-fired power plant operating in the western United States. The federal government owns $24.3 \%$ of the 2.25 -gigawatt plant, which amounts to 547 megawatts (MW) of capacity. ${ }^{2}$

While each of the plant's four utility partners includes its share of NGS in its individual integrated resource plan (IRP), neither Reclamation nor the U.S. Department of the Interior (DOI) have conducted comparable planning for the federal share of the plant and the load it supplies. The purpose of this study is to provide Reclamation and DOI with an objective analysis similar to that contained in an IRP, but independent of the utility partners' IRPs. By focusing on the unique public interests that depend on the federal share of NGS, this baseline study can help the federal government develop a road map for meeting all of its goals with respect to water delivery, clean energy, emission reduction, and economic development.

There is no recommendation for action in this report. Rather, its aim is to provide a credible, thorough description of baseline conditions that might affect federal decisions regarding NGS. It describes facts and trends embedded in current data, but there are no conclusions about how Reclamation or DOI should respond to the trends. The interdependencies among the many sectoral trends and federal goals are complex, and the aim of this study is to provide a foundation from which options can be tested in a deliberate manner.

The next volume of this study will examine a number of plausible clean energy options - or "glide paths" - in greater depth. A glide path refers to a staged transition from NGS to other sources of electricity that have fewer emissions. The glide path approach has additional flexibility to minimize economic disruption to operations of the Central Arizona Project (CAP), Arizona Indian tribes, and other interests that currently depend on the federal government's share of NGS.

This study begins with an analysis of costs that are likely to affect the economics of any NGS transition strategy, including the capital cost of renewable technologies, natural gas prices, and wholesale power prices. The study then reviews important structural changes that are happening throughout the electricity sector, including responses to public policy. The cost analysis and sectoral trends then feed into two types of power system models: one simulating trends that influence decisions to add new generating capacity; and one simulating economic dispatch of the Western grid.

The report concludes with two companion analyses. One applies a computable general equilibrium model to evaluate the macroeconomic impact of reducing NGS from its current three-unit operation to two-unit operation, currently planned for 2019. The other special analysis examines the potential impact of climate change - specifically, how extreme drought might affect power sector operations in the Southwest, and what these impacts might mean for federal decisions regarding NGS.

\footnotetext{
${ }^{2}$ Four electric utilities-Salt River Project, Arizona Public Service Company, NV Energy, and Tucson Electric Power (TEP) — own the remaining shares of the 2.25-gigawatt (GW) plant.
} 


\section{Cost Trends}

\section{Economic Competitiveness of NGS}

Electricity produced at NGS is currently more expensive than electricity purchased on the wholesale spot market. Price trends examined in this analysis suggest a turnaround might be years away, especially if natural gas prices remain low.

Enhanced recovery methods have helped to keep natural gas supplies high and prices low since 2015. ${ }^{3}$ This has affected wholesale power prices throughout the West. Peak-period electricity prices at the Mead Hub, the electricity trading point nearest to NGS, averaged around $\$ 32$ per megawatt-hour (MWh) for 2015, which was 33\% below the average for $2014 .{ }^{4}$ Data for the first half of 2016 indicated a further $22 \%$ slide compared to the first half of 2015. In comparison, the all-in cost of NGS energy for CAP pumping is currently about $\$ 38 / \mathrm{MWh}$, based on budget projections by the Central Arizona Water Conservation District. ${ }^{5}$

Even if all other components of this cost remain unchanged after adjusting for inflation, two future hikes in NGS costs are likely: an increase of nearly \$3/MWh after 2019, when a new NGS site lease agreement with the Navajo Nation is scheduled to take effect, and an estimated $\$ 9.84 / \mathrm{MWh}$ increase in 2030 related to the installation of new $\mathrm{NO}_{\mathrm{x}}$ controls. ${ }^{6}$ Allowing for increasing coal prices consistent with modeling forecasts by the Energy Information Administration (EIA), these two changes would bring NGS costs to between $\$ 39 / \mathrm{MWh}$ and $\$ 41 / \mathrm{MWh}$ in 2020 , and between $\$ 48 / \mathrm{MWh}$ and $\$ 53 / \mathrm{MWh}$ in 2030 (all in 2015 dollars). The midpoints of the NGS cost projections are shown by the black line in Figure ES-1.

The shaded area in Figure ES-1 shows the plausible range of future peak-period wholesale power prices at the Mead Hub. The lower bound of the range assumes that natural gas prices continue to be low, using EIA forecasts that assume high levels of oil and natural gas recovery. The upper bound assumes higher natural gas prices as modeled in EIA's reference case as of late 2016. The projections suggest that NGS could remain more expensive than power purchased at market prices - at least until 2018 if natural gas prices increase and possibly until 2025 if prices for natural gas and wholesale power remain low.

\footnotetext{
${ }^{3}$ EIA, "Use of natural gas for power generation hits record highs," news release, August 4, 2016, http://www.eia.gov/naturalgas/weekly/archive/2016/08 04/index.cfm.

${ }^{4}$ At the California Independent System Operator's MEADS_2_N101 node, annual average price for peak-hour deliveries (day-ahead purchases). Peak hours are 6 a.m. to 9 p.m. Monday through Saturday, except for holidays. Prices during off-peak hours are typically $\$ 3 / \mathrm{MWh}$ to $\$ 4 / \mathrm{MWh}$ lower than peak period prices for the same week, based on data for 2015 and the first half of 2016. SNL Energy, database of wholesale power prices.

${ }^{5}$ CAP, 2016-17 Biennial Budget (Phoenix: Central Arizona Project, 2015), http://www.capaz.com/documents/departments/finance/2016 2017-Biennial-Approved-Budget.pdf. As operator of CAP, the Central Arizona Water Conservation District is the largest consumer of power from the federal share of NGS.

${ }^{6}$ Because of the time required to design and build the selective catalytic reduction (SCR) modifications, we assume SCR-related costs begin in 2026 and gradually increase to $\$ 9.84 / \mathrm{MWh}$ in 2030.
} 


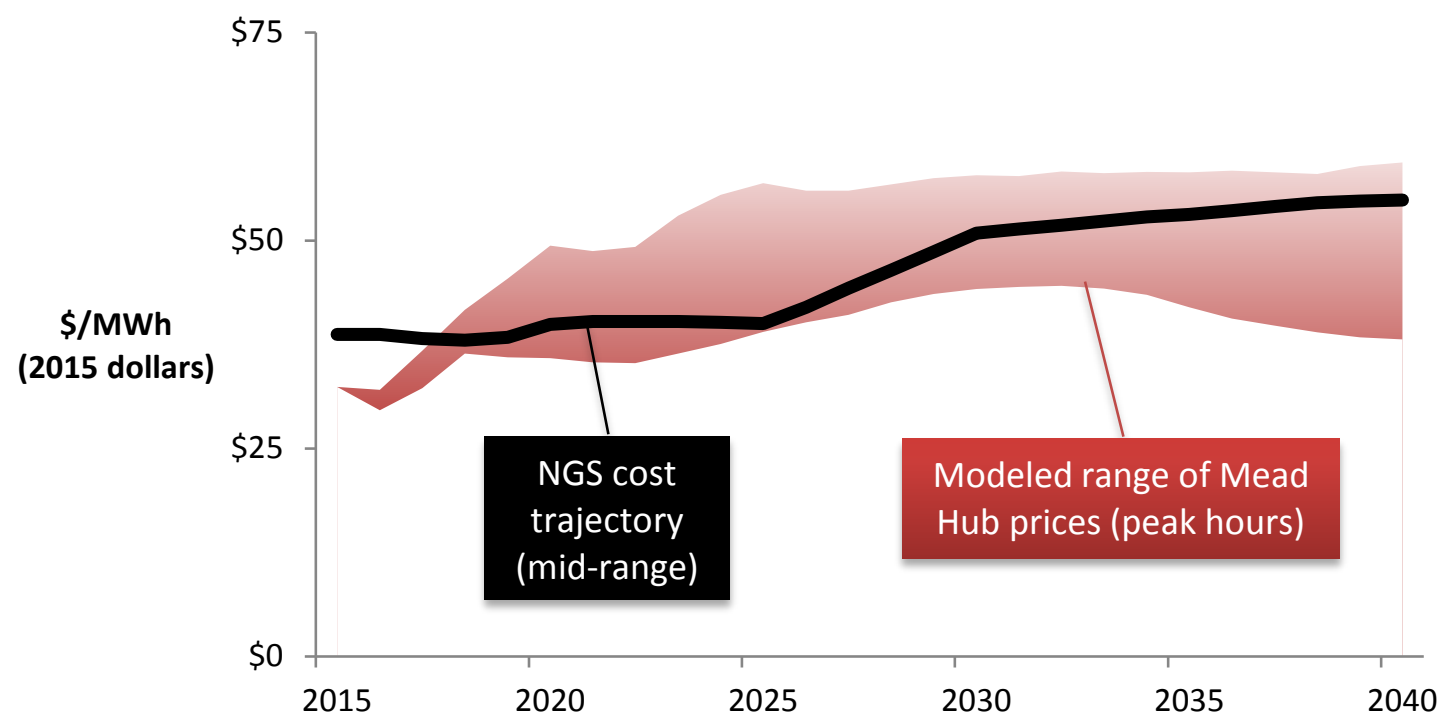

Figure ES-1. Projections for NGS generation costs, Mead Hub peak power prices

These trends mean that the ability to sell surplus power from the federal share of NGS on the wholesale market is uncertain and will likely remain so for a period of time that will be determined by natural gas prices. ${ }^{7}$

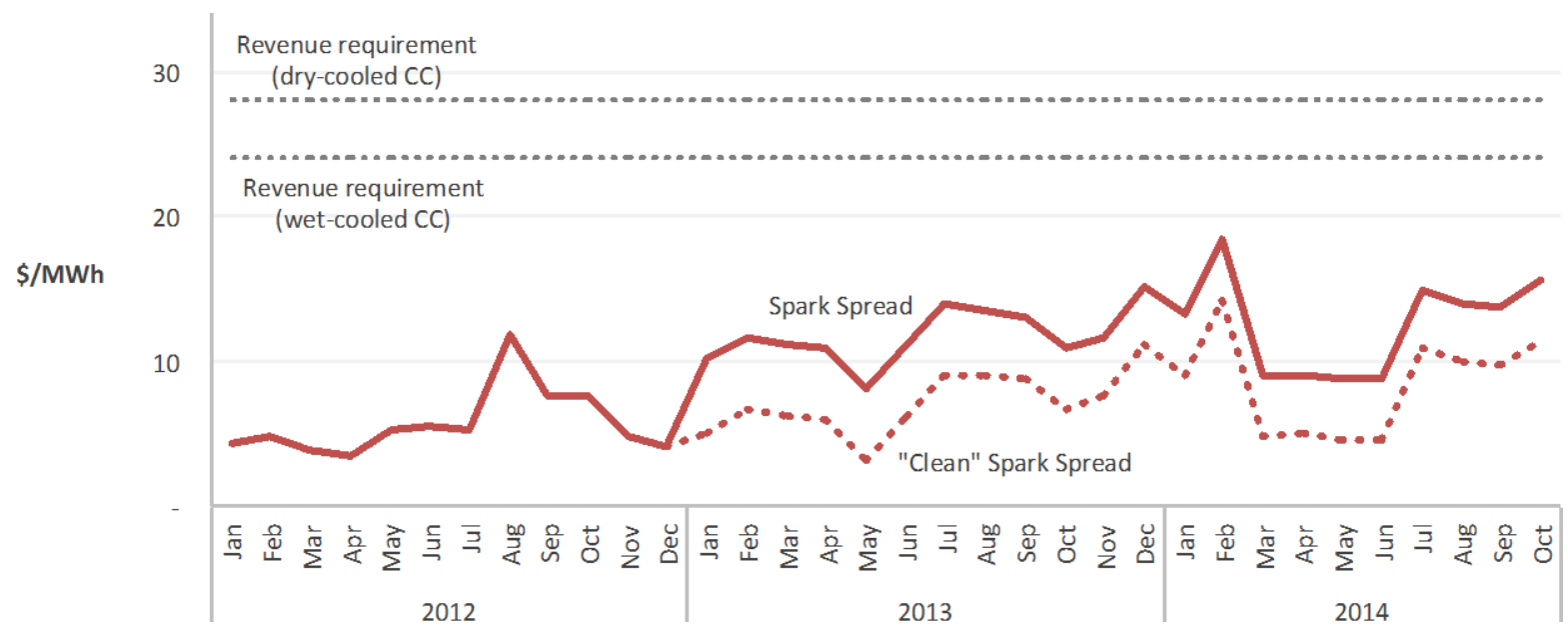

Figure ES-2. Monthly spark spreads based on historical prices at the Mead Hub

\section{New Natural Gas Capacity}

The same market conditions that cast uncertainty over the ability to sell NGS surplus power also add to the economic risk of building a new natural gas combined cycle (NGCC) generator. This analysis calculates that a new, highly efficient NGCC operating at a 70\% capacity factor would need to clear $\$ 24 / \mathrm{MWh}$ in net revenues to recover its capital costs. In recent years, however, the margin between wholesale power prices and variable operating costs has not been that large.

\footnotetext{
${ }^{7}$ About $15 \%$ of federal generation capacity that is available for surplus is dedicated to Salt River Project under a special long-term contract that is independent of the market trends summarized in this section.
} 
Figure ES-2 illustrates the spark spread analysis used in this study to test the economics of building a new highly efficient NGCC. A spark spread is the real-time difference between the market prices for power that prevail during the operating hour and the generator's variable cost of operation (generally, a function of the generator's heat rate and the price of fuel, with a markup for variable operating costs besides fuel). ${ }^{8}$ At no time since 2012 has the spark spread reached the $\$ 24 /$ MWh benchmark for capital cost recovery. ${ }^{9}$

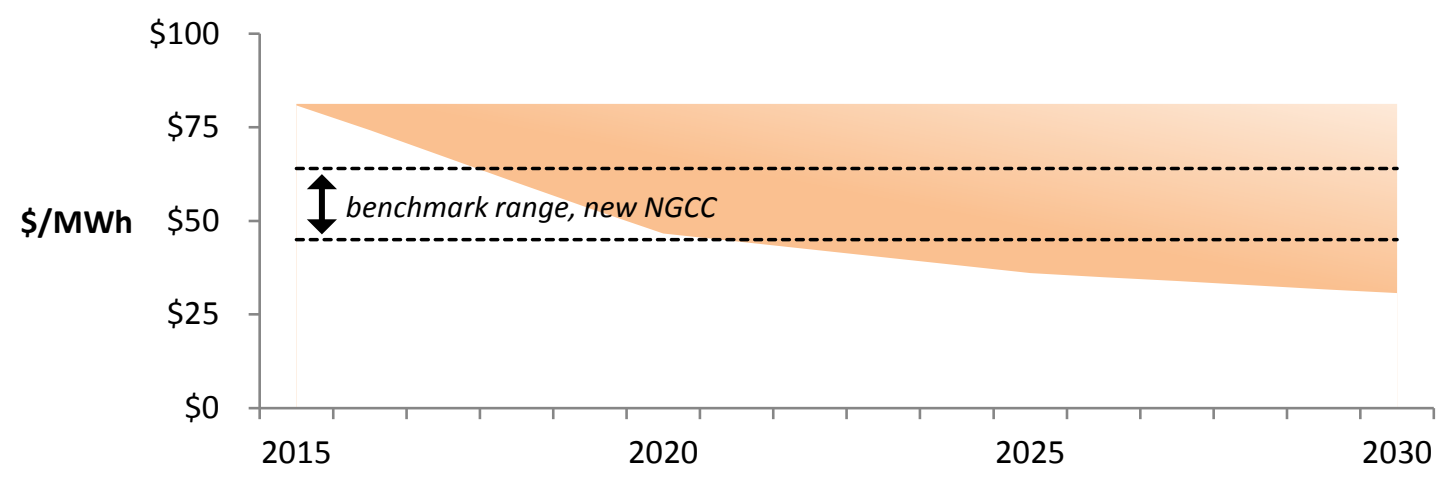

Figure ES-3. Range of projected LCOE for utility-scale solar in Arizona, 2015-2030 ${ }^{10}$

For consistency over time, the solar LCOE calculation does not include the investment tax credit, and does not account for potential curtailment.

\section{New Renewables}

Even though wholesale power prices have been low, the costs of utility-scale solar and wind power have continued to decline. Arizona has some of the most productive solar resource potential in the United States, which significantly improves the amount of energy generated for every dollar of capital investment. Figure ES-3 shows cost trends for utility-scale solar photovoltaic (PV) plants in Arizona, expressed as the levelized cost of energy (LCOE), compared to the all-in cost of a newly built NGCC. ${ }^{11}$

Nevertheless, while well-sited utility-scale solar and wind are trending toward a general cost balance with new NGCC, the cost of producing electricity at existing natural gas generators is at this time economically superior to new capacity of any type, as indicated by low wholesale power prices. However, state renewable energy requirements continue to push new development of solar, wind, and geothermal generation.

\footnotetext{
${ }^{8}$ This analysis also tests a "clean" spark spread, which adds the cost of procuring emission allowances. A clean spark spread more fully measures the economics of supplying electricity to California, where emission costs are effectively a component of a generator's variable operating cost.

${ }^{9}$ Low wholesale power prices and the resulting spark spread would not necessarily limit the ability of a regulated utility to build a new generator and recover the capital costs directly through customer rates. Approval for cost recovery would be decided by the utility's regulator.

${ }^{10}$ Nate Blair, Karlynn Cory, Maureen Hand, Linda Parkhill, Bethany Speer, Tyler Stehly, David Feldman, Eric Lantz, Chad Augustine, Craig Turchi, and Patrick O'Connor, Annual Technology Baseline Supporting Data (Golden, CO: National Renewable Energy Laboratory, 2015), http://www.nrel.gov/analysis/data tech baseline.html. An update to this analysis was released in late 2016. See Chapter 2 for a discussion of the 2016 updates.

${ }^{11}$ Ibid.
} 


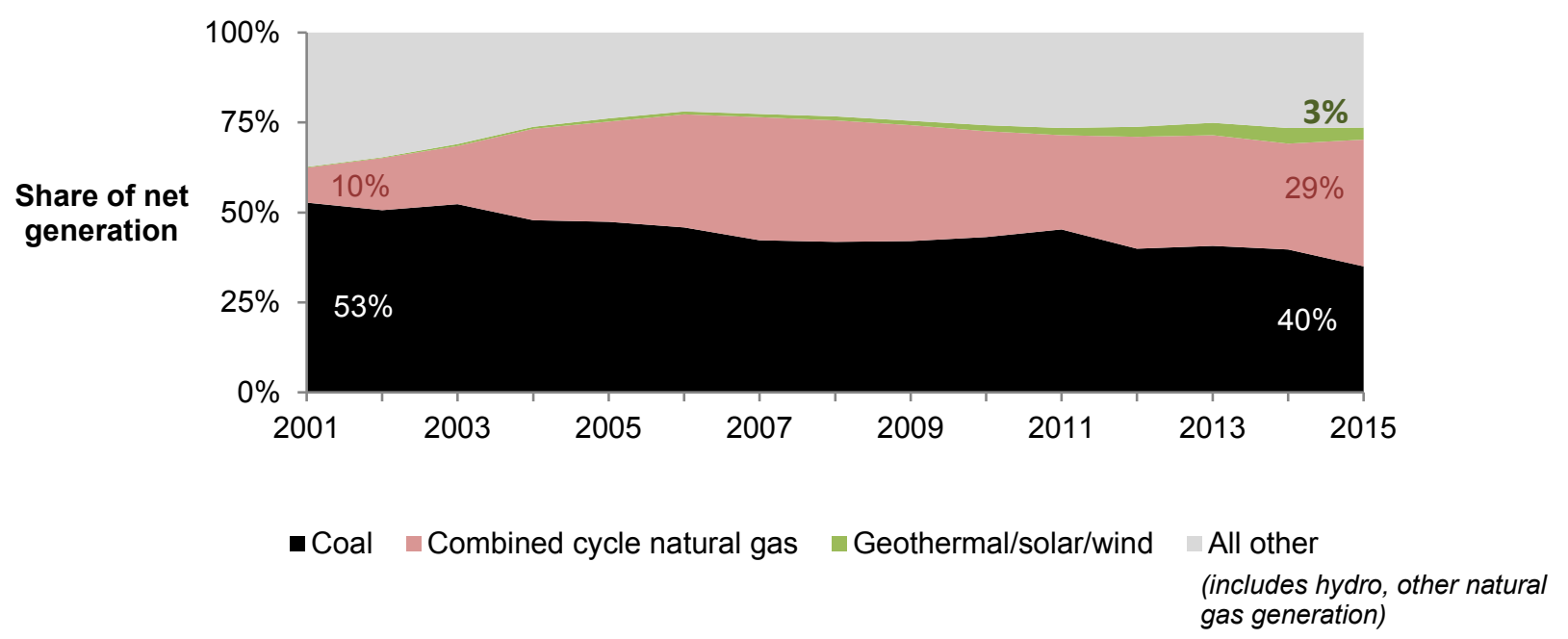

Figure ES-4. Changing generation mix in the Desert Southwest ${ }^{12}$

\section{Sectoral Trends}

\section{Less Reliance on Coal}

The Desert Southwest electric reliability area—Arizona, southern Nevada, and western New Mexico - relies less on coal and more on natural gas and renewables for generating electricity than it did two decades ago. ${ }^{13}$ Low natural gas prices since 2015 have accelerated this trend in recent months, but Figure ES-4 shows that the transition has in fact been persistent since 2001. This trend is also occurring throughout the Western Interconnection and nationwide.

\section{Less Reliance on Large Generators}

In 2000, more than half of all electric generation in the Southwest came from plants that were larger than $2 \mathrm{GW}$ in capacity. In addition to NGS, this group of plants included Hoover Dam and the Palo Verde Nuclear Generating Station. Even with the addition of the 2.2-GW Gila River Project in 2003, the share of generation coming from plants larger than $2 \mathrm{GW}$ has fallen to around $30 \%$ today. Excluding renewables, which tend to be smaller and more dispersed, Arizona's electric generation picture is about $20 \%$ less concentrated today than it was in $2001 .{ }^{14}$ These trends suggest that very large central station generators are not as dominant as they were two to four decades ago.

\footnotetext{
12 "EIA Form EIA-860 detailed data"; "Form EIA-923 detailed data," https:/www.eia.gov/electricity/data/eia923/.

${ }^{13}$ The Desert Southwest subregion is part of the Western Electricity Coordinating Council (WECC), the reliability entity responsible for the Western Interconnection.

${ }^{14}$ Chapter 3 explains the analytical methodology used to measure generator concentration.
} 


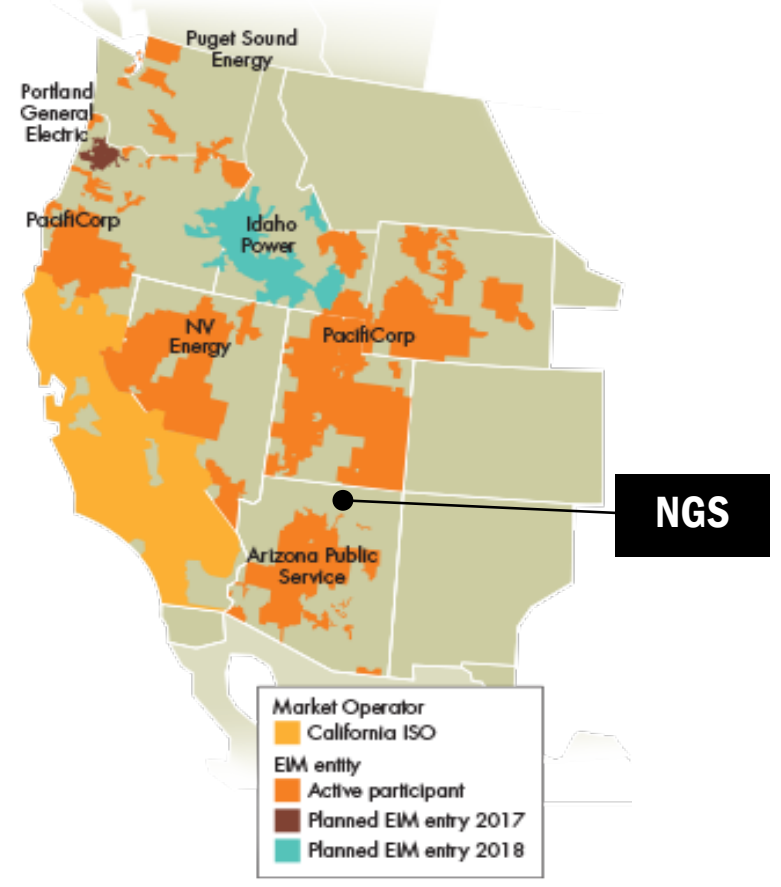

Figure ES-5. Utilities participating in the energy imbalance market

Map source: California Independent System Operator

\section{Greater Coordination Among Utilities}

Not only is the West's generation fleet becoming less concentrated and more dispersed, but it is also becoming more coordinated operationally. Four major utilities outside Californiaincluding APS and NV Energy, which own shares of NGS - have joined an energy imbalance market (EIM) operated by the California Independent System Operator. Two more utilities have announced plans to join in the near future. Figure ES-5 maps the utilities in the West that are participating in the EIM.

While a regional transmission organization (RTO) manages a wide range of wholesale operations under an integrated market, an EIM is more limited. Its primary function is to resolve real-time imbalances between actual load and scheduled generation. Combining imbalances across several control areas tends to reduce the net imbalance that all control areas have to correct, provides access to a larger roster of flexible resources to address the net imbalance, and reduces the cost of managing larger amounts of wind and solar generation. For federal decisions related to NGS, an expanded EIM (as well as other movements toward regional coordination) could:

- Reduce the ability to sell surplus power from NGS, because non-coal alternatives such as renewables and natural gas generation are likely to become more cost competitive and easier to manage

- Favor NGS transition strategies that provide operational flexibility

- Increase the feasibility and the advantages of a multi-resource strategy for procuring CAP pumping power (in contrast to relying on a single resource such as NGS). 


\section{Regional Utility Planning Outlook}

Utilities in Arizona, Nevada, and California are planning for futures with less coal generation on the grid. NGS itself is scheduled to reduce operations by about one-third beginning in 2019. In addition,

- Three of the five coal-fired units at Four Corners Generating Station (also on the Navajo Reservation) retired in 2015, reducing the plant's operating capacity to $1.5 \mathrm{GW}$ from its previous $2.1 \mathrm{GW}$.

- NV Energy retired three units at its 550-MW Reid Gardner coal plant in 2014 and plans to retire the last one in $2017 .^{15}$

- One of the four units at the Cholla plant (just south of the Navajo and Hopi Reservations in Arizona) retired in 2015; APS and PacifiCorp have announced plans to discontinue burning coal at the remaining units sometime after $2020 .^{16}$

- TEP discontinued burning coal at its dual-fuel H. Wilson Sundt Unit 2 in 2015 and is now running the 156-MW unit on natural gas.

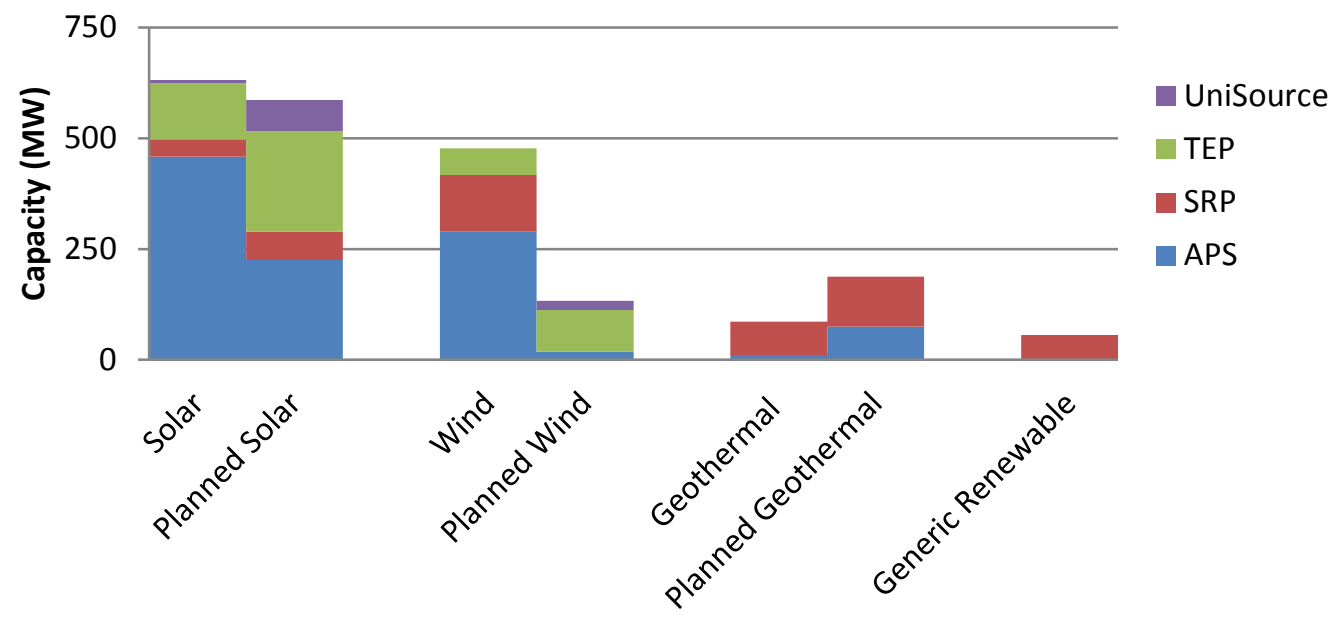

Figure ES-6. Arizona utilities' existing and planned renewable capacity through 2025

Figure ES-6, which is derived from utility planning documents as detailed in Chapter 3, shows that most Arizona utilities expect solar resources to constitute the majority of the new capacity used to comply with 2025 renewable portfolio standard (RPS) requirements, followed by geothermal and wind. Utilities throughout the Southwest have indicated plans to add some $7 \mathrm{GW}$ of new generating capacity over the course of their planning cycles, mostly natural gas and renewables.

\footnotetext{
${ }^{15}$ NV Energy, "NV Energy Seeks Approval for Renewable Energy Project and Earlier Retirement of Coal Generation," press release, August 15, 2016.

${ }^{16}$ Arizona Public Service Company, 2014 Integrated Resource Plan (executive summary), regulatory filing, Nov. 7, 2014, https://www.aps.com/en/ourcompany/ratesregulationsresources/resourceplanning/Pages/resourceplanning.aspx; PacifiCorp, 2015 Integrated Resource Plan Update, regulatory filing, March 31, 2016, http://www.pacificorp.com/es/irp.html.
} 


\section{Carbon Policies}

As of this writing, the U.S. Environmental Protection Agency's (EPA's) rule for reducing carbon emissions from existing power plants has been stayed by the U.S. Supreme Court pending review by the District of Columbia Court of Appeals. NGS would be controlled by the rule's 2030 goal for the Navajo Nation rather than the goal for Arizona, and the Navajo Nation is on track to meet its goal 10 years early once operations at NGS are reduced. Table ES-1 shows the carbon emission targets for the Navajo Nation and the State of Arizona under the Clean Power Plan (CPP); Figure ES-7 shows where the Navajo Nation's carbon emissions are likely to be in 2020 after reducing operations at NGS.

The Navajo Nation and the Hopi Tribe could be affected indirectly by how Arizona, California, and Nevada comply with carbon reduction goals. Because the Tribes are unlikely to have any further carbon reduction requirement, any renewable resources developed on their land for sale to a utility would most likely be eligible to count toward the CPP goal of the purchasing utility's state. This will depend on carbon trading rules and on the ability of renewable projects sited in Indian Country to compete with projects built elsewhere.

Table ES-1. Carbon Emission Goals for Navajo Nation and Arizona

\begin{tabular}{lllll}
\hline & \multicolumn{3}{c}{ Navajo Nation } & \multicolumn{2}{c}{ Arizona } \\
\hline & tons & Ib/MWh & tons & Ib/MWh \\
$\mathbf{2 0 1 2}$ (historic) & $29,629,453$ & 2,123 & $40,465,035$ & 1,552 \\
$\begin{array}{l}\mathbf{2 0 2 0} \text { projection } \\
\text { without CPP }\end{array}$ & $20,464,699$ & 2,124 & $39,511,785$ & 1,409 \\
$\mathbf{2 0 3 0}$ goal & $\begin{array}{l}21,700,587 \\
\left(22,955,804^{*}\right)\end{array}$ & 1,305 & $\begin{array}{l}30,170,750 \\
\left(32,380,196^{*}\right)\end{array}$ & 1,031 \\
\hline
\end{tabular}

${ }^{*}$ These alternative mass-based goals include a complement for emissions from new sources. Any existing coal-fired generators that are re-powered to use natural gas as a fuel would be treated as a new source by EPA, and would therefore be subject to new-source emission standards and not to the CPP.

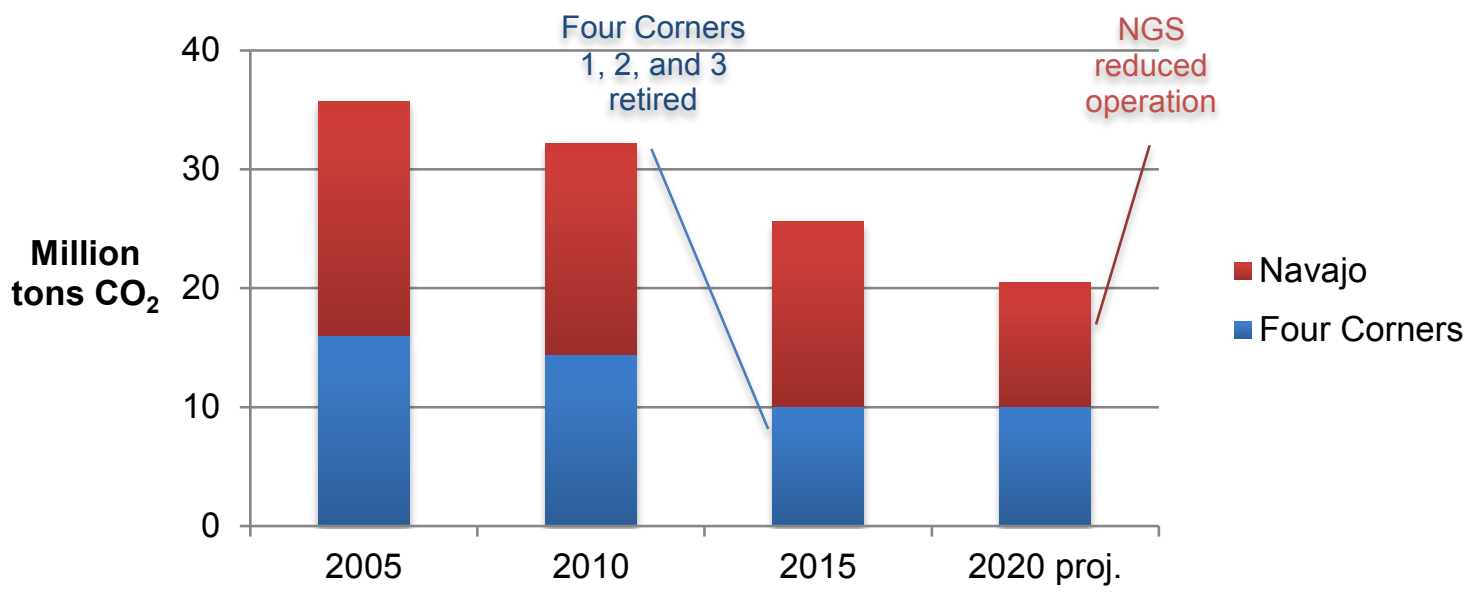

Figure ES-7. $\mathrm{CO}_{2}$ emissions from existing Navajo Nation generators 


\section{Modeling Trends}

The baseline analysis includes two types of power system modeling:

- Capacity expansion modeling, which simulates decisions to build new generators in future years

- Production cost modeling, which simulates the economically optimal dispatch of generators on the grid during a test year.

Both modeling tasks began by replicating the western grid under conditions likely to prevail in 2024, including known generator retirements, transmission projects currently under construction, load growth as currently forecasted by utilities. Detailed parameters for generators and transmission lines were the same used by the Western Electricity Coordinating Council (WECC) and numerous utilities in the West for their own system modeling. Holding these baseline conditions constant, the models varied only the utilization of NGS to see how the rest of the grid would respond. The central scenario in both modeling studies simulated reduced operation at NGS to two-unit operation rather than continuing to operate all three 750-MW units. This is consistent with the federal implementation plan adopted by EPA for $\mathrm{NO}_{\mathrm{x}}$ reduction at NGS beginning in 2019. Other scenarios tested the effect of continued operation at all three units, complete plant closure, and complete plant closure in 2030 . Some sensitivity scenarios were also run assuming high natural gas prices.

\section{Capacity Expansion Modeling}

The capacity expansion modeling suggests that reduced operation at NGS appears to have little effect on the market fundamentals driving new generator investments in WECC. Even when simulating full NGS retirement in 2019, trends for adding new capacity did not change significantly.

A number of regions of WECC appear to have generating capacity well in excess of peak reserve margin requirements, which could persist at least in the short term. Large reserve margins dampen the economic need to build new generation capacity. In these circumstances, load growth and the retirement of old generators tend to result in more use of existing capacity, rather than the construction of new capacity.

Simulations of new capacity additions also indicate that:

- The generation mix will likely continue its shift from coal to natural gas, although the prevailing price of natural gas could affect the speed of this change.

- Sustained high prices for natural gas could yield greater reliance on new renewable resources for latter-year expansion (around 2030).

- Future carbon policies (whatever form they may take) could accelerate the switch from coal to natural gas.

- New renewable capacity deployment appears to be driven largely by state RPS targets.

NGS retirement tends to shift some renewable capacity additions from new wind to new solar generation in 2030. This is due to solar's hourly correlation with load, its contribution to meeting peak demand, and its effect on the need for firm capacity in 2030 if NGS were completely retired 
in 2020. ${ }^{17}$ Overall, however, NGS retirement shows little effect on the total amount of renewable electricity produced.

Only high natural gas prices significantly influence capacity expansion results: high prices tend to increase the use of renewable technologies by 2030, especially if all three units retire in 2020. Results suggest that high natural gas prices and full NGS retirement in 2020 could result in net renewable capacity additions of nearly 3,000 MW across WECC by 2030, including 1,200 MW in the Southwest focus region. This would exceed what is currently required under RPS targets. Overall, high natural gas prices appear to have a stronger influence on renewable energy expansion than does NGS retirement.

\section{Production Cost Modeling}

Production cost modeling results suggest that while a shutdown by itself could increase the average per-megawatt-hour cost of producing electricity by $2.7 \%$ in the Southwest focus area, high natural gas prices resulted in cost increases 10 times as great. ${ }^{18}$ Thus even a complete shutdown of NGS tends to be overshadowed by the potential impact of higher natural gas prices.

The average capacity factor of NGCCs in the Southwest focus region would likely increase under any retirement scenario, but would still remain below the average for all of WECC. This is consistent with results from capacity expansion modeling, which found that high reserve margins and low utilization of existing NGCC capacity dampen the need to build new generation to replace NGS.

One effect of reducing production at NGS is a reduction in exports from the Southwest focus region to California. This reduces the total cost of production (and, consequently, generator revenues) within the focus region. It does not, however, significantly change the average cost of production that stays within the region.

For the rest of WECC, the change in net generation is consistent across all NGS retirement scenarios. One notable trend, however, is in the use of natural gas generation when fuel prices are high. The use of natural gas tends to shift from the Southwest to other parts of WECC under high natural gas prices. This could indicate that the West's most efficient NGCC plants are located outside the Southwest. ${ }^{19}$ Higher natural gas prices would tend to favor running the most efficient plants, all other conditions held unchanged.

\section{Implications for Federal Decisions Related to NGS}

The formal modeling done here (capacity expansion modeling and production cost modeling) suggests that an NGS transitional glide path may benefit from a diverse portfolio of generation

\footnotetext{
${ }^{17} \mathrm{PV}$ and CSP share these characteristics.

${ }^{18}$ Modeled natural gas prices were based on three forecast scenarios used in EIA's 2015 Annual Energy Outlook. Low natural gas prices are from a scenario using assumptions that result in higher estimates of recoverable supplies (such as closer spacing between wells and additional improvements in recovery technology), with large supply correlated to low prices. Another scenario with assumptions that reduce the supply of natural gas results in high prices. EIA's reference scenario was used for midrange price forecasts.

${ }^{19}$ Ambient air temperature affects the operating efficiency of a thermal generator. Arizona's climate could be a factor that contributes to making thermal generators in the north somewhat more efficient during the summer.
} 
resources. Attempting a megawatt-for-megawatt replacement of NGS with one new plant may constitute a path that would conflict with underlying market trends.

Natural gas generation will likely play some part in an NGS glide path strategy. What is uncertain is whether market conditions would support building a new NGCC plant rather than increasing the utilization of existing plants. Capacity expansion modeling suggests not; production cost modeling also suggests redispatching existing plants could accommodate the entire range of NGS scenarios with local per-megawatt-hour generation cost increases no greater than $2.7 \%$.

The capacity expansion modeling also suggests that solar PV could be an important strategic element of an NGS glide path. Reducing the use of NGS seems to increase the relative cost effectiveness of solar in the Southwest focus area, such that on a West-wide basis the demand for new renewables tends to change in profile: less wind outside the Southwest, and more solar in the Southwest. One key variable will likely be the future cost of utility-scale PV. If costs continue to fall as they have over the past three years, the economic momentum toward PV will be even greater than represented in the modeling conducted for this analysis.

\section{Macroeconomic Impacts}

County-level computable general equilibrium (CGE) analysis indicates that shutting down one generating unit at the NGS station would have a measurably greater impact on Native American populations in northeastern Arizona than on other household groups. Some decreases in employment, household income, and government revenue could affect all regions, but the size of the Arizona economy and labor force makes these changes small at the state level compared to the impact on Coconino, Navajo, and Apache counties.

Decreases in household income are most significant in relatively high-income Native American households (incomes between $\$ 75,000$ and $\$ 92,000$ per year). This segment of the population in Coconino, Navajo, and Apache counties loses about $6 \%$ of its income when NGS operations are cut from three units to two units. Among everyone else in these three counties starting at this same income bracket, the reduction in income is one-tenth the magnitude. This reflects the loss of relatively high paying jobs that are held by Native Americans at NGS and the Kayenta Mine. In Coconino County, the decline in household income for all Native American households is about $2 \%$; it is nearly $2.5 \%$ in Navajo and Apache counties. In dollars, the annual decreases amount to nearly $\$ 10$ million and $\$ 22$ million, respectively.

\section{Extreme Drought}

Power sector modeling often tests the resilience of the grid to rare, extreme contingency events. In the Southwest, one such possible event is an extended drought in which Colorado River Basin flows leave reservoir levels too low for power generation at Hoover Dam and Glen Canyon Dam. Hydrological modeling conducted by the U.S. Bureau of Reclamation, which manages the Colorado River Basin, indicates that such a drought is improbable but plausible. This extreme drought scenario could affect federal decisions in at least two ways. First, the loss of federal hydropower could create a need for replacement electricity supplies, a contingency that could be included in the federal government's NGS-related decisions. Second, it suggests the need to examine NGS glide path options with respect to their ability to cushion the system-wide impact of extreme drought. 


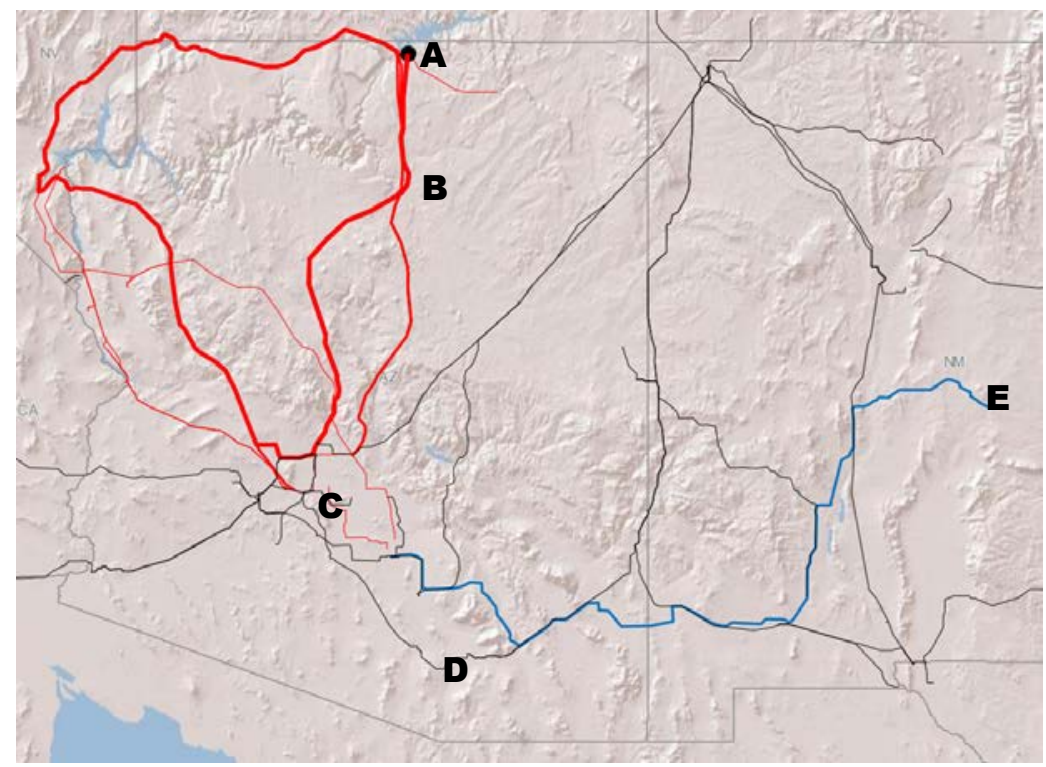

\author{
Solar glide path \\ 700 MW of utility-scale PV spread \\ among points $A, B, C$, and $D$ \\ Expanded wind glide path \\ $1,000 \mathrm{MW}$ of wind at point $\mathrm{E}, 500$ \\ MW of wind at point $B$ \\ 700 MW of utility-scale PV spread \\ among points $B, C$, and $D$ \\ $250 \mathrm{MW}$ of natural gas at $\mathrm{B}$ \\ Moenkopi glide path (point B) \\ $500 \mathrm{MW}$ of wind \\ $500 \mathrm{MW}$ of $\mathrm{PV}$ \\ $750 \mathrm{MW}$ of natural gas
}

Figure ES-8. Glide paths tested in the analysis of extreme drought

Map data: SNL Energy, ESRI. Red lines indicate transmission associated with NGS. Blue line indicates the proposed SunZia transmission project. Black lines indicate all other major transmission.

This analysis used production cost modeling to simulate the effects. All else held constant, an extreme drought that eliminates Hoover Dam and Glen Canyon Dam from the region's electric generation fleet could increase the cost of generating electricity by $1.3 \%$ for the entire Western Interconnection. The effect would likely be more pronounced in Arizona, where modeling results suggested a reduction in electricity exports and higher average cost of generation. If no other resources are added to the system, extreme drought would tend to promote greater reliance on Arizona's remaining coal and NGCC generators. The increase in coal utilization due to drought appears to be unchanged by high natural gas prices.

The extreme drought modeling tested three glide paths for replacing electricity from the federal share of NGS with electricity produced from new solar, wind, and natural gas facilities (see Figure ES-8). All three glide paths tested here appear to have some capacity to mitigate the impact of extreme drought. ${ }^{20}$ That is, locational marginal prices (LMPs) at points in Arizona would tend to increase less if an extreme drought were to occur. ${ }^{21}$ LMPs in the solar glide path (700 MW of additional utility-scale PV spread across four theoretical locations in Arizona) would increase $1.3 \%$ in an extended drought, compared to a $1.6 \%$ increase if no new capacity were added to the system. Both of the other two glide paths would see larger increases in average LMPs under an extreme drought, but they would also tend to reduce LMPs overall under normal nondrought conditions, from an average of $\$ 33.98 / \mathrm{MWh}$ with no added capacity to as low as $\$ 33.08 / \mathrm{MWh}$ for the Moenkopi glide path (a 2.6\% reduction). So while the additional drought

\footnotetext{
${ }^{20}$ Extreme drought would have other system impacts on thermal generators, such as degraded operational efficiency and higher cost of cooling water due to scarcity and competition. Because the primary aim of this exercise was to test how the glide path scenarios would respond to drought, these other effects were not modeled.

${ }^{21}$ LMPs measure the incremental system cost of adding one more megawatt of load at a given point on the grid.
} 
impact mitigation would be small, LMPs in these drought scenarios would still tend to be lower than LMPs in the solar glide path.

Even with the addition of glide path resources, managing extreme drought could involve leaning more heavily on the coal resources remaining on the system in 2030, as well as on the existing NGCC capacity. For both types of resources under all glide path scenarios, the capacity factor tends to increase in drought years compared to nondrought years under the same glide path scenario.

\section{Summary}

The public interests that depend on the federal share of NGS are different from the traditional interests of the plant's utility co-owners, but they are affected by the same changes that are currently evident throughout the electricity sector. Adding new generation capacity of any kind entails economic challenges caused by an abundance of existing capacity, low natural gas prices, and the resulting low prices for wholesale power. Current market conditions are also likely to limit the ability to sell surplus NGS power on the wholesale market at least in the short run. Mead Hub prices are currently below the cost of power at NGS, which tends to make surplus NGS power uncompetitive for short-term sales. Whether and when NGS will again become economically competitive will depend on how quickly natural gas prices recover from their current low levels.

These and other changes from historical conditions will influence what an optimal NGS transitional glide path might be, its timing, and how well it can meet the public interests that currently rely on the federal government's share of NGS. 
This page intentionally blank. 


\section{Table of Contents}

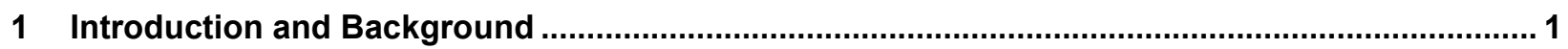

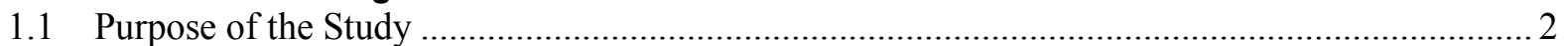

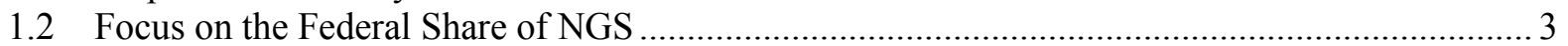

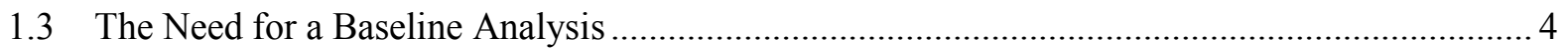

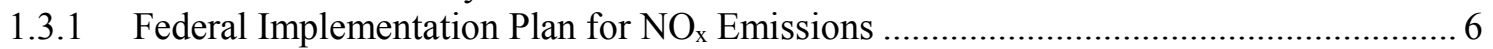

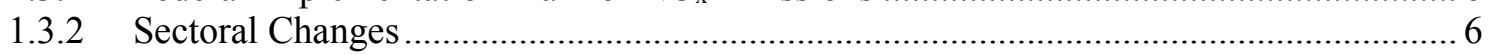

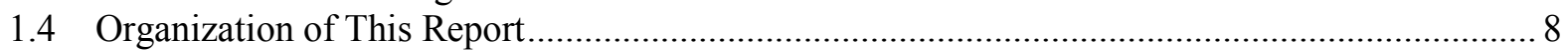

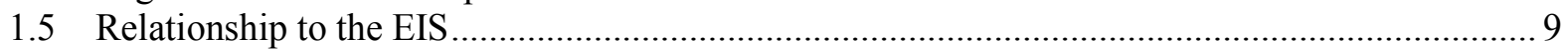

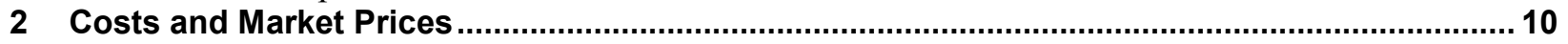

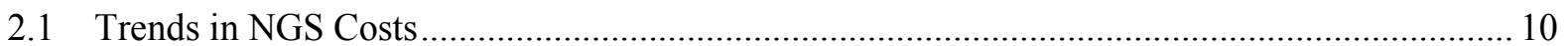

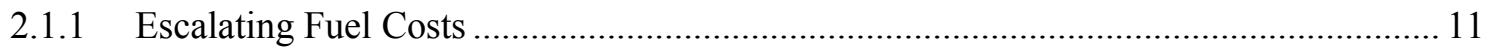

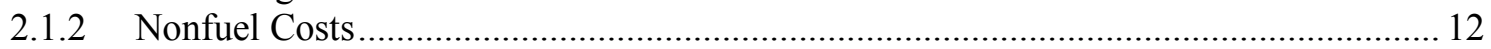

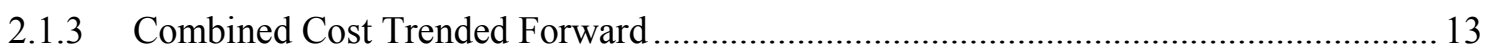

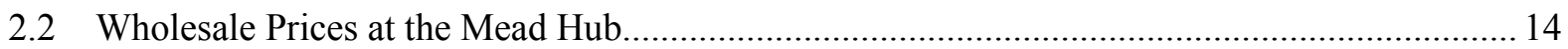

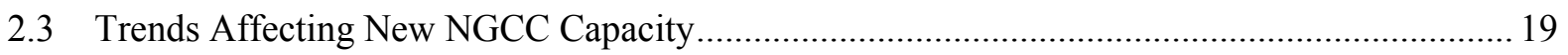

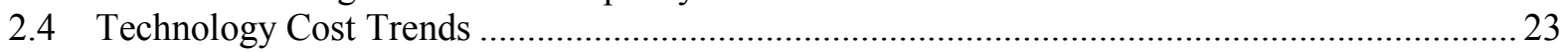

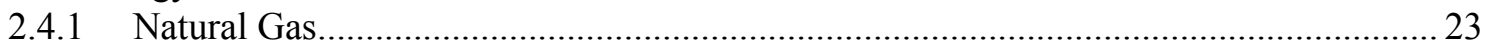

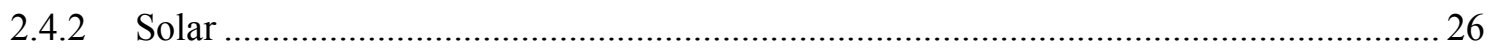

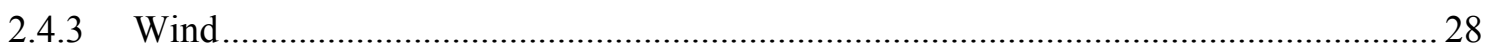

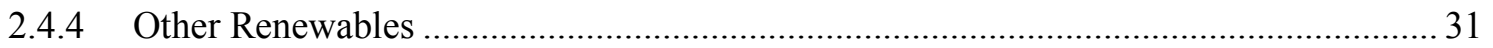

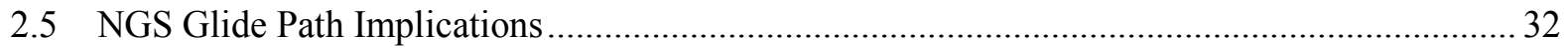

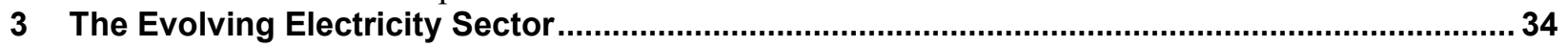

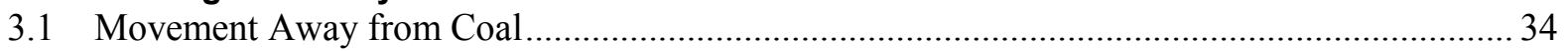

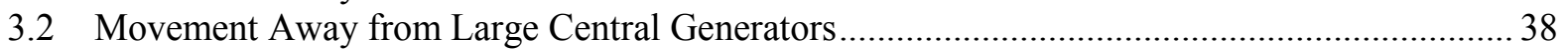

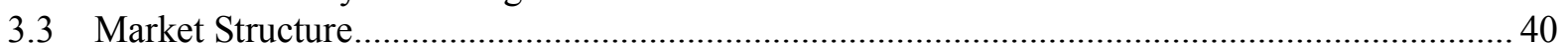

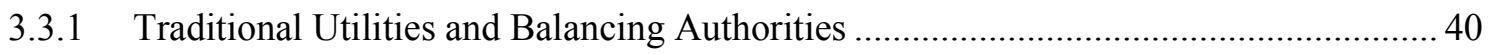

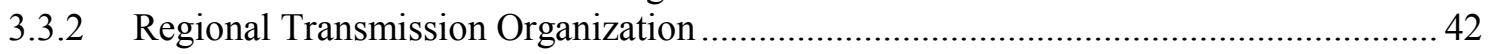

3.3.3 Energy Imbalance Market and Partial Coordination Options ......................................... 44

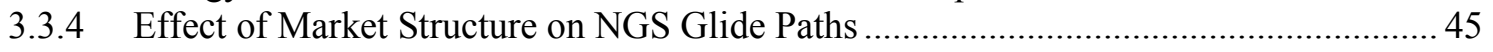

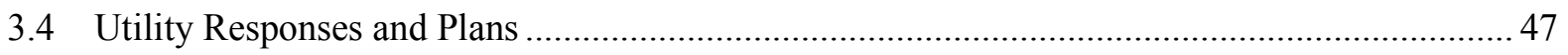

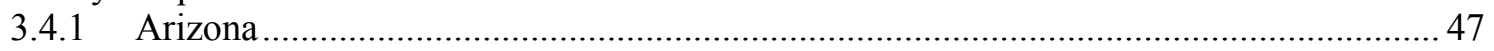

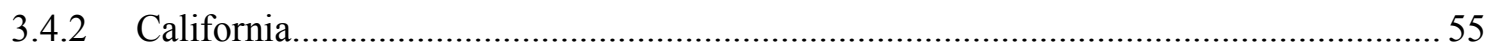

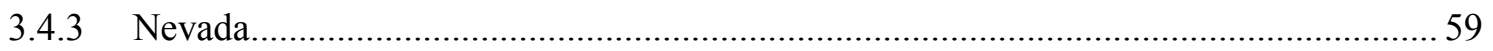

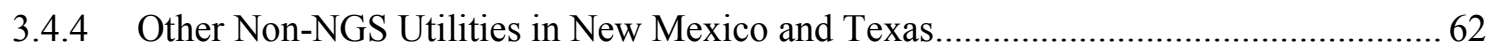

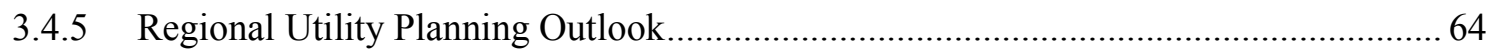

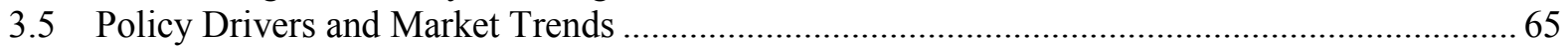

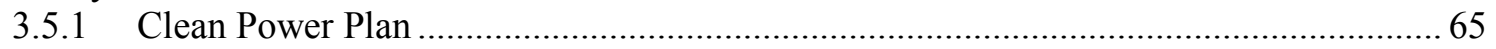

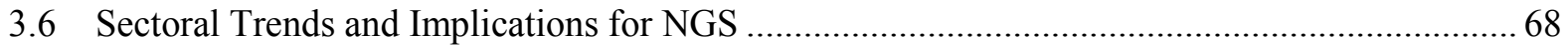

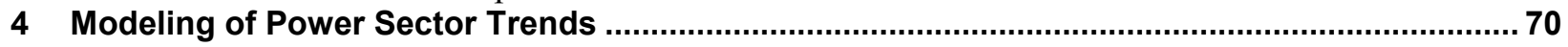

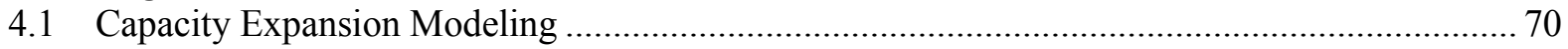

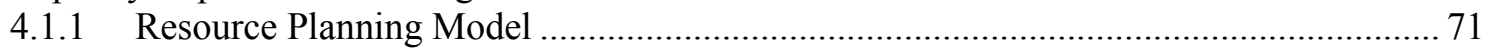

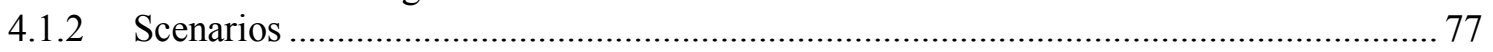

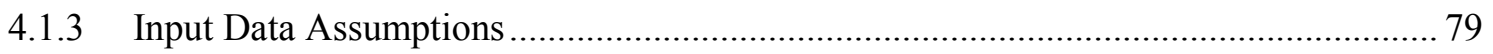

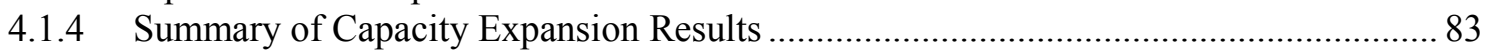

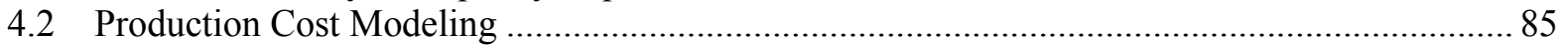

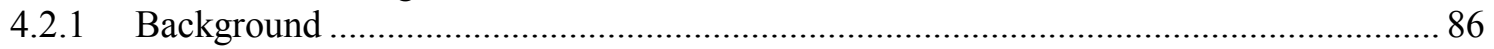

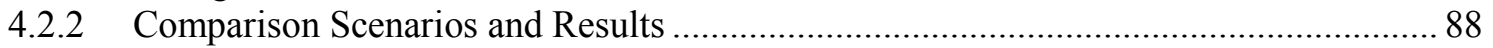

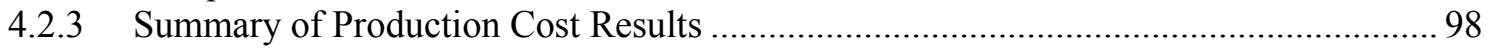

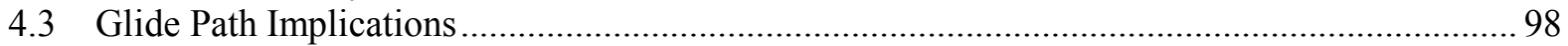




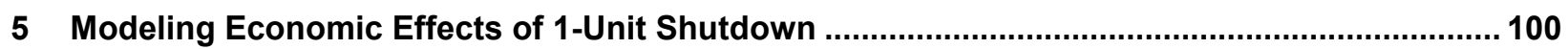

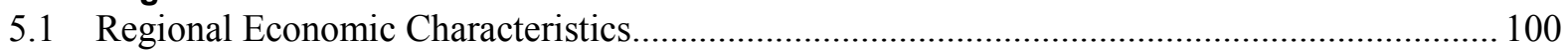

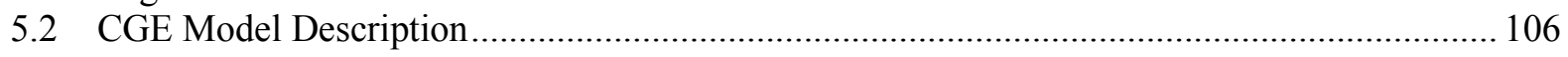

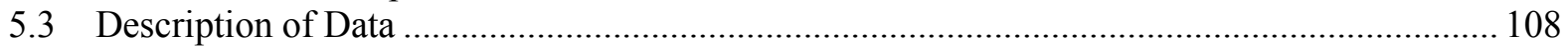

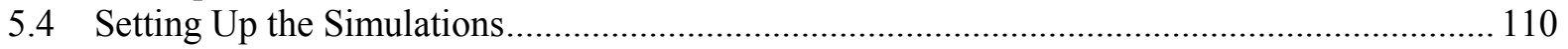

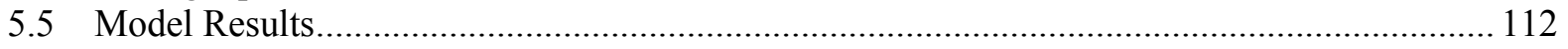

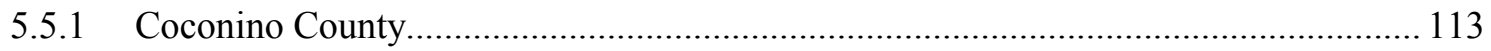

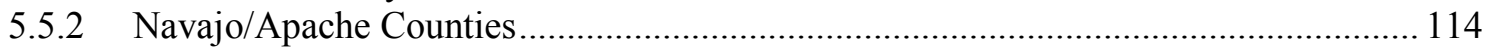

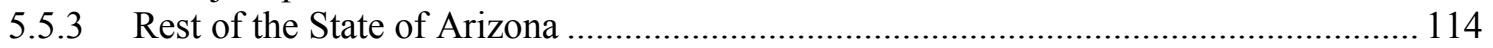

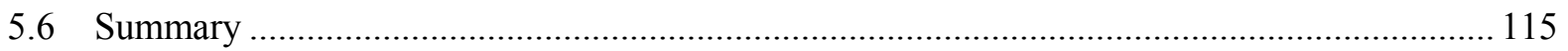

6 Potential Impact of Extreme Drought on Southwest Power Operations .................................. 116

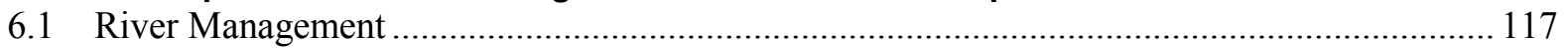

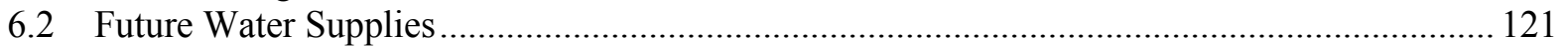

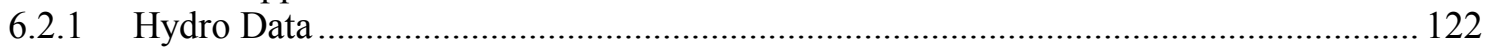

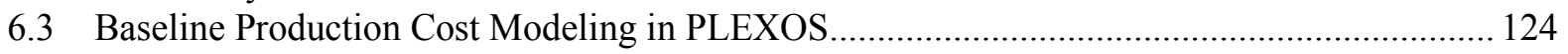

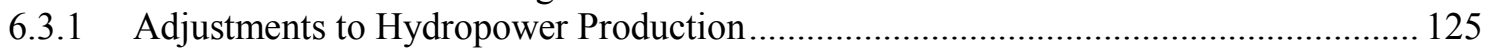

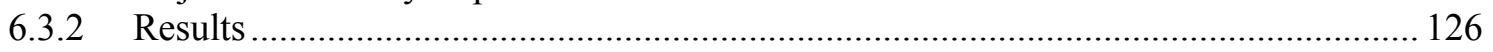

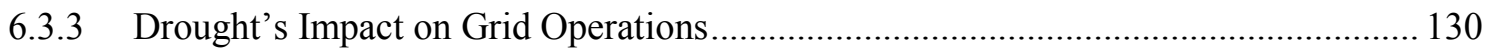

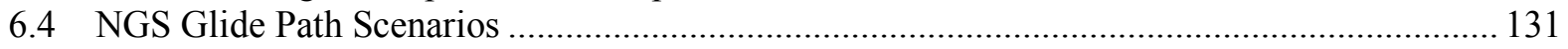

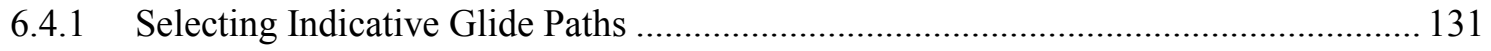

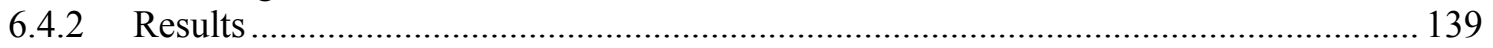

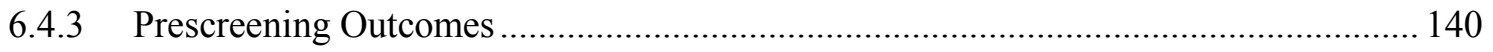

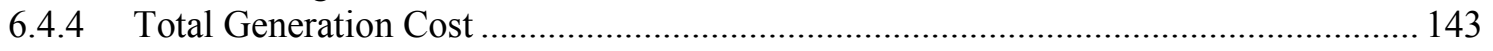

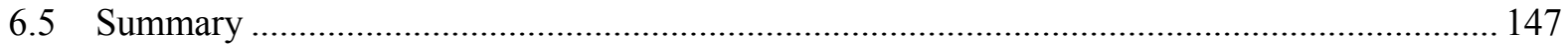

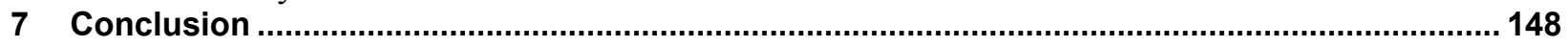

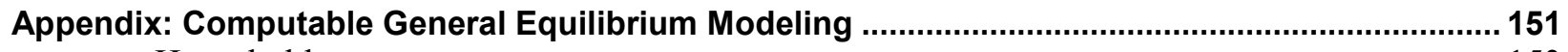

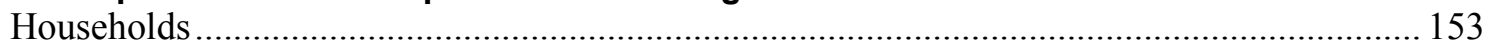

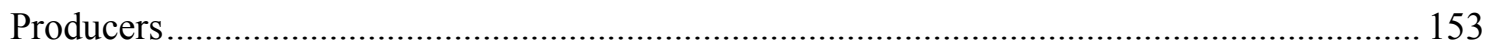

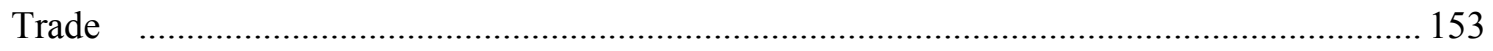

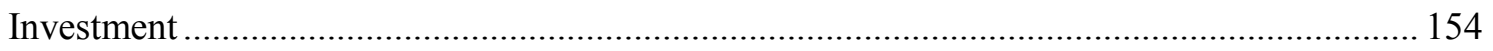

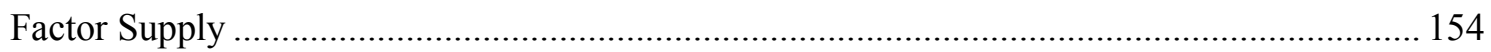

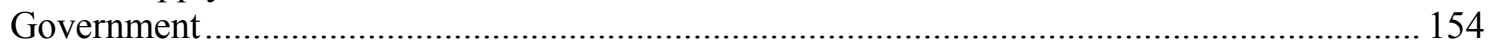

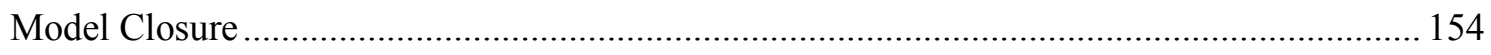

\section{List of Figures}

Figure ES-1. Projections for NGS generation costs, Mead Hub peak power prices.................................. ix

Figure ES-2. Monthly spark spreads based on historical prices at the Mead Hub.................................... ix

Figure ES-3. Range of projected LCOE for utility-scale solar in Arizona, 2015-2030 ...........................

Figure ES-4. Changing generation mix in the Desert Southwest..........................................................

Figure ES-5. Utilities participating in the energy imbalance market......................................................ii

Figure ES-6. Arizona utilities' existing and planned renewable capacity through 2025 ........................xiii

Figure ES-7. $\mathrm{CO}_{2}$ emissions from existing Navajo Nation generators .....................................................

Figure ES-8. Glide paths tested in the analysis of extreme drought ........................................................iii

Figure 1-1. Uses and economic flows related to NGS ....................................................................5

Figure 1-2. NGS, CAP, service territories of original NGS owners, and major transmission lines ............. 5

Figure 2-1. Range of future NGS power costs forecasted by NREL ................................................ 14

Figure 2-2. Mead Hub historical day-ahead peak and off-peak price (average for year) ......................... 15

Figure 2-3. Mead Hub peak energy prices (2015 actual, projections for 2016-2040) ............................ 18

Figure 2-4. Mead Hub off-peak energy prices (2015 actual, projections for 2016-2040)....................... 18 
Figure 2-5. Spark spread and clean spark spread at the Mead node ................................................... 20

Figure 2-6. Selective spark spreads at Mead (70\% of hours with highest prices) .................................. 21

Figure 2-7. Spark spreads in Arizona inferred from utility avoided costs ............................................ 22

Figure 2-8. Range of projected LCOE for utility-scale solar in Arizona, 2015-2030 .............................. 28

Figure 2-9. Range of projected LCOE for New Mexico wind, 2015-2030 ............................................ 30

Figure 2-10. Range of projected LCOE for Arizona wind, 2015-2030 .............................................. 30

Figure 2-11. Comparison of range of NGCC, regional wind, and Arizona solar LCOEs, 2015-2030 ...... 32

Figure 3-1. Changing generation mix, Desert Southwest and WECC ............................................... 35

Figure 3-2. Southwest net generation by renewable fuel type, 2001-2014 ......................................... 36

Figure 3-3. WECC-wide demand for renewables under current state requirements and goals ................. 37

Figure 3-4. Distribution of Desert Southwest generation by plant size ................................................. 40

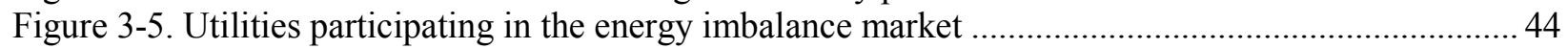

Figure 3-6. Arizona's existing renewable resources and major transmission, July 2016 ........................ 49

Figure 3-7. Cumulative estimated load, energy efficiency, and renewable energy contributions for APS,

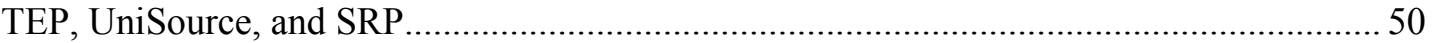

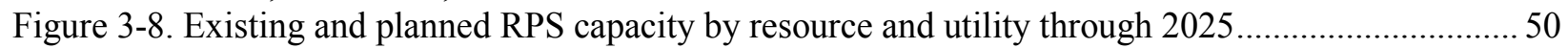

Figure 3-9. Comparison of 2013 and projected 2022 SRP energy mix ................................................ 52

Figure 3-10. Comparison of 2014 and projected 2029 APS energy mix ................................................5

Figure 3-11. Comparison of 2013 and projected 2028 TEP energy mix ................................................. 54

Figure 3-12. Comparison of 2013 and projected 2028 UniSource energy mix ......................................55

Figure 3-13. Comparison of 2014 and projected 2034 LADWP energy mix ......................................... 59

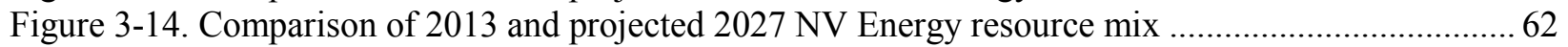

Figure 3-15. Comparison of Southwest utility capacity factors for coal and NGCC plants ...................... 65

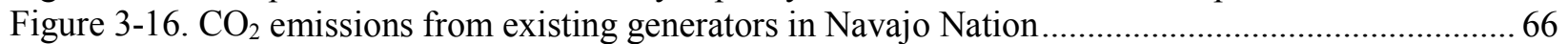

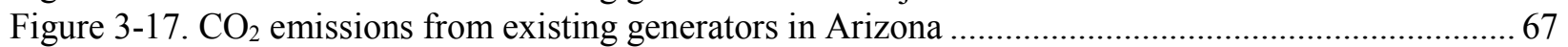

Figure 4-1. Combined nodal and zonal spatial structure of NREL's Resource Planning Model............... 73

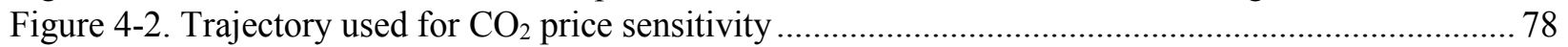

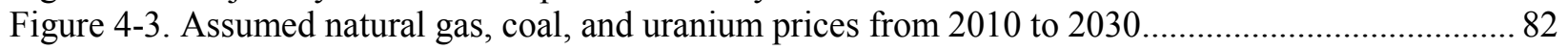

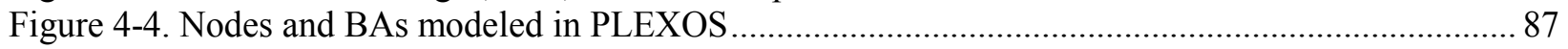

Figure 4-5. LMP duration curves for four areas in WECC (2 NGS units operating in 2030) ................... 88

Figure 4-6. LMP duration curves for APS, comparing baseline with historical operations ....................... 90

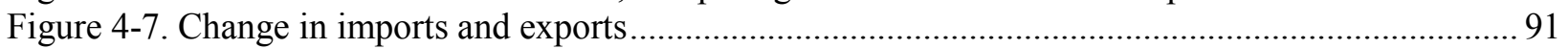

Figure 4-8. LMP duration curves for APS comparing full NGS retirement in 2030 .............................. 92

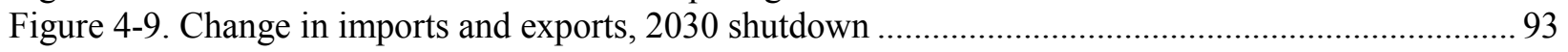

Figure 4-10. LMP duration curve for APS comparing full NGS retirement in 2020 ............................ 94

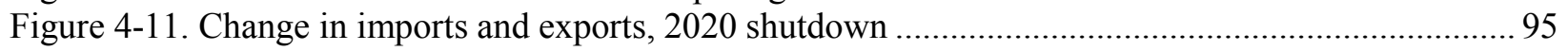

Figure 4-12. LMP duration curve for APS comparing high gas prices............................................... 96

Figure 4-13. Change in imports and exports, 2030, high natural gas prices ............................................ 97

Figure 5-1. Population for Coconino and Apache/Navajo counties................................................... 101

Figure 5-2. Employment for Coconino and Apache/Navajo counties ............................................... 102

Figure 5-3. Circular flow diagram of a regional economy............................................................... 107

Figure 6-1. The Colorado River Basin, major dams in the river basin, and major projects..................... 118

Figure 6-2. Unregulated inflow into Lake Powell, Powell-Mead storage, and percent capacity.............. 119

Figure 6-3. CRSS projections of Lake Mead future pool elevations .................................................... 123

Figure 6-4. Electricity production at Glen Canyon Dam based on selected hydrological scenarios ........ 125

Figure 6-5. Electricity production at Hoover Dam based on selected hydrological scenarios ................. 125

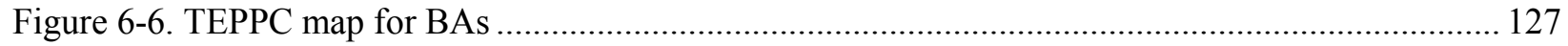

Figure 6-7. Price duration curve for Arizona BAs, excluding hours higher than \$60/MWh................... 129

Figure 6-8. Transmission map showing proposed transmission connections for replacement generation in

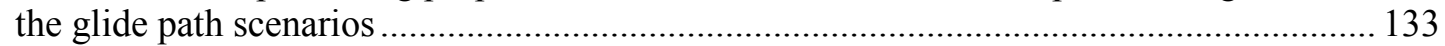

Figure 6-9. Wind Resources at 100m Hub Height for Arizona and New Mexico ................................... 134 
Figure 6-10. Locations of modeled wind sites near the Moenkopi substation...................................... 135

Figure 6-11. Map showing the location of modeled wind sites at the terminus of the SunZia line.......... 135

Figure 6-12. Seasonal and hourly capacity factors for Arizona wind generation ................................. 136

Figure 6-13. Seasonal and hourly capacity factors for New Mexico wind generation ............................ 136

Figure 6-14. Locations of solar PV power plants in Arizona ............................................................. 137

Figure 6-15. PV production profile for Page (average MW, hour of the day by month)........................ 138

Figure 6-16. PV production profile for Cameron (average MW, hour of the day by month) .................. 138

Figure 6-17. PV production profile for Mesa (average MW, hour of the day by month)....................... 139

Figure 6-18. PV production profile for Tucson (average MW, hour of the day by month).................... 139

Figure 6-19. Price duration curve with high prices excluded for Arizona BAs for the NGS retirement and natural gas price scenarios

Figure 6-20. Capacity factors for coal plants in Arizona BAs for NGS retirement and natural gas prices scenarios.

Figure 6-21. Capacity factors for NGCC plants in Arizona BAs for the NGS retirement and natural gas

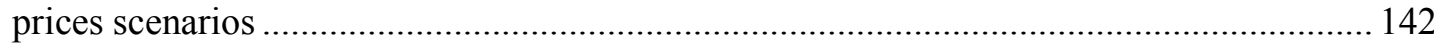

Figure 6-22. Net imports for NGS retirement and natural gas prices scenarios .................................... 143

Figure 6-23. Capacity factors for NGCC plants in Arizona BAs for capacity expansion strategies ........ 146

Figure 6-24. Capacity factors for coal in Arizona BAs for capacity expansion strategies ...................... 147

\section{List of Tables}

Table ES-1. Carbon Emission Goals for Navajo Nation and Arizona .................................................... xiv

Table 1-1. Analyses Relating to NGS Conducted by NREL …............................................................. 3

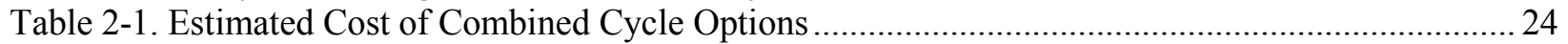

Table 2-2. Detailed Assumptions in Estimating LCOE for Combined Cycle ….......................................25

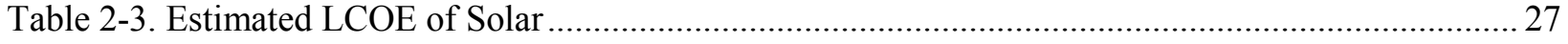

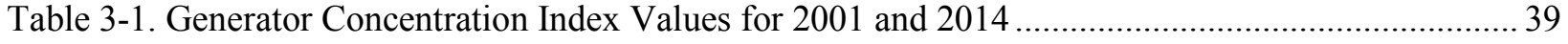

Table 3-2. Disposition of Power for Arizona's Three Major Utilities in 2014 (MWh) ............................ 41

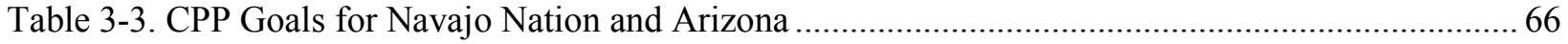

Table 4-1. Balancing Areas (BAs) Modeled in NREL's Resource Planning Model ................................ 74

Table 4-2. Start Year (2010), Prescribed, and Retiring Capacity in NREL's Resource Planning Model

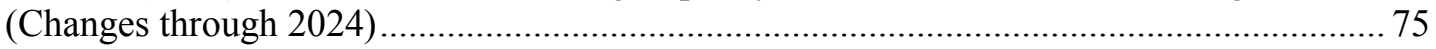

Table 4-3. NGS Retirement, Natural Gas Price, and $\mathrm{CO}_{2}$ Price Assumptions Across Modeled Scenarios 78

Table 4-4. Technology Cost and Performance Assumptions for New Generation Capacity ….................. 80

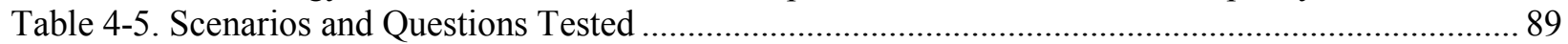

Table 4-6. Operational Results for Baseline, and Percentage Change from Historical Operation ............. 91

Table 4-7. Net Generation by Fuel Type for Baseline, and Percentage Change from Historical Operation91

Table 4-8. Natural Gas Capacity Factors for Baseline, and Difference from Historical Operation ........... 91

Table 4-9. Operational Results, 2030 Shutdown (Percentage Change from Baseline)............................. 93

Table 4-10. Net Generation by Fuel Type, 2030 Shutdown (Percentage Change from Baseline) ............. 93

Table 4-11. Natural Gas Capacity Factors, 2030 Shutdown (Percentage Point Change from Baseline)... 93

Table 4-12. Operational Results, 2020 Shutdown (Percentage Change from Baseline)........................... 95

Table 4-13. Net Generation by Fuel Type, 2020 Shutdown (Percentage Change from Baseline) ............. 95

Table 4-14. Natural Gas Capacity Factors, 2020 Shutdown (Percentage Point Change from Baseline).... 95

Table 4-15. Operational Results, 2030 Shutdown, High Gas Prices........................................................ 97

Table 4-16. Net Generation by Fuel Type, 2030 Shutdown, High Gas Prices .......................................... 97

Table 4-17. Natural Gas Capacity Factors, 2030 Shutdown, High Gas Prices ......................................... 97

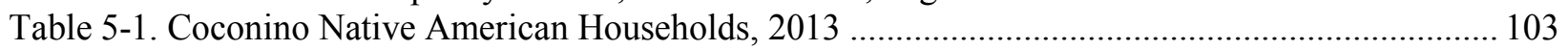

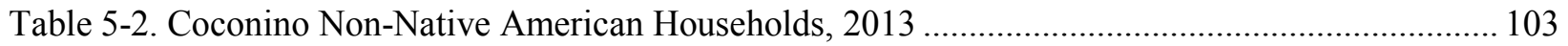

Table 5-3. Navajo/Apache Native American Households, 2013 ........................................................... 104 
Table 5-4. Navajo/Apache Non-Native American Households, 2013

Table 5-5. Rest of Arizona Native American Households, 2013 ........................................................ 105

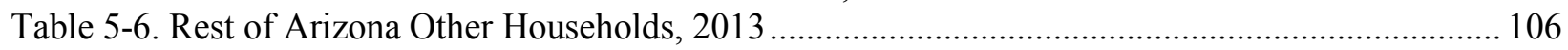

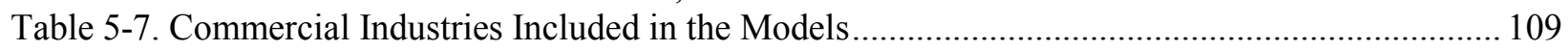

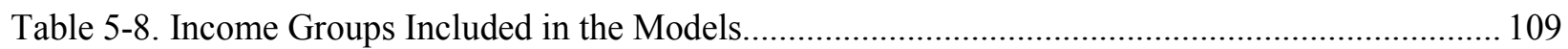

Table 5-9. Local Government Functions Included in the Models ....................................................... 109

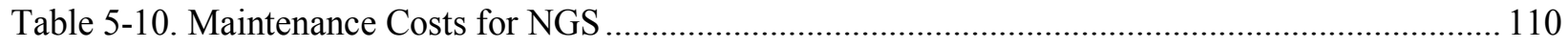

Table 5-11. Employment, Migration, and State and County Tax Revenue Impacts............................... 112

Table 5-12. Changes in Real Household Income (\$ Millions) for Native Americans .............................. 113

Table 5-13. Changes in Real Household Income (\$ Millions) for Non-Native Americans ...................... 113

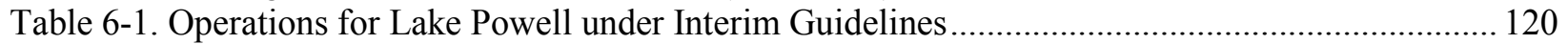

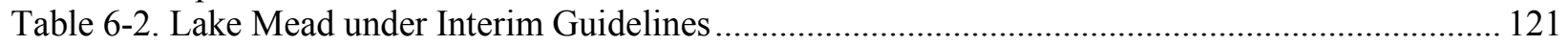

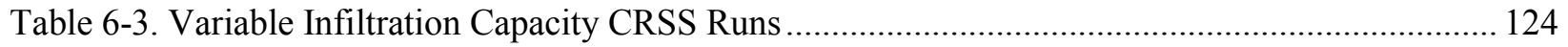

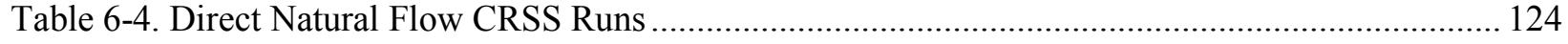

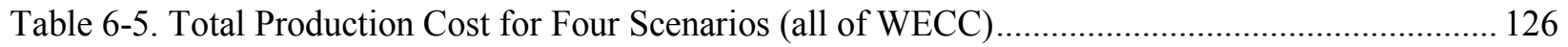

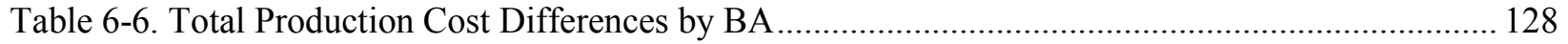

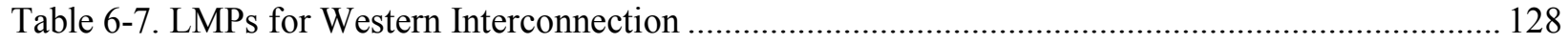

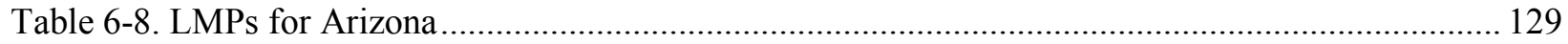

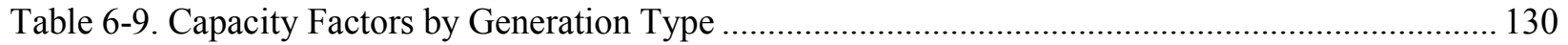

Table 6-10. Four Glide Path Scenarios for Capacity Expansion ........................................................ 132

Table 6-11. The Amount and Type of Replacement Generation Connected at Different Transmission

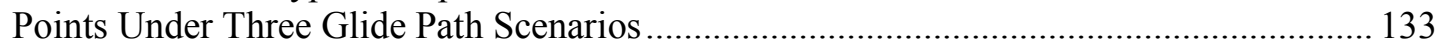

Table 6-12. Impact of Extreme Drought on Total Generation Cost......................................................... 140

Table 6-13. Median and Mean LMPs for WECC: No Drought and Extreme Drought Assumptions....... 140

Table 6-14. The Median and Mean LMPs for Arizona BAs and Percent Difference Between the No Drought Case and the Extreme Drought Case for the Couplets.......................................... 141

Table 6-15. Total Generation Cost for Capacity Expansion Strategies ................................................... 144

Table 6-16. Median and Mean LMPs for WECC Under Capacity Expansion Glide Paths...................... 145

Table 6-17. Median and Mean LMPs for Arizona Under Capacity Expansion Glide Paths .................... 145 


\section{Introduction and Background}

This study is the first of two volumes investigating long-term strategies for integrating and, over time, replacing the federal government's interest in Navajo Generating Station (NGS) with electric generation sources that emit less pollution. This volume of the study examines baseline conditions in the electricity sector independent of NGS - changes that would have an effect on all NGS constituencies regardless of whether or not the coal plant continues to operate as it has historically. Volume 2 evaluates a number of approaches for replacing the federal share of NGS with other sources of power, using the findings of this volume as a baseline for measuring the effects.

NGS has been operating since 1974. It is the largest coal-fired generating station operating in the Western Interconnection, with 2,250 megawatts (MW) of operating capacity. The plant was initiated by the U.S. Department of the Interior (DOI) in the late 1960s to provide a firm source of electricity for operating the pumps of the Central Arizona Project (CAP), which delivers most of Arizona's share of water from the Colorado River to Phoenix and Tucson. The U.S. government leveraged the plant's economies of scale by inviting a number of utilities to be coowners, ultimately partnering with Salt River Project (SRP), the Los Angeles Department of Water and Power (LADWP), Arizona Public Service Company (APS), Tucson Electric Power (TEP), and Nevada Power (now doing business as NV Energy). ${ }^{22}$

A number of factors have converged over the past few years that could affect how long NGS may continue to operate. Many of these issues are considered in an environmental impact statement (EIS) DOI is currently preparing for NGS. ${ }^{23}$ The draft EIS specifically addresses the question of whether the Secretary of the Interior should issue a Record of Decision that authorizes the plant to continue operating from 2019 to as long as 2044 under a new site lease with the Navajo Nation (the current lease expires in 2019). The draft EIS also addresses a number of other related decisions by the federal government that will arise in 2019 or shortly afterward, some of which concern the Kayenta Mine Complex, NGS' sole supply of fuel. ${ }^{24}$

"Glide path" is a term used frequently throughout both volumes of this report. In contrast to the draft EIS No-Action Alternative - in which DOI would not authorize any new administrative action, causing the plant to close in 2019 - a glide path refers to a staged transition from NGS to other sources of electricity that have fewer emissions. The glide path approach has additional flexibility to minimize economic disruption to CAP operations, Arizona Indian tribes, and other interests that currently depend on the federal government's share of NGS. A glide path contemplates continuation of NGS past 2019 to support a strategic transition in a

\footnotetext{
${ }^{22}$ LADWP sold its NGS share to SRP, with the transfer completed in July 2016. LADWP, "LADWP Accelerates Coal Power Reduction with full Divestment from Navajo Generating Plant 3.5 Years Ahead of Schedule," press release, July 7, 2016.

${ }^{23}$ U.S. Bureau of Reclamation, Navajo Generating Station-Kayenta Mine Complex Project Draft Environmental Impact Statement (Washington, D.C.: U.S. Department of the Interior Bureau of Reclamation, October 2016).

${ }^{24}$ The draft EIS "describes the potential environmental impacts from the proposed continued operations of [NGS and associated facilities] for an additional 25 years, from December 23, 2019 through December 22, 2044, plus sufficient time for decommissioning of the NGS plant and its associated facilities and reclamation of the ... Kayenta Mine Complex.... The lease under which NGS currently operates will expire on December 22, 2019." Ibid., p. 1-1.
} 
manner that simultaneously improves cost effectiveness, reduces pollution in an expeditious manner, and minimizes potential disruption to economically vulnerable populations. A glide path is similar to the EIS' Partial Federal Replacement Alternative, which would authorize operation after 2019 and "replace some portion of the United States' share of energy generated by NGS with energy generated from renewable resources or generation that reduces emissions from existing levels." 25

\subsection{Purpose of the Study}

This study follows earlier analysis of NGS by the National Renewable Energy Laboratory (NREL) that focused on the impact of adding selective catalytic reduction (SCR) to reduce nitrogen oxide $\left(\mathrm{NO}_{\mathrm{x}}\right)$ emissions at NGS. ${ }^{26}$ Among its other conclusions, the study found that:

- An NGS shutdown or a significant increase in NGS power costs would likely have a larger economic impact on interests that were dependent on the federal share of NGS than on electricity customers of the plant's utility co-owners

- There was no contingency planning for the federal share of NGS comparable to the integrated resource planning (IRP) done by each utility co-owner for its own service area.

A year after NREL released its first NGS study, DOI, EPA, and the U.S. Department of Energy (DOE) issued a joint statement committing to develop a long-term road map for the federal government's interests in NGS. The statement says that the agencies will

"work together to support Arizona and tribal stakeholders' interests in aligning energy infrastructure investments made by the Federal and private owners of the NGS (such as upgrades that may be needed for NGS to comply with Clean Air Act emission requirements) with long term goals of producing clean, affordable and reliable power, affordable and sustainable water supplies, and sustainable economic development, while minimizing negative impacts on those who currently obtain significant benefits from NGS, including tribal nations. These goals will inform Federal decisions moving forward." 27

The agencies also tasked NREL with conducting a study "to inform further development of the NGS road map." 28 The study is not the road map itself. Rather, it is designed to be a knowledge base. Decisions by various federal agencies regarding policy and new infrastructure constitute the road map; both volumes of this study provide a common body of objective information about power sector dynamics and technological options relating to a road map's electricity-related elements, as illustrated in Table 1-1.

\footnotetext{
${ }^{25}$ Department of the Interior, "Notice of Intent to Prepare an Environmental Impact Statement and Notice of Public Scoping Meetings for the Navajo Generating Station-Kayenta Mine Complex Project, Arizona," Federal Register 79 (2014): 28548.

${ }^{26}$ Hurlbut et al., Navajo Generating Station and Air Visibility Regulations.

${ }^{27}$ Department of the Interior, Department of Energy, and Environmental Protection Agency, "Joint Federal Agency Statement Regarding Navajo Generating Station,” January 4, 2013, 2.

${ }^{28}$ Ibid.
} 
Table 1-1. Analyses Relating to NGS Conducted by NREL

NREL study of NGS and Federal Resource Planning

Purpose: Establish knowledge base for federal resource decisions regarding NGS

\begin{tabular}{|c|}
\hline $\begin{array}{c}\text { Volume 1: } \\
\text { Baseline }\end{array}$ \\
\hline $\begin{array}{c}\text { Volume } 2: \\
\text { Glide path options }\end{array}$ \\
\hline
\end{tabular}

Decision making by DOI, DOE, EPA:

(Road map for policy and

infrastructure actions)

A road map would also be affected by factors apart from the power sector. Many of these other issues are institutional in nature and require a legal knowledge base that is beyond the primarily technical and economic scope of this study. The objective here is to provide a comprehensive picture of what is happening in the electric sector in order to facilitate coordination among multiple decision makers, whoever those decision makers might be.

\subsection{Focus on the Federal Share of NGS}

This study only addresses the federal government's allocation of NGS. The federal share is $24.3 \%$, which amounts to $547 \mathrm{MW}$. Four electric utilities own the remaining $75.7 \%$, and each of these utilities has its own IRP process. ${ }^{29}$ This study is not intended to replace, supplement, or even inform utility planning. On the other hand, these utility plans are important for the study's baseline because they indicate how the utilities are responding to the same sectoral trends that will influence the formation of transitional glide path for the federal share of NGS.

This study provides the federal government - especially DOI and the U.S. Bureau of Reclamation-with analysis for long-term planning comparable to what the utility partners do for their own needs. Such planning has not been done previously. Today, however, uncertainty over future carbon policies and continued low natural gas prices are affecting utility expectations, which could affect the utility partners' continued interest in NGS. LADWP, one of the plant's five original utility co-owners, has divested its position, and NV Energy has announced plans to do so by $2019 .{ }^{30}$

The federal share of NGS provides electricity for two purposes. The first is for CAP pumping. The Mark Willmer facility, the first and largest of 14 CAP pumping stations, is on the Colorado River and withdraws about half of Arizona's water allocation under the Colorado River Compact, which amounted to 1.5 million acre-feet in $2015 .{ }^{31}$ A battery of pumps lifts the water nearly 800 feet in elevation along a seven and one-quarter mile course from the river to the head of the 335-mile canal, which delivers Colorado River water to Phoenix, Tucson, and others in Central Arizona. CAP supplies irrigation to tribes such as the Gila River Indian

\footnotetext{
${ }^{29}$ In July 2016, LADWP completed the sale of its share in NGS to Salt River Project. LADWP was one of the original utility partners in NGS.

${ }^{30}$ NV Energy, "NVision Emission Reduction and Capacity Retirement Plan," fact sheet, April 3, 2013. In 2013, Nevada Gov. Brian Sandoval signed into law Senate Bill 123, which accelerates NV Energy's retirement of major coal assets, including divestiture from NGS.

${ }^{31}$ Bureau of Reclamation, Colorado River Accounting and Water Use Report: Arizona, California, and Nevada (Calendar Year 2015) (Washington, D.C.: Department of the Interior, May 2016).
} 
Community and to non-Indian agricultural users. CAP pumping requires about two-thirds of the federal government's share of NGS generation.

Federal capacity at NGS that is not used for CAP pumping is available for generating surplus power that can be sold to others. Revenues from federal surplus power sales go to the Lower Colorado River Basin Development Fund ("Development Fund"), which was created to facilitate repayment of CAP construction costs. In 2004, the Arizona Water Settlements Act (AWSA) expanded the use of the Development Fund so that some of its provisions could be implemented through the fund. Under the AWSA, the Development Fund pays the tribes' fixed operation, maintenance, and replacement charges associated with CAP water delivery. Money in the Development Fund that remains after paying other obligations may be used for other statutory purposes such as water infrastructure improvements for the CAP tribes.

In addition to these two uses of electricity, the Navajo Nation and the Hopi Tribe depend on NGS and the Kayenta Mine for tribal government revenues and for some of the Tribes' highest-wage jobs. NGS itself is located on the Navajo Reservation; the mine is situated near the Hopi-Navajo border. Thus while the two tribes are not themselves CAP water users, their status as energy producing tribes means they could be vulnerable to significant economic disruption if NGS were retired without a carefully considered transition plan. This would impact federal interests in promoting economic development in Indian Country.

Consequently, the public interests that are at stake with respect to the federal share of NGS are significantly different from the public interests that are at stake with respect to the utilities' shares of the plant. Figure 1-1 illustrates how these two sets of public interests differ. Utilities and their regulatory bodies aim to provide their customers with reliable electricity service at rates that are just and reasonable, consistent with the requirements of the Federal Power Act, state utility codes, and other requirements governing public power. In contrast, the public interest with respect to the federal share of NGS is defined by laws relating to the Colorado River Compact, laws governing the development and use of CAP, the AWSA, federal policy toward Indian tribes, and other laws that do not enter into the traditional utility IRP process. Such an array of interests requires a specially suited knowledge base, which is what this analysis is designed to provide.

\subsection{The Need for a Baseline Analysis}

The planning horizon for both volumes of this study is after 2019, and several major changes are expected after that time. These changes are of such a magnitude that historical operations would not constitute a valid "business-as-usual" benchmark for the planning horizon. Enough is known about those changes to model how NGS will operate. The more complicated question is how this new mode of operation will interact with system-wide changes affecting the rest of the Southwest power sector. 


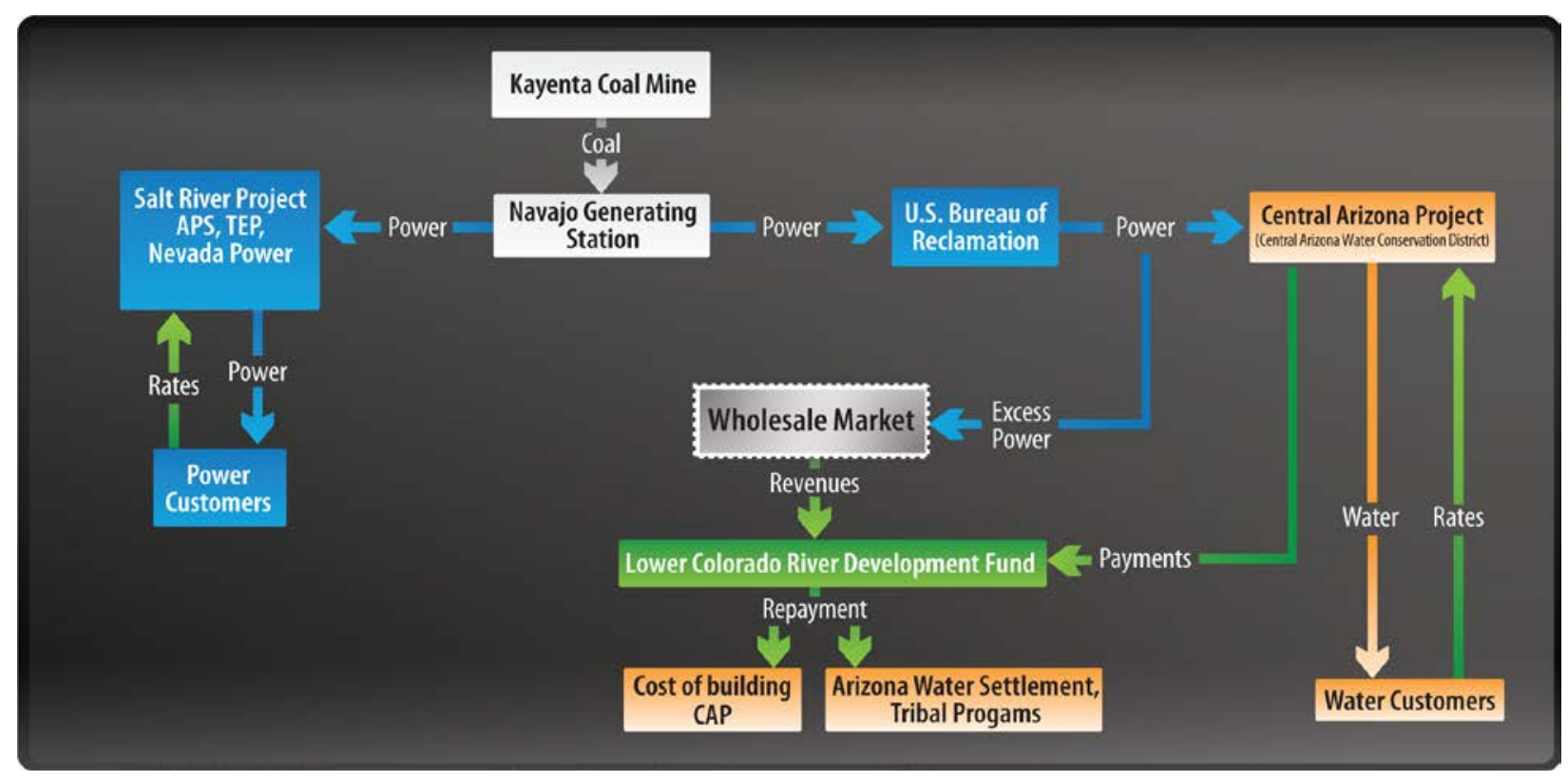

Figure 1-1. Uses and economic flows related to NGS

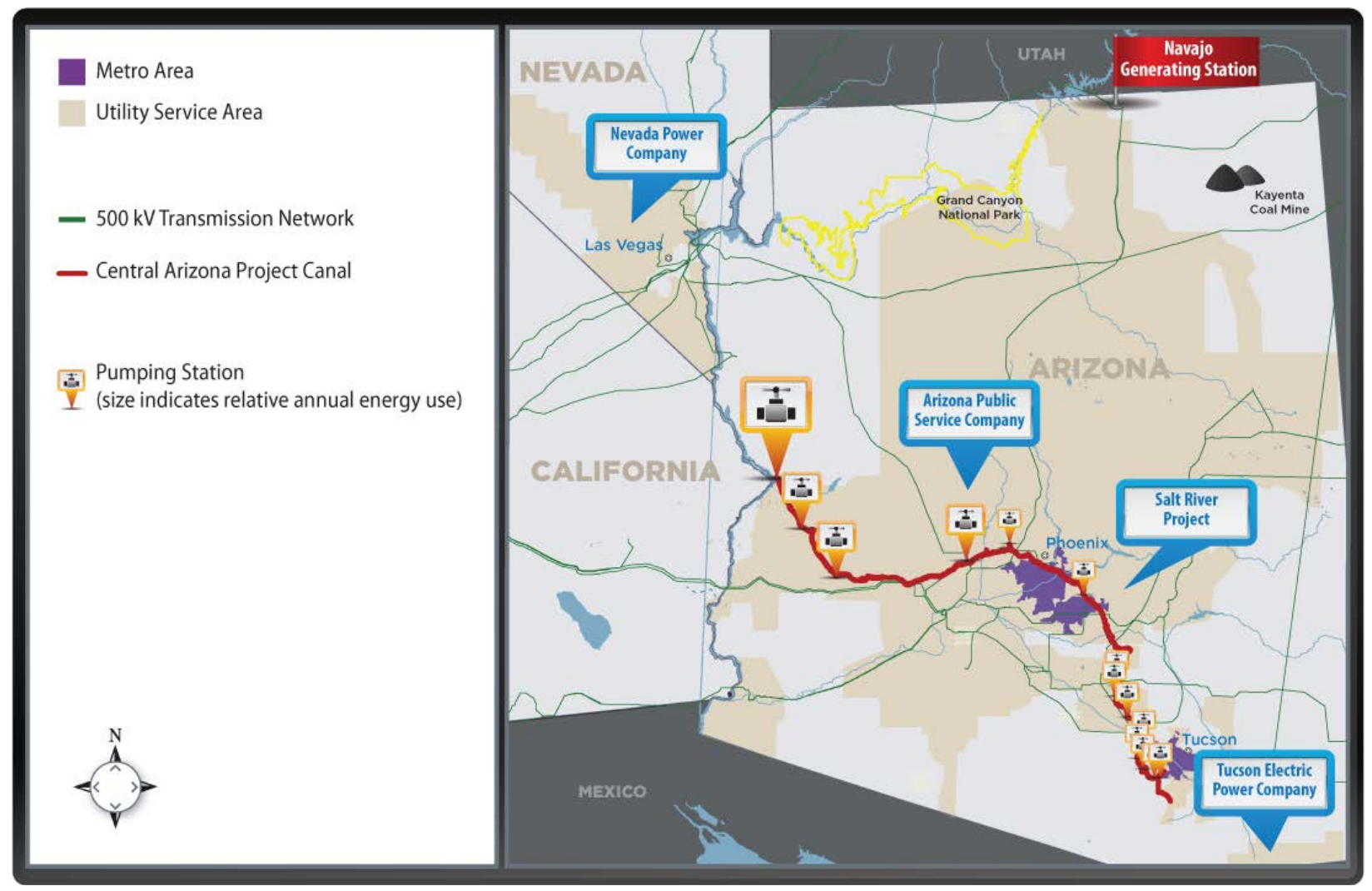

Figure 1-2. NGS, CAP, service territories of original NGS owners, and major transmission lines

Figure 1-2 shows the location of NGS in northern Arizona, the path of the CAP aqueduct, the major transmission network connecting the two, and the service territories of the plant's utility co-owners. Apart from the changes specific to NGS, other sector-wide trends are at play, involving policies such as renewable energy requirements and emission reductions. Structural 
changes affect how new capital investment is financed and how the grid itself is operated. Another major sectoral influence is the supply and price of natural gas, which - especially in 2015 and 2016 - has changed the economic balance between coal and natural gas in generating electricity. Persistently low natural gas prices correlate with less use of coal-fired generation and increasing reliance on natural gas combined cycle (NGCC) generators. (Chapter 3 examines this sectoral phenomenon in greater detail.)

\subsubsection{Federal Implementation Plan for NOx Emissions}

EPA's 2013 proposed rule for new $\mathrm{NO}_{\mathrm{x}}$ standards for NGS led to the formation of a Technical Working Group (TWG) comprising DOI, NGS utility co-owners, the Navajo Nation, Gila River Indian Community, the Central Arizona Water Conservation District (which operates the CAP), and two environmental organizations (Western Resource Advocates and Environmental Defense Fund). The TWG negotiated an alternative to the proposed rule, which EPA used as the basis for its final federal implementation plan (FIP) setting new $\mathrm{NO}_{\mathrm{x}}$ standards for $\mathrm{NGS}^{32}$

Among the FIP's major provisions are curtailing NGS operations after 2019 and deferring the installation of new $\mathrm{NO}_{\mathrm{x}}$ control technologies until 2030. Curtailment will involve either the actual retirement of one 750-MW unit at the plant, or reducing annual operations at all three units to an equivalent level. $\mathrm{NO}_{\mathrm{x}}$ emission standards for 2030 and later are based on the installation of SCR controls at the units still in operation.

The baseline operational assumptions used in this analysis are consistent with the FIP. The central scenario used in all the formal modeling for this analysis includes NGS operating with just two units from 2020 to 2044, new capital investment for SCR on the remaining two units in 2030, and the recovery of additional SCR capital costs occurring over a 15 -year period (2030 through 2044) rather than the usual 30 or 40 years. Changing NGS from three units to two could result in some redispatch of the rest of the system, which is why establishing a future baseline requires detailed power system modeling (presented in Chapter 4).

\subsubsection{Sectoral Changes}

System changes happening throughout the power sector (nationally as well as in the Southwest) also favor a careful examination of baseline conditions. Many of the conditions that made NGS a reasonable supply option for CAP half a century ago are not as pivotal today. When the federal government first proposed an NGS partnership with utilities in the late 1960s, utilities were all low-risk monopolies that for the most part operated independently of one another. Load was growing rapidly as the economy was becoming more electricity-intensive. There was no National Environmental Policy Act (NEPA), and major amendments to the Clean Air Act had yet to take effect. Nearly $60 \%$ of the nation's electricity generation came from coal or fuel oil (compared to $33 \%$ today), wide adoption of new processes enabling large

\footnotetext{
32 EPA, “Approval of Air Quality Implementation Plans; Navajo Nation; Regional Haze Requirements for Navajo Generating Station; Final Rule," Federal Register 79 (2014): 46514. See also Department of the Interior et al., "Technical Work Group Agreement Related to Navajo Generating Station."
} 
supercritical boilers was just beginning, and large-scale nuclear generation was still in its infancy. ${ }^{33}$

Today, demand in many parts of the West is no longer growing due in part to significant improvements in energy efficiency. For the new capacity that is required, environmental factors enter into the investment decision far more than they did half a century ago.

Government policies such as renewable energy targets and pollution standards under the Clean Air Act affect decisions to add new generation capacity - what type of capacity to add, and whether measures such as energy efficiency and demand response can delay when the capacity might be added. Many utilities are also trying to position themselves so that their generation portfolios are less vulnerable to rules on carbon emissions, regardless of what such rules might eventually be. For example, coal-fired generation accounts for only $3 \%$ of new capacity installed in the Western Interconnection since 2001, down from 29\% from 1980 through 2000. Reliance on existing coal units for the West's electricity needs has fallen from $35 \%$ in 2001 to $28 \%$ in $2015 .^{34}$

Utility operations today are more technically sophisticated than they were 50 years ago, a trend that appears to be continuing. NGS and the interests that rely on the federal government's share of the plant are not isolated from these changes. Technology, customer behavior, modes of grid operation, and priorities for public policy are different than they were in the late 1960s when NGS was the preferred alternative to damming the Grand Canyon.

The function of this baseline volume is to lay out some of the salient changes and to track where those changes may lead the power sector regardless of what happens to NGS. Some of these trends can be modeled to measure the likely effect on future capital investment, dispatch, and power production costs; the results are presented in other sections of this report. Here, we provide the introductory narrative of the key evolutionary factors at work and explain how they affect the options for transitioning from NGS to clean energy sources.

These underlying changes can be grouped into three categories:

- Changes in the cost and efficiency of key technologies, especially photovoltaic (PV) solar, natural gas generation, and NGS itself

- Changes in how the wholesale power sector can operate, with greater use of demandside resources such as distributed generation and increasing value of operational flexibility

- Changes in policy priorities, including state renewable energy requirements and federal rules to reduce greenhouse gas (GHG) emissions from power plants.

Each of these areas is significantly different today compared to the late 1960s. Each utility's IRP reflects its current expectations for these trends.

\footnotetext{
33 "EIA Form EIA-860 detailed data," 2013, https://www.eia.gov/electricity/data/eia860/. About 3.4 GW of supercritical coal capacity had come online before 1967 in the United States; by the time NGS was fully operational 10 years later, more than $66 \mathrm{GW}$ had come online. Additions peaked in 1973.

34 "EIA Form EIA-860 detailed data"; "Form EIA-923 detailed data," https://www.eia.gov/electricity/data/eia923/.
} 


\subsection{Organization of This Report}

This baseline analysis comprises three main topic areas. The first tracks recent cost trajectories and quantifies plausible ranges for trends extending into the near-term future. Chapter 2 begins by examining the cost of power from NGS and then projects those costs forward to 2040 . Inputs for the cost projections are the Energy Information Administration's (EIA's) forecast of coal prices, estimates of the cost impact of a new site lease with the Navajo Nation, and estimates of the cost of installing SCR on two units in 2030. The chapter then examines wholesale power prices at the Mead Hub in southern Nevada. This analysis quantifies the historical relationship between natural gas prices and wholesale power prices and then projects the trends forward using a range of natural gas price forecasts from the EIA. Finally, the chapter charts recent trends in the cost of renewable energy technologies. Utility-scale PV, which is currently the dominant renewable technology in the Arizona market, has fallen in cost significantly over the past 5 years. This section draws on NREL's most recent surveys and modeling to estimate solar costs as of mid-2016.

The report then takes a qualitative look at structural trends in the power sector. This includes not only the trend away from large coal and to mid-sized natural gas generators and renewables, but trends toward greater operational coordination across a larger geography. This has implications for the ability to sell NGS surplus power, the competitiveness of natural gas alternatives, the ability to manage greater penetrations of renewable resources, and the portfolio of resources included in an NGS glide path strategy. The chapter concludes with an overview of how utilities in the Southwest are responding to the sectoral changes.

The analysis then turns to modeling. The first modeling task examines the economic tendencies that drive the addition of new generation capacity over time. Assumptions about demand growth along with technical assumptions related to existing generation and transmission capacity are the same used by WECC and western utilities in their regional modeling. This analysis adds sensitivity cases based on different natural gas prices and different assumptions about how states meet renewable energy goals. These results for new capacity additions are then used for the next modeling task, which simulates dispatch patterns, localized energy costs, and changes in regional imports and exports of power for a test year. As with the capacity expansion modeling task, this detailed production cost modeling starts with assumptions about generator specifications, transmission limits, and reliability requirements common to those used by most utilities in their own regional modeling. The aim is to simulate what production costs are likely to be in the absence of any NGS glide path strategy.

Finally, the baseline volume includes two additional analyses. The first examines the economic impacts attributable to shifting NGS from historical three-unit operation to the two-unit operation required under the FIP. Using a series of computable general equilibrium (CGE) models, this chapter specifically examines the effects on the state and local economies after 2019. This baseline change examines the effect on total employment, and disaggregates the effect by income level and by county. More importantly, the analysis disaggregates the total effects between the counties' Native American populations and all other persons.

The other special analysis examines the potential effect of extreme drought on power grid operations in the Southwest. The aim of this analysis is to model how the system might be dispatched differently if extended drought conditions eliminated the ability of Hoover Dam and 
Glen Canyon Dam to provide hydropower. The analysis quantifies the effect of drought against normal operations, then models how three potential NGS glide path strategies might affect the Southwest's resiliency to extended drought.

\subsection{Relationship to the EIS}

NEPA requirements proscribe what the EIS must address. NREL's study of NGS is designed to complement the draft EIS by examining transition glide paths that are not anchored any specific date.

Because of much of the analysis needed to assess glide path scenarios is the same as analysis DOI needed to evaluate draft EIS alternatives - and because of the need for consistency between this study and the draft EIS - all of the analysis that was done for this volume was made available for the draft EIS. NREL also provided DOI with additional analysis specific to the draft EIS where needed. The analytical crossovers included assessments of trends in the power sector, the application of power sector forecasts by the EIA, up-to-date estimates of generation technology costs, analysis of renewable energy production potential at sites of particular relevance to the draft EIS, and system-wide technical modeling to compare the impacts of different scenarios under different assumptions about natural gas prices and other variables.

In some cases, the draft EIS timeline precluded the ability to update certain types of information. This volume includes data observed after the draft EIS analysis was performed. Key updates included trends in natural gas prices, trends in wholesale power prices at the Mead trading hub, and project costs for utility-scale PV projects. Here we present the analyses as they were provided for the draft EIS, followed by the relevant data updates. In all cases the updated data showed the continuation (and in some cases, the acceleration) of trends identified in analyses provided for the draft EIS. No trend reversed, and no accelerated or extended trend appeared to contradict any finding or conclusion in the draft EIS. NREL will continue to provide DOI with updates on market trends to inform preparation of the final EIS. 


\section{Costs and Market Prices}

Economics will be a standard metric for any NGS glide path option. Many choices will have macroeconomic consequences, but this chapter focuses on the factors that are directly related to the wholesale generation of power. Among other things, these factors include capital costs (the cost of the generation equipment along with the cost of financing), the cost of fuel, and changes in electricity demand that increase or decrease the market price of power.

Very few of these factors remain predictably constant. As the analyses in this chapter will show, even the cost of NGS power is likely to increase over time. This (combined with recent declines in the cost of solar and wind power and the historical volatility of natural gas prices) suggests that the systematic cost differences between conventional generation and commercially mature renewables could vanish sometime in the near future regardless of how NGS continues to operate. The objective of this chapter is to track current observed trends to the fullest extent permitted by the data.

A crucial question for any NGS glide path scenario is whether the clean technologies used in the strategy have a reasonable and timely chance of being priced competitively. One measure for competitiveness is how the technology's all-in cost compares to wholesale power prices. Historical trends provide some indication of whether and when a particular technology might be cost effective.

This chapter examines trends for the following costs:

- The cost of power from NGS

- Wholesale power prices at the Mead Hub

- The levelized cost of a newly built NGCC plant (assumed here to be the benchmark for future generation capacity additions), analyzed against trends in wholesale prices at the Mead Hub

- Trends in the levelized costs of wind and solar power, taking into account historical cost decreases and the technological potential for future cost decreases.

Unless otherwise noted, all data used in these analyses are adjusted for inflation using the Producer Price Index final demand for all commodities by month. Annual averages are calculated on a 12-month basis from the most recent monthly data available.

\subsection{Trends in NGS Costs}

The future cost of power from NGS is crucial to the examination of glide path options, but much of the data needed to construct a precise measure of NGS costs are considered proprietary by the plant's owners. Consequently, any analysis intended to inform public discussion faces a potential tradeoff: precision versus whether others can replicate the results. For this analysis of costs, NREL aimed to construct a methodology for projecting NGS cost trends into the future that relied on publicly available information, but relied on initial inputs that were reasonably close to actual NGS costs. 
The steps were:

1. Begin with the most recent known total cost of power from NGS

2. Separate the total cost into fuel and nonfuel components

3. Accelerate the fuel component along high and low trajectories modeled by the EIA in its 2015 Annual Energy Outlook

4. Hold the nonfuel component constant in real dollars except for two adjustments: the additional costs of the new lease agreement (assumed to take effect in 2020); and the additional cost of $\mathrm{NO}_{\mathrm{x}}$ controls (assumed to take effect in 2030)

In its biennial budget for 2014-2015, the Central Arizona Water Conservation District projected that the cost of NGS power for the CAP in 2015 would be $\$ 37.67 / \mathrm{MWh}^{35}$ This figure is the starting point (step \#1), on the assumption that it represents the all-in cost of NGS power - capital costs, fixed expenses, and variable expenses.

To isolate fuel costs, the analysis relied on reports filed by APS, the largest NGS utility partner under the jurisdiction of FERC. APS reported to FERC that its total fuel costs for NGS in 2014 amounted to $\$ 46.6$ million (in nominal dollars), and that it took $1,981 \mathrm{GWh}$ of energy from the plant for the same period. ${ }^{36}$ This equates to $\$ 23.71 / \mathrm{MWh}$ for fuel costs (adjusted for inflation to 2015 dollars), leaving $\$ 13.91 / \mathrm{MWh}$ for non-fuel costs. This analysis assumes that these costs are reasonably comparable across all NGS owners including the Bureau of Reclamation.

\section{Update to draft EIS Analysis}

APS filed its 2015 FERC Form 1 in March 2016. The company reported NGS fuel costs of $\$ 32.4$ million on generation of $1,386 \mathrm{GWh} .{ }^{37}$ This equates to $\$ 23.38 / \mathrm{MWh}$, a decrease of $1.4 \%$ compared to the inflation-adjusted estimate for 2014. In the Central Arizona Water Conservation District's most recent budget, the 2015 NGS cost is $\$ 37.99$, a $1 \%$ increase from the previous budget's projection for $2015 .^{38}$

\subsubsection{Escalating Fuel Costs}

EIA models all major components of the U.S. energy sector using its National Energy Modeling System (NEMS), which concurrently simulates energy production, consumption, and prices against various macroeconomic assumptions. The NEMS coal module simulates the economic relationships between supply and price for 22 market regions, disaggregating by coal producing regions and by types of coal categorized by heat content and sulfur content. ${ }^{39}$

The highest price trajectory for coal simulated in NEMS assumes high oil prices driven by relatively high demand for liquid fuels and relatively low global supply. The lowest price

\footnotetext{
${ }^{35}$ CAP, 2014-15 Biennial Budget (Phoenix: Central Arizona Project, 2013), http://www.capaz.com/documents/departments/finance/2014-2015-Biennial-Budget.pdf.

${ }^{36}$ APS, “2015 FERC Form 1: Electric Utility Annual Report,” 2015.

37 APS, “2016 FERC Form 1: Electric Utility Annual Report,” 2016.

${ }^{38}$ CAP, 2016-17 Biennial Budget.

${ }^{39}$ EIA, Coal Market Module of the National Energy Modeling System: Model Documentation 2014 (Washington, D.C.: EIA, 2014), http://www.eia.gov/forecasts/aeo/nems/documentation/coal/pdf/m060\%282014\%29.pdf.
} 
trajectory assumes relatively high shale gas recovery as well as higher oil and gas recovery rates. These two scenarios form the upper and lower bounds of a plausible range of future coal prices. $^{40}$

Starting with $\$ 23.71 / \mathrm{MWh}$ in 2015, we applied the year-to-year percentage price increases for each scenario's forecast of western coal prices. Using this methodology, NGS fuel costs would rise between $12 \%$ and $21 \%$ by 2030 . The range is narrow over the entire time - a band smaller than $\pm 2 \%$ of the median out to 2020 , increasing to $\pm 5 \%$ out to 2040 .

\subsubsection{Nonfuel Costs}

NGS nonfuel costs include mainly financing costs on major capital equipment, governmental payments such as taxes and leases, plant operations and maintenance (O\&M) costs, payroll, and other costs of doing business. Components of these costs could increase or decrease for numerous reasons, many of which are case-specific and not suited to systematic generalization. We therefore held these costs unchanged over time, with two exceptions. We treated both exceptions in accordance with the TWG Agreement; specifically, provisions that call for reducing operations equivalent to the retirement of one NGS unit after 2019.

The first exception is the cost of the new site lease agreement with the Navajo Nation. Media accounts of the lease approved by the Navajo Nation Council report that the agreement will increase annual revenues to the tribe by $\$ 41$ million. ${ }^{41}$ In reality, some of these costs will be fixed payments and others could change based on reductions in NGS net generating capacity. Consistent with the provisions of the new lease, we carry the payment of $\$ 9$ million per year forward as a constant lump sum, and reduce by $33 \%$ the $\$ 34$ million in additional payments that are adjusted according to changes in the plant's net generating capacity. The reduction is consistent with the retirement of one unit (or an equivalent reduction) as outlined in the TWG Agreement. This total is about $\$ 31$ million per year more than the tribe has received under the current lease. Finally, we distribute the additional \$31 million per year over the average annual net generation of two units at NGS (calculated from 2001 through 2014), resulting in an effective cost of $\$ 2.74 / \mathrm{MWh}$ in 2015 dollars. (The lease agreement includes inflation escalators, which we assume would keep the real-dollar value reasonably constant over time.)

The TWG Agreement calls for the installation of SCR and baghouses no later than 2030. It also calls for retiring one of the plant's three units in 2020 (or an equivalent reduction in operation at all three units), in lieu of installing SCR earlier. For the purposes of this analysis, NREL modeled a scenario with one unit retiring in 2020, SCRs installed on the remaining two units in 2030, and continued operation of two units to 2044 .

We carry forward from NREL's earlier NGS study the estimates of costs related to SCR with baghouses. ${ }^{42}$ These estimates were based on a three-unit upgrade plan; here, capital costs and

\footnotetext{
40 EIA, Assumptions to the Annual Energy Outlook 2015 (Washington, D.C.: EIA, 2015), http://www.eia.gov/forecasts/aeo/assumptions/pdf/0554\%282015\%29.pdf.

41 "Navajo Generating Station Lease Extension Approved for Another 25 Years," Arizona Community Press, August 12, 2013, http://azcommunitypress.org/2013/08/12/navajo-generating-station-lease-extension-approvedfor-another-25-years/.

${ }^{42}$ Hurlbut et al., Navajo Generating Station and Air Visibility Regulations.
} 
the annual O\&M costs are reduced by one-third to represent best available retrofit technology improvements on two units rather than three. One significant change from the Phase 1 analysis is the assumption that capital costs will be recovered over 15 years rather than 30 . This embodies the assumptions that NGS owners will defer the upgrade as long as allowed under the TWG Agreement (2030) and will operate the remaining two units through 2044. This accelerated capital cost recovery increases the cost of NGS power attributable to the new $\mathrm{NO}_{\mathrm{x}}$ controls beyond what was estimated in the Phase 1 analysis. As with the cost of the new lease, we further assume generation at the two remaining units from 2030 through 2044 is consistent with historical operation from 2001 through 2014. In 2015 dollars, this works out to an additional $\$ 9.84$ per MWh in 2030. Because of the time required to design and build the SCR modifications, we assume SCR-related costs begin in 2026 and gradually increase to $\$ 9.84 / \mathrm{MWh}$ in $2030 .^{43}$

\subsubsection{Combined Cost Trended Forward}

Total NGS costs are the combination of fuel costs trended forward and the discrete changes in nonfuel costs. The trend at key benchmark years (based on EIA's coal price forecasts in 2015, used in the earlier analysis NREL provided for the draft EIS) were:

- In 2020, between $\$ 44 / \mathrm{MWh}$ and $\$ 46 / \mathrm{MWh}$

- In 2030, between $\$ 66 / \mathrm{MWh}$ and $\$ 69 / \mathrm{MWh}$

The assumptions used to compute this cost forecast represent the boundary conditions specified in the TWG Agreement. The assumptions do not account for major unforeseen changes in the political or economic landscape that could accelerate NGS retirement or reduce operations more than the TWG Agreement dictates.

Some nonfuel costs are unrelated to whether NGS operates as two units or as three. Some of these costs, moreover, would be reallocated among the remaining NGS owners if and when one owner were to divest its ownership position. These effects are not captured in the simplified methodology applied here due to concerns over proprietary information, and due to the fact that the terms of the divestitures and reallocations are unknown as of this writing. Nevertheless, it is likely that reallocation will result in costs for the remaining owners that trend slightly higher than trends modeled here. This lends greater probabilistic weight to the higher bounds of the range estimated here.

\section{Updates to draft EIS Analysis}

Fuel costs were adjusted based on APS' 2015 FERC Form 1 data and on EIA's 2016 coal price forecasts. The resulting trend for NGS costs in 2020 is between $\$ 39 / \mathrm{MWh}$ and $\$ 41 / \mathrm{MWh}(8 \%$ to $15 \%$ less than when calculated based on data for the previous year as provided to the draft EIS). Projected to 2030, the trend is between $\$ 48 / \mathrm{MWh}$ and $\$ 53 / \mathrm{MWh}(20 \%$ and $30 \%$ less than

\footnotetext{
${ }^{43}$ Because SCR technology meets a rarefied type of demand, there is insufficient market information to estimate how its cost or efficiency might change between now and 2030. This analysis defaults to the assumption that, in the absence of information suggesting a change in any direction, inflation-adjusted costs will plausibly remain constant. However, the range for total NGS costs in 2030 as defined by potential variations in coal prices is equivalent to a $\pm 25 \%$ variation in $\mathrm{SCR}$ costs.
} 
earlier calculations). Figure 2-1 depicts the updated cost trends. The net effect of these updates on the overall economic competitiveness of NGS needs to account for updated projections of wholesale power prices at the Mead Hub, which are also significantly lower when EIA's 2016 forecasts are used. The next section describes the analysis of wholesale prices, and the update includes a discussion of the potential impact on NGS economic competitiveness.

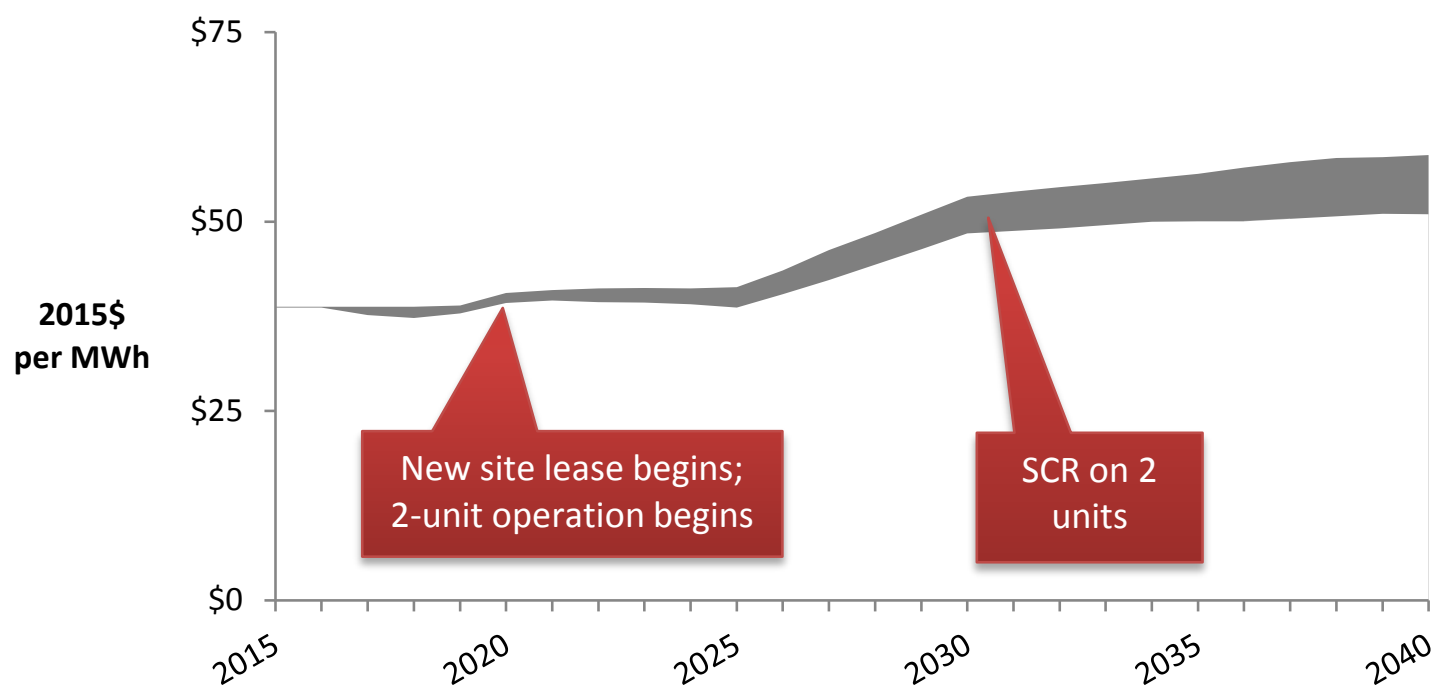

Figure 2-1. Range of future NGS power costs forecasted by NREL ${ }^{44}$

\subsection{Wholesale Prices at the Mead Hub}

Reclamation has a special long-term sale contract for 220,800 MWh of surplus power annually from the federal share of the plant during high-load hours. This amounts to about $15 \%$ of what is normally available out of the federal share after providing power for CAP, and provides a stream of revenue that for the most part does not change with prices on the spot market. ${ }^{45}$ The remainder of the federal surplus is available for other buyers. Whether this remaining portion of the surplus is sold or curtailed is influenced significantly by wholesale market conditions.

The Mead Hub, to which NGS connects via its northern transmission line, is one of the most active wholesale power trading points in the Southwest. ${ }^{46}$ This section builds a market analysis around Mead Hub prices using their historical correlation with natural gas prices. The analytical questions are:

- What is a plausible range of future market prices at the Mead Hub, and where might future NGS generation costs fall in relation to that range?

\footnotetext{
${ }^{44}$ Coal price forecast data are based on EIA, "Energy Prices," in Annual Energy Outlook 2016 (Washington, D.C.: EIA, 2016), http://www.eia.gov/forecasts/aeo/section_prices.cfm, National Energy Modeling System, Coal Production and Minemouth Prices by Region. Price forecasts for Western coal are indexed to 2015, and index values are applied to fuel costs reported by APS in its FERC Form 1 filings.

${ }^{45}$ Reclamation received about $\$ 36$ million from this contract in 2015 , which was applied toward reducing CAP costs.

${ }^{46}$ Geographically, Mead is the switchyard adjacent to the Hoover Dam in southern Nevada. Market information services such as SNL Energy identify Mead as an electricity trading hub; CAISO's market includes Mead as a price node.
} 
- What does the plausible range of future Mead prices suggest about the economics of a newly built NGCC plant?

- Are the likely economics of a new utility-scale wind or solar facility significantly different from the economics of a new NGCC?

This section specifically addresses the first two questions; the next section addresses the third.

The time series used in this analysis begins April 1, 2009, the go-live date of the California Independent System Operator's (CAISO's) current market design. From April 1, 2009, to October 31, 2014, Mead day-ahead prices have increased from an annual average of about $\$ 38 / \mathrm{MWh}$ in 2009 to $\$ 47 / \mathrm{MWh}$ in 2014 (Figure 2-2). ${ }^{47}$ The decline in Mead prices from 2011 to 2012 corresponds to the decline in natural gas prices over that same period, while the subsequent rise can be attributed to a combination of natural gas price increases and the launch of California's GHG cap-and-trade program on January $1,2013 .{ }^{48}$

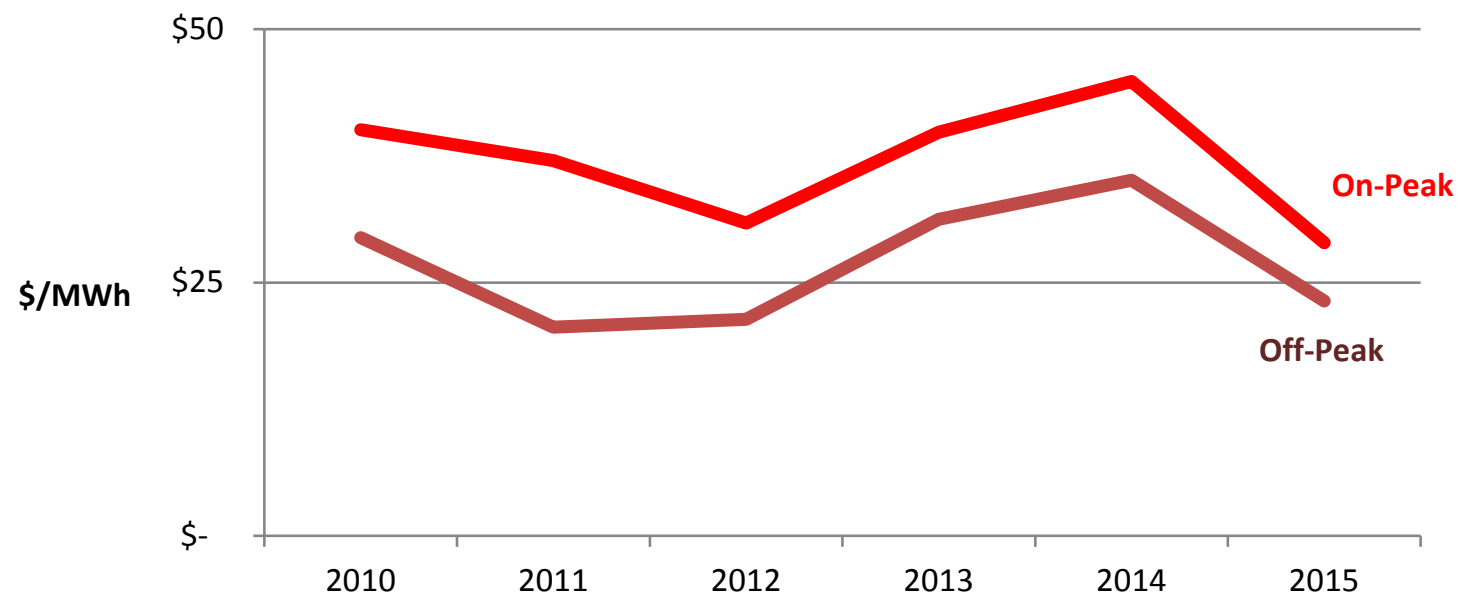

Figure 2-2. Mead Hub historical day-ahead peak and off-peak price (average for year) ${ }^{49}$

The first step of this analysis was a statistical comparison of the historical relationship between natural gas prices and wholesale power prices. Natural gas prices are often correlated with power prices, and the statistical analysis examined the systematic strength of this relationship specific to the Mead Hub. The objective was to identify a plausible range of future power prices within which to test the cost of a newly constructed NGCC (and, ultimately, the cost of future renewable technologies).

\footnotetext{
${ }^{47}$ Day-ahead prices from each source are employed for this analysis because the vast majority of energy is transacted in the day-ahead market (as opposed to 15-minute- or 5-minute-ahead markets). According to the CAISO's Department of Market Monitoring, 97\% of physical system load was transacted in the day-ahead market in 2013. See CAISO, 2013 Annual Report on Market Issues \& Performance (Folsom: California Independent System Operator, 2014), http://www.caiso.com/Documents/2013AnnualReport-MarketIssue-Performance.pdf, 1. ${ }^{48}$ CAISO, 2014 Annual Report on Market Issues \& Performance (Folsom: California Independent System Operator, 2015), http://www.caiso.com/Documents/2014AnnualReport_MarketIssues_Performance.pdf, 43. 49 SNL Energy," Mead Hub day-ahead spot power price indexes, annual averages."
} 
The model tested wholesale power prices (peak and off-peak prices modeled separately) against natural gas prices and total load. Both of these parameters - as well as the model overall—demonstrated strong explanatory power at high levels of confidence. ${ }^{50}$ The resulting equations were:

$$
\begin{aligned}
& \hat{P}_{\text {peak }, t}=-19.08+8.77 * \text { gas }_{t}+0.97 * \text { peak } M W_{t} \\
& \hat{\mathrm{P}}_{\text {offpeak }, \mathrm{t}}=-3.84+6.73 * \text { gas }_{\mathrm{t}}+0.58 * \text { offpeak } \mathrm{MW}_{\mathrm{t}}
\end{aligned}
$$

where

$\begin{array}{lll}\widehat{\mathrm{P}}_{\text {peak }, t} & = & \text { predicted on-peak power price for year } t \\ \widehat{\mathrm{P}}_{\text {offeak }, t}= & \text { predicted off-peak power price for year } t \\ \text { gas } & = & \text { EIA projected Henry Hub natural gas price for year } t \\ \text { peak } \mathrm{MW}_{\mathrm{t}}= & \text { projected average peak-hour load for year } t \\ \text { off-peak } \mathrm{MW}_{\mathrm{t}}= & \text { projected average off-peak-hour load for year } t\end{array}$

Many factors, in addition to natural gas price and load, influence wholesale energy prices. These can include temperature, power generation resource mix, power plant availability, and other changes in system operations. A more complex model for more precisely predicting future power prices would be necessary to incorporate the effect of these factors. The goal here is more modest: to establish a plausible range of future wholesale energy prices. The assumption here is that load and the price of natural gas exert the strongest influences on power prices, and that the effects of other exogenous factors occur largely during extreme weather events or other system shocks that are outside the scope of the questions examined here.

Two sets of EIA natural gas price forecasts were applied: one from EIA's reference case in its

\begin{tabular}{|c|c|c|c|}
\hline & & On-Peak & Off-Peak \\
\hline & Number of observations: & 765.000 & 909.00 \\
\hline & Adjusted $\mathrm{R}^{2}$ & 0.710 & 0.629 \\
\hline & Intercept & -19.075 & -3.838 \\
\hline & Natural gas price & GAS & GAS \\
\hline & Coefficient & 8.77 & 6.73 \\
\hline & t statistic & 38.42 & 38.501 \\
\hline & $P$ value & $<0.0001^{*}$ & $<0.0001^{*}$ \\
\hline & Day-ahead load & ONLOAD & OFFLOAD \\
\hline & Coefficient & 0.97 & 0.58 \\
\hline & t statistic & 20.21 & 9.10 \\
\hline & $P$ value & $<0.0001^{*}$ & $<0.0001^{*}$ \\
\hline & \multicolumn{3}{|c|}{${ }^{*}$ Significant at $95 \%$ confidence interval } \\
\hline
\end{tabular}
2015 Annual Energy Outlook; and a High Oil and Gas Resource sensitivity case in which EIA 
tested high natural gas supply assumptions and their resulting low natural gas prices. ${ }^{51}$ Projected load was based on analysis by the California Energy Commission (CEC), which expects energy demand to increase $1.23 \%$ per year from 2013 to 2025 across California. ${ }^{52}$ This analysis applies the CEC forecast to hourly load (averaging peak and off-peak hours for each day) observed from 2013 to 2015 , projecting these averages yearly through $2030 .^{53}$

\section{Updates to draft EIS Analysis}

The analysis of prices at the Mead Hub that NREL provided to Reclamation for the draft EIS in October 2015 was based on EIA natural gas price forecasts that were current as of that date. EIA revised its natural gas price projections in 2016, taking into account the low prices seen in $2015 .{ }^{54}$ The CEC also adjusted its demand growth projection at the end of 2015: down to $0.97 \%$ per year from 2014 to 2026 , compared to the previous projection of $1.23 \%$ per year from 2013 to $2025 .{ }^{55} \mathrm{CEC}$ attributed the slower rate through 2025 to additional appliance standards and a reassessment of energy efficiency standards for buildings.

Figure 2-3 and Figure 2-4 show the updated projections for Mead Hub prices along with the updated NGS cost forecast described in the previous section. 56 The updated projections resulted in trends for day-ahead peak wholesale energy prices at Mead Hub that were lower than those originally calculated based on earlier EIA natural gas price forecasts. Actual 2015 prices were $12 \%$ to $23 \%$ less than the earlier projections, with the trend out to $20306 \%$ to $11 \%$ lower. Thus the projections for both wholesale power prices and NGS costs were adjusted downward from the analyses initially provided for the draft EIS.

\footnotetext{
${ }^{51}$ In this case, EIA predicts higher technological development and recovery per well, with closer well spacing than the reference case, resulting in Henry Hub natural gas spot prices 36\% below the Reference case in 2020 and $44 \%$ below the Reference case in 2040. See EIA, "Energy Prices."

${ }^{52}$ Chris Kavalec, California Energy Demand Updated Forecast, 2015-2025 (Sacramento: California Energy Commission, 2014), http://www.energy.ca.gov/2014publications/CEC-200-2014-009/CEC-200-2014-009-SD.pdf.

${ }^{53}$ The observed average for on-peak load from 2013-2015 was $28.74 \mathrm{GW}$. The observed average off-peak load used to conduct the prediction is the observed average for off-peak load from 2013-2015, or 22.71 GW.

${ }^{54}$ See EIA, "Energy Prices" in Annual Energy Outlook 2016.

${ }^{55}$ Both cases refer to Mid Energy Demand scenario of statewide electricity demand. For projections updated at the end of 2015, see Kavalec, California Energy Demand Updated Forecast, 2015-2025.

${ }^{56}$ Because the upper and lower bounds of each range were modeled separately, each one has its own confidence interval. The approximate $95 \%$ confidence interval of the predicted on-peak price with the given parameters is $+/-$ \$9.40. The interval for off-peak prices is $+/-\$ 7.80 / \mathrm{MWh}$.
} 


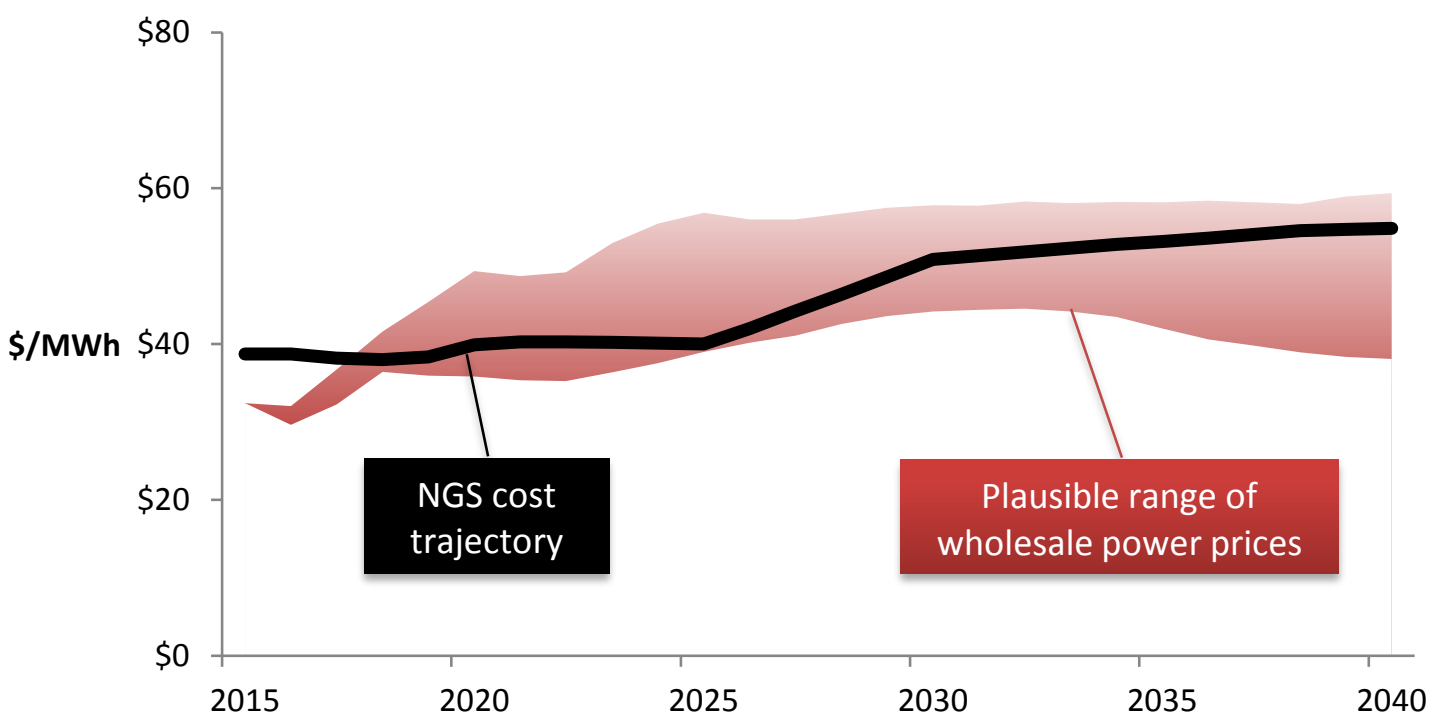

Figure 2-3. Mead Hub peak energy prices (2015 actual, projections for 2016-2040)

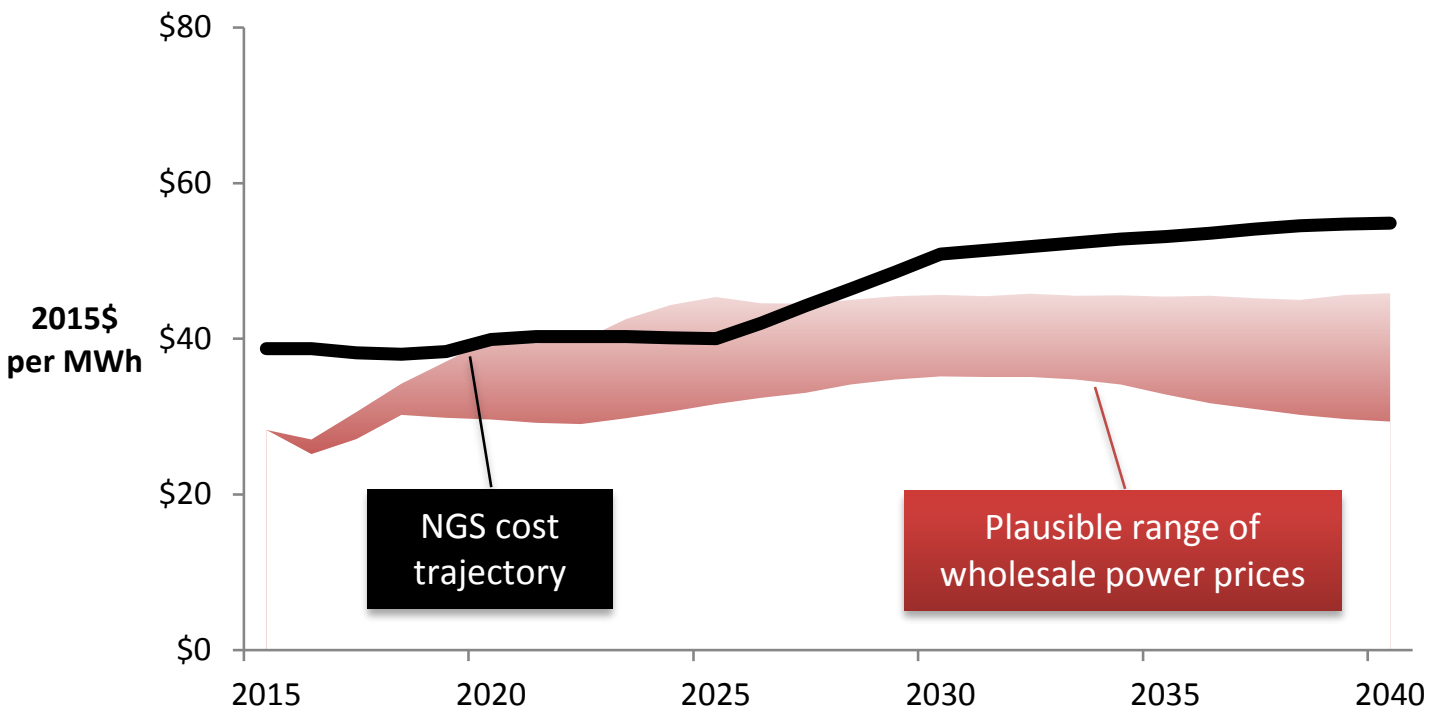

Figure 2-4. Mead Hub off-peak energy prices (2015 actual, projections for 2016-2040)

The updated projections suggest that in the near term, generating electricity at NGS is likely to be more expensive than the cost of purchasing power on the wholesale market, which could affect the government's ability to sell NGS surplus power. One indication of economic competitiveness is that NGS net generation for 2015 was $18 \%$ less than in 2014, with data for the first half of 2016 showing further reductions compared to the first half of $2015 .{ }^{57}$ This drop

\footnotetext{
${ }^{57}$ SNL Energy, "Database on unit net generation." Average reductions were calculated by unit and exclude months affected by maintenance outages.
} 
in generation is consistent with the near-term trends shown in Figure 2-3 and Figure 2-4, where NGS costs are higher than wholesale power prices.

The updated trends suggest that NGS could remain more expensive than power purchased on the wholesale market until 2018 if natural gas prices move higher, and possibly until 2025 if prices for natural gas and wholesale power remain low. These trends mean that the ability to sell surplus power from the federal share of NGS on the wholesale market is uncertain and will likely remain so for a period of time that will be determined by natural gas prices.

\subsection{Trends Affecting New NGCC Capacity}

A standard spark spread calculation based on these projected prices suggests that market prices are unlikely to provide enough revenue to support investment in a new NGCC for much of the projection period. ${ }^{58}$ High gas prices offer the most revenue to a new NGCC plant in 2030 about \$28/MWh during peak hours, declining to about \$14/MWh during off-peak times. In this favorable case, a new wet-cooled plant might meet minimum revenue requirements during onpeak times as early as 2023, whereas a dry-cooled plant might be economic at on-peak times in 2030 .

The spark spread is a measure of the theoretical operating profits of a power plant in the electricity market considering fuel costs as the only operating expense. ${ }^{59}$ The spark spread measures the headroom for recovering all other variable (O\&M) and fixed costs (capital cost). The formula for the spark spread is:

$$
\mathrm{SS}_{t}=\mathrm{P}_{t}-\left(\mathrm{HR} \times \mathrm{NG}_{t}\right)
$$

where

\begin{tabular}{|c|c|c|}
\hline $\mathrm{SS}_{\mathrm{t}}$ & $=$ & spark spread at time $t$ \\
\hline$P_{t}$ & $=$ & wholesale power price at time $t$ \\
\hline HR & $=$ & heat rate corresponding to the type of turbine examined \\
\hline $\mathrm{NG}_{\mathrm{t}}$ & $=$ & price of natural gas at time $t$ \\
\hline
\end{tabular}

If the energy from a new NGCC plant is imported into California, the rules of the state's GHG cap-and-trade program require the importer to acquire and retire carbon allowances to offset the carbon dioxide $\left(\mathrm{CO}_{2}\right)$ emissions from the plant's operations. In practice, many generators have incorporated the cost of allowances as a component of broader costs, which include both the expense of buying natural gas and of procuring allowances to cover emissions from its combustion. This gives rise to a "clean" spark spread:

$$
\mathrm{SSC}_{t}=\mathrm{P}_{t}-\left(\mathrm{HR} \times \mathrm{NG}_{t}+A_{t} \times \mathrm{E}\right)
$$

where

\footnotetext{
${ }^{58}$ It is expected that capital costs will remain constant through 2030, suggesting that critical revenue requirements will also remain constant. See Blair et al., Annual Technology Baseline Supporting Data.

${ }^{59}$ For more on spark spreads, see "An Introduction to Spark Spreads," Today in Energy, February 8, 2013, http://www.eia.gov/todayinenergy/detail.cfm?id=9911.
} 


$\begin{array}{lll}\mathrm{SSC}_{\mathrm{t}} & = & \text { clean spark spread at time } t \\ \mathrm{~A}_{\mathrm{t}} & = & \text { price of GHG allowances at time } t \\ \mathrm{E} & = & \text { emission factor of the turbine examined }\end{array}$

A spark spread is calculated for an assumed indicative heat rate. This analysis uses 6.5 million British thermal units per megawatt-hour ( $\mathrm{mmBtu} / \mathrm{MWh}$ ) as representative of a highly efficient, newly constructed NGCC - assumed throughout this analysis to be the conventional technology most likely to compete with renewables for new capacity opportunities. ${ }^{60}$ Natural gas prices are taken from CAISO's SoCal natural gas price index. Power prices are the dayahead locational marginal prices (LMPs) for CAISO's Mead node. The clean spark spread uses GHG allowance price as reported by CAISO's daily index.

A new plant's revenue requirement for recovering capital costs - that is, the margin it needs to earn above wholesale power prices - is based on the plant running at a $70 \%$ capacity factor. A new NGCC is assumed to cost $\$ 1,200 /$ kilowatt $(\mathrm{kW})$ for wet cooling and $\$ 1,300 / \mathrm{kW}$ for dry cooling, financed over 30 years at a weighted average capital cost of $8.12 \%$, with no significant change in constant-dollar capital costs over the period examined. This works out to $\$ 24 / \mathrm{MWh}$ for wet-cooled installations and $\$ 28 / \mathrm{MWh}$ for dry-cooled installations.

Neither the standard nor the clean spark spread indicate operating revenue from energy prices at Mead that are sufficient to cover the capital costs of a new NGCC facility (see Figure 2-5). The margin has been improving since 2012, but at no time has it reached the $\$ 24 / \mathrm{MWh}$ benchmark for a new wet-cooled NGCC.

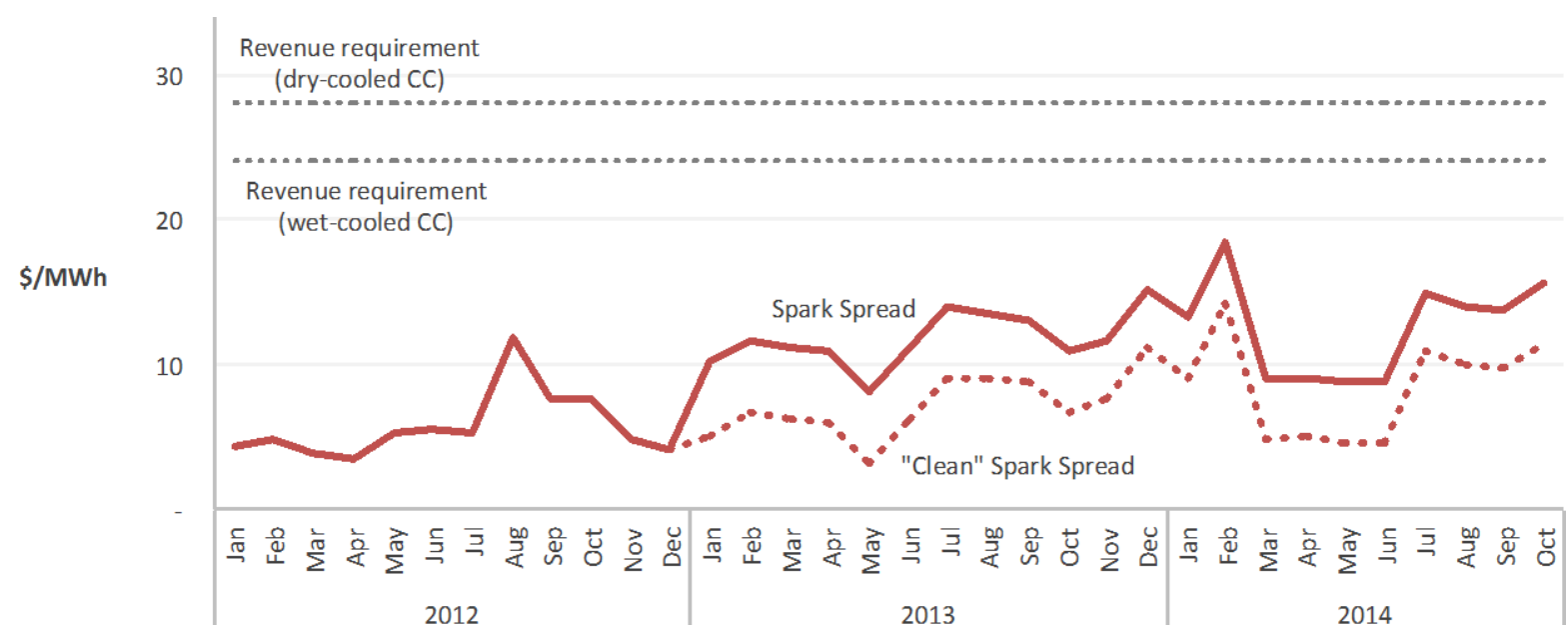

Figure 2-5. Spark spread and clean spark spread at the Mead node

\footnotetext{
${ }^{60}$ Very few NGCC plants achieve this level of efficiency, but we use that benchmark here to exaggerate the influences that enter into the spark spread calculation. EIA's Annual Energy Outlook assumes a heat rate of 7.05 $\mathrm{mmBtu} / \mathrm{MWh}$ for new conventional NGCC plants. Other EIA analyses suggests that the most efficient NGCC plants have a heat rate somewhat below $7 \mathrm{mmBtu} / \mathrm{MWh}$. See "Daily Prices," Today in Energy, http://www.eia.gov/todayinenergy/prices.cfm. Using either of these higher indicative heat rates would have pushed the spark spread even further below the revenue requirement benchmark, making new investment even less profitable.
} 


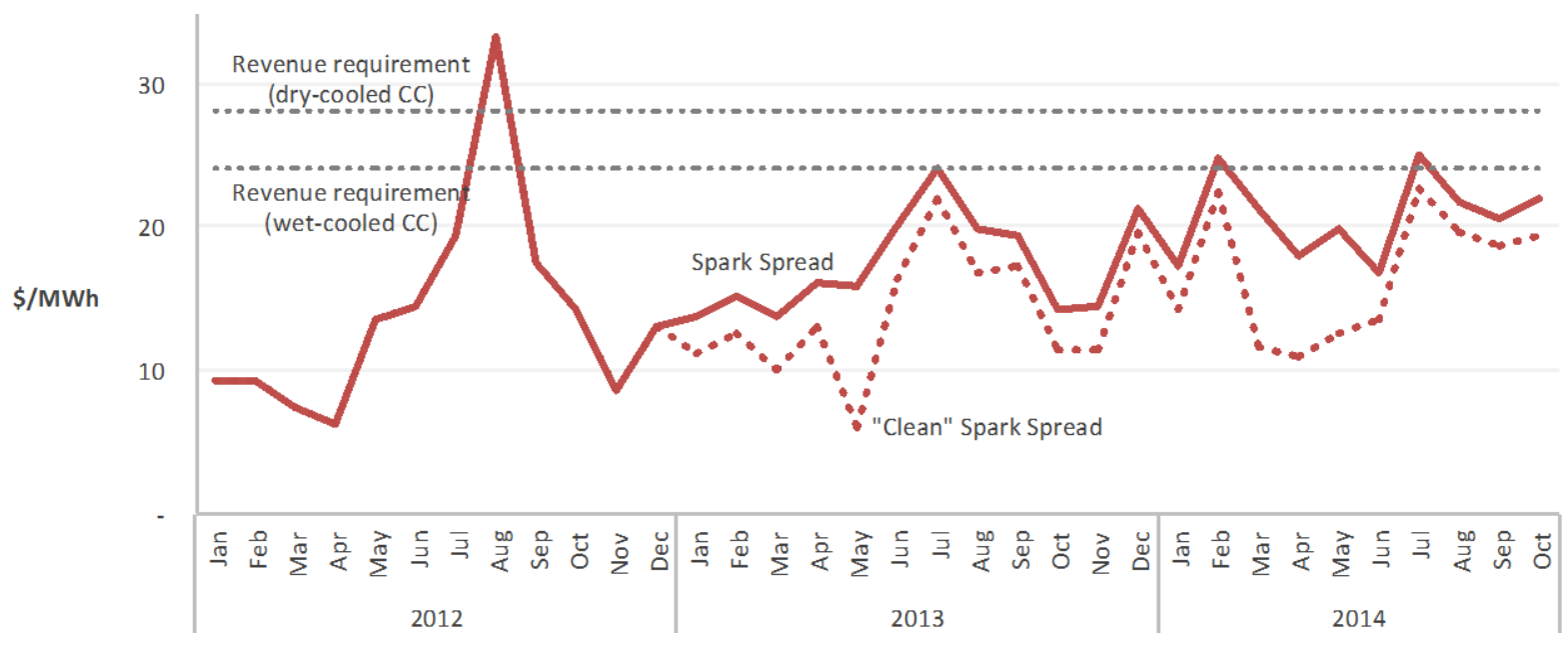

Figure 2-6. Selective spark spreads at Mead (70\% of hours with highest prices)

A "selective" spark spread (Figure 2-6) provides slightly more economic headroom than a conventional spark spread analysis does and can provide a sensitivity test to supplement the basic spark spread trend. A selective spark spread indirectly adds economic value to a new NGCC plant that could be associated with potential decision factors besides wholesale prices. Such factors could include local reliability needs, policy directives, or differences in risk aversion. In this sensitivity, the spark spread is derived from the $70 \%$ of hours during the year when spark spreads are the highest. (Recall that a facility with a $70 \%$ capacity factor would only run part of the time.) That is, the NGCC plant hypothetically operates selectively and only during those $70 \%$ of hours when wholesale power prices are high and natural gas prices are low. While in practice an NGCC would not be operated in this manner, modeling it is useful as a sensitivity analysis because it serves as a way to systematically augment the value of a new NGCC in the spark spread framework.

Even using this optimistic assumption of perfectly selective hourly operation, the standard and clean spark spreads rarely reach into the revenue requirement range. This supports the conclusion that recent Mead Hub prices generally have not been favorable to the construction of a new NGCC plant.

A new NGCC facility that is part of an NGS glide path strategy could also provide power for Arizona. Unlike CAISO, wholesale energy prices for Arizona's three vertically integrated utilities - APS, SRP, and TEP — are not set by day-ahead and real-time auctions based on a security-constrained economic dispatch, nor do they face emissions costs.

Avoided costs that have been determined for APS and TEP function as an approximation of the utilities' marginal cost, although without the day-to-day specificity that LMPs provide in CAISO. The avoided costs of SRP are determined via the utility's power purchase prices. Some of these rates vary by season and peak period. To represent the "best case" estimate of operating revenues for all three utilities, the highest known purchased power price is employed. All avoided cost values for the utilities were in the \$20-\$30/MWh range. 


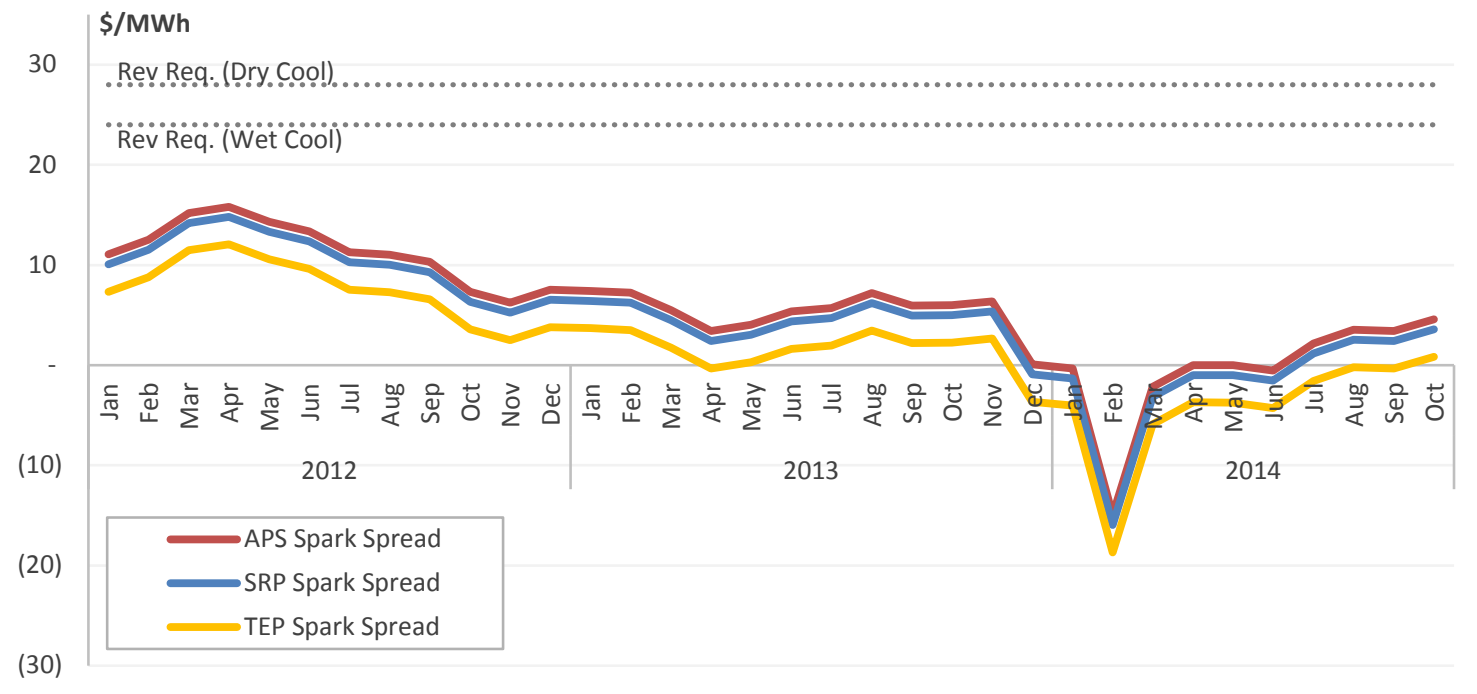

Figure 2-7. Spark spreads in Arizona inferred from utility avoided costs

Figure 2-7 illustrates the spark spreads for a new NGCC facility in this market based on the utilities' current avoided costs. The spark spread for all three Arizona utilities falls short of the revenue requirements for a new NGCC facility.

A utility may, for its own reasons, build a new NGCC and obtain approval for adding it to rate base even if wholesale power prices are low. Rate base revenues for a regulated utility come from customers directly through retail rates. This revenue stream, which is separate from the wholesale power prices examined here, provides a regulated utility with a virtually guaranteed source of capital cost recovery. (Nonutility merchant generators do not have a comparable source of guaranteed revenue for capital costs and must rely solely on negotiated prices and wholesale power prices.)

Utility-specific decisions for adding a new NGCC are not represented in this analysis. The aim here is to assess how observable prices can shape current and future market conditions, recognizing that these modeled conditions will affect — but not necessarily determine — actual capacity expansion decisions. Similarly, the analysis is not intended to present a formal forecast of energy prices in the Southwest through 2030. Rather, it provides more information for decision making and provides qualitative conclusions about the state of the regional wholesale energy market.

\section{Updates to draft EIS Analysis}

Spark spread values fell further during the first half of 2016 compared to the first half of 2015. As noted previously, natural gas prices were about 26\% lower while Mead Hub prices were $19 \%$ to $\$ 22 \%$ lower. The resulting spark spread values (for a highly efficient new NGCC with a heat rate of $6.5 \mathrm{mmBtu} / \mathrm{MWh}$ ) fell by between $7 \%$ and $12 \%$, indicating even further erosion in the ability to recover capital costs on a new NGCC. 


\subsection{Technology Cost Trends}

The expected costs of different electricity sources are one key input into utilities' decisions regarding new generation. Solar and wind generation have seen significant cost declines recently, while increases in shale gas production have resulted in cheaper natural gas prices and, consequently, lower prices throughout the wholesale power market. As a result, these three sources of electricity have been the most commonly procured resources in recent years, with solar and wind generally procured to satisfy state renewable energy mandates and natural gas used to serve additional load requirements. ${ }^{61}$

The costs associated with both solar and wind will likely further decline in the future. In comparison, natural gas generation costs are expected to increase over time in connection with higher fuel costs. The pace at which renewable energy costs decline and natural gas costs increase will affect the viability and timing of NGS clean energy glide path scenarios.

Assumptions about the future cost of electricity generation from these sources are inherently uncertain. The approach used here examines renewable energy cost trends relative to a newly built NGCC plant. The future all-in cost of each technology is represented by its estimated levelized cost of energy (LCOE), which annualizes capital costs based on a common set of economic assumptions and captures potential changes in future fuel costs. NREL developed its Annual Technology Baseline (ATB) and Standard Scenarios as a regularly updated platform for cross-technology comparison, and these estimated costs form the basis of examining NGS glide path options. ${ }^{62}$

\subsubsection{Natural Gas}

Natural gas combined cycle plants are a mature technology, so significant technology improvements to reduce capital costs will likely be small. This suggests that the capital cost of combined cycle plants could remain relatively stable out to 2030 . The price of natural gas, on the other hand, has historically been variable and difficult to predict.

NREL estimated the all-in cost of electric generation for several potential full-replacement and partial-replacement alternatives for the federal share of NGS as supporting analysis for the draft EIS. The estimates of all-in costs combined fixed capital costs and variable costs into an LCOE, expressed in dollars per megawatt-hour $(\$ / M W h)$. Values were calculated assuming an in-service date of 2020, consistent with the time frame examined in the draft EIS.

The LCOE for combined cycle generation was calculated as a range of values that were a function of the future cost of natural gas. Capital costs were held constant out to 2020. The

\footnotetext{
${ }^{61}$ See April Lee, "Half of Power Plant Capacity Additions in 2013 Came from Natural Gas," Today In Energy, April 8, 2014, http://www.eia.gov/todayinenergy/detail.cfm?id=15751; April Lee, "Natural Gas, Solar, and Wind Lead Power Plant Capacity Additions in First-Half 2014," Today in Energy, September 9, 2014, http://www.eia.gov/todayinenergy/detail.cfm?id=17891.

${ }^{62}$ NREL, 2016 Annual Technology Baseline, Golden, CO: National Renewable Energy Laboratory http://www.nrel.gov/analysis/data tech baseline.html (ATB), 2016. NREL updates the ATB on a yearly basis to provide a realistic and timely set of input assumptions to be applied consistently in NREL's significant analyses throughout the following year. This work leverages and continues significant activity already being funded by DOE through program offices for individual electricity generation technologies and for specific market segments.
} 
baseline assumption for Henry Hub natural gas prices was $\$ 4 / \mathrm{mmBtu}$, which was consistent with 2014 prices. The initial analysis postulated that abundant gas supplies and low demand could pull prices down to $\$ 3 / \mathrm{mmBtu}$, and that supply scarcity and higher demand could push prices up to $\$ 5 / \mathrm{mmBtu}{ }^{63}$ In addition, NREL calculated two sets of all-in costs for NGCC: one with an adder for potential future carbon prices and one without. Table 2-1 shows the estimated costs resulting from the analysis conducted for the draft EIS.

Table 2-2 lists the assumptions used in estimating NGCC costs. In some cases, specific inputs were used. These included the cost of cooling water (\$73 per acre-foot in the vicinity of NGS), and the application of dry-cooled technology rather than wet-cooled technology. Installations near NGS and in the Las Vegas/Mead area were modeled as wet-cooled due to the availability of water. The installation at Moenkopi was modeled as dry-cooled; the cost of drilling a well for groundwater was added to overall capital costs, and the cost of well maintenance was added to annual O\&M costs.

One important assumption to note is the $70 \%$ assumed capacity factor for a new combined cycle plant. NGS operates as a baseload plant, so NREL's analysis for the draft EIS assumed that a new combined cycle plant used as a full or partial NGS replacement would also operate as a baseload plant. Typically, however, combined cycle plants in Arizona and Nevada operate as intermediate or load-following plants with a regional average capacity factor of $40 \% .{ }^{64} \mathrm{~A}$ lower capacity factor would increase the effective LCOE because costs would be applied over fewer megawatt-hours.

Table 2-1. Estimated Cost of Combined Cycle Options

\begin{tabular}{ll}
\hline \multicolumn{1}{c}{ Option } & \multicolumn{1}{c}{ Levelized costs (\$/MWh) } \\
\hline NGCC near NGS (wet cooling, baseload) & $\$ 55$ to $\$ 70$ (with carbon adder) \\
& $\$ 48$ to $\$ 64$ (without carbon adder) \\
NGCC near Moenkopi substation (dry cooling, baseload) & $\$ 59$ to $\$ 75$ (with carbon adder) \\
& $\$ 52$ to $\$ 68$ (without carbon adder) \\
\hline
\end{tabular}

\footnotetext{
${ }^{63}$ This departs from the statistical analysis of Mead Hub price trends described earlier in this chapter, which was completed after the analysis of technology costs was completed for the draft EIS. This section presents the analysis as it was provided to for the draft EIS.

${ }^{64}$ Capacity-weighted average for combined cycle plants operating and reporting data for 2015 . Three plants operated at a capacity factor of $69 \%$ or higher: the Chuck Lenzie Generating Station (1,202 MW); the Harry Allen Expansion Station (524 MW); and Saguaro (105 MW). All three plants are in Nevada.
} 
Table 2-2. Detailed Assumptions in Estimating LCOE for Combined Cycle

\begin{tabular}{|c|c|c|}
\hline Input & \multicolumn{2}{|l|}{ Assumption } \\
\hline Natural gas (reference cost, 2014) & \multicolumn{2}{|c|}{$\$ 4$ per mmBtu } \\
\hline Natural gas sensitivity (high supply, low demand) & \multicolumn{2}{|c|}{$\$ 3$ per mmBtu } \\
\hline Natural gas sensitivity (low supply, high demand) & \multicolumn{2}{|c|}{$\$ 5$ per mmBtu } \\
\hline $\mathrm{CO}_{2}$ cost (2014 equivalent) & \multicolumn{2}{|c|}{$\$ 15$ per ton } \\
\hline Water for cooling & \multicolumn{2}{|c|}{$\$ 73$ per acre-foot } \\
\hline Inflation rate & \multicolumn{2}{|c|}{$2.5 \%$} \\
\hline Weighted average cost of capital & \multicolumn{2}{|c|}{$8.12 \%$} \\
\hline Financing term & \multicolumn{2}{|c|}{30 years } \\
\hline Plant capacity & \multicolumn{2}{|c|}{$500 \mathrm{MW}$} \\
\hline Base load capacity factor & \multicolumn{2}{|c|}{$70 \%$} \\
\hline \multirow[t]{2}{*}{ Intermediate capacity factor } & \multicolumn{2}{|c|}{$40 \%$} \\
\hline & Wet Cooling & Dry Cooling \\
\hline Capital costs & $\$ 1,200 / \mathrm{kW}$ & $\$ 1,300 / \mathrm{kW}$ \\
\hline Year of capital cost estimate & 2014 & 2011 \\
\hline Heat rate (desert climate) & $6,596 \mathrm{Btu} / \mathrm{kWh}$ & $6,795 \mathrm{Btu} / \mathrm{kWh}$ \\
\hline Water use (desert climate) & $2,693 \mathrm{gpm}$ & 119 gpm \\
\hline $\mathrm{CO}_{2}$ emission rate & 192.5 tons/hour & 193.0 tons/hour \\
\hline
\end{tabular}

\section{Updates to draft EIS Analysis}

Natural gas prices continued to decline after the completion of the price analyses for the draft EIS. Prices at all Southwest hubs averaged $\$ 2.63 / \mathrm{mmBtu}$ in 2015 , which was $12 \%$ below the lower-bound value used in analyses for the draft EIS. Prices averaged $\$ 1.91 / \mathrm{mmBtu}$ during the first half of 2016, which was about 26\% below first half 2015 levels.

For the updated analysis in this volume, we reduce the lower bound of the range by setting the assumed price of natural gas to the observed 2015 average. This reduces the LCOE to $\$ 45 / \mathrm{MWh}$. The upper bound of the range is unchanged from the analysis done for the draft EIS.

Combined cycle technology is used in this volume to provide a reference point for renewable energy costs. The reference point is not intended to be a prediction of future combined cycle costs; therefore, there is no need to include the cost of dry cooling or the cost of a carbon adder. It should be noted, however, that if drought conditions persist to the point of favoring dry-cooled technology, the additional cost impact would likely be between $\$ 3$ per MWh and $\$ 4$ per MWh, all other factors held constant. If future carbon policies were to add costs equivalent to California carbon allowance prices, the impact could be between $\$ 7 / \mathrm{MWh}$ and $\$ 14 / \mathrm{MWh}$. 
Note that these projections for a new combined cycle plant are generally higher than the trends shown in Figure 2-3 and Figure 2-4 for wholesale market prices at the Mead Hub, which typically reflect the cost of energy from existing combined cycle plants. This suggests that regardless of whether a new combined cycle plant or renewable options have a cost advantage relative to each other, either might not be competitive against existing combined cycle capacity.

\subsubsection{Solar}

The cost of solar generation has fallen significantly in recent years. This trend will most likely continue, but the degree is uncertain. ${ }^{65}$ Solar is one of the most productive renewable energy resources in the Southwest and is therefore likely to be an important component of any NGS transition plan.

Several potential projects were identified during the draft EIS public scoping period conducted by Reclamation from May 16 to August 31, 2014. These project concepts were assumed to be reasonably indicative of what could be developed, recognizing that other projects were possible and that those identified during scoping had no development preference. NREL assisted Reclamation in screening proposed projects against criteria for feasibility, then conducted cost analyses using site parameters associated with the projects that passed screening. Geographic focus areas were chosen based on proximity to transmission dedicated to delivering power from NGS to the CAP. These areas included the substation near NGS itself, the area west of Phoenix, and near the Lake Mead transmission hub in southern Nevada.

The analysis began with NREL's ATB. The ATB's projections for solar costs use technology improvement scenarios generated by DOE to represent a plausible range of future solar PV costs. The high cost scenario assumes solar costs decline 50\% from the 2010 baseline through 2020; the low cost scenario assumes solar PV costs decline $75 \%$ over the same period. ${ }^{66}$ The ATB's methodology for calculating LCOE uses three generic capacity factors. The highest is $28 \%$, which is consistent with single-axis tracking installations in Arizona. ${ }^{67}$ Based on the scenarios in the ATB, a plausible range of levelized cost for utility-scale solar costs in 2020 was $\$ 48 / \mathrm{MWh}$ to $\$ 89 / \mathrm{MWh}$. This included a plausible project cost range of $\$ 1.07 /$ watt $(\mathrm{W})$ to $\$ 2.14 / \mathrm{W}$ in 2020 . The LCOE calculations include accelerated depreciation but do not include the investment tax credit (ITC).

The next stage of the cost analysis tested specific sites identified during draft EIS scoping. NREL's System Advisor Model (SAM) Version 2014.1.14 Revision 1 was used to simulate power purchase agreement (PPA) prices for 16 potential PV facilities ranging from 32 to 500 $\mathrm{MW}_{\mathrm{AC}}$. The solar insolation for the specific coordinates of each facility was used to estimate generation. All systems were assumed to be single-axis tracking PV systems, the same

\footnotetext{
${ }^{65}$ David Feldman, Galen Barbose, Robert Margolis, Ted James, Samantha Weaver, Naïm Darghouth, Ran Fu, Carolyn Davidson, Sam Booth, and Ryan Wiser, Photovoltaic System Pricing Trends (Golden, CO: National Renewable Energy Laboratory, 2014), http://www.nrel.gov/docs/fy14osti/62558.pdf.

66 The 2010 baseline is in 2010 dollars. See DOE, SunShot Vision Study (Washington, D.C.: DOE, 2012), http://energy.gov/sites/prod/files/2014/01/f7/47927.pdf.

${ }^{67}$ DOE Office of Energy Efficiency and Renewable Energy, "Global Solar Radiation at Latitude Tilt - Annual, Arizona," accessed August 2016, http://apps1.eere.energy.gov/states/images/maps/map_large_pv_AZ.jpg.
} 
configuration modeled in the ATB. The site modeling was based on equipment purchased in 2019, project completion in 2019, and 2020 as the first full year of operation. A separate calculation estimated generator-to-substation tie-in line costs - "gen-tie" costs - and line-loss costs based on the distance to the nearest CAP substation.

Total project cost per watt was calculated using SAM and ranged from $\$ 1.54$ to $\$ 1.57 / \mathrm{W}$, taking into account local land values, taxes, and other project variables defined by the known location of the project. Project costs were further checked against the Energy Department's SunShot initiative report, Photovoltaic Pricing Trends: Historical, Recent, and Near-Term Projections (2014 Edition). ${ }^{68}$ That study modeled utility-scale system costs and found a drop of $6 \%$ from 2012 to 2013 . The modeled 2013 cost for a $20-\mathrm{MW}$ facility was $\$ 1.88 / \mathrm{W}$. Assuming a facility coming online in 2019 is under contract in 2017, the pricing can be estimated at $\$ 1.47 / \mathrm{W}$. The report estimated that utility-scale systems would reach $\$ 1.30$ $\$ 1.95 / \mathrm{W}$ by 2016 . These estimates are comparable to the costs modeled in SAM for this project.

Table 2-3 shows the estimated costs of the partial replacement alternatives by area. Solar located adjacent to the existing NGS site and connecting to the Navajo substation had the lowest cost. The other potential project tested in this area was more than 60 miles from the substation. The cost of a tie-line to the substation (including the effects of line losses) increased the effective LCOE by about $\$ 12 / \mathrm{MWh}$.

Table 2-3. Estimated LCOE of Solar

\begin{tabular}{|l|l|}
\hline Location & Levelized cost (\$/MWh) \\
\hline NGS & $\$ 52$ to $\$ 64$ \\
\hline Lake Mead & $\$ 55$ to $\$ 106$ \\
\hline Phoenix & $\$ 54$ to $\$ 85$ \\
\hline
\end{tabular}

\section{Updates to draft EIS Analysis}

The cost of utility-scale solar has continued to fall since the time of the initial analysis conducted for the draft EIS. In the 2016 ATB, the baseline values for PV overnight project costs were between $2 \%$ and $3 \%$ less than what they were in the ATB at the time of the draft EIS analysis. ${ }^{69}$ The resulting LCOE baseline is $7 \%$ to $8 \%$ lower. Figure $2-8$ shows NREL's most recent ATB cost analyses as of May 2016, based on single-axis tracking PV installed in areas such as Arizona that are capable of a $28 \%$ capacity factor.

\footnotetext{
${ }^{68}$ See Feldman et al., Photovoltaic System Pricing Trends.

${ }^{69}$ ATB, 2016. The 2015 ATB based its PV cost trajectories on DOE's 2012 SunShot Vision Study. The 2016 ATB uses a different methodology, incorporating 20 published utility-scale PV price projections from 10 institutions. It uses the median and minimum of these published projections as mid-case and low-case PV price trajectories, and it extends current prices as a high trajectory.
} 


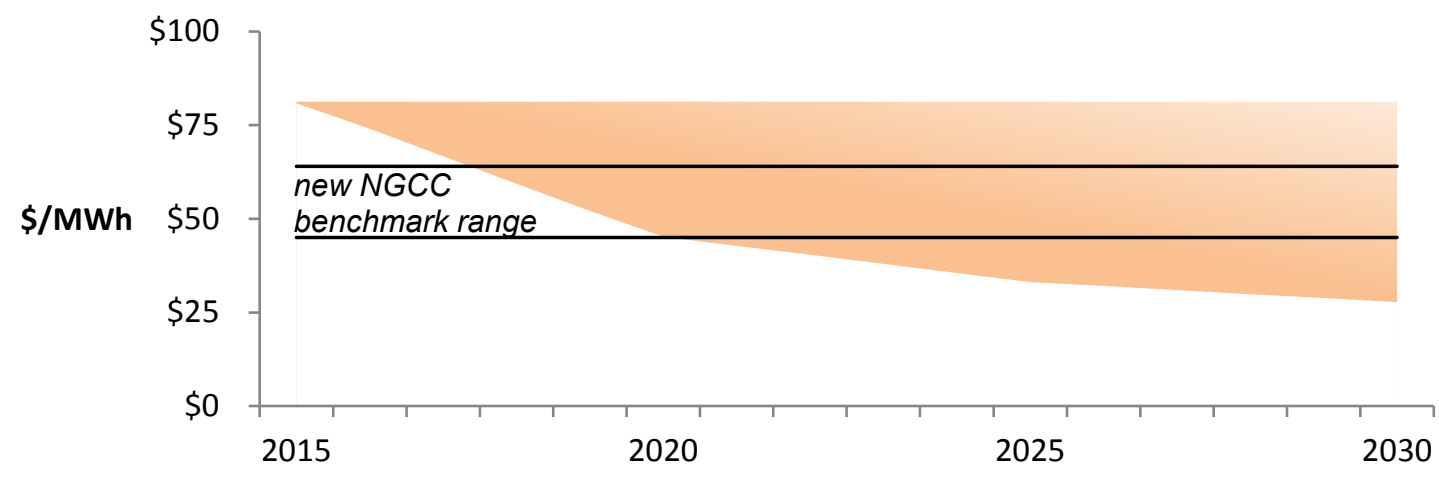

Figure 2-8. Range of projected LCOE for utility-scale solar in Arizona, 2015-2030 ${ }^{70}$

Solar LCOE calculation does not include the investment tax credit, and does not account for potential curtailment.

In addition, updates to NREL's PV System Cost Benchmark suggest that system costs during the first quarter of 2016 fell $21 \%$ from a year earlier. ${ }^{71}$ This benchmark is a "bottom-up" estimate based on recent market intelligence on system hardware costs and "soft" costs such as installation, permitting, labor, and land acquisition. As a measure of installation cost, the benchmark tends to be lower than comparable measures of PV prices to purchasers because it does not include project profit and return on equity. It also does not include the cost of ongoing O\&M.

Here we rely on both measures to triangulate a plausible cost trend for utility-scale PV out to the critical time of 2019. While single-year changes do not necessarily indicate a trend, the new modeling results do suggest a greater likelihood that costs will approach the lower bound of the plausible range shown in Figure 2-8. Both methodologies suggest continued decreases in project costs. This is corroborated anecdotally by recent prices on utility-scale solar PPAs. In at least one case, a fixed-price PPA was below $\$ 50 / \mathrm{MWh} .^{72}$

\subsubsection{Wind}

In contrast to solar, wind generation saw some of its lowest capital costs in the early 2000s, at which point increased demand began to push turbine prices higher. ${ }^{73}$ Performance improvements, including higher hub heights and larger rotor diameters, have reduced wind

\footnotetext{
70 This figure is derived from Blair et al., Annual Technology Baseline, http://www.nrel.gov/analysis/data tech baseline.html.

${ }^{71}$ Ran Fu, Donald Chung, Travis Lowder, David Feldman, Kristen Ardani, and Robert Margolis, U.S. Solar Photovoltaic System Cost Benchmark: Q1 2016, Technical Report NREL/TP-6A20-66532 (Golden, CO: National Renewable Energy Laboratory, 2016).

${ }^{72}$ In September 2015 NV Energy received approval for two PPAs: one for SunPower's Boulder Solar Project at a non-escalating price of \$46 per MWh; and one for First Solar's Playa Solar II project at an escalating price beginning at $\$ 38.70$ per MWh for the first year. Application of Nevada Power Company d/b/a/ NV Energy for approval of the first amendment to its 2014 Emission Reduction and Capacity Replacement Plan as it relates to two new renewable energy purchased power agreements, Public Utilities Commission of Nevada Docket No. $15-$ 07003 (final order), Sept. 9, 2015.

${ }^{73}$ Eric Lantz, Ryan Wiser, and Maureen Hand, IEA Wind Task 26: The Past and Future Cost of Wind Energy (Golden, CO: National Renewable Energy Laboratory, 2012), http://www.nrel.gov/docs/fy12osti/53510.pdf.
} 
generation costs since $2008 .^{74}$ The ATB assumes the cost of wind will continue to decline through 2030, though at a slower rate than solar. ${ }^{75}$

Like solar, the LCOE for wind is a function of the technology employed and the resource potential associated with a given location. For modeling purposes ATB categorizes wind resources into sequential Techno-Resource Groups (TRGs) based upon factors including wind speed, capacity factor, and technology costs. TRG 1 locations have both the highest wind speed and capacity factor, and the lowest technology costs.

Wind power plants within Arizona or New Mexico could serve Arizona's load, especially with new transmission projects that are in advanced stages of development as of this writing. ${ }^{76}$ Analysis conducted by NREL for the Western Governors' Association (WGA) in 2009 indicated that top-tier wind sites in New Mexico generally have higher capacity factors than top-tier wind sites in northern Arizona. ${ }^{77}$ Subsequent updates to the WGA analysis incorporate wind power at higher turbine heights, with more differentiation in wind technology costs. ${ }^{78}$ On the basis of the analysis for WGA, this study uses TRG 2 as indicative of New Mexico wind generation, while potential wind projects in Arizona are assumed to be from TRG 5 locations.

ATB offers a range of cost and performance projections for each TRG through 2030 . The overnight cost of wind generation from TRG 2 locations could decline by $0 \%$ to $14 \%$ from the 2015 baseline. In comparison, ATB predicts that the overnight cost of wind generation from TRG 5 locations may decline by $0 \%$ to $4 \%$ from 2015 through $2030 .^{79}$

\footnotetext{
${ }^{74}$ Ibid.

${ }^{75}$ See http://www.nrel.gov/analysis/docs/ATB_Data_Inputs_V6.xlsm. See also Lantz et al., IEA Wind Task 26.

${ }^{76} \mathrm{New}$ Mexico wind is a plausible option, because the SunZia transmission project is expected to deliver 3,000 MW of electricity, including wind, from New Mexico into the Arizona market by 2020. See http://www.sunzia.net/index.php.

${ }^{77}$ Western Governors' Association, Western Renewable Energy Zones - Phase 1 Report (Denver: Western Governors' Association, 2009).

${ }^{78}$ Western Interstate Energy Board, "Western Renewable Energy Zone Generation and Transmission Model," http://www.westernenergyboard.org/wieb/wrez/tool/GTMWG\%203.xlsm.

${ }^{79}$ These cost reduction assumptions were derived from a literature review of more than 15 independent studies evaluating the future of wind costs. See Nate Blair, Karlynn Cory, Maureen Hand, Linda Parkhill, Bethany Speer, Tyler Stehly, David Feldman, Eric Lantz, Chad Augustine, Craig Turchi, and Patrick O’Connor, “Annual Technology Baseline - Review Draft" (presentation, March 27, 2015), http://www.nrel.gov/analysis/pdfs/ATB_Summary_V13.pdf.
} 


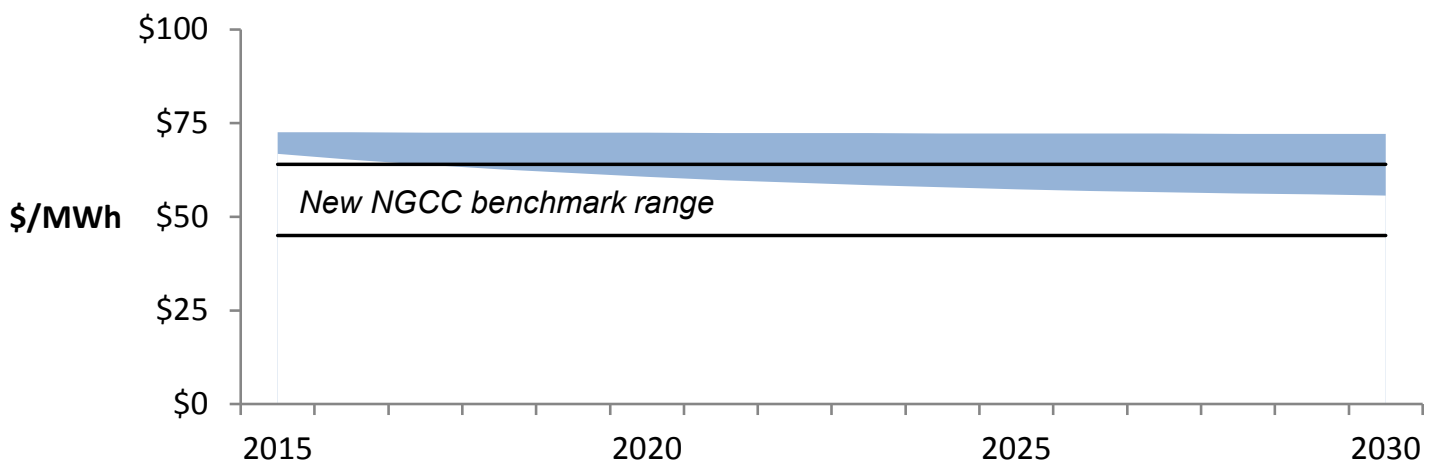

Figure 2-9. Range of projected LCOE for New Mexico wind, 2015-2030 ${ }^{80}$

Wind LCOE calculation does not include the production tax credit. New Mexico wind costs include an additional \$22/MWh to account for the cost of long-distance transmission.

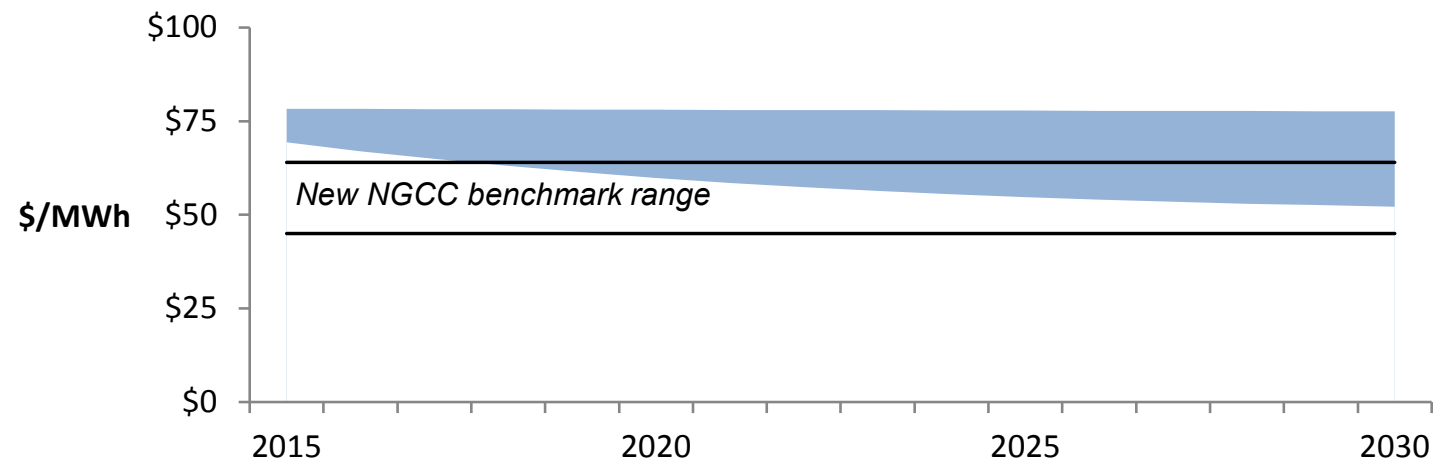

Figure 2-10. Range of projected LCOE for Arizona wind, 2015-2030 ${ }^{81}$

Wind LCOE calculation does not include the production tax credit.

This analysis includes a $\$ 22 / \mathrm{MWh}$ adder to the LCOE range for TRG 2 wind from New

Mexico. This adder approximates the additional long-distance transmission cost of transporting New Mexico wind power to the Arizona market. ${ }^{82}$ A similar adder is not applied to the TRG 5

${ }^{80}$ This figure is derived from Blair et al., Annual Technology Baseline, http://www.nrel.gov/analysis/data tech baseline.html.

${ }^{81}$ Ibid.

${ }^{82}$ This $\$$ MWh adder was derived from the expected capital cost of the 515 mile, 3,000-MW transmission line ( $\$ 2$ billion). Following practice at CAISO for transmission cost estimation, we assume that total costs are $145 \%$ of capital costs. We then assume cost recovery over 40 years, and a $9 \%$ weighted average cost of capital. This results in an annual revenue requirement of about $\$ 84,000$ per MW of transmission capability. Following current ATB estimates for TRG 2 wind projects, we assume a capacity factor of $49 \%$ for projects sited in central New Mexico, which would generate 4,292 MWh for each MW of generating capacity, or 4,078 MWh delivered if line losses are $5 \%$. This results in a total cost of $\$ 22 / \mathrm{MWh}$ for an annual reservation of transmission capacity. Actual transmission charges will be different, but this methodology is assumed to be a reasonable approximation for adjusting the LCOE of New Mexico wind power delivered to Arizona. For SunZia cost estimate, see Mark Etherton, "SunZia Southwest Transmission Project" (presented at Arizona Corporation Commission $8^{\text {th }}$ Biennial 
LCOE range because it is assumed that Arizona wind would connect to the existing Arizona transmission network.

Using these assumptions, some new wind plants in New Mexico may be cost competitive with NGCC before 2020. However, this is more likely to be the case in 2020, when the cost band for New Mexico wind generally matches that of NGCC. Similarly, some wind projects in Arizona could be cost competitive with NGCC in 2020, but this is more likely to be the case by 2025 .

\section{Updates to draft EIS Analysis}

The cost of wind power has also continued to fall since the time of the initial analysis conducted for the draft EIS, although to a lesser degree than solar costs. Figure 2-9 and Figure 2-10 show NREL's most recent cost analyses as of May 2016, based on TRG 2 wind development in New Mexico and TRG 7 wind development in Arizona. Projected costs do not include the federal PTC.

\subsubsection{Other Renewables}

Other renewable resources might contribute to viable glide path options through 2030 . These include hydroelectric, biomass, and geothermal.

Hydroelectric power generation is the largest source of renewable generation in Arizona, with monthly generation over $391 \mathrm{GWh} .{ }^{83}$ Though some recent studies suggest significant hydroelectric resource potential has yet to be exploited, the EIA does not expect significant expansion of hydroelectric capacity nationwide because due to its cost. ${ }^{84}$ Some efficiency improvements at Hoover, Glen Canyon, and other large hydro facilities may be possible, but they are not addressed here.

Portions of Arizona have a good biomass resource, but the state produces only $18 \mathrm{GWh}$ of electricity monthly from biomass. ${ }^{85}$ As is the case with hydroelectric, the cost of new biomass

Transmission Assessment Workshop, May 15, 2014),

http://www.sunzia.net/presentation pdfs/8th bta sunzia 5 15 2014v2.pdf.

${ }^{83}$ EIA, "Table 1.13.A. Utility Scale Facility Net Generation from Other Energy Sources," EIA Electric Power

Monthly Data for May 2016, July 26, 2016,

http://www.eia.gov/electricity/monthly/epm table grapher.cfm?t=epmt 1 1 13 a

${ }^{84}$ Michelle Bowman, "EIA projections show hydro growth limited by economics not resources," Today in Energy, July 10, 2014, http://www.eia.gov/todayinenergy/detail.cfm?id=17051. Also see Shih-Chieh Kao, Ryan A. McManamay, Kevin M. Stewart, Nicole M. Samu, Boualem Hadjerioua, Scott T. DeNeale, Dilruba Yeasmin, M. Fayzul K. Pasha, Abdoul A. Oubeidillah, and Brennan T. Smith, New Stream-reach Development: A Comprehensive Assessment of Hydropower Energy Potential in the United States (Washington, D.C.: DOE Wind and Water Power Technologies Office, 2014),

http://nhaap.ornl.gov/sites/default/files/ORNL_NSD_FY14_Final_Report.pdf; Douglas G. Hall and Randy D. Lee, Assessment of Opportunities for New United States Pumped Storage Hydroelectric Plants Using Existing Water Features as Auxiliary Reservoirs (Idaho Falls: Idaho National Laboratory, 2014),

http:/hydropower.inel.gov/resourceassessment/d/pumped-storage-hydro-assessment-report-published-version20mar14.pdf.

${ }^{85}$ For resource potential, see "Solid Biomass Resources by County," last modified August 4, 2014, http://www.nrel.gov/gis/images/biomass_2014/national_biomass_solid total_2014-01.jpg; for generation, see EIA, “Table 1.18.A. Utility Scale Facility Net Generation from Solar Thermal,” EIA Electric Power Monthly Data for May 2016, July 26, 2016, http://www.eia.gov/electricity/monthly/epm table grapher.cfm?t=epmt 1 1 18 a. 
production exceeds both wind and solar. ${ }^{86}$ Biomass generation technology is mature, making further significant cost reductions unlikely through $2030 .^{87}$

Geothermal generators near the Salton Sea and elsewhere within California's Imperial Valley could potentially serve as a resource in an NGS glide path scenario. Geothermal production is generally more expensive than solar, wind, or NGCC; Salton Sea geothermal can be even more expensive due to the fact that water from the underground heat reservoirs is briny and requires more corrosion-resistant materials. The technology currently employed in geothermal generation is mature, and its costs are unlikely to decline significantly through $2030 .{ }^{88}$

\subsection{NGS Glide Path Implications}

The persistence of low prices at the Mead Hub is likely to be a source of economic inertia affecting new generation capacity of all types in the Southwest. This analysis suggests that the inertia could continue well past 2020. Even if wind and solar become economically competitive with a new NGCC, low market prices could still slow down new additions. Observed market prices and their near-term trends corroborate the capacity expansion modeling results described in Chapter 4, which suggest that market conditions would not favor new gas-fired generation in the Southwest until around 2030.

Figure 2-11 compares estimated LCOEs for wind power in Arizona and New Mexico, solar power in Arizona, and NGCC. The bar reflects the mean likely cost; the whiskers represent the plausible range of future costs based on renewable energy technology improvements and natural gas fuel prices.

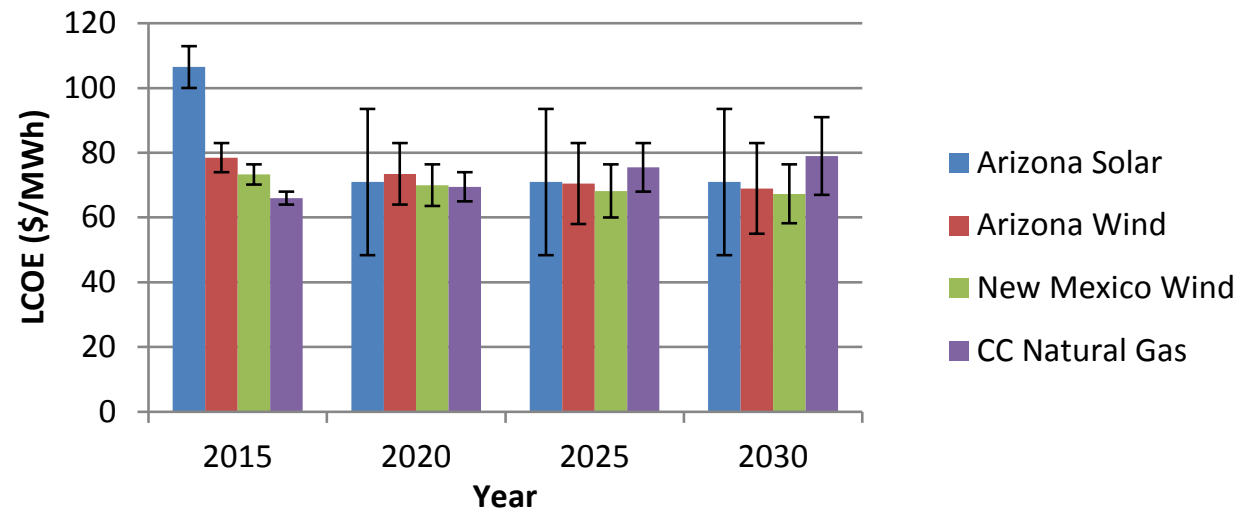

Figure 2-11. Comparison of range of NGCC, regional wind, and Arizona solar LCOEs, 2015-2030 ${ }^{89}$

Color bars indicate midrange values; whiskers indicate the range of plausible values.

\footnotetext{
${ }^{86}$ See: $\mathrm{http} / / /$ www.nrel.gov/analysis/docs/ATB_Data_Inputs_V6.xlsm.

${ }^{87}$ Ibid.

${ }^{88}$ Ibid.

${ }^{89}$ This figure is derived from Blair et al., Annual Technology Baseline, http://www.nrel.gov/analysis/data tech baseline.html.
} 
The cost trends illustrated in Figure 2-11 suggest that solar and regional wind are trending toward being cost competitive with new NGCC by 2030; wind generation from New Mexico and Arizona could be cost competitive by 2020. In Arizona, which has some of the nation's best solar resources, PV could be cost competitive as early as 2020 or 2025 depending on whether the industry sustains its current pace of technological improvements.

Current cost trends suggest that wind and solar could be economically feasible components of an NGS clean energy glide path. Both are likely to be reasonably close to the all-in cost of a new NGCC between 2020 and 2030. This means that varying the proportions of wind, solar, and natural gas included in a potential NGS clean energy transition strategy need not significantly change the overall cost of the plan as measured by the technologies' LCOE.

These cost trends also suggest two key timing considerations. First, the band of uncertainty about future reductions in the cost of utility-scale PV will decrease over time. Second, whether low-cost wind power from New Mexico can be part of a glide path will depend on the development of new transmission that is still moving through the permitting and approval process. Deferring these options to a later point in a glide path implementation schedule could reduce both cost and uncertainty. 


\section{The Evolving Electricity Sector}

The electricity sector in Desert Southwest (Arizona, New Mexico, and southern Nevada) and elsewhere is changing in ways that are likely to affect any NGS transitional glide path. The generation of electricity is trending away from coal and away from large central-station plants. Public policy is one driver, but just as important is the natural evolution of the sector toward operational practices that demand and deliver greater economic efficiency.

This chapter looks at the changes in how bulk power is produced, bought, and sold throughout the West. This is relevant to potential NGS glide paths in two ways. First, this analysis identifies the potential for more efficiency - and thus lower cost per megawatt-hour-in supply options for obtaining CAP pumping power. Second, this examination provides background in understanding the market for surplus power sales. Adapting to these future market conditions will be important to the success of any glide path strategy and to maximize benefits to stakeholders.

Market structure directly affects the marketability of surplus power from NGS. As operations become more sophisticated, load-serving entities that might be in the market for a PPA have a wider choice of suppliers across a larger geographic footprint. Sophisticated market structures reduce the cost of integrating variable renewable resources, eroding some of the economic edge NGS surplus might have in these markets.

\subsection{Movement Away from Coal}

The use of coal as a primary generation technology has been declining for more than a decade. About $40 \%$ of the Desert Southwest's electricity now comes from coal, down from more than half in 2001. This mirrors a similar trend for the entire western U.S. grid, where coal has declined to $28 \%$ of net generation. As Figure 3-1 shows, the trend has been gradual and persistent.

NGCC plants and renewables have been filling the gap. Over the past 15 years, NGCC plants have grown from about one-tenth of the generation mix to more than one-quarter. New plant additions enabled much of this shift in the Desert Southwest up to 2007, when more than a dozen major new NGCC plants were placed in service. Since 2013, the shift has been driven by low natural gas prices.

For Arizona and the rest of the Desert Southwest, the use of renewables has been growing at a slower pace than for the West overall. Geothermal and wind were the first nonhydro renewables that expanded in the West, and most of that growth occurred outside of Arizona. ${ }^{90}$ Deployment of solar, which is Arizona's leading renewable resource, has increased over the past 5 years as per-megawatt project costs have fallen. Figure 3-2 shows the breakdown of utility-scale renewable generation across the Southwest.

${ }^{90}$ Ibid. 

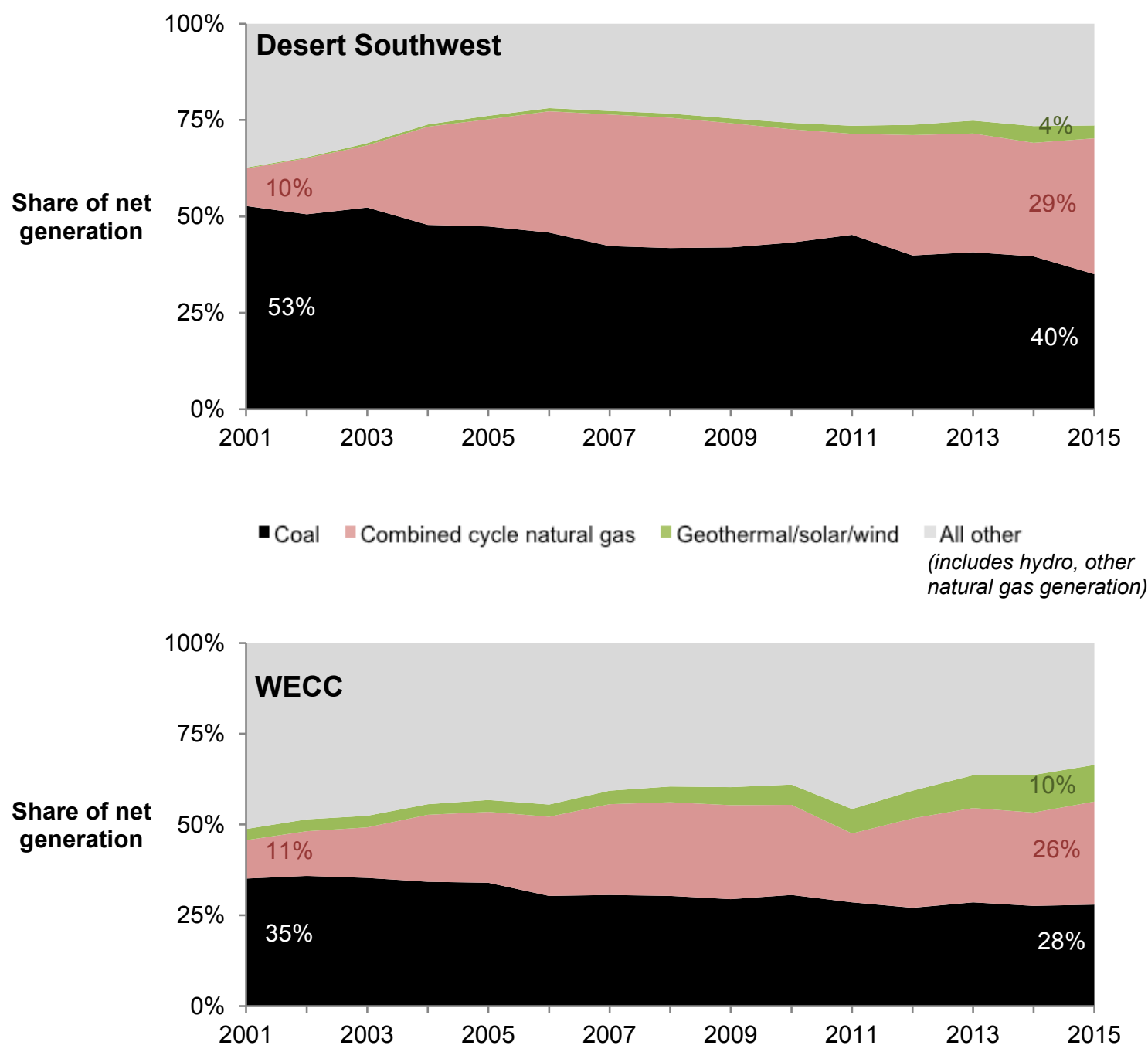

Figure 3-1. Changing generation mix, Desert Southwest and WECC ${ }^{91}$

One factor that could have significant implications for the future of power generation in the Southwest is the effect of drought on hydroelectric production. The data for hydroelectric generation in Figure 3-2 indicates a general reduction, with average production for the 5 years ending in 2015 more than 11\% lower than generation for the 5 years ending in 2005.

${ }^{91}$ EIA, "Form EIA-923 detailed data with previous form data (EIA-906/920)," 2001-2014, https://www.eia.gov/electricity/data/eia923/. 


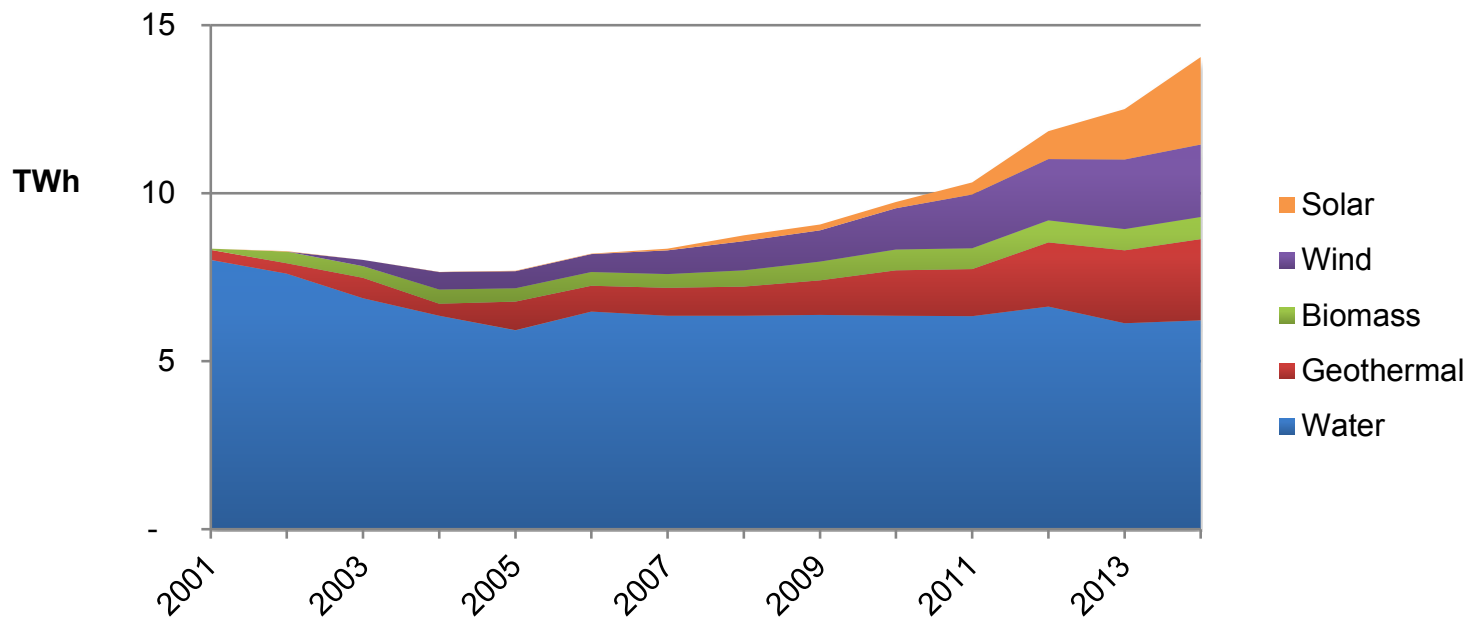

Figure 3-2. Southwest net generation by renewable fuel type, 2001-2014 ${ }^{92}$

Utilities across the Western Electricity Coordinating Council (WECC) reliability region plan to procure a significant amount of generation through 2024, most of it from new capacity powered by renewable resources. As of mid-2016, more than $89 \mathrm{GW}$ of new capacity was planned or under construction in WECC; more than half is planned from wind, solar, geothermal, or biomass. The situation is similar in the Southwest, where about $55 \%$ of the more than $20 \mathrm{GW}$ under construction or planned was from renewable resources. ${ }^{93}$

Much of the planned expansion of renewable capacity across WECC is a result of state-level renewable portfolio standard (RPS) programs. Figure 3-3 shows the growth in renewable energy procurements called for in state laws throughout the Western United States, based on laws in force, as of mid-2016. Both California and Oregon recently increased their RPS requirements to $50 \%$, which substantially increases demand for renewables. California's legislation, SB350, signed into law in October 2015, calls for utilities to procure $50 \%$ of their electricity from renewables by 2030. In March 2016, Oregon adopted a 50\% RPS by 2040 and a phase-out of electricity from coal by 2035.

\footnotetext{
92 EIA, "EIA Form 906, 920 and 923 databases," 2001-2014. Data for this chart includes all of Nevada and the Imperial Irrigation District in southeastern California, both of which have significant geothermal development. ${ }_{93}$ Derived from SNL Financial Inc., Regional Power Market Summary, accessed July 5, 2016. Data include all publicly announced projects and those in various stages of development and construction.
} 


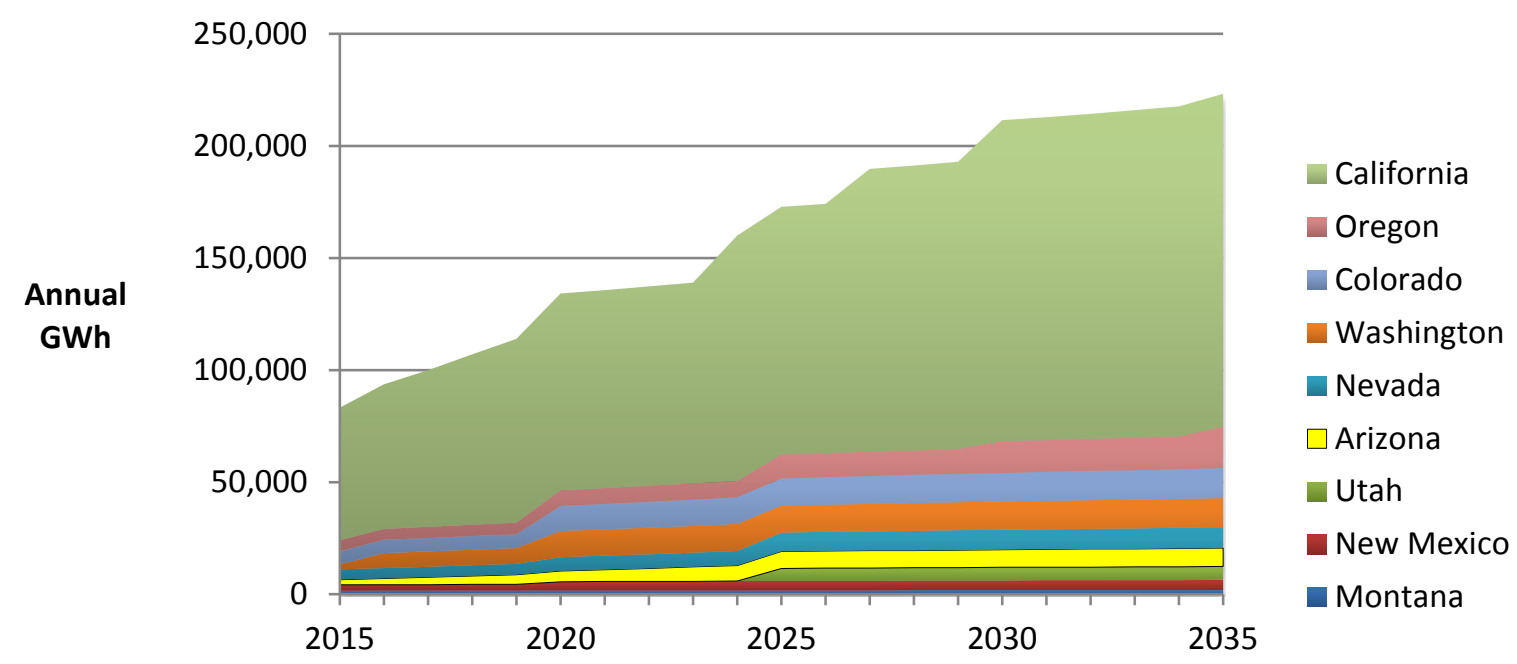

Figure 3-3. WECC-wide demand for renewables under current state requirements and goals ${ }^{94}$

Utah renewable energy demand for 2025 was calculated based on 2015 retail sales for investor-owned utilities, municipal utilities, and cooperatives. Sales for 2015 were increased by $0.45 \%$ per year (PacifiCorp's projected annual growth rate for its Utah operations), and the state's 2025 goal of $20 \%$ was applied to projected sales from 2025 through 2035. PacifiCorp constitutes about $90 \%$ of the sales to which Utah's goal would apply.

Projections for demand by state do not indicate supply by state. Idaho and Wyoming have no renewable energy standard or goal.

Historically, the Southwest subregion of WECC has been a significant net exporter of electricity to the largest consumer in the West - California. Historical transfers have been on the order of 44 terawatt-hours (TWh) annually. ${ }^{95}$ Nearly a quarter of these exports are associated with the shares of NGS and the Palo Verde Nuclear Generating Station that are owned by utilities in California.

This section examines two structural changes affecting the shift from coal, both of which are happening nationally as well as regionally:

- The movement away from big central-station plants and toward a portfolio of smaller and more diverse generators

- The trend toward integrated operations across a large geographical footprint.

Both of these sectoral trends allow for more flexibility in implementing NGS glide path strategies. After examining the structure of these two trends, the chapter will describe how utilities in the Southwest are responding, as indicated in their most recent IRPs.

\footnotetext{
${ }^{94}$ Galen Barbose, U.S. Renewables Portfolio Standards: 2016 Annual Status Report, LBNL-1005057 (Berkeley, CA: Lawrence Berkeley National Laboratory, April 2016) for all western states except Utah; EIA, "Form EIA826 detailed data: Monthly Electric Utility Sales and Revenue Report with State Distributions," 2015, for Utah preliminary data for 2015; PacifiCorp, 2015 Integrated Resource Plan Update (Portland, OR: PacifiCorp, 2016) for annual MWh growth forecast for PacifiCorp/Rocky Mountain Power in Utah.

${ }^{95}$ EIA, "California Profile Analysis," accessed July 3, 2014, http://www.eia.gov/state/analysis.cfm?sid=CA.
} 


\subsection{Movement Away from Large Central Generators}

One widespread trend across the electric sector is a reduced reliance on large central-station plants and greater use of more diverse resource portfolios. This reverses the trends seen in the 1960s, 1970s, and 1980s, when large central-station plants such as NGS came online and grew to account for a large share of total generation. ${ }^{96}$

A number of structural reasons contribute to this shift. Two of the most important are a slowdown in load growth and the difficulty of attracting capital for large generators like NGS. Demand (in terms of total energy sold to customers) doubled nationally during the 1960s and continued at a robust pace until about $2000 .{ }^{97}$ Utilities, which were still regulated monopolies, were able to expand their capital bases by offering low-risk stock dividends backed by revenues from a franchised and expanding customer base.

By the turn of the century, load growth had slowed considerably, and a growing share of the generation base was in the hands of merchant generators rather than utilities. Merchant generators provided a mere $1 \%$ of U.S. net generation in 1990, but by 2000 the share had risen to $12 \%$. In 2010 , nonutility merchant generators provided nearly one-third of the nation's electricity supply. ${ }^{98}$

This chapter quantifies the change by constructing a generator concentration index that measures the degree of fragmentation in the U.S. power sector, the WECC region, and Arizona. The metric is based on the Herfindahl-Hirschman Index, which is used in antitrust law to measure the degree to which a market is concentrated in the hands of one or a few companies - mathematically comparable to the objective of this analysis. The index is the sum of the squared values of all market shares, with each entity's market share expressed as a percentage multiplied by 100 . The index value decreases when total generation is distributed among a larger number of plants in smaller shares.

This index of generator concentration within a given market was applied to three aggregations of the electricity sector: the United States as a whole, the U.S. western grid (the WECC reliability region), and the state of Arizona. For each slice of the generation fleet, we compared results for 2014 with results for 2001 using EIA's annual survey of generator operation data. ${ }^{99}$

\footnotetext{
${ }^{96}$ EIA, "EIA Form EIA-860 detailed data," https://www.eia.gov/electricity/data/eia860/.

${ }^{97}$ EIA, "Form EIA-861 detailed data files: Electric power sales, revenue, and energy efficiency," 2014. https://www.eia.gov/electricity/data/eia861/; Federal Power Commission, Statistics of Privately Owned Electric Utilities in the United States, various volumes from 1960 through 1975.

${ }^{98}$ EIA, "Form EIA-923," various years.

${ }^{99}$ EIA's database for 2015 was not final as of this writing.
} 
Table 3-1. Generator Concentration Index Values for 2001 and $2014^{100}$

\begin{tabular}{|lrr|rr|} 
& All Generation Sources & \multicolumn{3}{c|}{ Coal, Gas, Nuclear Plants Only } \\
\hline United States & $\mathbf{2 0 0 1}$ & $\mathbf{2 0 1 4}$ & $\mathbf{2 0 0 1}$ & $\mathbf{2 0 1 4}$ \\
\hline WECC & 22.40 & 19.11 & 27.28 & 24.91 \\
\hline Arizona & 115.71 & 86.13 & 191.10 & 158.97 \\
\hline
\end{tabular}

Index values were calculated using the formula:

$$
\text { concentration index }=\sum_{i} \operatorname{share~}_{i}^{2}
$$

where $i$ is an individual generating plant and share $_{i}$ is the plant's percentage share of total net generation multiplied by 100. In this table, values are comparable over time but not between geographic scales.

Table 3-1 shows that electricity generation grew less concentrated between 2001 and 2014, regardless of the geographic lens. The trend was especially pronounced for WECC, which has been one of the strongest growth regions for renewable energy. Wind, solar, and geothermal projects tend to be smaller and more numerous, so when renewables are used to offset some of the power from a large coal plant, the same amount of generation will be spread among several generators.

The trend toward more diversified portfolios is still evident even when taking renewables out of the picture entirely. Table 3-1 also shows that when only coal, natural gas, and nuclear capacity are measured, concentration has changed over time. This group is also moving toward portfolios with more and smaller components: less generation from large plants, more generation from mid-sized plants.

The regional picture provides a glimpse of how this trend is unfolding. In 2000, more than half of the electricity generated in the Desert Southwest came from plants larger than $2 \mathrm{GW}$ : NGS, Palo Verde Nuclear Generating Station, and Hoover Dam. Even with the addition of the 2.5GW Gila River combined cycle plant in 2003, reliance on plants larger than 2 GW gradually diminished to one-third of all generation by 2015 . Mid-sized plants between $500 \mathrm{MW}$ and 2 GW in capacity made up most of the difference. Figure 3-4 illustrates the change over time. The Desert Southwest saw 13 mid-sized NGCC plants put into service after 2000.

These trends suggest that if one NGS unit (or the entire plant) were to close, market conditions will not necessarily favor replacing it with one single new plant, megawatt-for-megawatt.

${ }^{100}$ EIA, “Form EIA-906,” 2001; EIA, “Form EIA-923,” 2014. 


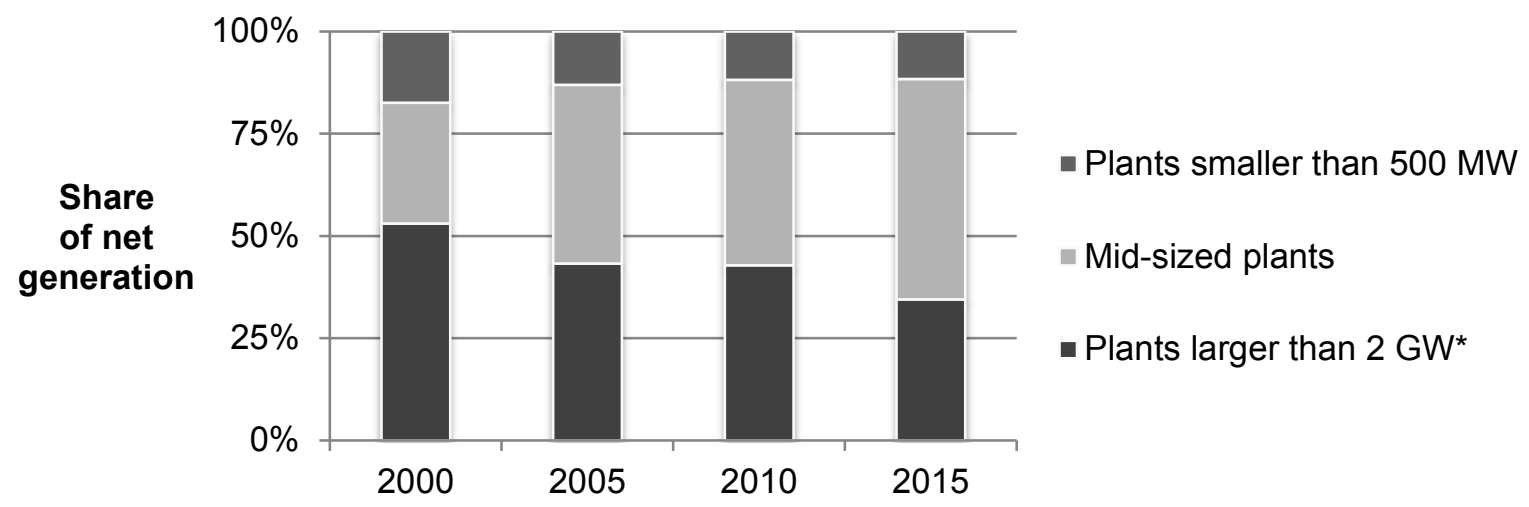

Figure 3-4. Distribution of Desert Southwest generation by plant size

*In addition to NGS, plants larger than $2 \mathrm{GW}$ include Palo Verde (nuclear), Gila River (combined cycle), and Hoover Dam (hydro).

\subsection{Market Structure}

Market structure can directly affect an NGS transitional glide path in many ways. An ideal strategy could leverage the opportunities offered by new markets while minimizing exposure to the new challenges.

Nearly all the trends toward operational modernization rely on pooling load and resource. This increases economic efficiency, cost savings, and access to operational flexibility. Conversely, treating CAP load and federal surplus power sales as though they are isolated from the rest of the market could sacrifice potential benefits or result in higher costs. Operators increasingly seek the portfolio of resources that can supply all demand at the lowest total cost of production. All these economic factors add up to a more geographically integrated market structure with a potential for increased savings in operations.

In the Western Interconnection, the pace of structural change has varied. Separately operated balancing authorities (BAs) still serve most of the geographical West. In California, however, most wholesale operations have been consolidated into a regional transmission organization (RTO) operated by CAISO. More recently, utilities and their regulators have gravitated toward an energy imbalance market (EIM), a third path that aims to replicate some of the advantages of RTO operations while maintaining a high degree of operational control by BAs.

NGS glide path resources and CAP have the ability to participate in any of the three types of existing wholesale power markets in the West. While geographically within an area served by traditional BAs, the high-voltage transmission lines built to link NGS and CAP also provide access both to the EIM market and to California.

\subsubsection{Traditional Utilities and Balancing Authorities}

Arizona has a wholesale power market that, as of 2016, looks much as it did when NGS came online in 1974. About $83 \%$ of the state's generation comes from utility-owned generators and federal hydropower. Bilateral contracts govern power purchased from nonutility generators and power traded among utilities. These bilateral agreements, along with a utility's schedule for its own generators, largely determine which units are dispatched to provide power for customers. 
Key grid-level operations - scheduling resources, maintaining load-interchange-generation balances, and supporting interconnection frequency in real time - are still managed by separate BAs associated with the state's major utilities. These BAs include APS, SRP, and TEP. The Western Area Power Administration's (WAPA's) Lower Colorado Region also operates as a $\mathrm{BA}$, primarily serving public power entities in the region.

A BA's primary function is to integrate the next day's operating plans so that its generation, load, and interchanges with neighboring BAs all remain in balance. Each BA does this separately for its own area, and normally BA-to-BA electricity exchanges are fairly small. Table 3-2 shows that even for APS, which has the largest exchange transactions of the state's major utilities, the amount of energy is small compared to what it procures and delivers to customers.

Table 3-2. Disposition of Power for Arizona's Three Major Utilities in 2014 (MWh) ${ }^{101}$

\begin{tabular}{lccccrrr}
\hline & \multicolumn{2}{c}{ Primary Operations } & \multicolumn{2}{c}{ Exchange Energy } & \multicolumn{2}{c}{ Wheeled Power } \\
Utility & Procurement & Sales & Received & Delivered & Received & Delivered \\
\hline APS & $34,227,840$ & $34,227,840$ & 823,724 & 945,331 & $36,600,168$ & $36,479,125$ \\
SRP & $37,629,219$ & $37,629,219$ & 124,525 & 148,607 & 100,459 & 100,459 \\
TEP & $14,115,999$ & $14,115,999$ & 99,903 & 66,506 & $15,368,574$ & $15,368,417$ \\
\hline
\end{tabular}

Note: "Procurement" includes generation from the utility's own plants and purchased power; "sales" includes retail sales, wholesale sales, and system losses; "exchange energy" is transfers between BAs for BA operations; "wheeled power" is pass-through transfers across the transmission utility's network that neither originate nor terminate in the BA area.

Table 3-2 also shows the amount of power that each utility wheels through its network. These transactions normally involve energy owned by an entity other than the utility, but that moves through the utility's transmission network under the terms of the utility's open access transmission tariff. In this case, the utility provides service as an energy carrier, not as an energy producer or seller. As shown in Table 3-2, APS and TEP are active as energy carriers, wheeling more energy on behalf of others than they provide to their own retail and wholesale energy customers.

While operations remain mostly separate, utilities in the state have engaged in some degree of coordinated transmission planning since 2001. Arizona state law requires all utilities to plan their transmission needs over a 10-year time horizon and to update their individual plans each year. Every two years, the Arizona Corporation Commission assesses all the plans to determine whether the existing and planned transmission is sufficient to meet the state's energy needs. ${ }^{102}$ Each utility presents the status of its own transmission plan in a public proceeding, from which commission staff conducts its assessment of system adequacy.

${ }^{101}$ EIA, "Form EIA-861 detailed data files," 2014.

102 Arizona Revised Statute $§ 40-360.02(\mathrm{G})$. 


\subsubsection{Regional Transmission Organization}

Of the markets most likely to affect an NGS glide path, California's is the most organized and most operationally consolidated. CAISO power prices might be higher than those in Arizona or Nevada, but competition is more robust and securing a PPA is never certain. The CAISO wholesale market is designed to promote access, transparency, and competition to a degree not present in Arizona or Nevada.

Most generator dispatch and ancillary service procurement in California is done through CAISO, which manages most transmission-level market operations for the state's three major investor-owned utilities (IOUs) and participating merchant generators. More than threequarters of the state's retail customers are within these three utility service territories, with most of the remainder served by large public power entities-Sacramento Municipal Utility District (SMUD), LADWP, and some large irrigation districts - that are not part of CAISO.

RTO functions include consolidated tariff administration and design, centralized congestion management, management of power flows to and from control areas adjacent to the RTO, combined ancillary services procurement, posting of system information (including total transmission capability and available transmission capability), market monitoring, planning and expansion, and interregional coordination. RTOs differ from traditional utilities and BAs in that they enable the seamless flow of power from one utility's network to another within the RTO control area. In theory, the public reaps benefits from lower operational costs and greater efficiency, compensating for what the utility gives up by no longer being a stand-alone operation.

The movement toward greater use of variable renewable resources has led to structural changes that accommodate these resources more effectively and at lower cost. Flexibility comes not only from combustion turbine gas units, but also from greater coordination among control areas over a larger footprint. A larger market footprint enables operational synergy, nets out some of the imbalance that needs real-time correction, and results in a larger pool of response options from which the least-cost solution may be selected.

In contrast with Arizona, nearly two-thirds of the California's power supply comes from competitive merchant generators that are not owned by a regulated utility. Many of these merchant generators are renewable.

CAISO operates a centralized, independent market with the following general responsibilities: ${ }^{103}$

- Controlling the operation of transmission facilities belonging to the participating transmission owners

\footnotetext{
${ }^{103}$ For more information on CAISO market operations, see CAISO, Fifth Replacement FERC Electric Tariff (Folsom: California Independent System Operator, June 27, 2016), http://www.caiso.com/Documents/ConformedTariff asof Jun3 2016.pdf. Summary descriptions of market functions are at http://www.caiso.com/market/Pages/MarketProcesses.aspx.
} 
- Ensuring open and impartial access to the transmission system for both consumers and suppliers

- Dispatching generation assets to balance supply and demand at the lowest system cost

- Procuring appropriate ancillary services and other reserves for reliability

- Transmission planning to address needs for expanded capacity

- Monitoring market participant behavior to detect manipulation

- Managing interregional coordination.

CAISO has one umbrella open access transmission tariff that governs operation of all its participating utilities' transmission systems as a single network. The major difference between the operation of a traditional utility BA and an RTO such as CAISO is in the dispatch of generation resources and management of congestion. Rather than having all generation within the BA area available for commitment and dispatch according to the utility's needs, CAISO executes what is called a security-constrained economic dispatch (SCED). "Securityconstrained" means any dispatch of resources must respect the thermal power flow limits across transmission facilities and various other stability and reliability requirements.

"Economic dispatch" means selecting the portfolio of resources that can provide the amount of energy required at the lowest marginal cost.

Economic dispatch occurs every hour in CAISO's centralized day-ahead market and every five minutes in the real-time market. Any generator can submit an offer curve that specifies the levels of output and the price required for each level of output. CAISO aggregates all offers into a market-wide supply curve from least to greatest cost. Load-serving utilities submit bids to buy energy, and the SCED software system dispatches the least-cost resources from the market-wide supply curve. On average, the day-ahead market clears roughly $95 \%$ of the energy necessary to meet load, while the real-time market provides the incremental $5 \%$ needed to balance generation and demand. Prices are calculated and published for each node on the CAISO system via its open-access same-time information system (OASIS) website.

SCED centralizes and replaces the system of manual redispatch used by utility BAs to meet load and manage congestion. In addition, CAISO accepts offers for and procures capacity for ancillary services, co-optimizing this process with energy procurement such that energy and ancillary services are supplied at lowest possible cost.

CAISO also conducts centralized annual transmission planning. It models how proposed configurations for new transmission capacity or upgrades to existing lines might improve reliability, reduce congestion-related costs, or meet policy objectives such as renewable energy procurements. When needs for new transmission projects are identified, they may be put out for competitive solicitation if the cost of the project is large enough.

Imports into CAISO are treated similarly to generation or other supply resources. Imported resources must offer their supply bids at one of the scheduling points identified in CAISO's full network model. The imports require separately secured transmission rights to reach these locations before offering into CAISO. If more resources are offered for import than can be 
accommodated, the line will become congested and the value of power will drop in order to incentivize a reduction in imports.

Seven nodes provide import access to CAISO's Southern California network.

- Mead, Blythe, and Parker in WAPA's Lower Colorado territory

- Palo Verde, North Gila, Four Corners, and Moenkopi in Arizona.

The Eldorado path includes transmission from the Four Corners and Moenkopi facilities. The frequency of congestion on these paths tends to be less than that on transmission elements from the Northwest, which see large flows of cheap hydroelectric power into California during the spring and early summer.

\subsubsection{Energy Imbalance Market and Partial Coordination Options}

CAISO also operates an EIM for itself, PacifiCorp, NV Energy, and as of 2016 APS and Puget Sound Energy. More utilities - including Idaho Power, Portland General Electric, LADWP, Sacramento Municipal Utility District, and Mexico's El Centro Nacional de Control de Energía - have either announced plans to join in the near future or have started the process leading to eventual participation. ${ }^{104}$ The map in Figure 3-5 shows current and planned EIM coverage. The gray shaded areas are served by traditional utilities operating in separate BAs with no current plan to join the EIM.

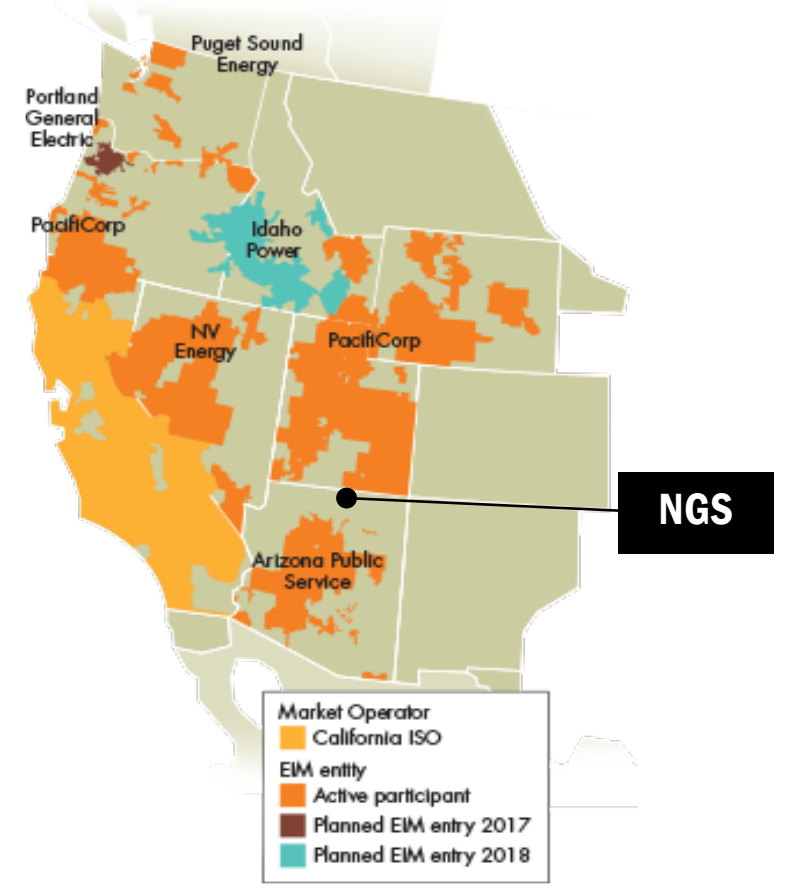

Figure 3-5. Utilities participating in the energy imbalance market Map source: California Independent System Operator

\footnotetext{
${ }^{104}$ CAISO, "Western EIM's new participants successfully begin testing stage," news release, Aug. 1, 2016; LADWP, "LADWP Takes Steps to Participate in the Western Grid's Wholesale Energy Imbalance Market (EIM)," news release, June 7, 2016; CAISO, "ISO welcomes BANC and SMUD's intention to join Energy Imbalance Market," news release, October 21, 2016.
} 
In addition, PacifiCorp is currently studying the costs and benefits of full membership in CAISO. This would extend the RTO's footprint beyond California and into parts of Oregon, Utah, Idaho, Washington, and Wyoming.

While not a full-fledged organized wholesale market like CAISO, an EIM is designed to achieve some of the same benefits within a limited operational space. First, an EIM combines imbalances between real-time demand and real-time generation across a larger geographic footprint. This allows for offsetting potential over-generation and under-generation in neighboring areas, resulting in a smaller aggregate imbalance and less deployment of balancing energy. In addition, pooling the flexible resources used to manage real-time imbalances enables better use of the most cost-effective resources and less reliance on those that are more expensive. $^{105}$

Unit commitment and day-ahead schedules in the EIM are largely unchanged from how they were done without an EIM and continue to govern most energy flows. What the EIM adds is automated dispatch of incremental energy to meet real-time imbalances every five minutes. This makes the EIM's role for PacifiCorp and for NV Energy comparable to CAISO's realtime energy market. ${ }^{106}$

With the addition of APS, LADWP, Idaho Power, Portland General, and Puget Sound, the EIM will comprise about $54 \%$ of the Western Interconnection's demand and about $41 \%$ of its net generation. ${ }^{107}$

For NGS and potential glide path options, an EIM means more operational flexibility in Nevada to accommodate energy flows from Arizona, especially solar and wind power. Declining coal capacity and increasing variable renewable generation from PV and wind tend to create a greater need for system flexibility to maintain reliability, which can be difficult for separately operating balancing authorities whose stock of flexibility resources is limited.

\subsubsection{Effect of Market Structure on NGS Glide Paths}

The federal government is one of many entities throughout the West aiming to increase the use of power from low-emitting energy sources. For several years, these stakeholders have been exploring avenues for reducing emissions at the lowest cost and with the least impact on reliability. Several studies have indicated that coordinating efforts across a larger geographic

\footnotetext{
${ }^{105}$ E3 (Energy and Environmental Economics), PacifiCorp-Iso Energy Imbalance Market Benefits, prepared for PacifiCorp and CAISO (San Francisco: E3, 2013), http://www.caiso.com/Documents/PacifiCorpISOEnergyImbalanceMarketBenefits.pdf; E3, NV Energy-ISO Energy Imbalance Market Economic Assessment, prepared for NV Energy and CAISO (San Francisco: E3, 2014), http://www.caiso.com/Documents/NV EnergyISO-EnergyImbalanceMarketEconomicAssessment.pdf.

${ }^{106}$ NV Energy and PacifiCorp are both owned by Berkshire Hathaway. CAISO, "Energy Imbalance Market," accessed December 2014, http://www.caiso.com/informed/Pages/StakeholderProcesses/EnergyImbalanceMarket.aspx.

107 CAISO and NV Energy, NV Energy's Participation in the Energy Imbalance Market (Folsom: California ISO, 2014).
} 
footprint tends to make the integration of variable renewable resources easier and more cost effective than when each BA does so separately. ${ }^{108}$

NGS' size and location on the grid make the plant a significant generation resource in three distinguishable western power markets: Arizona, California, and Nevada. The electricity sector's operational transformation has penetrated each of these markets in different ways and to different degrees. This, in turn, could affect NGS glide path strategies in at least three major ways:

- Reduce the ability to sell surplus power from NGS, because non-coal alternatives such as renewables and natural gas generation are likely to become more cost competitive and easier to manage ${ }^{109}$

- Favor NGS transition strategies that provide operational flexibility

- Increase the feasibility and the advantages of a multiresource strategy for procuring CAP pumping power (in contrast to relying on a single resource such as NGS).

As operations become more sophisticated, load-serving entities that might be in the market for a PPA have a wider choice of suppliers across a larger geographic footprint. Sophisticated market structures reduce the cost of integrating variable renewable resources, eroding some of the economic edge NGS surplus might have in these markets.

On the other hand, a more sophisticated market structure can increase the array of costeffective options for replacing NGS as a source of CAP pumping power, if a glide path strategy takes advantage of how the market works. Variable renewables are easier to manage under a sophisticated market regime, making them easier to combine into a multiresource portfolio that could supply some or all of CAP's energy needs.

One consequence of these structural changes for an NGS transitional glide path is that wholesale power purchases will tend to be less costly because the grid is operating with greater economic efficiency. A glide path that combines variable renewables such as wind and solar with firming power purchased from the wholesale market would tend to be less expensive and more economically viable as an alternative to NGS power.

Another consequence is that the economic competitiveness of NGS (as well as other coal plants continuing to operate in the West) will tend to erode. The marginal resource is often NGCC plants. ${ }^{110}$ As greater market organization improves the efficiency of how these plants are used, there will be downward pressure on wholesale market prices in addition to any

\footnotetext{
${ }^{108}$ GE Energy, Western Wind and Solar Integration Study, NREL/SR-550-47434, prepared for NREL (Golden, CO: National Renewable Energy Laboratory, 2010), http://www.nrel.gov/docs/fy10osti/47434.pdf.

109 This does not mean that non-coal alternatives can achieve the purpose and need described in the draft EIS. Revenues from surplus federal power sales are limited by law to NGS, and the ability to substitute other sources might depend on institutional changes not examined in this study.

${ }^{110}$ Marginal resource refers to the most expensive generator dispatched to meet load, based on the unit's variable operating cost. Being on the margin means that if demand were to diminish, that resource would be the first one curtailed due to its high cost per megawatt-hour.
} 
influence from natural gas prices. The ability of NGS to provide surplus power at competitive prices may diminish, which could have significant impacts on the Lower Colorado River Basin Development Fund, which relies on surplus NGS power sales for revenue.

\subsection{Utility Responses and Plans}

This section provides an overview of utilities' current IRPs and other planning processes. What these utilities anticipate about the future could influence the federal government's development of a policy road map for safeguarding the interests that currently depend on NGS. The assumption here is that a federal road map will be more effective if it is reasonably congruent with utility planning.

A number of issues in utility planning that could affect federal planning for an NGS road map, including:

- What market trends are utilities anticipating, and how are they responding to them?

- Are utilities anticipating other changes in their conventional generation fleet apart from what might happen with NGS? Do they plan to retire other conventional generation? Are they planning (or have they recently placed in service) new conventional generation to ensure the ability to meet load?

- Do utilities anticipate the need for new resources in order to meet their renewable energy goals?

Answers to these questions might suggest new points of public-private collaboration to achieve crucial federal objectives with respect to an NGS road map. These federal objectives include:

- Securing a long-term source of clean, reliable power for CAP pumping

- Promoting clean energy development on tribal lands, especially the lands of tribes affected directly by NGS

- Identifying the potential for additional federal power sales on the wholesale market or directly to utilities, with revenue from these sales supporting the Lower Colorado River Basin Development Fund

NGS has historically served the Arizona, California, and Nevada markets. In the future, each of these markets will constitute a unique demand environment for NGS and anything that might replace it partially or completely, due in part to the different market structures described in the previous section.

\subsubsection{Arizona}

Of the three states, Arizona represents the strongest market for surplus coal generation. The state has not imposed restrictions on coal-fired generation (unlike California and Nevada).

Renewable generation related to an NGS glide path could also find a market in Arizona, particularly for solar projects. Arizona utilities expect to add about $600 \mathrm{MW}$ of solar to meet their RPS requirements through 2025. The current RPS rule requires the state's IOUs and 
electric cooperatives to source $15 \%$ of their retail electricity sales from renewable sources such as solar, wind, biomass, and hydroelectric by 2025 and thereafter. ${ }^{111}$ In 2015 , the requirement was 5\% renewables and the target increases $1 \%$ annually through 2025 . Almost one-third of that renewable generation must be sourced from customer-sited distributed generation, leaving the remainder-just over $10 \%$ of retail sales - to come from utility-scale renewables. ${ }^{112}$ APS, TEP, and UniSource account for $81 \%$ of the retail load covered by the policy. ${ }^{113}$ SRP is not required to comply with the RPS because it is neither an IOU nor an electric cooperative, but has adopted a voluntary sustainable resource standard under which it has committed to meeting $20 \%$ of its retail demand through renewable and energy efficiency resources by $2020 .^{114}$

All obligated utilities have been in or near compliance with current RPS requirements since 2008. ${ }^{115}$ Figure 3-6 shows existing renewable energy capacity used by the four utilities to meet state RPS requirements and SRP's voluntary goal. The data include both utility-owned and third-party capacity. All of the solar generation that serves Arizona load is sited in-state, while geothermal generation is predominantly out-of-state.

\footnotetext{
${ }^{111}$ Arizona allows utilities to use new small hydroelectric projects under $10 \mathrm{MW}$ as well as increased capacity at existing hydroelectric facilities to comply with the standard. For more details about the fuel sources that are eligible, see http://www.azcc.gov/divisions/utilities/electric/res.pdf.

${ }^{112}$ For this discussion we set aside issues affecting the distributed generation requirement under the RPS. For a

full discussion of Arizona's RPS see: http://programs.dsireusa.org/system/program/detail/268,

${ }^{113}$ Each obligated utility and their historical compliance reports can be found here: http://www.azcc.gov/divisions/utilities/electric/environmental.asp. EIA, "Table 3. Top Five Retailers of Electricity, with End Use Sectors, 2012 Arizona," last updated 2013, http://www.eia.gov/electricity/state/arizona/xls/sept03az.xls.

114 SRP, 2014 Resource Stewardship Sustainability Portfolio (Tempe, AZ: Salt River Project, 2015), http://www.srpnet.com/about/financial/pdfx/ResourceStewardship-2014.pdf.

115 Galen Barbose, RPS Compliance Summary Data (Berkeley, CA: Lawrence Berkeley National Laboratory, 2014), http://emp.lbl.gov/sites/all/files/RPS\%20Compliance\%20Data_October\%202014_0.xlsx.
} 


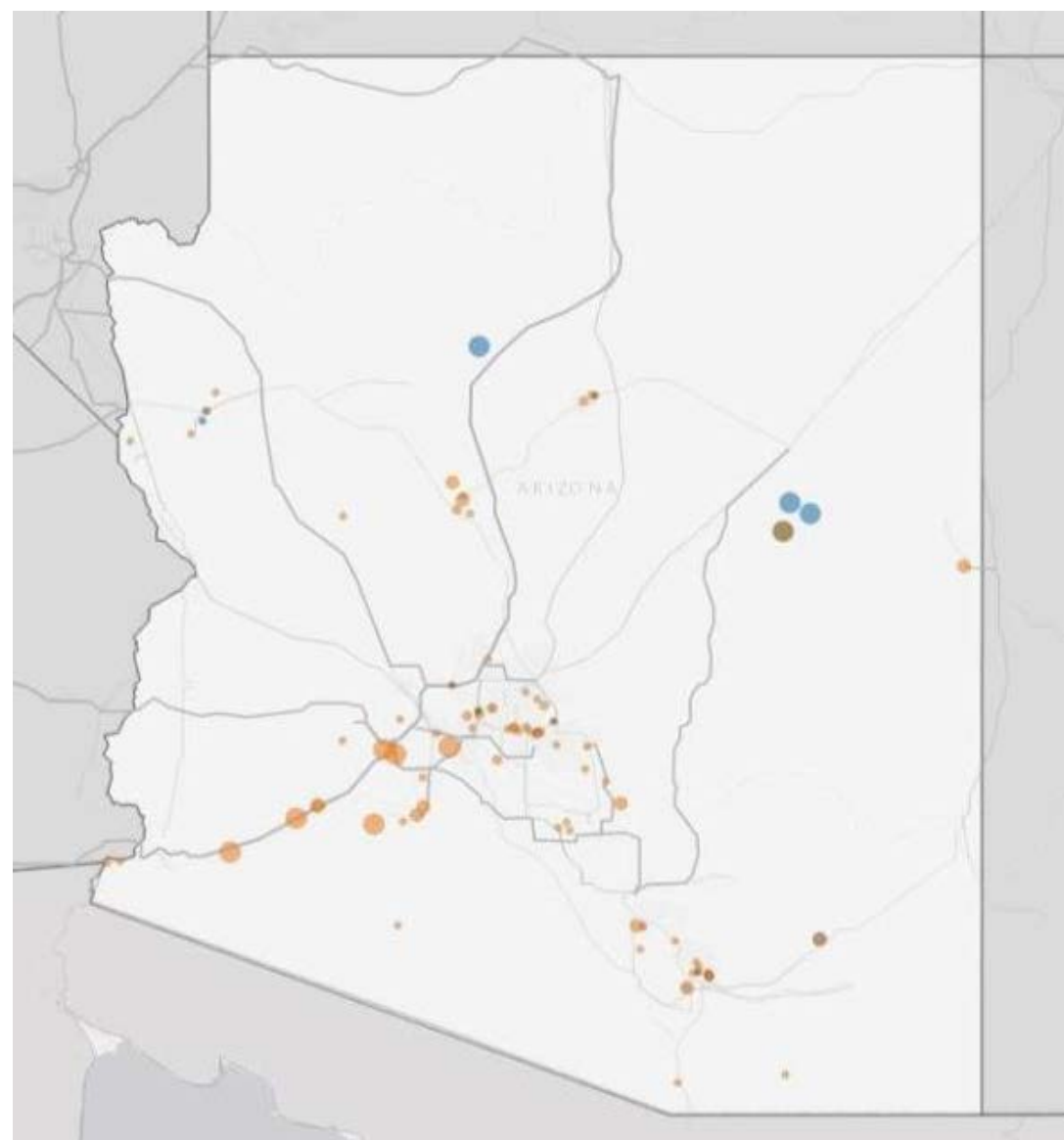

Solar

Wind

Biomass

Heavy lines indicate $500 \mathrm{kV}$ transmission.

Large circles indicate annual net generation greater than 100,000 MWh.

Figure 3-6. Arizona's existing renewable resources and major transmission, July $2016^{116}$

All four utilities - APS, TEP, Unisource, and SRP - expect to maintain compliance with their renewable generation targets going forward. The success of these utilities' energy efficiency programs will affect how much renewable capacity these utilities add to their generation portfolios. APS, TEP, and UniSource are obligated to achieve Arizona's 22\% Energy Efficiency Resource Standard. ${ }^{117}$ SRP is not required to meet the state standard, but it includes energy efficiency in its voluntary target. ${ }^{118}$

Figure 3-7 shows how energy efficiency could play an increasing role in reducing demand growth. The chart also indicates the portion of adjusted demand renewable resources are expected to supply. If growth is higher than assumed, or efficiency measures are not as effective as expected, more renewable energy generation will be required to meet the RPS.

\footnotetext{
${ }^{116}$ SNL Financial Inc., geographic information system queried July 6, 2016.

${ }^{117}$ Annie Downs and Maggie Molina, State Energy Efficiency Resource Standards (EERS) (Washington, D.C.: American Council for Energy Efficient Economy, 2014), http://www.aceee.org/files/pdf/policy-brief/eers-042014.pdf.

${ }^{118}$ SRP, “Renewable Energy,” accessed October 2016, http://www.srpnet.com/environment/renewable.aspx.
} 


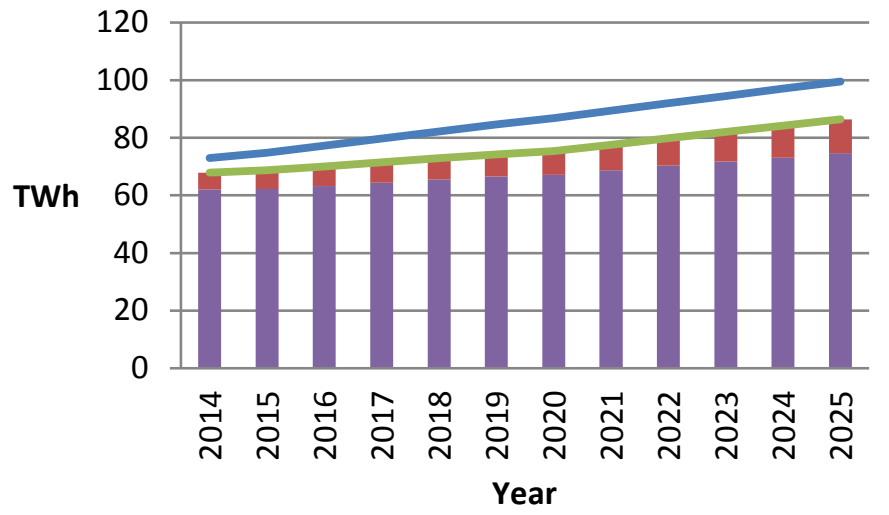

Renewable Generation

Non-Renewable

Generation

Expected Demand

without Energy Efficiency

Demand After Expected

Energy Efficiency

Figure 3-7. Cumulative estimated load, energy efficiency, and renewable energy contributions for APS, TEP, UniSource, and SRP ${ }^{119}$

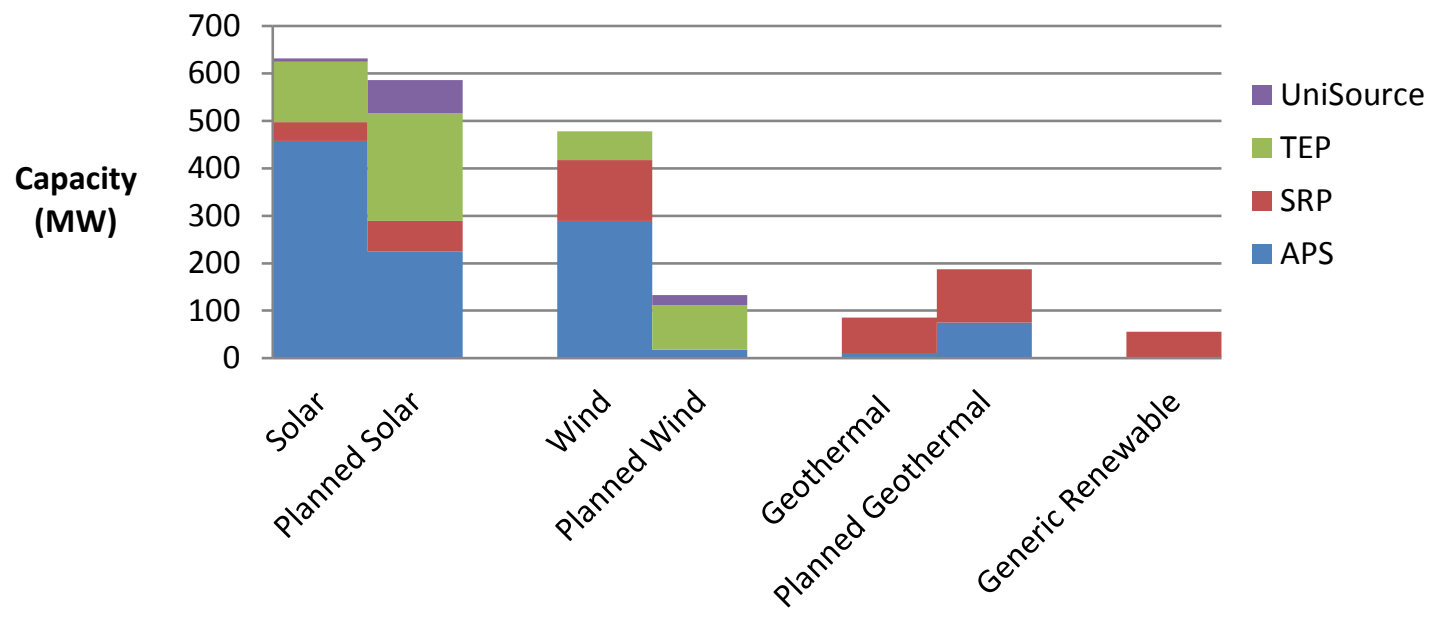

Figure 3-8. Existing and planned RPS capacity by resource and utility through $2025^{120}$

Figure 3-8 shows that most utilities expect solar resources to constitute the majority of the new capacity used to comply with 2025 RPS requirements, followed by geothermal and wind. These utilities' IRPs do not provide information regarding the possible location of most future projects, although, as Figure 3-6 illustrates, nearly all of the state's solar development to date has occurred near transmission lines in the southern part of the state.

\footnotetext{
${ }^{119}$ SRP does not distinguish between the retail load it expects to achieve from renewable energy and that from energy efficiency. This report divides the $20 \%$ estimated generation of these two sources equally in 2020 and beyond at $10 \%$ each. This assumption is based upon the fact that SRP expects the two sources to meet $20 \%$ of its 2022 load, and renewable sources will account for $10 \%$ of the utility's generation capacity in 2022 . See SRP, 2014 Resource Stewardship Sustainability Portfolio.

${ }^{120}$ Existing and planned renewable generation is derived from each utilities IRP including, APS, TEP, and UniSource. In comparison, most of SRP's planned renewable generation capacity is unknown. See note 119 regarding this report's handling of SRP's future renewable energy generation. The known capacity was identified from recent SRP publications including their 2012 IRP and 2014 Resource Stewardship Sustainability Portfolio.
} 


\subsubsection{Salt River Project}

SRP holds a $42.9 \%$ share of NGS (965 MW), with its acquisition of LADWP's stake in NGS effective July 2016. This brings the amount of generating capacity in SRP's balancing authority area to about $6,690 \mathrm{MW}$, based on information filed by SRP for $2014 .{ }^{121}$ Between 3,934 MW and 5,263 MW from firm resources external to SRP's BA were available during the summer season. In this same filing, SRP projected that annual peak load in the BA area would increase by an average of $2.4 \%$ annually through 2024 , with the fastest growth occurring from 2019 to 2022.

SRP's most recent IRP as of this writing was filed in 2012 with WAPA. ${ }^{122}$ That plan identified a need to procure more resources over its planning period through 2016, most of it expected to be natural gas and renewable resources. SRP projected a $581 \mathrm{MW}$ gap between supply and demand by 2017 , taking into account a planning reserve margin of $12 \%$. SRP expected to fill the gap with $156 \mathrm{MW}$ of renewable energy and up to $610 \mathrm{MW}$ of generation through shortterm reserve purchases.

Since publishing its IRP, SRP has purchased $625 \mathrm{MW}$ of natural gas-fired capacity at the combined cycle Mesquite Generating Station in Maricopa County, Arizona. ${ }^{123}$ SRP has also signed contracts to purchase $64 \mathrm{MW}$ of solar capacity from two facilities within Arizona, along with $112 \mathrm{MW}$ of geothermal generation: $25 \mathrm{MW}$ from the Cove Fort geothermal facility in Beaver County, Utah, ${ }^{124}$ and up to $87 \mathrm{MW}$ from the CalEnergy Geothermal Project. ${ }^{125}$

SRP has a 30-year PPA for all the output of the Hudson Ranch I geothermal project (55 MW) in California's Imperial Valley. For five years beginning in October 2016, SRP will resell the output to LADWP as part of SRP's acquisition of LADWP's stake in NGS. ${ }^{126}$ Figure 3-9 compares SRP's 2013 energy mix to its expected mix in $2022 .{ }^{127}$

\footnotetext{
${ }^{121}$ SRP, "FERC Form 714 for the year ending Dec. 31, 2014," 2015. This report shows 6,213 MW of available plant capacity at peak, calculating contributions from NGS at SRP's original $21.7 \%$ ownership share. The acquisition of LADWP's $21.2 \%$ share adds $477 \mathrm{MW}$.

${ }^{122}$ SRP, Integrated Resource Plan FY 2013 (Phoenix: Western Area Power Administration, 2012), https://www.wapa.gov/EnergyServices/Documents/SRP2013.pdf.

${ }^{123}$ SRP, 2013 SRP Annual Report (Tempe, AZ: Salt River Project, 2013).

${ }^{124}$ SRP, Third Quarter Report SRP Fiscal Year 2014 (Tempe, AZ: Salt River Project, 2014). The Cove Fort facility is in early development and SNL Financial does not have a confirmed operation date for the plant.

${ }^{125}$ SRP, 2014 Resource Stewardship Sustainability Portfolio.

${ }^{126}$ LADWP and SRP, "Asset Purchase and Sale Agreement between Department of Water and Power of the City of Los Angeles and Salt River Project Irrigation Improvement and Power District," 2015. The appendix pertaining to the Hudson Ranch agreement is at http://clkrep.lacity.org/onlinedocs/2015/15-0645_misc_23_05-21-2015.pdf (accessed July 14, 2016).

${ }^{127}$ SRP, 2014 Resource Stewardship Sustainability Portfolio
} 


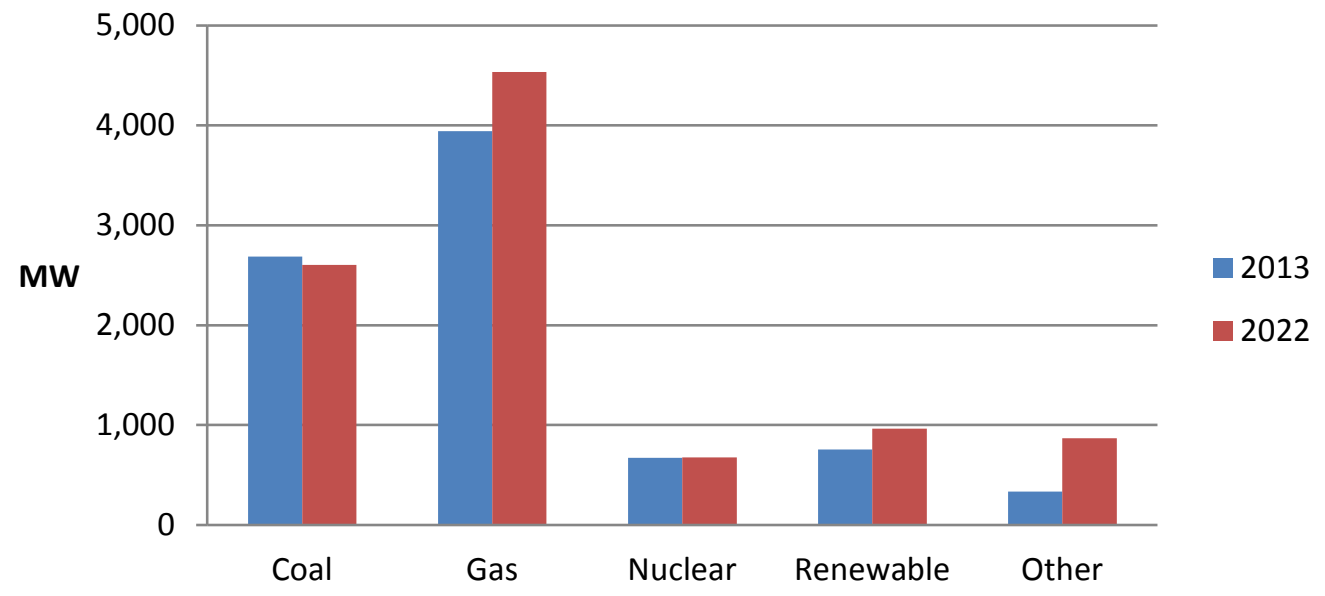

Figure 3-9. Comparison of 2013 and projected 2022 SRP energy mix ${ }^{128}$

\subsubsection{Arizona Public Service Company}

APS, which holds a 14\% share in NGS (315 MW), owns more than 9,100 MW of capacity to service a load of about $8,100 \mathrm{MW} .{ }^{129}$ APS produced over $26,000 \mathrm{GWh}$ of electricity in 2013. ${ }^{130}$

APS's market position may change significantly as a result of the recent retirement of Cholla Unit 2 and the expiration of a number of existing PPAs. Amidst these developments, the utility's peak demand is expected to significantly increase over its planning period through 2029. To accommodate this demand, APS intends to invest considerably in natural gas, energy efficiency, and renewable energy. Despite the significant changes expected in the APS energy mix, the utility plans to continue to be a net purchaser of electricity across its planning period.

APS expects peak demand to increase from the current 8,100 MW to nearly 13,000 MW in 2029. ${ }^{131}$ APS also expects 1,400 MW of PPAs to expire over this time frame. In addition, APS anticipates reducing its coal generation fleet by $647 \mathrm{MW}$ with the retirement of Cholla Unit 2 generating station by 2016 and discontinuing the use of coal at its remaining units at the plant in the mid-2020s. ${ }^{132}$

APS plans to address demand requirements in part through a 290-MW expansion of its existing natural gas-fired Ocotillo facility in Maricopa County, Arizona, by 2018. Over the longer term, APS expects to meet demand through significant investment in natural gas facilities totaling 4,205 MW, ${ }^{133} 425 \mathrm{MW}$ of renewable energy, and 1,772 MW of energy efficiency and demand

128 Ibid.

129 APS, 2014 Integrated Resource Plan (Phoenix: APS, 2014), http://www.aps.com/library/resource\%20alt/2014_IntegratedResourcePlan.pdf.

${ }^{130}$ Derived from SNL Financial Inc., “Arizona Public Service 2013 Plant portfolio summary data,” www.snl.com.

${ }^{131}$ See APS, 2014 Integrated Resource Plan.

132 Ryan Randazzo, "APS plans to close one of the four generators at Cholla Power Plant," AZ Central, September 11, 2014, http://www.azcentral.com/story/money/business/2014/09/11/aps-plans-close-one-four-generatorscholla-power-plant/15455255/.

${ }^{133}$ APS suggests this generation will be composed of combustion turbine and combined cycle plants, but does not specify quantities. See APS, 2014 Integrated Resource Plan. 
response resources by 2029. The emphasis on energy efficiency is in part driven by APS' requirement to meet Arizona's Energy Efficiency Resource Standards. The impacts of this expected generation expansion on APS's energy mix are depicted in Figure 3-10.

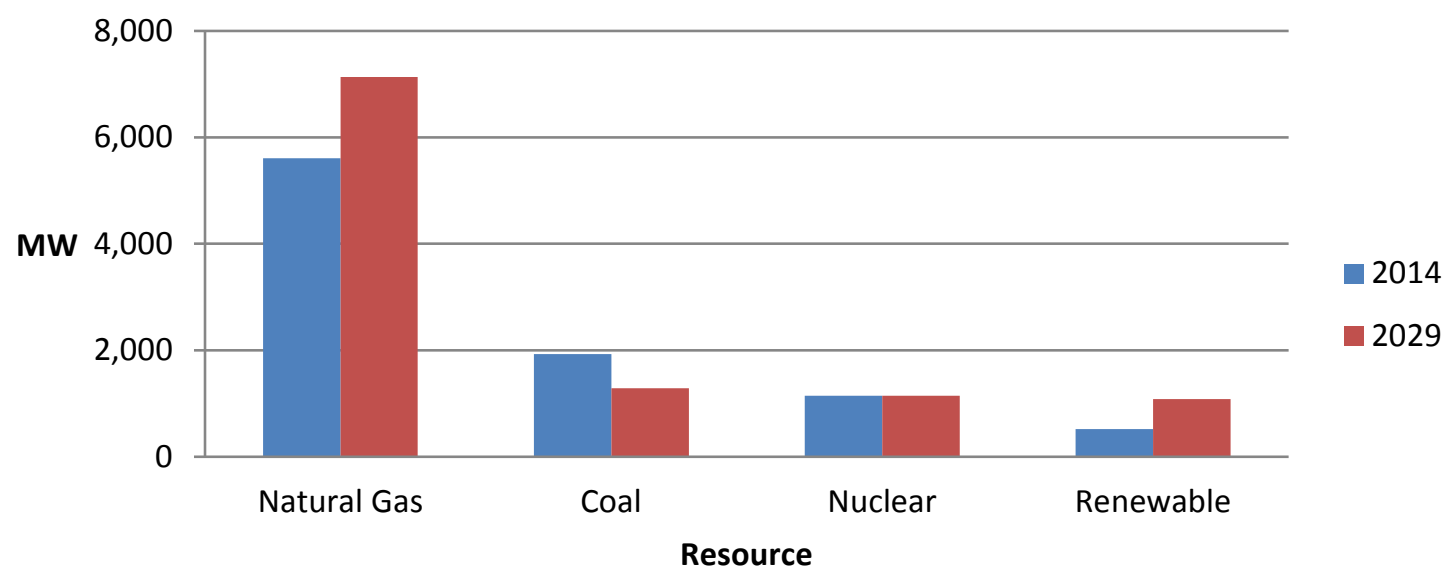

Figure 3-10. Comparison of 2014 and projected 2029 APS energy mix ${ }^{134}$

\subsubsection{Tucson Electric Power Company}

TEP holds a $7.5 \%$ share in NGS (169 MW) and owns nearly 2,600 MW of total capacity that serves a peak load of 2,400 MW. ${ }^{135}$ In 2013, TEP produced almost $11,000 \mathrm{GWh} .{ }^{136}$

TEP expects to see its load significantly increase by 2028 . Over the same time period, TEP plans to retire $32 \%$ of its existing coal fleet in response to regulatory environments while also diversifying its energy portfolio. TEP intends to add over $900 \mathrm{MW}$ of natural gas resources by 2019 and expects significant increases in renewable generation and energy efficiency to meet state mandates. Much like other utilities, the increase in variable renewable resources poses reliability concerns, but TEP has included energy storage in its planned response. Finally, the decline in TEP's coal-fired generation along with increased future demand could cause TEP to shift away from being a net exporter of electricity by 2023 .

TEP is planning for its peak demand to increase by about $525 \mathrm{MW}$ by $2028 .{ }^{137}$ This increased demand is expected to require an additional 1,110 MW of capacity. Despite the need for new capacity, TEP plans to reduce its existing coal capacity by $492 \mathrm{MW}$, or $32 \%$, by 2018 . More specifically, the utility plans to reduce its coal commitments at Springerville Unit 1 by 197 MW in 2015 and at San Juan Unit 2 by 170 MW in 2017. TEP discontinued using coal at its dual-fuel Sundt Unit 4 (173 MW) in 2015.

\footnotetext{
${ }^{134}$ Derived from APS, 2014 Integrated Resource Plan, and also includes the retirement of three units at Cholla (613 MW), which were announced after the publication of the 2014 IRP. See Randazzo, "APS plans to close one of the four generators at Cholla Power Plant."

135 TEP, Tucson Electric Power 2014 Integrated Resource Plan (Tucson: TEP, 2014), https://www.tep.com/doc/planning/2014-TEP-IRP.pdf.

${ }^{136}$ See SNL Financial Inc., "Arizona Public Service 2013 Plant portfolio summary data."

137 TEP, 2014 Integrated Resource Plan.
} 
To replace this generation, TEP plans to acquire $413 \mathrm{MW}$ of natural gas generation from Gila River Power Station in Maricopa County, Arizona; commission a new 550-MW NGCC facility by 2019 ; and build $270 \mathrm{MW}$ of peaking natural gas generation from six new combustion turbines in 2019, 2023, and 2026.

TEP also anticipates renewable energy sources to contribute $15 \%$ of its nameplate capacity by 2016 and expects a total of 529 MW of renewable energy capacity by 2028 . In the near term, TEP plans to procure almost $100 \mathrm{MW}$ of solar generation from three Arizona-based projects. To maintain compliance with the Arizona's Energy Efficiency Resource Standards, TEP plans to add $259 \mathrm{MW}$ of energy efficiency resources and $50 \mathrm{MW}$ of demand response by 2028 . Finally, TEP will procure $50 \mathrm{MW}$ of battery energy storage between 2019 and 2028 . The utility argues that this capacity will provide needed ancillary services to better accommodate the increase in variable renewable generation over its planning period. ${ }^{138}$

TEP does not expect to extend wholesale contracts after their expirations in 2023. Figure 3-11 compares TEP's existing energy mix to its potential mix in 2028.

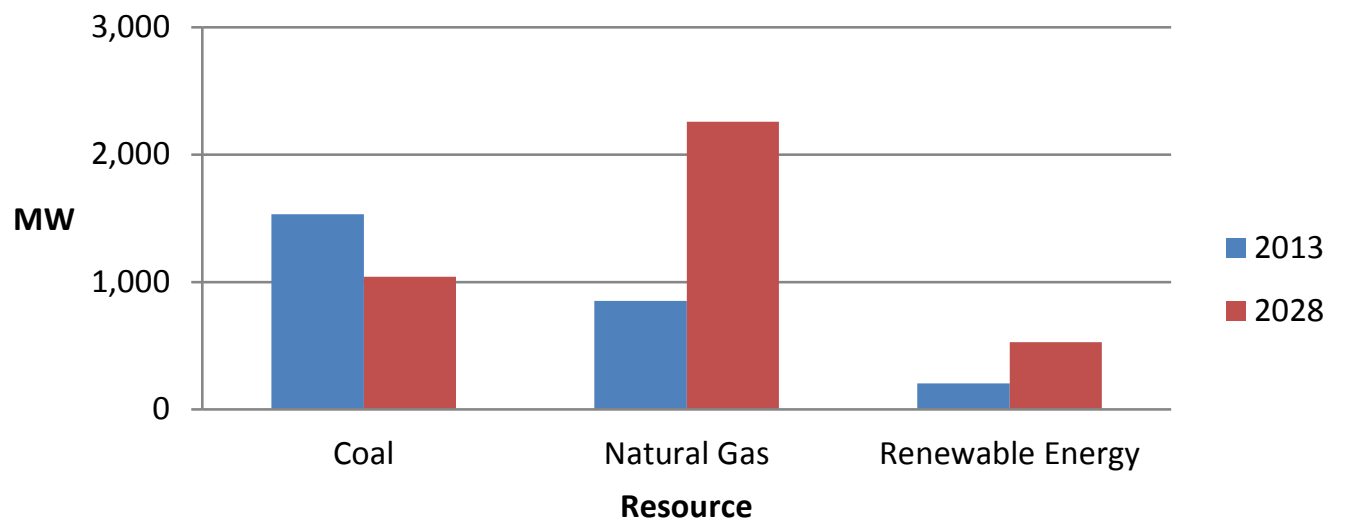

Figure 3-11. Comparison of 2013 and projected 2028 TEP energy mix ${ }^{139}$

\subsubsection{UniSource Energy}

UniSource, TEP's sister company, does not hold a share in NGS. Its peak demand requirement is $424 \mathrm{MW}$, making it small relative to SRP, APS and TEP. The utility generated nearly 1,700 GWh of retail sales in 2013, and this generation was largely sourced from its natural gas combustion turbines $(159 \mathrm{MW}) .{ }^{140}$ The utility also sources electricity from wind and solar generation $(41 \mathrm{MW}){ }^{141}$

UniSource is unique in that, historically, it has purchased much of the electricity required to meet its retail load through short-term market purchases. For example, in 2013, the utility

\footnotetext{
${ }^{138}$ Ibid.

1392028 data derived from TEP, 2014 Integrated Resource Plan; 2013 data derived from SNL Financial Inc.

${ }^{140}$ Derived from UniSource Energy (2014). UniSource Energy 2014 Integrated Resource Plan. https://www.uesaz.com/doc/planning/2014-UES-IRP.pdf.

${ }^{141}$ SNL Financial Inc. does not have data on 2013 net generation from these sources: www.snl.com.
} 
relied on $325 \mathrm{MW}$ of market-based PPAs to meet the majority of its retail obligations. In future years, UniSource plans to shift away from power purchases to more owned generating capacity. By 2028, the utility expects peak demand to increase from its current $424 \mathrm{MW}$ to 469 MW. To meet future demand, UniSource plans to significantly increase its ownership in natural gas and renewable capacity, including a 25\% share of Gila River Project Station Unit 3 in Maricopa County, Arizona, (138 MW) and the development of $111 \mathrm{MW}$ of combustion turbines by 2019 .

UniSource will also add $133 \mathrm{MW}$ of renewable generation and has already signed a contract to procure $51 \mathrm{MW}$ from the Red Horse 2 Solar Farm in Cochise County, Arizona. UniSource will also invest in nearly 2 MW of battery storage with two units coming online in 2019 and 2024, respectively. The new natural gas and renewable generation resources will position UniSource to phase out its short term market purchases by 2019. Though the utility is small, its decline in purchases could have some impact on power flows in the market. Figure 3-12 compares UniSource's energy mix in 2014 to its expected mix in 2028.

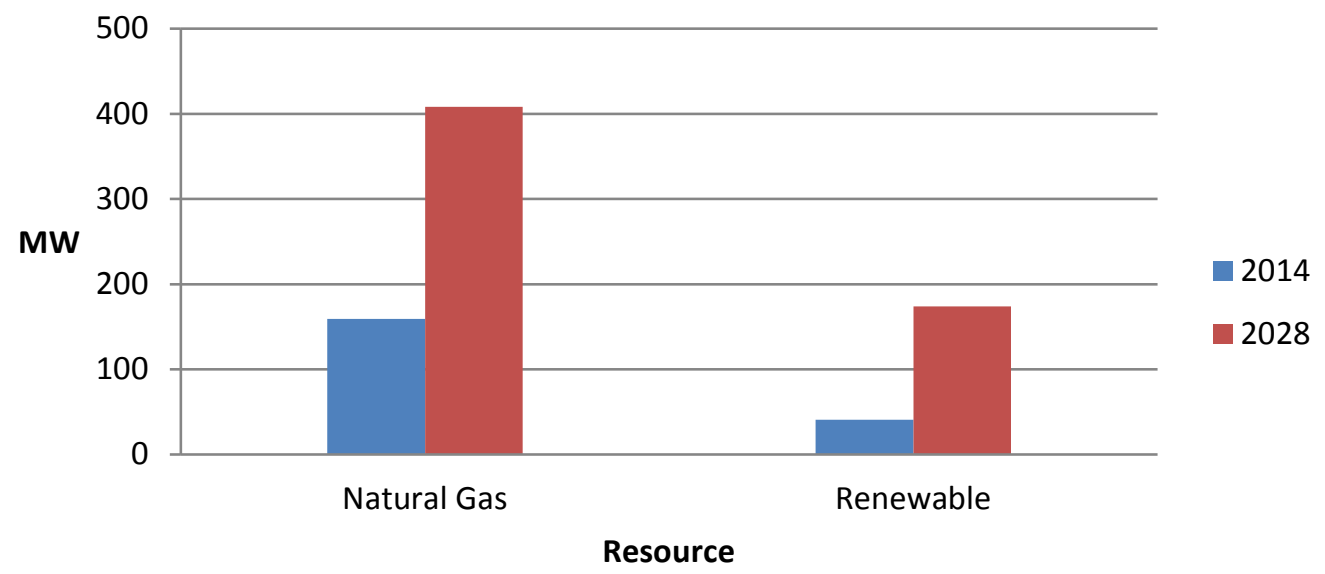

Figure 3-12. Comparison of 2013 and projected 2028 UniSource energy mix ${ }^{142}$

\subsubsection{California}

Export of NGS generation to California effectively ended in 2016 with LADWP's divestiture of its ownership in the plant. This action was consistent with the provisions of SB1368, which precludes California utilities from investing in conventional coal generators, either within California or out of state. ${ }^{143}$ This measure is part of the state's long term strategy to reduce reliance on coal-fired generation in favor of cleaner sources of electricity. ${ }^{144}$ This trend is likely to continue as the California Air Resources Board expects the state to achieve

\footnotetext{
142 Derived from UniSource Energy, 2014 Integrated Resource Plan.

143 Access the bill at http://www.energy.ca.gov/emission_standards/documents/sb_1368_bill_20060929_chaptered.pdf.

${ }^{144}$ EIA, "California Profile Analysis." See also Sylvia Bender, Pam Doughman, David Hungerford, Suzanne Korosec, Todd Lieberg, Melinda Merritt, Mark Rawson, Heather Raitt, and John Sugar, Implementing California's Loading Order for Electricity Resources (Sacramento: California Energy Commission, 2005), http://www.energy.ca.gov/2005publications/CEC-400-2005-043/CEC-400-2005-043.PDF.
} 
compliance with long-term carbon reduction goals outlined in AB32, ${ }^{145}$ in part by driving emissions to near zero across the utility sector by $2050 .{ }^{146}$ Due to these related policies, NGS coal-fired generation would not be eligible to supply a future California market.

New renewable capacity that is developed in line with a strategy to offset the federal share of NGS may be marketable in California, in part because of the significant demand for renewable electricity as a result of California's RPS. California's RPS was initially enacted in $2002^{147}$ and amended in 2006, ${ }^{148} 2011,{ }^{149}$ and most recently in $2015 .{ }^{150}$ The most recent legislation, SB350, which was signed into law by Governor Brown in October 2015, retains the compliance schedule of $33 \%$ renewables by 2020 and increases the requirement to $50 \%$ by 2030 .

The ability of renewables from an NGS glide path to compete in the California market is limited by the deliverability requirements contained in the state RPS law. These provisions essentially create a preference (by way of a larger quota) for in-state resources or those physically delivered into the state. Similar to the earlier law, SB350 specifies three categories of eligible resources and places limits on the amount of generation by category:

- Category 1: Qualifying renewable generation interconnected with or dynamically transferred to a California BA, or scheduled from an eligible renewable resource without substituting electricity from another source (not less than $75 \%$ of procurements starting in 2017) $)^{151}$

- Category 2: Qualifying renewable generation scheduled into a California BA, after being firmed and shaped

- Category 3: Qualifying renewable generation that is not covered under Category 1 or 2, such as unbundled renewable energy credits (not more than $10 \%$ of procurements starting in 2017).

In recent years, California utilities have largely been in compliance with RPS requirements and are expected to meet near-term targets. ${ }^{152}$ In 2014, all retail sellers were required to meet $20 \%$

\footnotetext{
${ }^{145}$ AB 32 requires a 15\% reduction in carbon emissions below 1990 levels by 2020 : http://www.leginfo.ca.gov/pub/05-06/bill/asm/ab_0001-0050/ab_32_bill_20060927_chaptered.html. The longterm 2050 goal is based upon Governor Brown's Executive Order S-3-05: http://gov.ca.gov/news.php?id=1861. ${ }^{146}$ California Air Resources Board, First Update to the Climate Change Scoping Plan (Sacramento: California Air Resources Board, 2014),

http://www.arb.ca.gov/cc/scopingplan/2013_update/first_update_climate_change_scoping_plan.pdf.

${ }_{147}$ The bill is available in full at http://www.energy.ca.gov/portfolio/documents/documents/SB1078.PDF.

$148 \mathrm{The}$ bill is available in full at $\mathrm{http}: / /$ www.leginfo.ca.gov/pub/05-06/bill/sen/sb 01010150/sb 107 bill 20060926 chaptered.pdf.

${ }_{149}$ The bill is available in full at http://www.leginfo.ca.gov/pub/11-12/bill/sen/sb_00010050/sbx1_2 bill_20110412 chaptered.pdf.

150 The full legislation is available at https://leginfo.legislature.ca.gov/faces/billCompareClient.xhtml?bill_id=201520160SB350.

${ }^{151}$ For additional details, see SB350 with revisions to Section 21, subsection 399.16, available at https://leginfo.legislature.ca.gov/faces/billCompareClient.xhtml?bill_id=201520160SB350.

${ }^{152}$ Galen Barbose, "RPS Compliance Summary Data, October 2014," last modified October 16, 2014, http://emp.lbl.gov/sites/all/files/RPS\%20Compliance\%20Data_October\%202014 0.xlsx.
} 
of their retail sales from renewable sources, and the three largest IOUs ${ }^{153}$-Pacific Gas and Electric (PG\&E), Southern California Edison (SCE), and San Diego Gas \& Electric (SDG\&E) - averaged 20.9\%. ${ }^{154}$ The California Public Utility Commission (CPUC) expects that these IOUs, which serve about $65 \%{ }^{155}$ of the California market, will meet the $25 \%$ target in 2016 based on existing and planned projects.

Meeting the 2020 standard and beyond will require significantly more renewable generation over that which is already planned because nearly a third of existing renewable capacity contracts are expected to expire by 2020 . The CPUC has indicated that each utility anticipates adding new resources to achieve compliance. ${ }^{156}$ SCE has $73 \%$ of its required 2020 procurement under contract, in comparison to PG\&E's 95\% and SDG\&E's 118\%. ${ }^{157}$

The state's utilities will likely need additional renewable generation to maintain compliance, but given the RPS preference for in-state generation, renewable generation from Arizona (including Indian Country) will only be marketable in California if it can meet the Category 1 or Category 2 deliverability requirements.

One concern with the expansion of renewable generation related to the RPS program is the risk to reliability associated with the variability of these resources, namely solar and wind. In part to address this issue, the California legislature enacted AB2514. The law granted the CPUC the authority to set long-term energy storage procurement targets for the three largest IOUs. ${ }^{158}$ The CPUC has since required the IOUs to procure a combined total of 1,325 MW of energy storage by $2020 .{ }^{159}$

\subsubsection{Los Angeles Department of Water and Power}

LADWP, which owned a 21.2\% share in NGS (477 MW) until July 2016, has a total fleet capacity of about 9,400 MW in service of a load of approximately 5,680 MW. ${ }^{160}$ LADWP generated about 12,200 GWh of electricity in 2013. ${ }^{161}$ LADWP currently owns one-third of the 500 kilovolt $(\mathrm{kV})$ transmission line from NGS to Mohave in southern Nevada. Its NGS divestiture agreement with SRP provides for LADWP's acquisition of $158 \mathrm{MW}$ of

\footnotetext{
${ }^{153}$ These three utilities serve about $65 \%$ of California's electricity load in 2012. See EIA, "California Electricity Profile 2012," released May 1, 2014, http://www.eia.gov/electricity/state/archive/2012/california/.

154 CPUC, Renewables Portfolio Standard Quarterly Report: $3^{\text {rd }}$ Quarter 2014 (San Francisco: Calirofnia Public Utilities Commission, 2014), http:/www.cpuc.ca.gov/WorkArea/DownloadAsset.aspx?id=5908.

155 EIA, “California Electricity Profile 2012.” http://www.eia.gov/electricity/state/california/xls/sept03ca.xls.

${ }^{156}$ CPUC, Renewables Portfolio Standard Quarterly Report: 1st Quarter 2015 (San Francisco: Calirofnia Public Utilities Commission, 2015), http://www.cpuc.ca.gov/WorkArea/DownloadAsset.aspx?id=5907.

157 See: http://www.cpuc.ca.gov/rps/.

158 The bill is available in full at http://www.leginfo.ca.gov/pub/09-10/bill/asm/ab 25012550/ab_2514_bill_20100929_chaptered.html. The law allowed public utilities to develop their own procurement plans if they determined that energy storage would be cost effective.

159 See "Decision 13-10-040," October 17, 2013, http://docs.cpuc.ca.gov/PublishedDocs/Published/G000/M079/K533/79533378.PDF.

${ }^{160}$ LADWP, 2014 Power Integrated Resource Plan (Los Angeles: LADWP, 2014), https://www.ladwp.com/cs/idcplg?IdcService=GET_FILE\&dDocName=OPLADWPCCB419127\&RevisionSelect ionMethod=LatestReleased.

${ }^{161}$ Derived from SNL Financial Inc., “LADWP 2013 Plant portfolio summary data,” www.snl.com.
} 
transmission rights on the Eldorado path in southern Nevada, which the utility says will provide import capability for additional renewable resources. ${ }^{162}$

LADWP will make significant changes to its energy mix over its planning period through 2034. These changes are driven in large part by the passage of SB1368, which prohibits California utilities from further investment in coal-fired electricity generation. ${ }^{163}$ In the same time period, LADWP expects nearly 1,400 MW of increased demand. LADWP intends to invest significantly in natural gas, renewable, energy efficiency, and demand response resources to replace the electricity derived from its existing coal fleet and meet its demand requirements. As has been the case historically, LADWP will continue to purchase electricity wholesale in order to meet excess demand obligations.

According to its 2014 IRP, LADWP plans to retire its entire coal-fired generation fleet by 2026. ${ }^{164}$ In order to meet this goal, LADWP will replace the power it receives from NGS with $500 \mathrm{MW}$ of natural gas generated at the Apex Power Project in Clark County, Nevada beginning in 2016. LADWP has also reached an agreement with 30 of the needed 36 participants that source electricity from the coal-fired Intermountain Power Project to convert one unit of the facility to natural gas $(600 \mathrm{MW}) .{ }^{165}$ LADWP expects a $1.1 \%$ growth rate in peak demand from the 2014 base case of 5,680 MW to 7,065 MW by 2034 . $^{166}$

LADWP has placed a particular emphasis on energy efficiency to meet $15 \%$ of its electricity demand by $2020 .{ }^{167}$ To date, LADWP meets about 7\% of its annual demand via energy efficiency resources and expects to invest more than $\$ 1.2$ billion to achieve the $15 \%$ goal by 2020. LADWP also expects a significant increase in demand response resources from the existing $5 \mathrm{MW}$ to more than $500 \mathrm{MW}$ by 2034.

\footnotetext{
${ }^{162}$ LADWP, "LADWP Accelerates Coal Power Reduction with Full Divestment from Navajo Generating Plant."

${ }^{163}$ SB 1368 was enacted in 2006 and sets a baseload generation carbon ceiling at the rate of emissions of a NGCC plant. The law's language can be accessed at http://www.energy.ca.gov/emission_standards/documents/sb_1368_bill_20060929_chaptered.pdf.

${ }^{164}$ LADWP, 2014 Power Integrated Resource Plan.

${ }^{165}$ Negotiations are ongoing. See Fitch Ratings, "Fitch Rates Intermountain Power Agency (UT) 2014 Series

A\&B Rev RfdgBonds 'AA-'; Outlook Stable,” Business Wire, May 5, 2014,

http://www.businesswire.com/news/home/20140505006079/en/Fitch-Rates-Intermountain-Power-Agency-UT-

2014\#.VG9UOnInIdU. Though each unit at Intermountain currently has a nameplate capacity of $900 \mathrm{MW}$,

LADWP suggests that the converted facility would produce $600 \mathrm{MW}$ of generation. LADWP, 2014 Power Integrated Resource Plan.

${ }^{166}$ LADWP, 2014 Power Integrated Resource Plan.

${ }^{167}$ LADWP notes that energy efficiency goals could be adjusted after the publication of the CEC's study of energy efficiency potential. In this report, CEC notes that investor owned utilities are on track to achieve targets, while publicly owned utilities are struggling to increase energy efficiency gains. See Elena Giyenko, Doug Kemmer, Sandra Fromm, and Cynthia Rogers, Achieving Cost-Effective Energy Efficiency in California: 2013 Status Update (Sacramento: California Energy Commission, 2014), http://www.energy.ca.gov/2014publications/CEC-200-2014-002/CEC-200-2014-002.pdf.
} 


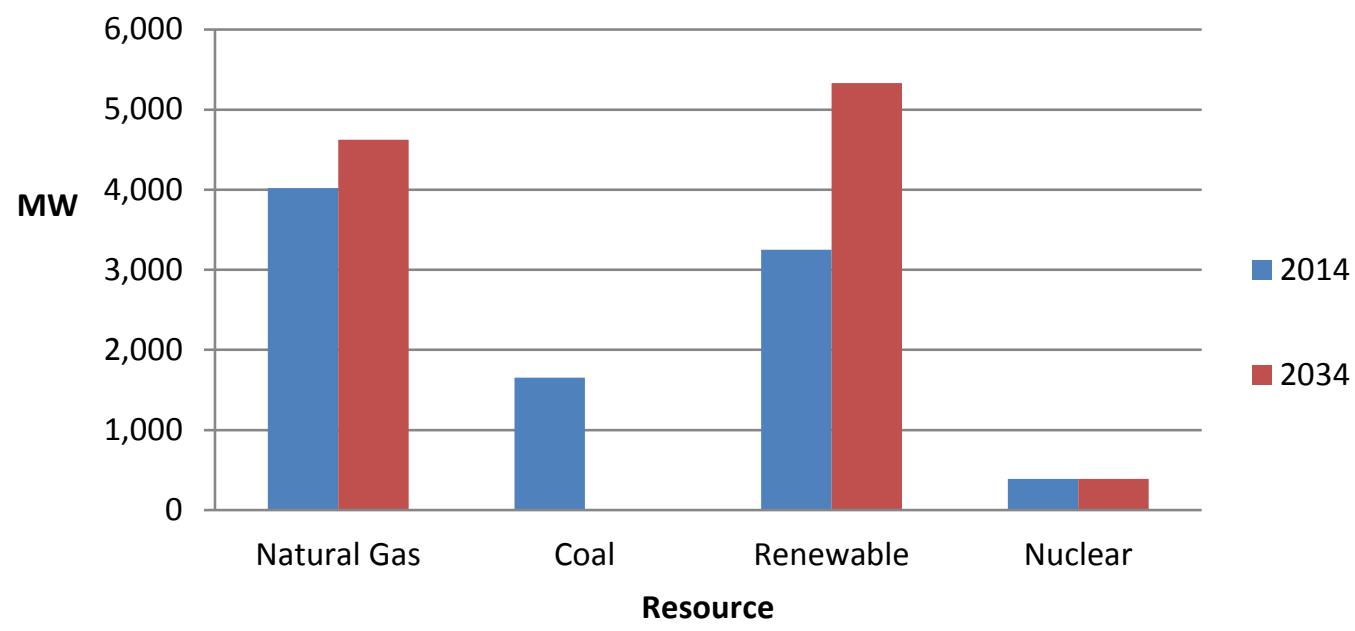

Figure 3-13. Comparison of 2014 and projected 2034 LADWP energy mix ${ }^{168}$

In its 2014 IRP, LADWP modeled a $40 \%$ by 2030 statewide RPS, in anticipation of an increased state standard. To meet the $40 \%$ target, the utility plan called for significant expansion of LADWP's solar generation with a goal of at least $800 \mathrm{MW}$ of locally sourced solar by 2023.

Despite these new additions, LADWP anticipates a consistent resource gap between existing sources and peak demand requirements of about $640 \mathrm{MW}$ from 2023 to 2034 and anticipates making short-term reserve purchases to accommodate this demand. Figure 3-13 illustrates the impacts these plans will have on the LADWP energy mix through 2034.

\subsubsection{Nevada}

Although Nevada has not prohibited utilities from procuring new coal generation resources as California has, utilities in Nevada have been required to reduce the amount of existing coal generation in their portfolios. In 2013, the legislature passed SB123, requiring the state's largest utility, NV Energy, to reduce its coal-fired generation by no less than $800 \mathrm{MW}$ by 2020, which includes NV Energy's stake in NGS (255 MW). ${ }^{169}$ The law also directs the utility to replace this coal generation with at least $350 \mathrm{MW}$ of renewable generation by 2021, and up to $550 \mathrm{MW}$ of generation from sources other than coal. NV Energy supported the bill, in part because it granted them the authority to build new rate-based generation. ${ }^{170}$

The bill does not preclude NV Energy from procuring coal generation in the future, but it will result in the retirement of most of the existing coal generation in Nevada. By 2025, NV Energy plans to divest itself of all remaining coal generation in its portfolio. ${ }^{171}$ As such, after NV

\footnotetext{
168 LADWP, 2014 Power Integrated Resource Plan.

169 The bill language is available in full at http://www.leg.state.nv.us/Session/77th2013/Bills/SB/SB123 EN.pdf.

${ }^{170}$ Andrew Doughman, "NV Energy bill wins passage, signaling state's shift from coal," Las Vegas Sun, June 4, 2013, http://www.lasvegassun.com/news/2013/jun/04/nv-energy-bill-wins-passage-signaling-shift-coal/.

${ }^{171} \mathrm{http}$ :/www.eia.gov/state/analysis.cfm?sid=NV. Also, see NV Power's 2013 and Sierra Pacific's 2014 IRPs.
} 
Energy retires its share in NGS by 2020, it is unlikely that there will be demand for NGS coal generation from utilities in Nevada.

On the other hand, NV Energy may have an appetite for new renewable capacity to both meet the state RPS and satisfy the requirements of SB123. Nevada's RPS currently requires IOUs to acquire renewable generation to meet $25 \%$ of retail electricity sales by $2025 ; 6 \%$ of the requirement must be derived from solar technology. ${ }^{172}$ Beginning in 2005, utilities were allowed to employ energy efficiency to meet $25 \%$ of the annual mandate, ${ }^{173}$ but later legislation began phasing this out, reducing the energy efficiency allowance to $10 \%$ from 2020 to 2024 and eliminating the allowance in 2025 and thereafter. ${ }^{174}$ In 2013 , Nevada's obligated utilities achieved $100 \%$ compliance ${ }^{175}$ with the state's RPS, while both of NV Energy's subsidiaries, Sierra Pacific and Nevada Power, exceeded their compliance requirements. ${ }^{176}$

Although out-of-state renewable generation is eligible for the RPS and not expressly prohibited by SB123, Nevada has significant amounts of high-quality solar and geothermal resources, providing ample competition for renewable generation from Arizona. ${ }^{177}$ In addition, SB123 requires the Nevada Public Utilities Commission to prioritize those renewable projects that will offer the greatest economic benefit to the state along with the greatest opportunity to produce jobs, which is likely to incentivize in-state procurement. ${ }^{178}$

The new One Nevada Transmission Line (ON Line) also affords a variety of options to NV Energy, including accessing low-cost wind resources from Montana and Wyoming and exporting geothermal and solar resources to neighboring states (e.g., California and Arizona). The new transmission line can also help balance in-state resources more effectively by transferring geothermal generation from northern portions of the state to the south and solar

\footnotetext{
172 Originally enacted in 1997, the standard had been revised numerous times, most significantly in 2009 and 2013. In 2009, SB 358 increased the renewable mandate on IOUs to $25 \%$ of retail sales by 2025 , and raised the solar set-aside from 5\% to 6\%. The law requires IOUs to meet $20 \%$ renewable generation from 2015 through $2019,22 \%$ from 2020 through 2024 , and $25 \%$ by 2025 and thereafter.

The full bill language is available at http://www.leg.state.nv.us/75th2009/Bills/SB/SB358 EN.pdf. For more information on the RPS and eligible resources, see DSIRE, "Energy Portfolio Standard Program Overview," last modified January 20, 2016, http://programs.dsireusa.org/system/program/detail/373.

${ }^{173}$ DSIRE, "Energy Portfolio Standard Program Overview," http://programs.dsireusa.org/system/program/detail/373.

174 "Nevada Senate Bill No. 252-Committee on Commerce, Labor and Energy," Nevada 77 $7^{\text {th }}$ Session, 2013 , http://leg.state.nv.us/Session/77th2013/Bills/SB/SB252_EN.pdf.

175 Barbose, "RPS Compliance Summary Data, October 2014..

${ }^{176}$ NV Energy, Renewable Portfolio Standard Annual Report Nevada Power Company d/b/a NV Energy Sierra Pacific Power Company d/b/a NV Energy, Compliance Year 2013 (Las Vegas: NV Energy, 2014), https://www.nvenergy.com/renewablesenvironment/renewables/images/2013ComplianceReport.pdf.

${ }_{177}$ David J. Hurlbut, Joyce McLaren, and Rachel Gelman, Beyond Renewable Portfolio Standards: An Assessment of Regional Supply and Demand Conditions Affecting the Future of Renewable Energy in the West, NREL/TP6A20-57830 (Golden, CO: National Renewable Energy Laboratory, 2013), http://www.nrel.gov/docs/fy13osti/57830-1.pdf.

${ }^{178}$ The bill language is available in full at http://www.leg.state.nv.us/Session/77th2013/Bills/SB/SB123 EN.pdf.
} 
generation from the south to the north. ${ }^{179}$ The state is also evaluating new transmission projects that would allow for further exports of renewable generation to California. ${ }^{180}$

NV Energy currently holds an $11.3 \%$ share in NGS (255 MW). Its generation fleet has a total capacity of 8,900 MW, serving load with a peak demand of 7,600 MW. ${ }^{181}$ In 2013, NV Energy produced approximately $27,266 \mathrm{GWh} .{ }^{182}$ Its two operating divisions-Nevada Power and Sierra Pacific_ _ account for about $95 \%$ of all retail sales in Nevada. ${ }^{183}$

NV Energy's position in the Southwest market is heavily influenced by the passage of SB123, which requires the retirement of much of the utility's coal fleet by $2020 .{ }^{184}$ The utility must retire this generation while accommodating more than 1,700 MW of increased demand through 2027. To do so, NV Energy will rely on significant new investments in natural gas and renewable capacity. Despite these additions, NV Energy anticipates continuing to be a net purchaser of electricity over its planning period.

The utility is limited in how it can meet increased demand because Nevada's SB123 requires NV Energy to retire more than $800 \mathrm{MW}$ of coal-fired capacity by $2020 .{ }^{185}$ In compliance with this mandate, NV Energy retired Reid Gardner Generating Station Units 1, 2, and 3 (300 MW) in 2015, plans to retire Reid Gardner Generating Station Unit 4 (257 MW) in 2017, and plans to divest its share of NGS (255 MW) by $2020 .{ }^{186}$

To replace retiring coal capacity, NV Energy plans to acquire 274 MW of NGCC-fired electricity from Las Vegas Cogeneration Units 1 and 2, along with 222 MW from the Sun Peak Generating Unit. To comply with SB123, the utility must procure $350 \mathrm{MW}$ of new renewable nameplate capacity. NV Energy has requested approval for a 15 MW solar facility at Nellis Air Force Base and expects to add the bulk of the remaining capacity (335 MW) by the end of

\footnotetext{
${ }^{179}$ Hurlbut et al., Beyond Renewable Portfolio Standards.

${ }^{180}$ John Candelaria and Carl Linvill, Assessing Renewable Energy Export Opportunities and the Potential Benefits of Nevada/California Electricity Exchanges (Agoura Hills, CA: Aspen Environmental Group, 2012), http://energy.nv.gov/uploadedFiles/energynvgov/content/NV_CA_Mutual_Benefits_and_Export_Opportunity_As sessment_Final_Report.pdf. See also Governor's Office of Energy, 2014 Status of Energy Report for the State of Nevada (Carson City: Nevada Governor's Office of Energy, 2015), http://energy.nv.gov/uploadedFiles/energynvgov/content/Media/StateofNevada2015StatusofEnergyReport.pdf.

${ }^{181}$ This information was derived from NV Energy's 2013 IRP, Volume 5, Docket Number 12-06053, available at http://puc.nv.gov/ and Sierra Pacific's 2014 IRP, Volume 4, Docket Number 13-07005, available at http://puc.nv.gov/.

${ }_{182}$ Derived from SNL Financial Inc., "NV Energy Inc. 2013 Plant portfolio summary data,” www.snl.com.

${ }^{183}$ EIA (2015), EIA-Form 826 database.

${ }^{184}$ North Valmy Station, which is owned by Sierra Pacific, is scheduled for retirement in 2025. See Henry Brean, "NV Energy proposes closing coal-burning plant early," Las Vegas Review-Journal, April 3, 2013, http://www.reviewjournal.com/business/energy/nv-energy-proposes-closing-coal-burning-plant-early.

${ }_{185}$ The bill language is available in full at http://www.leg.state.nv.us/Session/77th2013/Bills/SB/SB123 EN.pdf.

186 This information was derived from NV Energy's 2014 amended IRP, accessed via SNL Financial Inc., www.snl.com.
} 
2021. ${ }^{187}$ The utility anticipates that this capacity will keep the utility in compliance with Nevada's RPS through 2020.

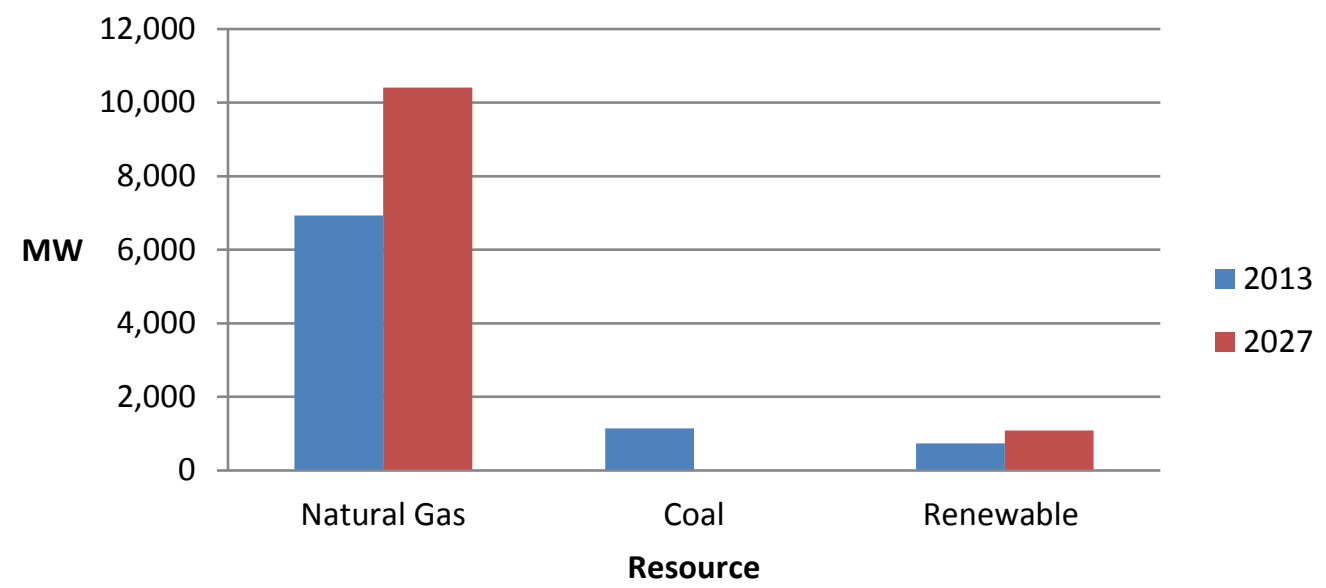

Figure 3-14. Comparison of 2013 and projected 2027 NV Energy resource mix ${ }^{188}$

Despite these additions, NV Energy anticipates an average $600 \mathrm{MW}$ gap between existing resources and planned demand through 2027, which they will meet, if necessary, with shortterm reserve purchases. Figure 3-14 denotes the differences between NV Energy's existing mix and what it may look like in 2027.

\subsubsection{Other Non-NGS Utilities in New Mexico and Texas}

In addition to UniSource in Arizona, two utilities without shares of NGS (and outside of the three states highlighted here) will contribute to the general market conditions of the region that could affect an NGS strategy: Public Service Company of New Mexico (PNM) and El Paso Electric (EPE) in Texas. They are part of the Southwest subregional network, as defined by the North American Electric Reliability Corporation. Consistent with trends throughout the Southwest, both of these utilities are shifting from coal to natural gas generation in coming years. This section discusses these utilities' plans and how they might affect the rest of the Southwest market.

\subsubsection{PNM Resources}

PNM expects relatively stable demand in comparison to the other utilities, but it plans to make significant changes to its portfolio through 2033. Currently, PNM has a total capacity of approximately 2,800 MW to serve a demand of about 1,900 MW. ${ }^{189} \mathrm{PNM}$ is planning for an

\footnotetext{
${ }^{187}$ NV Energy had planned to construct the 200 MW Moapa Solar Project to meet part of this requirement, but the Nevada Public Utilities Commission has rejected that request. See Sean Whaley, "Nevada PUC rejects NV Energy plan for Moapa solar plant," Las Vegas Review-Journal, October 27, 2014, http://www.reviewjournal.com/business/energy/nevada-puc-rejects-nv-energy-plan-moapa-solar-plant. 188 This figure has been recreated from NV Power's 2013 IRP, and its 2014 amended IRP along with Sierra Pacific's 2014 IRP.

${ }^{189}$ SNL Financial Inc., "PNM Resources 2013 Plant portfolio summary data,” www.snl.com.
} 
increase in peak demand of about 325 MW from 2014 through $2024 .{ }^{190}$ In the same period, PNM will retire 340 MW of coal-fired electricity from the San Juan Generating Station Units 2 and 3. PNM expects to replace this capacity and meet increased demand by expanding its share in the Palo Verde nuclear plant by 134 MW (2018), commissioning three new $177 \mathrm{MW}$ gas turbines (2018, 2023-2024, 2026-2028), and adding more than $280 \mathrm{MW}$ of solar and $200 \mathrm{MW}$ of wind by 2028 .

To comply with New Mexico's Energy Efficiency Resource Standards, PNM also intends to significantly increase its energy efficiency savings from $75.6 \mathrm{GWh}$ in 2013 to $658 \mathrm{GWh}$ by 2020. This planned expansion will allow PNM to continue to be a net exporter of electricity. Currently, PNM exports more than $483 \mathrm{GWh}$ of electricity, and it expects this total to increase to more than $810 \mathrm{GWh}$ by $2033 .{ }^{191}$

\subsubsection{El Paso Electric}

In the near term, EPE plans to make changes to its generation fleet, primarily because much of its current fleet is aging and needs to be replaced. ${ }^{192}$ EPE currently owns approximately 2,500 MW to serve a peak demand of almost 1,900 MW. ${ }^{193}$ Much of its planned expansion will be sourced from natural gas, specifically peaking facilities, through 2021 . The utility anticipates adding some solar and biomass generation to its fleet, but this will not significantly alter its renewable portfolio.

According to EPE's IRP, it expects a 716-MW deficit between current capacity and demand by 2021. ${ }^{194}$ This is in part because the utility will retire the aging Rio Grande Unit 7 and Newman units $1-4$ by 2025 , which collectively account for $520 \mathrm{MW}$ of EPE's existing natural gas capacity. EPE intends to sell its 108-MW share in Four Corners by $2021 .^{195}$

To replace this generation, EPE intends to increase capacity substantially during the planning period of 2012-2031, with 2,490 MW of newly built capacity by 2031. In the short term, EPE plans to add Unit 9 (87 MW) to its natural gas-fired Rio Grande facility and a new phase of the 352-MW Montana Generating Station in Texas by 2017 to serve as a flexible, peaking resource. EPE also plans to add two more natural gas combustion turbine peaking facilities (70 MW each) in 2018 and 2019. It also expects to convert one existing facility to NGCC to produce $148 \mathrm{MW}$ by 2021.

EPE has plans for an additional $20 \mathrm{MW}$ of biomass generation that would count toward compliance with New Mexico's RPS. As of this writing, the utility was also exploring the

\footnotetext{
${ }^{190}$ PNM Resources, PNM Integrated Resource Plan 2014-2033 (Albuquerque: PNM Resources, 2014), https://www.pnm.com/irp.

${ }^{191}$ Ibid.

192 El Paso Electric, Integrated Resource Plan of El Paso Electric Company for the Period 2012-2031 (El Paso: El Paso Electric, 2012), www.epelectric.com/document/integrated-resource-plan-2012-2031-7-16-12.

${ }^{193}$ Ibid.

194 Ibid.

195 El Paso Electric, 2013 Annual Report (El Paso: El Paso Electric, 2013), http://files.shareholder.com/downloads/ABEA-2OZSXJ/2598535802x0x745117/8DCF1CF2-F5F2-4377-AB32195C24F25EC8/2013_Annual_Report.pdf.
} 
acquisition of a 48.5-MW solar project that could serve Texas customers only and as a result would not apply toward the New Mexico RPS requirements. ${ }^{196}$

\subsubsection{Regional Utility Planning Outlook}

Overall, a significant expansion in demand is expected across the region. Eight utilities anticipate a combined expansion in demand of approximately $12 \mathrm{GW}$ over the course of their IRPs, with APS, EPE, and NV Energy anticipating the largest individual expansions.

Planned new generation projects for meeting this growth in demand include about $3 \mathrm{GW}$ of natural gas capacity and nearly $4 \mathrm{GW}$ of renewable energy. ${ }^{197}$ In addition to the $3 \mathrm{GW}$ of new natural gas generation projects specified in their IRPs, the utilities indicated additional unspecified needs amounting to $11 \mathrm{GW}$.

Although all of the utilities plan to expand their fleet to accommodate increasing demand, LADWP, SRP, NV Energy, and APS have suggested they will need to purchase electricity from other suppliers to meet at least some of their demand over the planning period. UniSource may also be a net electricity purchaser at least until 2019. ${ }^{198}$

These purchasing developments are not likely to disrupt the regional power flows because most utilities examined in this review, with the exception of TEP and UniSource, expect to retain a similar market position as either a net purchaser or net seller of electricity. However, the type of generation that net purchasers such as LADWP seek to procure is likely to target renewable and flexible natural gas resources rather than coal. This could impact the market for surplus generation from the federal share of NGS.

\subsubsection{Potential Need for Flexible Generation}

Another consideration for future market conditions is the type of generation that may be needed in the future as the resource mix and demand in the region changes. In the IRPs reviewed here, several utilities said much higher energy demand in the future, coupled with the expansion of variable renewables, such as wind and solar, will require more flexible generation than they currently have available. Collectively, the utilities plan to add nearly $4 \mathrm{GW}$ of renewable energy capacity in the near term and about $1 \mathrm{GW}$ of peaking capacity during that same period.

Most of these utilities are currently employing their coal plants to serve baseload purposes, with NV Energy the only entity running its coal resources below $70 \%$ since 2008 . In comparison, only NV Energy and EPE were utilizing their newest combined cycle plants near or above $50 \%$ (Figure 3-15).

\footnotetext{
${ }^{196}$ See El Paso Electric, Integrated Resource Plan of El Paso Electric Company for the Period 2012-2031. This report also does not factor this project into its assessment of El Paso Electric's future or the regional outlook.

${ }^{197}$ Some utilities, like NV Energy, have not specified the MW capacity of some future facilities and so they are not included here.

${ }^{198}$ APS only anticipates purchasing electricity in 2017 and 2018 at 364 and $240 \mathrm{MW}$ respectively. As such, this figure averages these two numbers. Similarly, UniSource expects to purchase electricity through 2018 and the purchased electricity is averaged over these 5 years. This information was derived from these utilities' IRPs.
} 


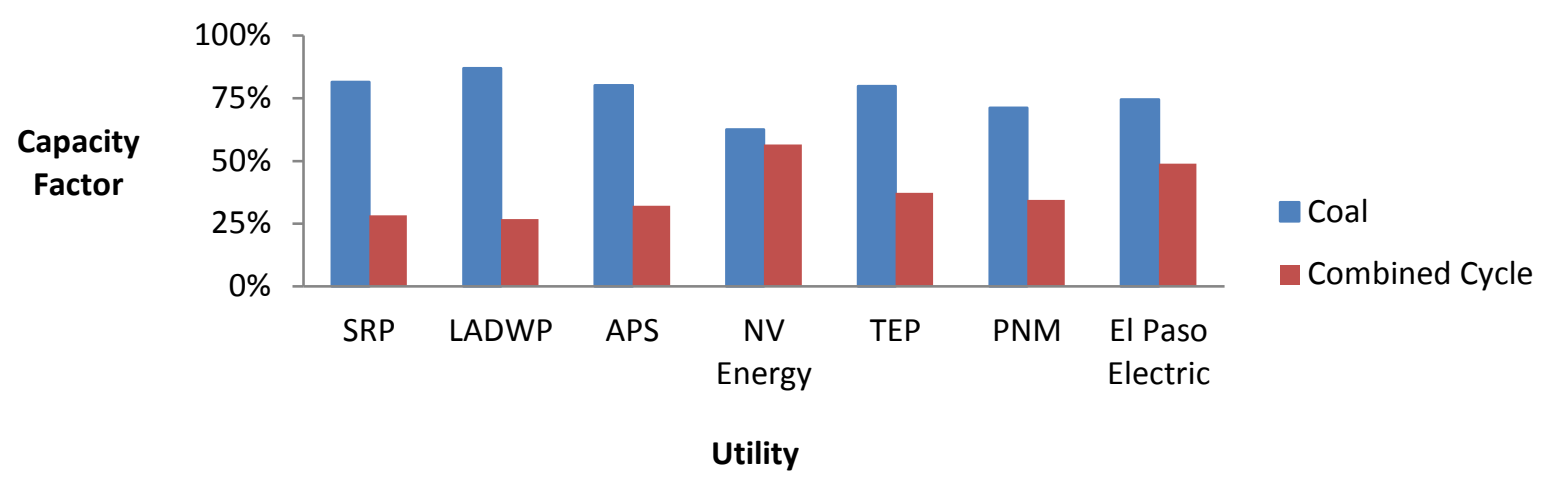

Figure 3-15. Comparison of Southwest utility capacity factors for coal and NGCC plants ${ }^{199}$

\subsection{Policy Drivers and Market Trends}

Utilities across the West have been actively managing emerging cost, market, and policy trends while also accommodating increasing load through their planning processes. How these utilities respond to all these factors will affect the regional demand for NGS and the viability of various glide path options. This section reviews select policy drivers and market trends in the West generally, particularly the Clean Power Plan (CPP).

\subsubsection{Clean Power Plan}

As of this writing, EPA's rule for reducing carbon emissions from existing power plants has been stayed by the U.S. Supreme Court pending review by the U.S. Court of Appeals for the District of Columbia Circuit. Currently, some states are continuing with stakeholder meetings and information-gathering, but the effect of the CPP on the electricity sector will be difficult to predict until the court has ruled on the issues before it.

The final rule calls for each state, tribe, and territory to develop a "best system of emission reduction" (BSER). ${ }^{200}$ A BSER can include a combination of three building blocks: improving coal plant efficiency; increasing natural gas dispatch; and increasing renewable generation. For each state, EPA developed interim targets beginning in 2022 and a final target in 2030 based upon state-specific analyses of the building blocks. These targets are expressed both as massbased emission caps (in total tons of carbon dioxide from existing sources) and as statewide average emission rates (in pounds of carbon dioxide equivalents per megawatt-hour generated from affected generators). Table 3-3 shows the 2030 goals for Navajo Nation and the state of Arizona.

\footnotetext{
199 This figure was adapted from SNL Financial Inc., "2013 power plant capacity factor data,” www.snl.com.

${ }^{200}$ EPA, "Carbon Pollution Emission Guidelines for Existing Stationary Sources: Electric Utility Generating Units (Clean Power Plan), final rule,” Federal Register 80 (2015): 64662.
} 
Table 3-3. CPP Goals for Navajo Nation and Arizona 201

\begin{tabular}{lllll}
\hline & \multicolumn{3}{c}{ Navajo Nation } & \multicolumn{2}{c}{ Arizona } \\
\hline & tons & Ib/MWh & tons & Ib/MWh \\
$\mathbf{2 0 1 2}$ (historic) & $29,629,453$ & 2,123 & $40,465,035$ & 1,552 \\
$\begin{array}{l}\mathbf{2 0 2 0} \text { projection } \\
\text { without CPP }\end{array}$ & $20,464,699$ & 2,124 & $39,511,785$ & 1,409 \\
$\mathbf{2 0 3 0}$ goal & $\begin{array}{l}21,700,587 \\
\left(22,955,804^{*}\right)\end{array}$ & 1,305 & $\begin{array}{l}30,170,750 \\
\left(32,380,196^{*}\right)\end{array}$ & 1,031 \\
\hline
\end{tabular}

${ }^{*}$ These alternative mass-based goals include a complement for emissions from new sources. Any existing coal-fired generators that are repowered to use natural gas as a fuel would be treated as a new source by EPA, and would therefore be subject to new-source emission standards and not to the CPP.

Even before the Supreme Court's stay, the CPP's potential impact on the Southwest was unusually complicated. NGS and the Four Corners Generating Station - two of the largest coalfired plants in the Western United States - are both located on the Navajo Reservation, which EPA treats as a sovereign jurisdiction separate from the states of Arizona, New Mexico, and Utah. This means that Arizona's compliance with carbon reduction targets could be unaffected by plans for NGS, in which case state planning would instead focus on four other existing coal plants: the 1,625-MW Springerville plant (jointly owned by TEP, Tri-State Generation and Transmission, SRP, and three investment groups); the 767-MW Cholla plant (owned by APS and PacifiCorp); the 762-MW Coronado plant (owned by SRP); and the 350-MW Apache plant (owned by Arizona Electric Power Cooperative).

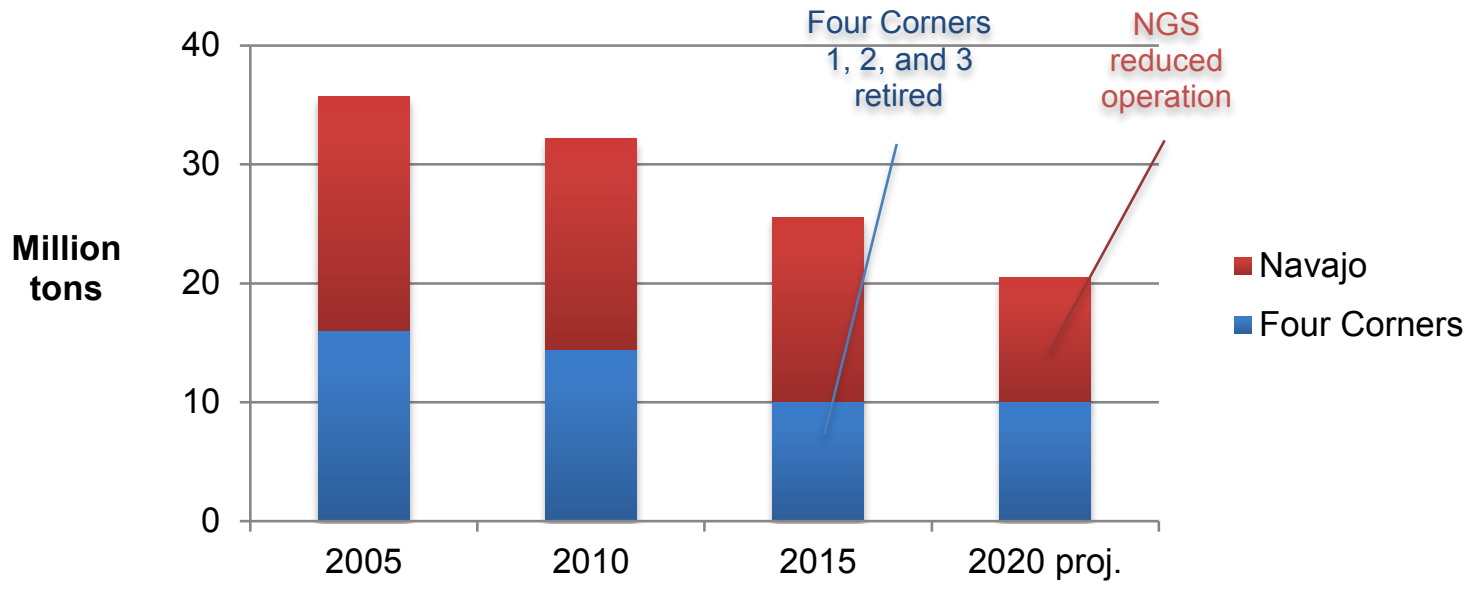

Figure 3-16. $\mathrm{CO}_{2}$ emissions from existing generators in Navajo Nation

Navajo Nation would effectively be in compliance with its final 2030 mass-based target (21.7 million tons $\mathrm{CO}_{2}$-equivalent per year) with the implementation of the TWG Agreement. The permanent retirement of Four Corners Units 1, 2, and 3 in 2015 reduced $\mathrm{CO}_{2}$ emissions by more than 5 million tons annually; the retirement of one NGS unit in 2019 (or equivalent

${ }^{201}$ Ibid. 
reduction in operation) would reduce emissions by another 6 million tons. ${ }^{202}$ Figure 3-16 shows the likely magnitude of the completed and planned reductions. In its proposed supplemental rule on applying the CPP to tribes and territories, EPA notes that these actions "would mean the Navajo territory would meet the proposed goal without additional actions beyond the shutdowns, if the goal is converted to a mass-based goal."203

Carbon emissions from Arizona's coal fleet would fall to around 24 million tons per year in 2020, based on the retirement of Cholla Unit 2 and the conversion of Apache Unit 2 from coal to natural gas. Figure 3-17 charts the historical and projected emissions from the Arizona coal fleet based on planned changes and historical unit emission rates. Assuming emissions from the state's existing combined cycle fleet continue at around 14 million tons, total energy demand remains stable, and other coal units operate as they did in 2015, Arizona would have a CPP compliance gap of more than 5 million tons per year in 2020.

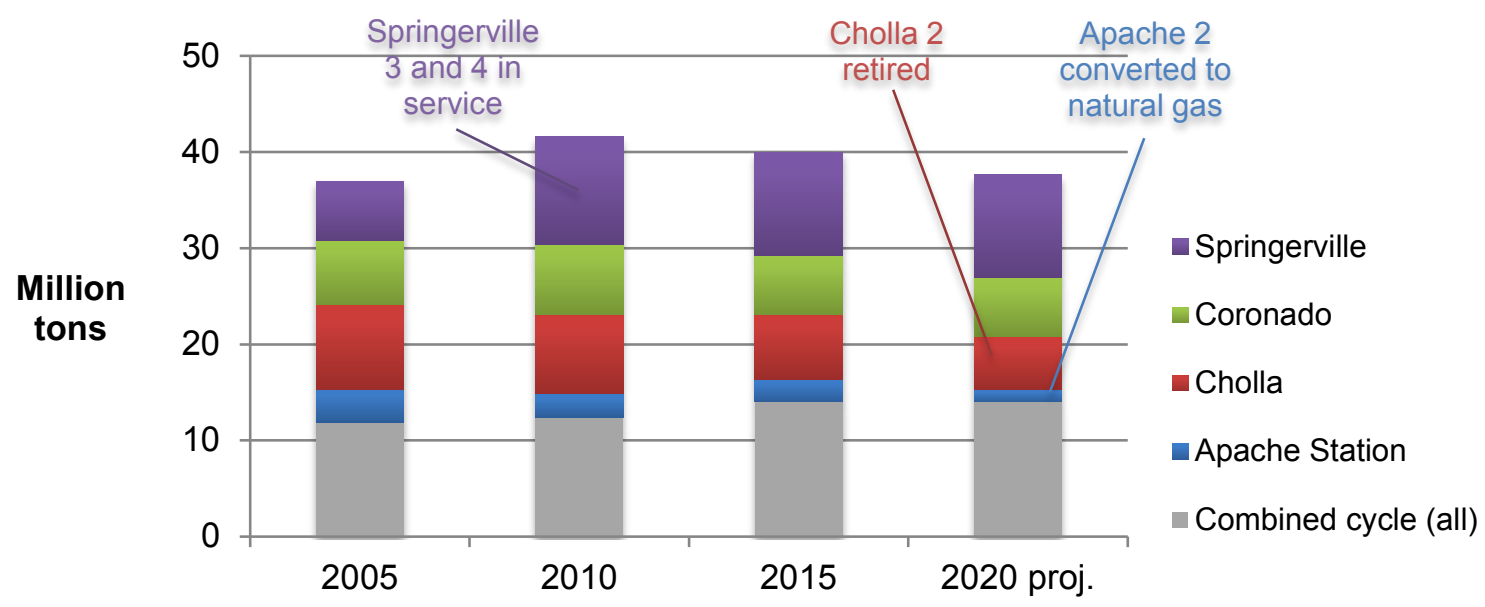

Figure 3-17. $\mathrm{CO}_{2}$ emissions from existing generators in Arizona

Not shown in this chart are announced plans by APS to discontinue burning coal at Cholla Units 1 and 3 sometime after 2020.

These trends indicate that while Arizona's coal fleet might be subject to additional operational changes to comply with the CPP by 2030 , NGS might not be. Whether this implies more regulatory stability for NGS relative to other coal units is difficult to predict. The CPP itself is uncertain as of this writing, and factors apart from the CPP could influence the use of NGS after 2019.

Under the CPP final rule, renewable energy developed on Indian land could be used to reduce carbon emissions in Arizona. This is unaffected by whether or not the Navajo Nation as a jurisdictional entity separate from Arizona has any further emission reduction burden under the

${ }^{202}$ EPA, "Carbon Pollution Emission Guidelines for Existing Stationary Sources: EGUs in Indian Country and U.S. Territories; Multi-jurisdictional Partnerships," Federal Register 79 (2014): 65482-65505. http://www.gpo.gov/fdsys/pkg/FR-2014-11-04/pdf/2014-26112.pdf.

${ }^{203}$ Ibid. 
CPP. Thus, while the rule itself might not directly lead to further reductions in NGS operations, it could incentivize new renewable energy development to close Arizona's compliance gap, and some of that development could occur on lands owned by tribes affected by NGS.

Another issue raised by Navajo Nation leaders in consultations with EPA is the disposition of allowances or emission reduction credits related to reductions in excess of interim and final goals. A proposed federal plan that EPA released for comment along with the final CPP contains an allocation methodology that would redirect allowances for retired units to new renewable energy projects after two years and not to the remaining units operating at the plant. ${ }^{204}$ During official tribal consultations, the Navajo Nation requested that EPA grant the credits to the Navajo Nation. As of this writing, EPA was still considering comments on the proposal and had not yet issued a final federal plan.

Carbon reduction policies in general may tend to increase the use of existing NGCC generators in the short term and encourage the addition of new renewable energy generation in the latter part of the 2020s. These findings are based on modeling of the entire Western Interconnection conducted by NREL using its Resource Planning Model, as described in detail in the next chapter.

\subsection{Sectoral Trends and Implications for NGS}

Utilities within the southwest region of WECC are generally following the broader trend toward procuring natural gas and renewables to meet future load and RPS requirements through 2020. New natural gas facilities make up a higher proportion of procurements in the Southwest as compared to WECC overall, and this is coupled with similarly low capacity factors for natural gas combined cycle plants in the region. In a departure from the WECCwide trend, southwestern utilities are expecting to procure almost exclusively solar and wind resources through 2020.

Major markets in the West-especially the West's largest market, California-are continuing to move away from coal-fired power procurements. Combined with the wholesale price trends examined in Chapter 2, this could add to the challenges for marketing surplus power from the federal share of NGS. These trends suggest that a glide path should be flexible with respect to its assumptions about continued use of NGS.

Low capacity factors for regional NGCC plants could have two related glide path effects: redispatch of existing NGCC could play a significant part in replacing NGS generation, and building a new NGCC as part of a glide path might not be economical. The expected procurement of solar and wind suggests that renewable resources could play a part in an NGS glide path strategy that includes the potential for selling power to others.

\footnotetext{
204 The proposed methodology would apply if a unit "does not operate for 2 consecutive calendar years, then such affected EGU will not be allocated the $\mathrm{CO}_{2}$ allowances ... for the next compliance period for which allowances

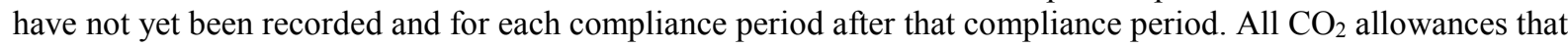
would otherwise have been allocated to such affected EGU will be allocated to the renewable energy set-aside for the State where such affected EGU is located and for the respective compliance periods involved" 80 FR 65067.
} 
Regardless of the outcome of the CPP, it is unlikely that NGS will be required to achieve further carbon emission targets related to the plan. This could have a positive effect on the use of NGS coal-fired generation in the state of Arizona, compared to the state's other coal-fired plants that might be subject to further requirements to reduce emissions. Furthermore, if the CPP is implemented, it could build a stronger market for renewable generation related to NGS in Arizona and the region more broadly, depending upon how states plan to meet carbon targets. 


\section{Modeling of Power Sector Trends}

Some of the baseline issues pertinent to the future of NGS lend themselves to computational modeling. For example, a decision to build a new generator or to retire an old one has interactive effects that ripple throughout the power sector due to the physics of the network. Thus, retiring one unit does not necessary imply a need to build a replacement megawatt-formegawatt, especially if other existing units in the system tend to have spare capacity at the right time. The optimality of a plant-level microeconomic decision can be computed against a macroeconomic backdrop that captures the complex network of physical and financial interactions.

Utilities employ such modeling in their own resource planning, and NREL has applied two tools for this baseline analysis of the federal share of NGS. The first model, NREL's Resource Planning Model (RPM), simulates the addition of new generation capacity and transmission over time, taking into account expected load growth, known generator retirements, power plant costs, and transmission limits on the flow of power from one point on the grid to another. The second model, PLEXOS, simulates the optimal hourly operation of the grid over a test year to assess the grid operations with the changing generator portfolio identified by the first model. PLEXOS holds generation and transmission capacity constant for the test year, varying external factors such as the price of natural gas.

This chapter describes RPM and PLEXOS and how they are applied for this baseline analysis. Once the results from each have been explained, the chapter concludes by synthesizing the modeled results into a narrative of underlying trends in the Western Interconnection.

The modeling in this chapter was completed prior to EPA's final adoption of the CPP, before California and Oregon increased their RPS targets to 50\%, and before Congress extended tax credits for new renewable energy investments. The reason for this timing is that the modeling was relevant to the development of the draft EIS covering federal actions in 2019 relating to NGS and the Kayenta coal mine. ${ }^{205}$ This baseline volume reports the modeling results as they were provided to the draft EIS, which was governed by its own strict timeline. Volume 2 of this study, which will examine NGS glide path options, will update the modeling reported here with more current assumptions about technology cost and the policy environment.

\subsection{Capacity Expansion Modeling}

The modeling described in this section addresses some of the key factors likely to affect new capital investment in electric generation capacity and transmission. The primary analytic objectives of this analysis are to:

- Identify long-term capacity expansion trends in the Western Interconnection

- Quantify how these long-term trends might change under NGS retirement scenarios

- Develop plausible capacity expansion scenarios that can be tested later with more detailed production cost analysis.

\footnotetext{
${ }^{205}$ U.S. Bureau of Reclamation, NGS-Kayenta Mine Complex Project Draft EIS.
} 
Many factors affect the long-term value of major infrastructure investments. Renewable technology costs are declining rapidly, especially for solar PV systems. ${ }^{206}$ The boom in unconventional production methods such as hydraulic fracturing has increased natural gas supplies and generally reduced prices, accelerating a shift from coal to natural gas. ${ }^{207}$ Current and future environmental regulations crafted to address carbon emissions, the use of water for thermal cooling, and other impacts could add new operational constraints to electric generation or impact retrofit and retirement decisions. These factors can be modeled and their influences on infrastructure expansion quantified.

In this chapter, we test for the effect of the future price of natural gas across a range of plausible future values. We also use a hypothetical price of carbon emissions to represent the effect of current and future environmental regulations not structurally included in the model. By accounting for a selection of key factors, we can model the possible direction of future generation and transmission investments in the Western Interconnection, and how different NGS retirement scenarios might affect these trends.

It is important to note that the results of this analysis do not represent forecasts or predictions. Rather, the scenarios were developed using an internally consistent modeling framework to simulate broad trends in the future power system. The objective is to test how much one factor can influence optimal choices for new generation and transmission, holding other factors unchanged. Future market conditions entail large uncertainties; however, many of these uncertainties (such as changes in future technology costs and water availability) are outside the limited range of input assumptions evaluated here. Models only simulate - and necessarily simplify_real-world decision-making.

\subsubsection{Resource Planning Model}

To model capacity expansion, we use RPM. RPM is a recently developed capacity expansion model designed to simulate a regional power system such as a utility service territory, state, or balancing authority (BA). RPM co-optimizes new generation, transmission expansion, and dispatch over time in 5-year increments beginning in 2010 and continuing until $2030 .{ }^{208}$ The model has high spatial resolution down to the individual generation unit for a select subset of units; solar and wind resource zones represent geographic areas with similar production characteristics. RPM models hourly dispatch for a representative sample of days throughout a year. Each hourly step balances generation with load, maintains the required amount of reserve capacity, and remains within operational constraints for individual generators and transmission

${ }^{206}$ Feldman et al., Photovoltaic System Pricing Trends; Galen Barbose, Samantha Weaver, and Naïm Darghouth, Tracking the Sun VII: An Historical Summary of the Installed Price of Photovoltaics in the United States from 1998-2013, LBNL-6808E (Berkeley, CA: Lawrence Berkeley National Laboratory, 2014), http://eetd.lbl.gov/sites/all/files/tracking the sun_vii report.pdf; Mark Bolinger and Samantha Weaver, UtilityScale Solar 2013: An Empirical Analysis of Project Cost, Performance, and Pricing Trends in the United States (Berkeley, CA: Lawrence Berkeley National Laboratory, 2014), https://emp.lbl.gov/sites/all/files/LBNL UtilityScale Solar 2013 report.pdf; Ryan Wiser and Mark Bolinger, 2014 Wind Technologies Market Report

(Washington, D.C.: U.S. Department of Energy, 2015), http://energy.gov/sites/prod/files/2015/08/f25/2014-WindTechnologies-Market-Report-8.7.pdf

207 EIA 2016.

${ }^{208}$ RPM's least-cost optimization algorithm minimizes overall system cost, including capital costs, fixed and variable operations and maintenance costs, and fuel costs. 
paths. An initial version of RPM for a Colorado-centric region is described in Mai et al. (2013), and Mai et al. (2015) provides a more detailed description of the current model. ${ }^{209}$

RPM models the Western Interconnection electricity system, which includes all or parts of 13 states in the Western United States, two western provinces in Canada, and a small region of northern Mexico. This geographic boundary comprises $36 \mathrm{BAs}$, which are the primary regional units in RPM. ${ }^{210}$ The model represents a focus region in nodal detail (specific points for generation and load), while the remaining regions are treated zonally to capture power transfers into and out of the focus region.

RPM captures in detail local factors that affect the optimal use of resources in a focus region comprising Arizona and parts of southern Nevada and the Four Corners area. The model draws on resources outside the focus region when they are more cost-effective. It also represents - in a reduced and computationally tractable form-import-export dynamics between the focus region and neighboring demand centers, and among other demand centers in the Western Interconnection outside the focus region. By simultaneously capturing local and regional dynamics, RPM is a suitable capacity expansion model for examining the local and regional effects of NGS glide path options.

Figure 4-1 shows the combined zonal and nodal structure of RPM and highlights the five BAs that constitute the focus region for this analysis: Arizona Public Service (APS), Nevada Power (NEVP), Salt River Project (SRP), Tucson Electric Power (TEP), and Western Area Power Administration Lower Colorado (WALC). This focus region comprises 704 nodes with load, generation, or both. ${ }^{211}$ Two-thirds are in Arizona, about 30\% are in southern Nevada, and the rest are divided between New Mexico and Southern California. As such, the remainder of this report refers to an Arizona-centric focus region. NGS is operated by SRP and is associated with that BA in the model. Table 4-1 identifies each of the model BAs, and shows the location of NGS within the modeled network.

\footnotetext{
209 Trieu Mai, Easan Drury, Kelly Eurek, Natalie Bodington, Anthony Lopez, and Andrew Perry, Resource Planning Model: An Integrated Resource Planning and Dispatch Tool for Regional Electric Systems, NREL/TP6A20-56723 (Golden, CO: National Renewable Energy Laboratory, 2013), http://www.nrel.gov/docs/fy13osti/56723.pdf; Trieu Mai, Clayton Barrows, Anthony Lopez, Elaine Hale, Mark Dyson, and Kelly Eurek, Implications of Model Structure and Detail for Utility Planning: Scenario Case Studies Using the Resource Planning Model, NREL/TP-6A20-63972 (Golden, CO: National Renewable Energy Laboratory, 2015), http://www.nrel.gov/docs/fy15osti/63972.pdf.

${ }^{210}$ Model BAs are closely, although not perfectly, aligned with real BAs as designated in the data used in WWSIS Phase 2. See D. Lew, G. Brinkman, E. Ibanez, A. Florita, M. Heaney, B.-M. Hodge, M. Hummon, G. Stark, J. King, S.A. Lefton, N. Kumar, D. Agan, G. Jordan, and S. Venkataraman, Western Wind and Solar Integration Study Phase 2, NREL/TP-5500-55588 (Golden, CO: National Renewable Energy Laboratory, 2013), http://www.nrel.gov/docs/fy13osti/55588.pdf.

${ }^{211}$ Another 638 nodes represent various network junctures.
} 


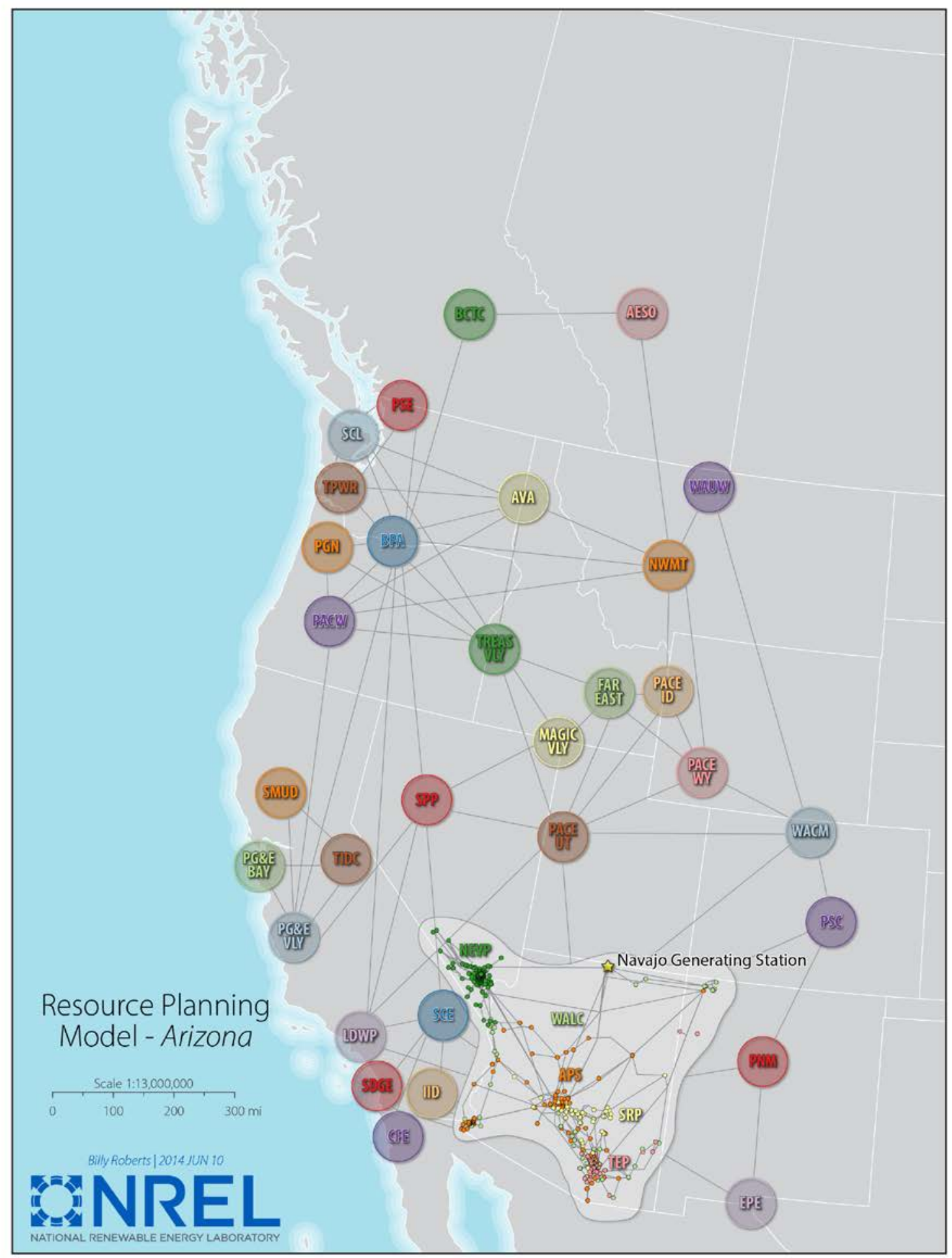

Figure 4-1. Combined nodal and zonal spatial structure of NREL's Resource Planning Model 
Table 4-1. Balancing Areas (BAs) Modeled in NREL's Resource Planning Model

\begin{tabular}{|c|c|c|c|c|c|}
\hline \multicolumn{2}{|c|}{ Focus Area BAs } & \multicolumn{4}{|l|}{ Other BAs } \\
\hline APS & Arizona Public Service & AESO & $\begin{array}{l}\text { Alberta Electric } \\
\text { System Operator }\end{array}$ & PG\&E_VLY & $\begin{array}{l}\text { Pacific Gas \& Electric } \\
\text { Valley Area }\end{array}$ \\
\hline NEVP & Nevada Power & AVA & Avista & PGN & $\begin{array}{l}\text { Portland General } \\
\text { Electric }\end{array}$ \\
\hline SRP & Salt River Project & ВСТC & $\begin{array}{l}\text { British Columbia } \\
\text { Transmission } \\
\text { Corporation }\end{array}$ & PNM & $\begin{array}{l}\text { Public Service New } \\
\text { Mexico }\end{array}$ \\
\hline TEP & Tucson Electric Power & BPA & $\begin{array}{l}\text { Bonneville Power } \\
\text { Administration }\end{array}$ & PSC & $\begin{array}{l}\text { Public Service } \\
\text { Colorado }\end{array}$ \\
\hline \multirow[t]{12}{*}{ WALC } & $\begin{array}{l}\text { Western Area Power } \\
\text { Administration Lower } \\
\text { Colorado }\end{array}$ & CFE & $\begin{array}{l}\text { Comisión Federal } \\
\text { de Electricidad }\end{array}$ & PSE & Puget Sound Energy \\
\hline & & EPE & $\begin{array}{l}\text { El Paso Electric } \\
\text { Company }\end{array}$ & SCE & $\begin{array}{l}\text { Southern California } \\
\text { Edison }\end{array}$ \\
\hline & & FAR_EAST & Far East & SCL & Seattle City Light \\
\hline & & IID & $\begin{array}{l}\text { Imperial Irrigation } \\
\text { District }\end{array}$ & SDGE & $\begin{array}{l}\text { San Diego Gas \& } \\
\text { Electric }\end{array}$ \\
\hline & & LDWP & $\begin{array}{l}\text { Los Angeles } \\
\text { Department of } \\
\text { Water and Power }\end{array}$ & SMUD & $\begin{array}{l}\text { Sacramento Municipal } \\
\text { District }\end{array}$ \\
\hline & & MAGIC_VLY & Magic Valley & SPP & Sierra Pacific Power \\
\hline & & NWMT & $\begin{array}{l}\text { Northwestern } \\
\text { Montana }\end{array}$ & TIDC & $\begin{array}{l}\text { Turlock Irrigation } \\
\text { District }\end{array}$ \\
\hline & & PACE_ID & $\begin{array}{l}\text { Pacificorp East - } \\
\text { Idaho }\end{array}$ & TPWR & Tacoma Power \\
\hline & & PACE_UT & $\begin{array}{l}\text { Pacificorp East } \\
\text { Utah }\end{array}$ & TREAS_VLY & Treasure Valley \\
\hline & & PACE_WY & $\begin{array}{l}\text { Pacificorp East } \\
\text { Wyoming }\end{array}$ & WACM & $\begin{array}{l}\text { Western Area Power } \\
\text { Administration } \\
\text { Colorado/Missouri }\end{array}$ \\
\hline & & PACW & Pacificorp West & WAUW & $\begin{array}{l}\text { Western Area Power } \\
\text { Administration Upper } \\
\text { Missouri }\end{array}$ \\
\hline & & PG\&E_BAY & $\begin{array}{l}\text { Pacific Gas \& } \\
\text { Electric Bay Area }\end{array}$ & & \\
\hline
\end{tabular}


Table 4-2. Start Year (2010), Prescribed, and Retiring Capacity in NREL's Resource Planning Model (Changes through 2024) 212

\begin{tabular}{|c|c|c|c|c|c|c|}
\hline \multirow[b]{2}{*}{ Generator Type } & \multicolumn{3}{|c|}{ Western Interconnection } & \multicolumn{3}{|c|}{ Arizona-Centric Focus Region } \\
\hline & $\begin{array}{c}2010 \\
\text { Capacity } \\
\text { (MW) }\end{array}$ & $\begin{array}{c}\text { Under } \\
\text { Construction } \\
\text { (MW) }\end{array}$ & $\begin{array}{l}\text { Retirements } \\
\text { (MW) }\end{array}$ & $\begin{array}{c}2010 \\
\text { Capacity } \\
\text { (MW) }\end{array}$ & $\begin{array}{c}\text { Under } \\
\text { Construction } \\
\text { (MW) }\end{array}$ & $\begin{array}{l}\text { Retirements } \\
\text { (MW) }\end{array}$ \\
\hline Coal & 36,774 & 405 & 7,574 & 8,836 & - & 1,370 \\
\hline NGCC & 60,582 & 1,941 & 269 & 15,313 & 423 & - \\
\hline NGCT & 20,140 & 3,736 & 1,650 & 2,372 & 521 & 50 \\
\hline NG-Other & 23,423 & 8 & 14,985 & 1,489 & - & 80 \\
\hline Nuclear & 9,681 & - & 2,246 & 4,035 & - & - \\
\hline Biomass & 1,559 & 76 & 40 & 30 & 3 & - \\
\hline Geothermal & 3,054 & 35 & - & - & - & - \\
\hline Hydropower & 70,164 & 103 & - & 3,884 & - & - \\
\hline PHES & 3,787 & 40 & - & 146 & - & - \\
\hline PV & 74 & 2,654 & - & 10 & 939 & - \\
\hline CSP & 429 & 1,887 & - & 75 & 250 & - \\
\hline Wind & 10,172 & 6,621 & - & - & 174 & - \\
\hline Total & 239,840 & 17,505 & 26,764 & 36,190 & 2,310 & 1,500 \\
\hline \multicolumn{7}{|c|}{$\begin{array}{l}\text { NGCC = natural gas combined cycle } \\
\text { NGCT = natural gas combustion turbines } \\
\text { PHES = pumped hydropower energy storage } \\
\text { PV = photovoltaic } \\
\text { CSP = concentrating solar power }\end{array}$} \\
\hline
\end{tabular}

In addition to the nodes and model BAs, we include additional spatial layers to represent renewable resources. RPM uses 100 solar and 100 wind resource areas in the Western Interconnection to describe the location-specific resource potential (developable area after accounting for various land use exclusions), performance (annual and hourly capacity factors), and grid interconnection distances. ${ }^{213}$

RPM allows for transmission capacity expansion, but in a limited way. RPM models power transfers between nodes and BAs using a simple transport model that constrains transmission based on individual line capacities within the focus region, and interface limits between BAs based on parameters from Lew et al. (2013). ${ }^{214}$ RPM can increase the size of existing lines, but it cannot add new transmission along new corridors that are not already included in the model.

\footnotetext{
${ }^{212}$ Under-construction capacity includes capacity installed since 2010 and capacity that is currently under construction. See WECC, 2024 Common Case datasets (Salt Lake City: Western Electricity Coordinating Council Transmission Expansion Planning Policy Committee, 2014). Retired capacity represents any plants that have retired since 2010 and planned retirements, but excludes NGS retirements.

${ }^{213}$ There are 38 solar and 23 wind resource regions within the Arizona-centric focus region.

${ }^{214}$ Hurdle rates from WECC, 2024 Common Case datasets are included in the model to represent friction in electricity transmission between BAs. Lew et al., Western Wind and Solar Integration Study Phase 2.
} 
RPM handles transmission modeling as a part of the security-constrained economic dispatch algorithm that co-optimizes load balancing and operating reserves. ${ }^{215}$ Generation schedules from variable generation technologies - including wind, solar PV, concentrating solar power (CSP) without thermal energy storage, and some hydropower-are fixed in the model, although RPM allows curtailment of these sources as part of its economic dispatch algorithm. ${ }^{216}$

Underlying data for existing infrastructure as of 2010 come from the Western Wind and Solar Integration Study (WWSIS) Phase 2. ${ }^{217}$ Table 4-2 presents the initial 2010 start-year capacity for the technologies modeled in RPM. Table 4-2 also presents the amount of capacity added or under construction since $2010^{218}$ and retirements prescribed exogenously to the model. ${ }^{219}$ Beyond prescribed new capacity, endogenous investment decisions for the type, amount, and location of new capacity are based on the needs of the system (e.g., planning reserve requirements), policies, and economic factors (e.g., assumed technology and fuel costs). ${ }^{220}$

RPM is an electric sector-only model and does not model cross-sectoral interactions. For example, fuel prices, electricity demand, and assumptions around energy policies are simply inputs; they do not change in response to RPM outcomes. Even within the electricity sector, RPM uses hourly electricity dispatch and basic operating reserves to inform high-level utilityscale planning, but it does not model factors that happen on a shorter timescale that affect reliability, such as voltage stability, frequency response, or transient effects. Finally, RPM

${ }^{215}$ We model three separate categories of operating reserves representing requirements over a range of timescales: regulation reserves (sub-5 minute), spinning contingency reserves (10 minute), and flexibility reserves ( 1 hour).

${ }^{216}$ While CSP with thermal energy storage is dispatchable, for simplicity we assume a fixed dispatch schedule for this technology.

${ }^{217}$ Lew et al., Western Wind and Solar Integration Study Phase 2 relied on data from the WECC, Assumptions Matrix for the 2020 Transmission Expansion Planning Policy Committee (TEPPC) Dataset, (Salt Lake City: Western Electricity Coordinating Council, 2012) with updates from WECC, 2024 Common Case datasets along with other revisions as described in Lew et al., Western Wind and Solar Integration Study Phase 2.

${ }^{218}$ Ventyx, "2010 Energy Market Data," accessed June 4, 2013. Ventyx has since been acquired by ABB. See also NREL, "SolarPACES Concentrating Solar Power Projects," accessed April 22, 2014, http://www.nrel.gov/csp/solarpaces/.

${ }^{219}$ WECC, 2024 Common Case datasets; A. Saha, Review of Coal Retirements (Concord, MA: M.J. Bradley \& Associates, LLC, 2013). A majority of the prescribed new capacity occurs by the 2015 solve year. Retirements are spread out over a longer period of time. Beyond the retirements listed in our main data sources, we include recent or announced retirements for San Onofre Nuclear Generating Station, San Juan Generating Station, Intermountain Power Plant, and Cholla Power Plant, and adjust the dates of retirement for portions of Reid Gardner Generating Station, Rio Grande Power Station, and Newman Generating Station. See SCE, "Southern California Edison Announces Plans to Retire San Onofre Nuclear Generating Station," news release, June 7, 2013, http://www.songscommunity.com/news2013/news060713.asp; PNM, "PNM, State Reach Agreement with EPA for Plan to Address Regional Haze at San Juan Generating Station," new release, February 15, 2013, https://www.pnm.com/0215-san-juan; SCPPA, Request for Information: Generation Replacement and Future Resources (Glendora: Southern California Public Power Authority, 2014), http:/www.scppa.org/file.axd?file=/2015/10/GenReplacement_FutureResources_RFI.pdf; Ryan Randazzo, "APS plans to close one of the four generators at Cholla Power Plant;" NV Energy, "Southern Service Territory IRP," First Amendment to NV Energy's 2013-2032 Integrated Resource Plan, May 2, 2014, PUCN Docket No. 14050032 (2):4; El Paso Electric, Integrated Resource Plan of El Paso Electric Company for the Period 2012-2031. ${ }^{220}$ EPA's final adoption of the CPP, decisions by California and Oregon to increase their RPS targets to $50 \%$, and extensions of federal tax credits for new renewable energy projects occurred after the modeling in this section was completed, and are therefore not included in the policy assumptions. 
decisions are based on system-wide optimization and thus do not fully consider local decision factors such as siting and permitting, local incentives, or other local economic and noneconomic conditions. Rather, RPM is designed as a tool for testing a key selection of system-wide factors that are broadly cross-sectional and temporally persistent.

\subsubsection{Scenarios}

We modeled long-term capacity expansion trends and NGS retirement impacts under 10 separate scenarios. Four "core" scenarios use a common set of input assumptions, changing only the timeline for retirement of the three NGS units (750 MW each):

- The core reference scenario assumes all three NGS units remain operational beyond 2030 .

- The core central scenario assumes one unit retires by 2020 , but the other two remain active past 2030 .

- The core gradual retirement scenario assumes one unit retires by 2020 and the other two units retire immediately prior to 2030.

- The core accelerated retirement scenario assumes all three units retire by $2020 .^{221}$

These core scenarios, described below, assume that no new energy policies are enacted by 2030. Other assumptions used in the core scenarios are based on mid-range estimates of fuel and technology costs. Section 4.1.3 describes the key input assumptions used across all core scenarios.

To address the uncertainties of future natural gas prices, we modeled four natural gas price sensitivity scenarios using low and high gas price projections from EIA. These sensitivities focus exclusively on the NGS reference and central scenarios described above, to isolate the effect of natural gas prices from factors modeled in other scenarios. In addition, we modeled a $\mathrm{CO}_{2}$ price sensitivity where the investment and dispatch decisions in RPM are influenced by an effective price on combustion-related $\mathrm{CO}_{2}$ emissions of the various generator types modeled. The $\mathrm{CO}_{2}$ price sensitivity is not intended to directly represent any particular policy. Rather, it represents the generic economic effect of how the Western Interconnection might evolve under clean energy legislation or regulations aimed at curbing greenhouse gas emissions, whether it is EPA's proposed CPP or some other approach. The $\mathrm{CO}_{2}$ price sensitivity uses the NGS retirement schedule of the central scenario.

Finally, we modeled a variant of the central scenario where state RPS requirements can be met through more liberalized credit trading than that represented in the core central scenario. This RPS sensitivity essentially represents frictionless renewable energy credit (REC) trading across the entire Western Interconnection. Table 4-3 summarizes the scenario framework.

\footnotetext{
${ }^{221}$ Because RPM uses 5-year increments, assuming a retirement by a given year assumes that the unit is available in all prior solution years but is not available that year or any other subsequent solution year. For example, 1 unit retired by 2020 implies that the unit is operational in the 2010 and 2015 model years, but not operational in 2020 , 2025 , and 2030 .
} 
Table 4-3. NGS Retirement, Natural Gas Price, and $\mathrm{CO}_{2}$ Price Assumptions Across Modeled Scenarios

\begin{tabular}{|c|c|c|c|c|c|}
\hline & & $\begin{array}{l}\text { NGS Retirement } \\
\text { Schedule }\end{array}$ & $\begin{array}{l}\text { Natural } \\
\text { Gas Price }\end{array}$ & $\mathrm{CO}_{2}$ Price & Notes \\
\hline \multirow{4}{*}{$\begin{array}{l}\text { Core } \\
\text { scenarios }\end{array}$} & Reference & No retirements & Mid & None & \multirow{4}{*}{$\begin{array}{l}\text { AEO } 2014 \text { Reference } \\
\text { scenario fuel, NG } \\
\text { technology } \\
\text { assumptions, mid wind } \\
\text { and solar assumptions }\end{array}$} \\
\hline & & 1 unit by 2020 only & Mid & None & \\
\hline & Gradual & $\begin{array}{l}1 \text { unit by } 2020 \text {, } \\
2 \text { units by } 2030\end{array}$ & Mid & None & \\
\hline & Accelerated & 3 units by 2020 & Mid & None & \\
\hline \multirow{4}{*}{$\begin{array}{l}\text { Natural gas } \\
\text { sensitivities }\end{array}$} & Reference & No retirements & High & None & \multirow{2}{*}{$\begin{array}{l}\text { AEO } 2014 \text { Low Oil and } \\
\text { Gas Resource Scenario }\end{array}$} \\
\hline & Central & 1 unit by 2020 only & High & None & \\
\hline & Reference & No retirements & Low & None & \multirow{2}{*}{$\begin{array}{l}\text { AEO } 2014 \text { High Oil and } \\
\text { Gas Resource Scenario }\end{array}$} \\
\hline & Central & 1 unit by 2020 only & Low & None & \\
\hline $\begin{array}{l}\mathrm{CO}_{2} \\
\text { sensitivity }\end{array}$ & Central & 1 unit by 2020 only & Mid & $\begin{array}{c}\text { Yes } \\
\text { (see Figure } \\
4-2)\end{array}$ & $\begin{array}{l}\text { LBNL Resource } \\
\text { Planning Portal }\end{array}$ \\
\hline $\begin{array}{l}\text { RPS } \\
\text { sensitivity }\end{array}$ & Central & 1 unit by 2020 only & Mid & None & Expanded REC Trading \\
\hline
\end{tabular}

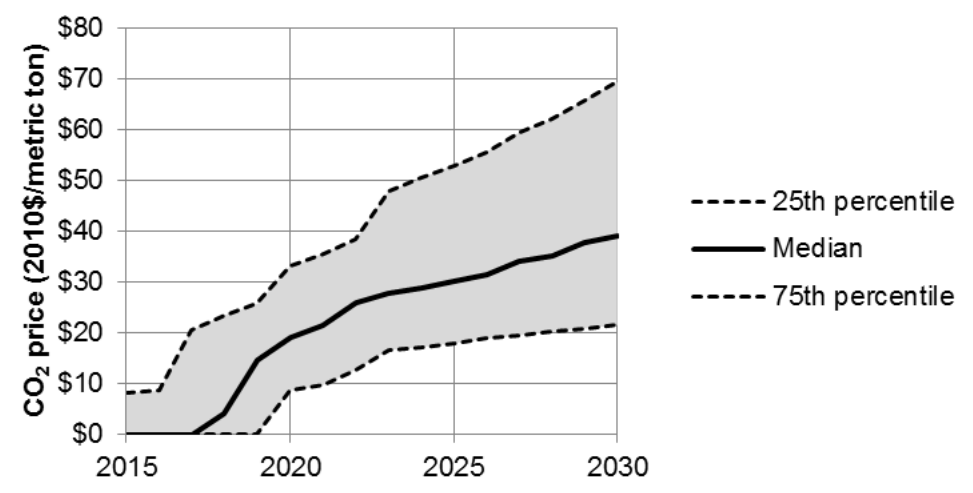

Figure 4-2. Trajectory used for $\mathrm{CO}_{2}$ price sensitivity

Note: $\mathrm{CO}_{2}$ prices are based on IRPs created between 2010 and 2013 by 14 load-serving entities in the Western United States as collected for LBNL's Resource Planning Portal. ${ }^{222}$ The median, $25^{\text {th }}$ percentile, and $75^{\text {th }}$ percentile trajectories shown above were calculated from the IRP scenarios with non-zero $\mathrm{CO}_{2}$ prices.

None of the scenarios represents a forecast or prediction. The scenarios do not reflect a policy or other recommendation pertaining to NGS retirements, but instead aim to capture a range of possible futures. These scenarios are intended to simulate broader trends in the future western electricity system, with the results quantifying potential impacts of various NGS retirement futures.

\footnotetext{
${ }^{222}$ Lawrence Berkeley National Laboratory, “Resource Planning Portal,” http://resourceplanning.lbl.gov.
} 


\subsubsection{Input Data Assumptions}

In this section we present the key input assumptions and data sources used across all core and sensitivity scenarios. We present assumptions about technology costs, fuel prices, demand growth, and policy assumptions, including RPS treatment and $\mathrm{CO}_{2}$ prices for the relevant sensitivity scenarios. ${ }^{223}$

RPM models the dispatch of all existing and new generators. Existing generators span a wide range of technologies (see Table 4-1). New capacity, however, is restricted to natural gas-fired, wind, and solar PV technologies. ${ }^{224}$ This restriction is consistent with currently observed market trends and helps to simplify the analysis and reduce computational complexity.

Table 4-4 shows the technology cost and performance assumptions used in this analysis for natural gas, wind, and solar PV technologies. Data for natural gas-fired technologies are based on the AEO 2014 Reference scenario. ${ }^{225}$ Data for wind are based on internal NREL analysis; ${ }^{226}$ data for solar PV are based on a combination of the $62.5 \%$ reduction and $75 \%$ reduction cost scenarios from the SunShot Vision Study. ${ }^{227}$ Technology assumptions were developed in 2013 and reflect the outlook from the DOE and NREL at the time. Changes in the markets or technologies could yield different projections.

\footnotetext{
${ }^{223}$ Many of the key input assumptions used are based on the baseline assumptions presented in Patrick Sullivan, Wesley Cole, Nate Blair, Eric Lantz, Venkat Krishnan, Trieu Mai, David Mulcahy, and Gian Porro, 2015 Standard Scenarios Annual Report: U.S. Electric Sector Scenario Exploration, NREL/TP-6A20-64072 (Golden, CO: National Renewable Energy Laboratory, 2015), http://www.nrel.gov/docs/fy15osti/64072.pdf.

${ }^{224}$ The exception to this is for prescribed capacity that is under construction or has recently been deployed between 2010 and the present (see Table 4-1). Cost and performance assumptions for these other technologies are largely based on the AEO 2014 Reference scenario for non-wind and non-solar technologies. See EIA, Annual Energy Outlook 2014 with Projections to 2040 (Washington, D.C.: EIA, 2014). Costs for new CSP capacity are based on the same cost reduction scenarios as PV from DOE, SunShot Vision Study.

${ }^{225}$ Natural gas technology cost and performance assumptions rely on the average between the "advanced" and "conventional" technology projections in the AEO 2014 Reference scenario from EIA, Annual Energy Outlook 2014.

${ }^{226}$ The methods and assumptions for wind technologies are detailed in DOE, Wind Vision: A New Era for Wind Power in the United States (Washington, D.C.: DOE, 2015), http://www.energy.gov/sites/prod/files/WindVision_Report_final.pdf.

${ }^{227}$ DOE, SunShot Vision Study.
} 
Table 4-4. Technology Cost and Performance Assumptions for New Generation Capacity

\begin{tabular}{|c|c|c|c|c|}
\hline & 2015 & 2020 & 2025 & 2030 \\
\hline \multicolumn{5}{|c|}{ Overnight Capital Costs (2010 \$/kW) } \\
\hline NGCC & 940 & 890 & 870 & 850 \\
\hline NGCT & 780 & 750 & 730 & 720 \\
\hline Wind (high-wind turbines) & 1,520 & 1,470 & 1,440 & 1,420 \\
\hline Wind (low-wind turbines) & 1,640 & 1,630 & 1,620 & 1,610 \\
\hline PV Fixed Tilt & 2,190 & 1,500 & 1,380 & 1,250 \\
\hline PV 1-Axis Tracking & 2,250 & 1,640 & 1,520 & 1,390 \\
\hline \multicolumn{5}{|l|}{ Fixed O\&M $(2010 \$ / k W-y r)$} \\
\hline NGCC & 14 & 14 & 14 & 14 \\
\hline NGCT & 7 & 7 & 7 & 7 \\
\hline Wind (high-wind turbines) & 47 & 46 & 45 & 44 \\
\hline Wind (low-wind turbines) & 47 & 46 & 45 & 44 \\
\hline PV Fixed Tilt & 15 & 7 & 7 & 7 \\
\hline PV 1-Axis Tracking & 15 & 7 & 7 & 7 \\
\hline \multicolumn{5}{|c|}{ Variable O\&M (2010 \$/MWh) } \\
\hline NGCC & 3 & 3 & 3 & 3 \\
\hline NGCT & 12 & 12 & 12 & 12 \\
\hline Wind (high-wind turbines) & 0 & 0 & 0 & 0 \\
\hline Wind (low-wind turbines) & 0 & 0 & 0 & 0 \\
\hline PV Fixed Tilt & 0 & 0 & 0 & 0 \\
\hline PV 1-Axis Tracking & 0 & 0 & 0 & 0 \\
\hline \multicolumn{5}{|l|}{ Heat Rate (mmBtu/MWh) } \\
\hline NGCC & 6.68 & 6.62 & 6.57 & 6.57 \\
\hline NGCT & 10.0 & 9.76 & 9.50 & 9.50 \\
\hline \multicolumn{5}{|l|}{ Capacity Factor (\%) } \\
\hline Wind (high-wind turbines) & $52 \%$ & $54 \%$ & $55 \%$ & $56 \%$ \\
\hline Wind (low-wind turbines) & $33 \%$ & $35 \%$ & $36 \%$ & $37 \%$ \\
\hline PV Fixed Tilt & $13-22 \%$ & $13-22 \%$ & $13-22 \%$ & $13-22 \%$ \\
\hline PV 1-Axis Tracking & $15-27 \%$ & $15-27 \%$ & $15-27 \%$ & $15-27 \%$ \\
\hline
\end{tabular}

Note: Data reflect technology cost and performance for new generation capacity only. Natural gas data are from the AEO 2014 Reference scenario. ${ }^{228}$ Wind data are from internal NREL analysis. PV data are based on a combination of the $62.5 \%$ reduction and $75 \%$ reduction cost scenarios from the SunShot Vision Study. ${ }^{229} \mathrm{PV}$ capacity is represented as $W_{D C}$ and PV capacity factor reflects AC output over DC capacity. The range of capacity factor for PV reflects regional variations in solar insolation and weather conditions.

${ }^{228}$ EIA, Annual Energy Outlook 2014.

${ }^{229}$ DOE, SunShot Vision Study. 
The overnight capital costs shown in Table 4-4 include costs of all equipment up to the plant gate and do not include the spur line and financing costs, which are included separately in the model. ${ }^{230}$ Spur line costs for new solar and wind capacity vary among resource regions according to the distance between the centroid of the wind or solar resource region and the connected bus. RPM also includes financing $\operatorname{costs}^{231}$ that vary among technologies to account for differences in construction periods, accelerated tax depreciation rules, and investment tax credits. ${ }^{232}$ RPM does not include fixed costs for existing 2010 infrastructure; however, variable O\&M costs and heat rates of existing generators based on values from Lew et al. (2013) are modeled because they affect dispatch decisions. ${ }^{233}$

Like much of the cost analysis of Chapter 2, the RPM analysis was conducted on a timeline that allowed it to be incorporated into early analysis for the draft EIS. Since that time, NREL has begun publishing an annually updated assessment of current and projected technology costs in its Annual Technology Baseline (ATB). For all technologies except PV, the costs shown in Table 4-4 are not significantly different from the midrange overnight costs in the 2016 ATB.

For utility-scale single-axis tracking PV, the older-vintage estimates in Table 4-4 are higher than mid-range values in the 2016 ATB - 29\% higher for 2015, and about 50\% higher for 2025 and 2030. These newer costs projections, had they been available at the time of the original analysis, would have strengthened any economic tendency toward PV embedded in the modeling. The objective, however, was not to forecast PV trends but to test the system-wide impact of curtailing operations at NGS. It is unlikely that lower PV costs would have affected the difference between NGS scenarios.

Figure 4-3 shows the fossil fuel and uranium price assumptions from AEO scenarios used in the present analysis. Fuel costs reflect delivered costs and are assumed to be uniform across regions and are modeled without seasonal or diurnal variations within each solve year. The solid lines in Figure 4-3 reflect prices from the AEO 2014 Reference scenario, which are used in all scenarios except the natural gas sensitivities. Dashed lines in Figure 4-3 show natural gas price projections from the AEO 2014 Low Oil \& Gas Resource and High Oil \& Gas Resource scenarios used in the high price and low price sensitivities, respectively. The natural gas sensitivities continue to use coal and uranium prices from the AEO 2014 Reference scenario. $^{234}$

\footnotetext{
${ }^{230}$ Real 2010 dollars are used throughout this report unless otherwise noted.

${ }^{231}$ Walter Short, Patrick Sullivan, Trieu Mai, Matthew Mowers, Caroline Uriarte, Nate Blair, Donna Heimiller, and Andrew Martinez, Regional Energy Deployment System (ReEDS), NREL/TP-6A20-46534 (Golden, CO: National Renewable Energy Laboratory, 2011), http://www.nrel.gov/docs/fy12osti/46534.pdf.

${ }^{232}$ Technology-specific financing costs are represented in RPM through different fixed charge rates. Fixed charge rates for NG-CC, NG-CT, wind, and solar PV are 0.126, 0.120, 0.105, and 0.091 respectively, for all years with the exception of a fixed-charge rate of 0.065 for solar PV in 2015 to represent the 30\% ITC available before 2017. These fixed-charge rates represent costs amortized over 20 years and using a nominal weighted average cost of capital of $8.9 \%$. We model current policies only, including an absence of the wind PTC for all future years and a changing solar ITC that drops from 30\% to $10 \%$ after 2016.

${ }^{233}$ Lew et al., Western Wind and Solar Integration Study Phase 2.

234 Ibid.
} 


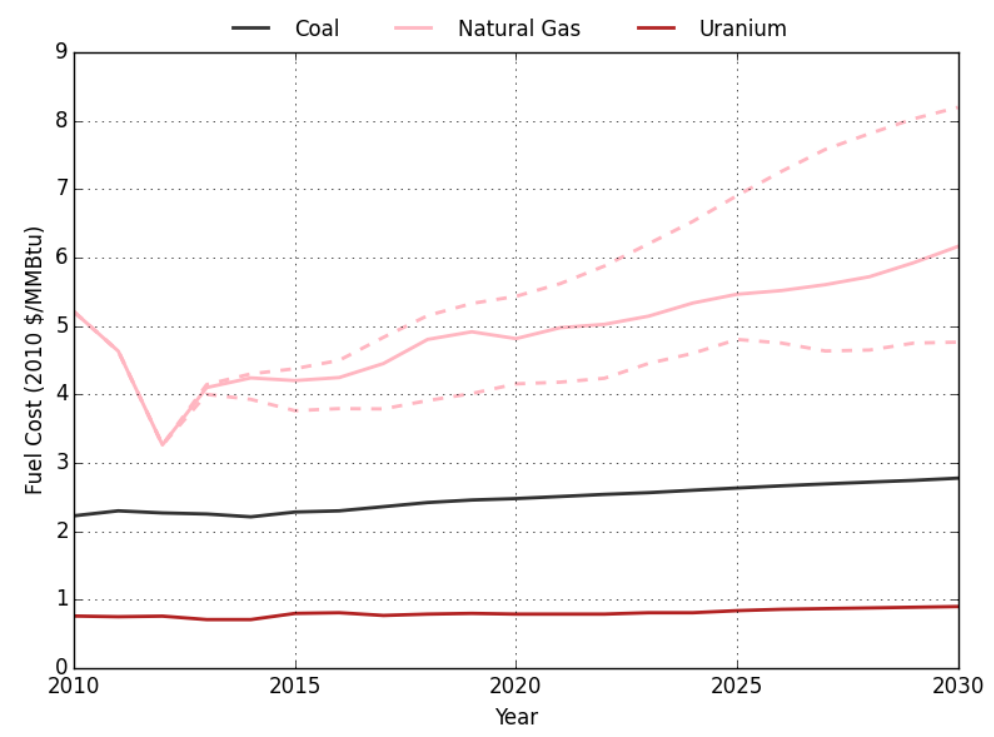

Figure 4-3. Assumed natural gas, coal, and uranium prices from 2010 to $2030^{235}$

Note: Solid lines reflect prices from the AEO 2014 Reference scenario. Higher and lower dashed lines reflect natural gas prices from the AEO 2014 Low Oil \& Gas Resource and High Oil \& Gas Resource scenarios, respectively.

With the exception of the $\mathrm{CO}_{2}$ price sensitivity scenario, all scenarios represent futures with current policies modeled as they are legislated as of January 1, 2014, and assume no new policies are enacted. These include existing state RPS and associated technology carve-outs at their current levels. ${ }^{236}$ RPS requirements are applied to each BA according to the state requirement associated with the load served. ${ }^{237}$ This is RPM's default configuration, which assumes no REC trading between BAs. Because REC trading does occur but is difficult to forecast, we include a sensitivity scenario that treats the state-level RPSs as an interconnectionwide constraint. This allows RPS compliance to be met on an interconnection-wide basis, essentially allowing whatever degree of trading is necessary to meet the aggregated RPS requirements at the least cost. The present version of RPM does not include a representation of California Assembly Bill 32 other state or local incentives, or changes in emission regulations. ${ }^{238}$

For the $\mathrm{CO}_{2}$ price sensitivity scenario, we applied a price to all electric sector directcombustion $\mathrm{CO}_{2}$ emissions. The $\mathrm{CO}_{2}$ prices modeled (Figure 4-2) are based on analysis from

\footnotetext{
${ }^{235}$ EIA, Annual Energy Outlook 2014.

${ }^{236}$ See www.dsireusa.org. Because RPM does not model distributed generation, we use fixed-tilt PV as a proxy for any distributed generation requirements.

${ }^{237}$ For example, a BA that serves half of its load in a state with a 20\% RPS and the other half in non-RPS states will have an obligation to serve $10 \%$ (half of $20 \%$ ) of its end-use demand from qualifying renewable sources.

${ }^{238}$ The CPP, Cross State Air Pollution Rule, and Mercury and Air Toxics Standards are not included explicitly; however, some of the recent and announced retirements included in the model may have considered these regulations. The current version of RPM does not include a representation of California AB32; however California's 33\%-by-2020 RPS policy is included. Further work is needed to understand the effect that AB32 and other state, regional, or federal policies would have on the results presented.
} 
Lawrence Berkeley National Laboratory (LBNL), ${ }^{239}$ which collected and standardized prices taken from IRPs from 14 load-serving entities in the Western United States. $\mathrm{CO}_{2}$ prices from the median trajectory of $\$ 19 /$ metric ton, $\$ 30 /$ metric ton, and $\$ 39 /$ metric ton are modeled for 2020, 2025, and 2030. No $\mathrm{CO}_{2}$ prices are modeled for 2010 and 2015. All other assumptions in the $\mathrm{CO}_{2}$ price sensitivity scenario are identical to the core central scenario (see Table 4-2).

Other key assumptions used in RPM include electricity demand growth and reserve margins. We use data from WECC to apply BA-specific demand growth rates, ${ }^{240}$ which result in an average annual growth rate of $1.1 \%$ per year within the Arizona-centric focus region and $0.9 \%$ across the entire Western Interconnection. We assume capacity reserve margins of $13-15 \%$ for four separate regions. ${ }^{241}$

\subsubsection{Summary of Capacity Expansion Results}

Retiring NGS appears unlikely to affect significantly the market fundamentals driving new generator investments in the Western Interconnection, even when testing full NGS retirement in 2020. The key factors validated by the RPM model include the following:

- A number of regions of the Western Interconnection appear to have generating capacity well in excess of peak reserve margin requirements, which this could persist at least in the short term. Large reserve margins dampen the economic need to build new generation capacity. Load growth and the retirement of old generators tends to result in more use of existing capacity, rather than the construction of new capacity.

- The generation mix will likely continue its movement from coal to natural gas, although the prevailing price of natural gas could affect the speed of this shift. Sustained high prices for natural gas appear likely to yield greater reliance on new renewable resources for latter-year expansion (around 2030).

- Future carbon policies (whatever form they might take) could significantly accelerate the switch from coal to natural gas.

- New renewable capacity deployment appears to be driven by state RPS targets, based on the technology assumptions used here.

The findings of this modeling analysis, however, reach only to a selection of key market factors affecting electric infrastructure investments in the Western Interconnection. While the electric sector might be able to adjust to full retirement of NGS by 2020, RPM cannot capture economic impacts beyond the electric sector that could be equally important. Other market

\footnotetext{
${ }^{239}$ Lawrence Berkeley National Laboratory, "Resource Planning Portal,” http://resourceplanning.lbl.gov.

${ }^{240}$ WECC, 2024 Common Case datasets.

${ }^{241}$ We allow transmission to contribute to resource adequacy for the CAMX subregion based on data from the the California Independent System Operator. See CAISO, “California ISO Maximum RA Import Capability for year 2012," accessed July 1, 2014, http://www.caiso.com/Documents/ISOMaximumResourceAdequacyImportCapability_Year2012.pdf. See also NERC, 2013 Summer Reliability Assessment (Atlanta: North American Electric Reliability Corporation, 2013), http://www.nerc.com/pa/RAPA/ra/Reliability\%20Assessments\%20DL/2013SRA_Final.pdf.
} 
changes might have influenced the modeled outcomes, had they been known at the time the analysis was done for the draft EIS. For example,

- Natural gas prices observed during 2015 and 2016 were lower than those assumed at the time of this analysis.

- The Clean Power Plan (or any substitute policy for reducing carbon emissions) could result in a stronger tendency toward renewables.

- Some states such as California and Oregon have increased their RPS goals since the completion of RPM modeling.

- Federal tax credits for renewables were extended after this analysis was completed.

Therefore, we caution against extending the conclusions of this analysis beyond the factors that have been modeled. Updated conditions will be considered in the next phase of modeling that focuses on NGS glide path options.

\subsubsection{Basic Effects of NGS Retirement}

Retiring one NGS unit in 2020 seems to have a limited effect on the installation of new capacity through 2030 - conventional as well as renewable technologies. Today, in most regions of the West, generation exceeds peak reserve margin requirements and will probably continue to exceed reserve margin requirements through 2030. Even retiring all three NGS units by 2020 has a limited and somewhat delayed effect on new capacity. Results indicate a net addition of $30 \mathrm{MW}$ of new NGCT capacity and $340 \mathrm{MW}$ of new renewable capacity by 2030, if accelerating full NGS retirement to 2020.

In the absence of NGS, replacement power strongly tends toward existing NGCC and other natural gas generators - by up to 12 TWh in 2020 and up to 17 TWh in 2030. Net power exports out of Arizona and nearby areas show a decline, although the Southwest region would probably remain a net exporter. Much of the NGCC capacity used to replace NGS is located in California, currently the destination for about $21 \%$ of the power generated by NGS.

NGS retirement tends to shift some renewable capacity additions from new wind to new solar generation in 2030. This is due to solar's hourly correlation with load, its contribution to meeting peak demand, and its effect on the need for firm capacity in 2030 if NGS were completely retired in $2020 .{ }^{242}$ In aggregate, however, the core NGS retirement scenarios show little effect on the total amount of renewable electricity produced.

The present value of system costs - new capital costs, variable O\&M costs, and fuel costs from 2015 to 2030 - for the Western Interconnection overall increases no more than $0.3 \%$ even in the most aggressive NGS retirement scenario. (Section 4.2 discusses production cost modeling and examines cost changes in further detail.)

${ }^{242}$ Both PV and CSP share these characteristics. 


\subsubsection{Natural Gas Prices}

Only high natural gas prices significantly influence capacity expansion results: high prices tend to increase the use of renewable technologies by 2030, especially if all three units retire in 2020. Results suggest that high natural gas prices and full NGS retirement in 2020 could result in net renewable capacity additions of nearly 3,000 MW across the Western Interconnection by 2030, including 1,200 MW in the Southwest focus region. This would exceed what is currently required under RPS targets. Overall, high natural gas prices appear to have a significantly stronger influence on renewable energy expansion than does NGS retirement.

Low natural gas prices, on the other hand, seem to have little effect on the results. Much of the potential increase in NGCC dispatch that would otherwise be due to NGS retirements could also be incentivized by low natural gas prices. In fact, full retirement of NGS in 2020 correlates with the same shift in NGCC utilization irrespective of whether natural gas prices follow baseline forecasts or are significantly lower. Renewable capacity expansion with low gas prices is the same as in the core retirement scenarios.

\subsubsection{Carbon Policies}

Factoring in a price on $\mathrm{CO}_{2}$ emissions tends to increase the amount of generation from natural gas in 2020 and 2025 at the expense of coal-fired generation (at the $\mathrm{CO}_{2}$ prices tested in this analysis). In 2025, renewable generation begins to displace generation from coal and natural gas.

For the entire Western Interconnection, retiring NGS could reduce the electric sector's $\mathrm{CO}_{2}$ emissions by $1 \%$ to $3 \%$. The estimated reductions are between 2 million and 7 million metric tons annually in 2020; and between 3 million and 10 million metric tons annually in 2030 .

\subsection{Production Cost Modeling}

Production cost modeling estimates the variable cost of generating power, which includes the cost of fuel, the cost of starting a generator unit, the cost of line congestion (which can restrict the use of what would otherwise be the least-cost generator unit), and other costs that arise when one more megawatt-hour of electricity is generated. Production costs typically represent one-quarter to one-half of what retail customers pay for electricity service. ${ }^{243}$

Production cost modeling does not capture the capital cost of generators and transmission lines, fixed operating costs that arise regardless of whether the unit runs, or other utility business costs such as billing, maintenance, and customer support. These costs may be calculated separately, but production cost modeling essentially treats them as "sunk" costs that are independent of production costs. Modeled scenarios therefore represent the most efficient and least-cost dispatch of a given set of generators and transmission. Production cost modeling

\footnotetext{
${ }^{243}$ CAISO locational marginal prices, which measure the variable cost of generation, were $\$ 52 / \mathrm{MWh}$ for peak hours and \$40/MWh for off-peak hours during the second quarter of 2014. Average retail rates in California during this same time were around 14.5 cents $/ \mathrm{kWh}$, or $\$ 145 / \mathrm{MWh}$. See CAISO, Q2 2014 Report on Market Issues and Performance (Folsom: CAISO, August 18, 2014), http://www.caiso.com/Documents/2014SecondQuarterReport-MarketIssuesandPerformance-August2014.pdf; EIA, Electric Power Monthly with Data for February 2015 (Washington, D.C.: EIA, April 2015), http://www.eia.gov/electricity/monthly/current_year/april2015.pdf.
} 
does not add new generation or retire any old units, although sensitivity scenarios can test how production cost results might change if certain units are added or retired.

This section and its supporting analysis examine how variable costs are likely to change over time, independent of decisions affecting NGS. Such a baseline is essential to illustrate possible future market conditions that differ from today's conditions. From this baseline, the chapter then analyzes the effect of retiring NGS while holding all other system factors the same. This foundational analysis assumes no new generation capacity — renewable or conventional — and no other measures to mitigate the impact of retiring NGS. (The mitigating effects of new generation associated with an NGS glide path will be examined in Volume 2 of this study.)

\subsubsection{Background}

Production cost modeling is a common tool used to compare how variable costs might change under evolving market conditions. A production cost model simulates real-time network conditions across a large region (in this case, the Western Interconnection), picking the combination of units that would minimize the cost of serving load system-wide over a specified time period. Production cost model parameters include:

- Forecasted energy demand at all load points on the network, at hourly or subhourly intervals

- The marginal cost of generation at each unit on the system, based on the unit's heat rate and the assumed cost of fuel

- The cost of cold-starting a generating unit, and the minimum level at which the unit must be run once started

- Limits on how quickly a unit can increase or decrease its output in response to changes in network load

- Known operational limits on each transmission line

- Requirements for system operating reserves.

Within these operational constraints, the model then dispatches enough power from the generation fleet to match demand at each moment (hourly or subhourly) over the course of a typical year.

WECC uses production cost modeling in its assessment of future transmission needs for the Western Interconnection. ${ }^{244}$ In addition to the basic production cost modeling inputs, WECC accounts for planned generator retirements as well as known transmission and generator additions. Utilities provide 10-year load forecasts for their territories, which WECC uses to model a reference case against which other 10-year scenarios are modeled. All technical inputs and forecasts are verified through a detailed stakeholder review process involving state regulatory officials, grid operators, utilities, generation owners, and environmental advocates.

The production cost analysis for this chapter uses the same data sets and baseline assumptions that WECC uses to model the grid for 2020, including assumptions about future transmission expansion, the timing of major plant retirements, reserve requirements, and all line limits

${ }^{244}$ WECC, Interconnection-wide Transmission Plan (Salt Lake City: WECC, 2013). 
affecting the transfer of power from one area to another. Other new generation was added to the WECC base case, consistent with results from the capacity expansion scenarios run using RPM (described earlier in this chapter).

Production cost modeling relies on a number of specialized terms and concepts. These terms make up the vocabulary to understand the results, so an understanding of what they mean is an essential starting point for this section's discussion.
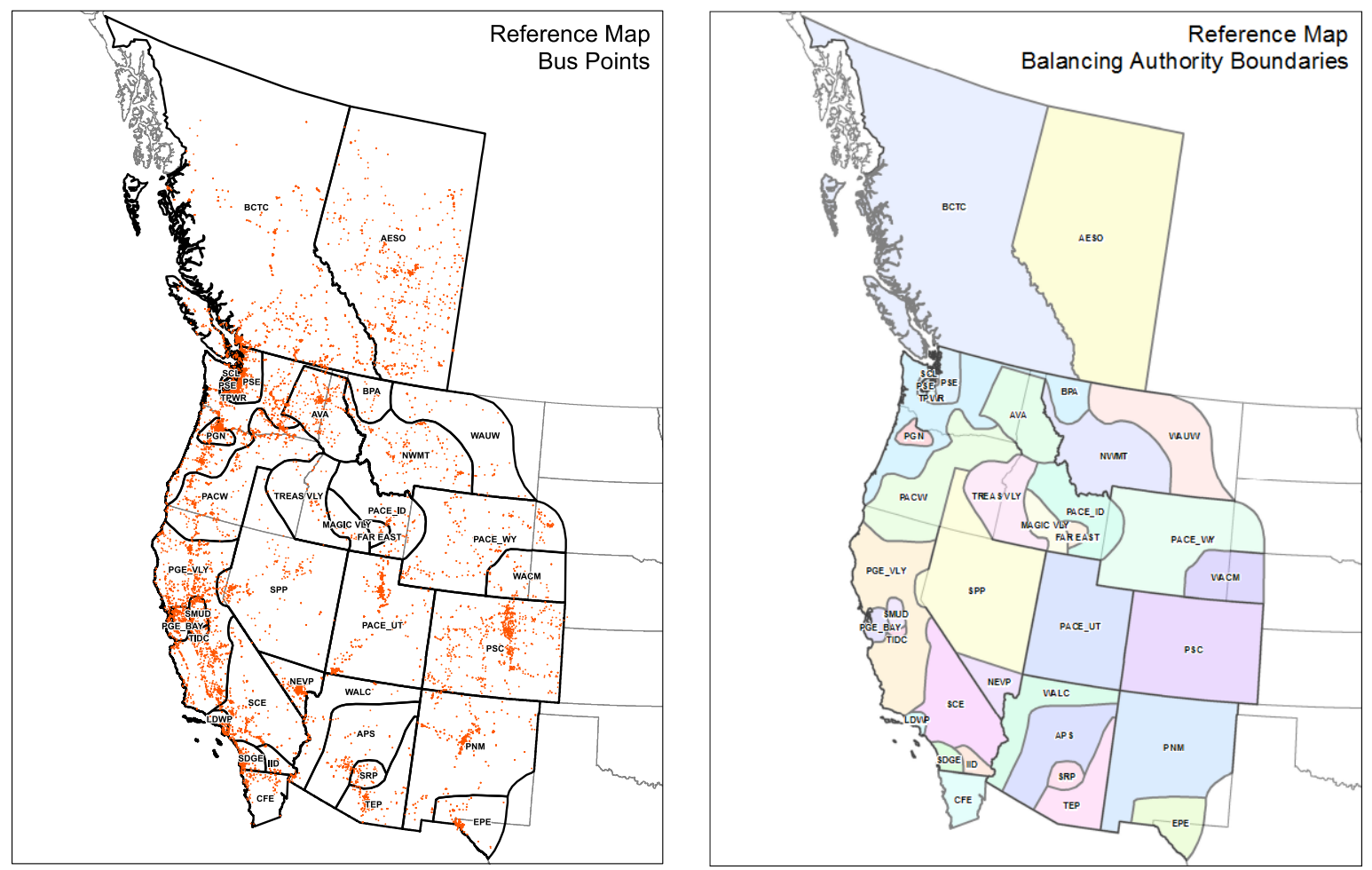

Figure 4-4. Nodes and BAs modeled in PLEXOS

- Balancing authority (BA) areas. A BA is the grid's geographical unit of central control. The North American Electric Reliability Corporation (NERC) defines a BA area as the specific collection of generators and load whose total metered output and consumption - monitored by the BA - must balance moment by moment. If demand increases by $20 \mathrm{MW}$, for example, the BA must issue instructions to one or more units in its portfolio to ramp up by $20 \mathrm{MW}$, or schedule a $20-\mathrm{MW}$ transfer from a neighboring BA. A large utility is often its own BA, although two or more utilities can participate in a single BA. ${ }^{245}$ The BAs that constitute NERC's Desert Southwest subregion include SRP, APS, TEP, Nevada Power NEVP, the Imperial Irrigation District (IID), WALC, PNM, and EPE.

- Nodes. Nodes are geographic points on the system where changes can occur that would affect real-time costs elsewhere on the system. They are points where either a generator connects to the grid, power leaves the transmission network to serve load, or

${ }^{245}$ Here, several small BAs are analytically combined with their surrounding BAs for the sake of clarity. 
transmission paths intersect. Figure 4-4 shows the nodes and BA areas included in PLEXOS modeling for the Western Interconnection.

- Locational marginal prices (LMPs). LMPs reflect the immediate cost of producing power at a given node. The value of an LMP - expressed in dollars per megawatthour - indicates the cost to the entire system of changing generation or demand at that node by one megawatt. Generally, an LMP increases due to any combination of two factors: the production cost of a particular generator, and transmission constraints that limit the ability to move low-cost power to a demand point.

For clarity, this analysis aggregates nodal outcomes by BA in many instances. Except for the Bureau of Reclamation, each NGS partner also operates as a BA, making this aggregation a convenient and relevant tool for combining information. Not only does it comport with how the system operates, it also provides a meaningful approach to estimate the impact on the areas most likely to be affected by an NGS glide path.

Figure 4-5 illustrates how LMPs can vary during the year from one BA to another. These LMP "duration curves" represent an entire year of hourly operation, with hourly values on the curve ordered nonchronologically in ascending order of price. A duration curve that remains low for many hours suggests lower production costs overall. Figure 4-5 compares hourly LMPs in four states, with each state represented by one of its large BAs. Production costs tend to be lower in the Northwest due to the large amount of hydropower on the system, and because summer load peaks are not as severe as in the rest of the interconnection. The highest costs are in California.

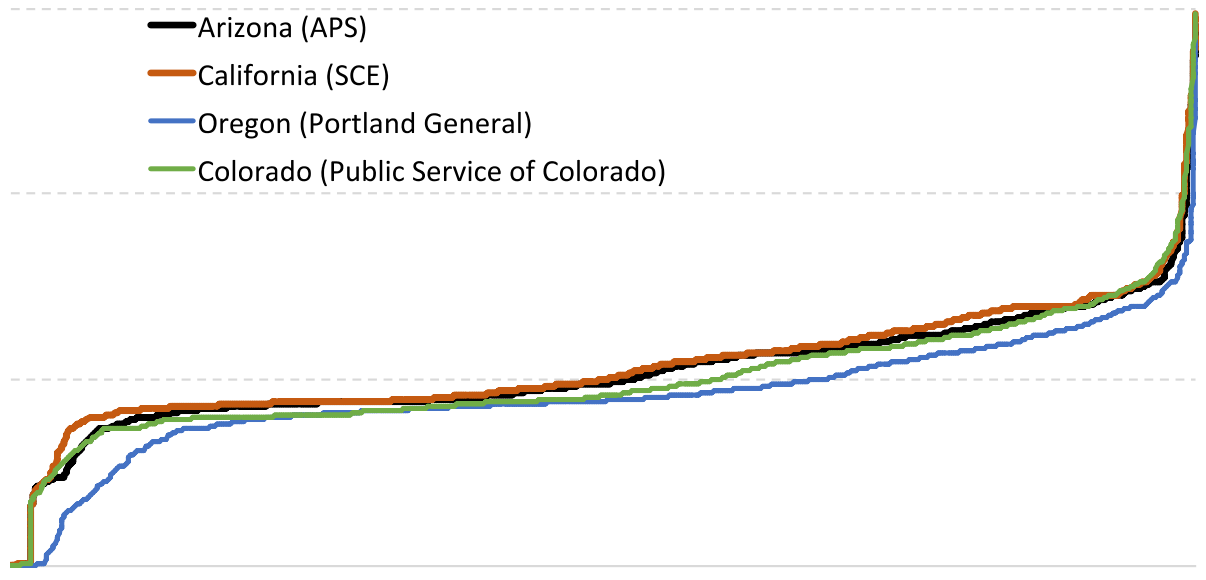

Figure 4-5. LMP duration curves for four areas in WECC (2 NGS units operating in 2030)

\subsubsection{Comparison Scenarios and Results}

The selection of scenarios for production cost modeling begins with the NGS TWG Agreement, which was adopted by EPA as the basis for a federal implementation plan for NGS compliance with $\mathrm{NO}_{\mathrm{x}}$ requirements under the Clean Air Act. The TWG Agreement reduces NGS operations by one-third starting in 2020 (by shutting down one unit or its equivalent), and defers the installation of additional $\mathrm{NO}_{\mathrm{x}}$ controls to 2030 .

This analysis takes the TWG Agreement as the status quo because it now governs maximum NGS operations through 2044. Each scenario examined in the production cost analysis is 
quantified relative to the TWG Agreement. The first step of the analysis is to isolate the likely impacts attributable to the TWG Agreement itself. For this baseline, the analysis compares operating NGS with two units (consistent with the TWG Agreement) against operations with all three units. By modeling conditions likely to prevail in 2030, the analysis accounts for the effect of other known plant retirements, known generator additions (including renewables), and utilities' most up-to-date load growth forecasts.

The analysis then examines two change scenarios against status quo of the TWG Agreement.

- The additional impact of completely retiring NGS in 2020. This corresponds to the accelerated retirement scenarios modeled in RPM. The current NGS site lease with the Navajo Nation expires in 2019. This scenario assumes the current lease expires with no federal action, which would result in shutting down the coal plant after 2019.

- The additional impact of completely retiring NGS in 2030. The TWG Agreement obligates NGS owners to install additional $\mathrm{NO}_{\mathrm{x}}$ control technology on the remaining two units if they operate past 2030. This scenario represents the owners' decision point - whether to upgrade NGS or retire it completely. System-wide production costs might not be a major factor influencing the owners' decision, but they do provide a measure of how adaptable the rest of the system might be to the owners' decision. This test includes a sensitivity scenario with high natural gas prices.

Table 4-5 summarizes the scenarios modeled in PLEXOS along with their corresponding analytical questions.

Table 4-5. Scenarios and Questions Tested

\begin{tabular}{lll}
\hline Scenario & Change Variable & Analytical Question \\
\hline TWG baseline & $\begin{array}{l}\text { Running two units in 2030 (TWG } \\
\text { Agreement), compared to running } \\
\text { three units in 2030 (reference) }\end{array}$ & $\begin{array}{l}\text { What future impact is attributable to the TWG } \\
\text { Agreement, compared to operation without } \\
\text { the agreement? }\end{array}$ \\
\hline \multirow{2}{*}{ EIS shutdown } & $\begin{array}{l}\text { Run two units in 2020 (TWG } \\
\text { Agreement), compared to shutting } \\
\text { down all three units in 2020 (draft } \\
\text { EIS no action alternative) }\end{array}$ & $\begin{array}{l}\text { What would be the additional impact of } \\
\text { completely retiring NGS in 2020, compared to } \\
\text { operation with the TWG Agreement? }\end{array}$ \\
\hline $\begin{array}{l}\text { Shutdown in } \\
\text { 2030 }\end{array}$ & $\begin{array}{l}\text { Run two units in 2030 (TWG } \\
\text { Agreement), compared to shutting } \\
\text { down all units in 2030 }\end{array}$ & $\begin{array}{l}\text { How would operation in 2030 consistent with } \\
\text { the TWG Agreement compare with shutdown } \\
\text { in 2030? }\end{array}$ \\
\hline $\begin{array}{l}\text { Shutdown in } \\
\text { 2030, high fuel } \\
\text { prices }\end{array}$ & $\begin{array}{l}\text { Same as shutdown in 2030, but with } \\
\text { high natural gas prices }\end{array}$ & $\begin{array}{l}\text { Is the outcome sensitive to natural gas } \\
\text { prices? }\end{array}$ \\
\hline
\end{tabular}




\subsubsection{TWG Baseline}

This part of the analysis tests how the baseline (a two-unit operation) differs from what might occur if NGS were operated as it has been historically (continuing to run all three units). Results indicate that Arizona would export less power under the TWG Agreement and two-unit operation, as shown in Figure 4-7. California may adjust by using its in-state natural gas generators more, while the rest of WECC - mostly the Bonneville Power Administration and other resources in the Northwest-may export more.

Total generation in the Southwest would fall by an estimated $2.1 \%$. This would also lead to a slight drop in total generation costs within the focus area. For the rest of WECC, system costs could increase by $1 \%$ (Table 4-6).

In contrast, the Southwest's average cost of production per megawatt-hour-which is normally higher than the WECC average-increases by $2 \%$ with the baseline conditions in effect. For APS, most of the increase would occur during hours when prices tend to be very low, as illustrated by the LMP duration curves in Figure 4-6. The curves show about 700 low-priced hours (corresponding generally to low-load hours) when the difference between historical operation and the baseline (shutting down one NGS unit) is as much as $23 \%$. $^{246}$

These results also suggest that the implementation of the TWG Agreement may result in more use of natural gas generation-5.6\% more in the Southwest, and $1.1 \%$ more in the rest of WECC (Table 4-7 and Table 4-8). All other generation resources both in the focus region and in the rest of WECC remain largely unchanged in this scenario.

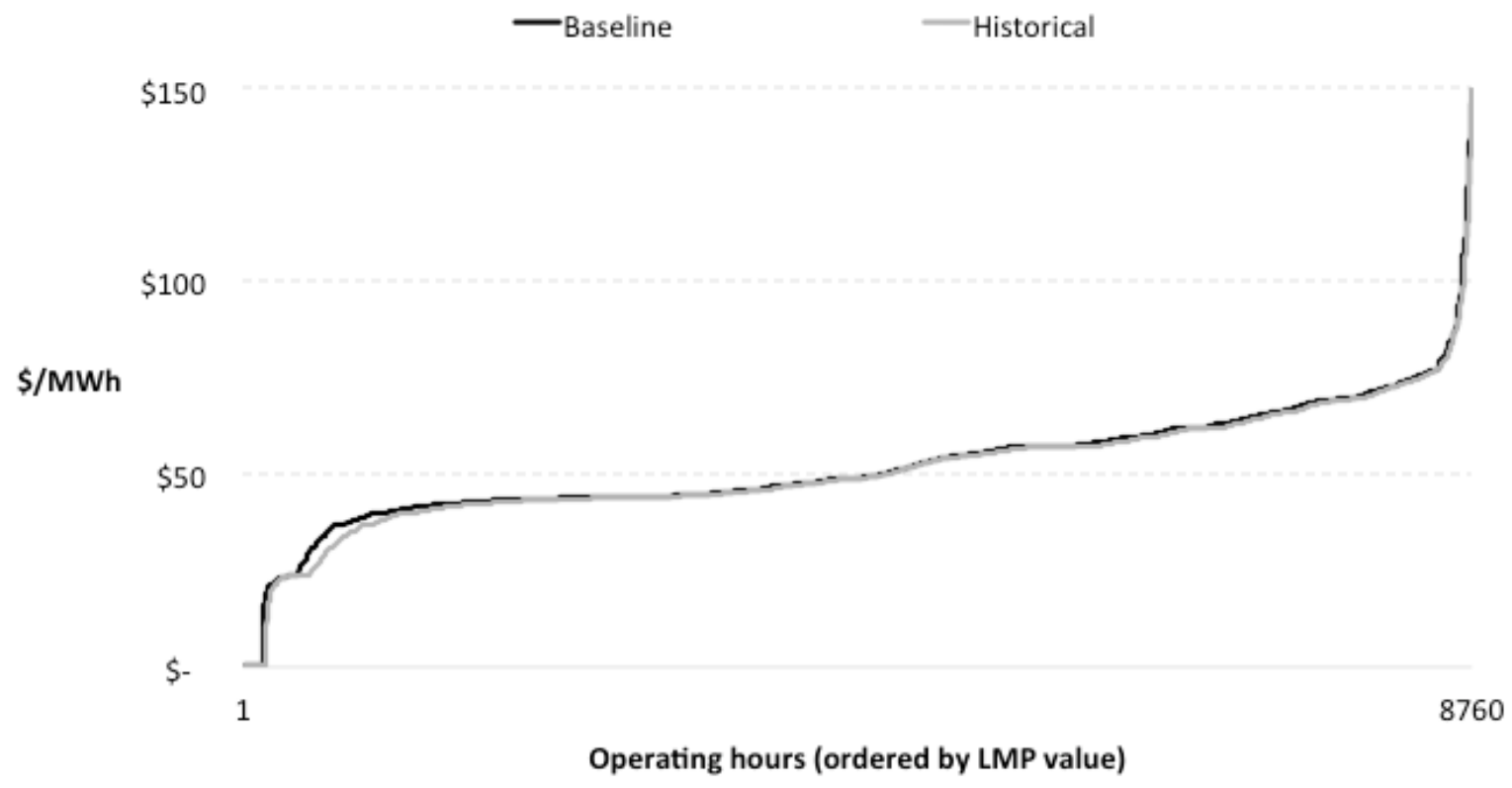

Figure 4-6. LMP duration curves for APS, comparing baseline with historical operations

\footnotetext{
${ }^{246}$ Points on the two curves are not time-synchronous. The hour with the $100^{\text {th }}$ lowest LMP on one curve may be a different hour than the $100^{\text {th }}$ lowest LMP on the other.
} 
Table 4-6. Operational Results for Baseline, and Percentage Change from Historical Operation

\begin{tabular}{lrrrr}
\hline & $\begin{array}{c}\text { Focus area and } \\
\text { percentage change from } \\
\text { historical }\end{array}$ & \multicolumn{3}{c}{$\begin{array}{c}\text { Rest of WECC and } \\
\text { percentage change from } \\
\text { historical }\end{array}$} \\
\hline Net generation $(\mathrm{GWh})$ & 156,567 & $-2.1 \%$ & 905,540 & $0.4 \%$ \\
Cost of generation (\$ millions) & $\$ 3,909$ & $-0.2 \%$ & $\$ 17,450$ & $1.0 \%$ \\
Average cost per MWh & $\$ 24.97$ & $2.0 \%$ & $\$ 19.27$ & $0.6 \%$ \\
\hline
\end{tabular}

Table 4-7. Net Generation by Fuel Type for Baseline, and Percentage Change from Historical Operation

\begin{tabular}{lrrrr}
\hline & \multicolumn{2}{c}{$\begin{array}{c}\text { Focus area and } \\
\text { percentage change from historical }\end{array}$} & \multicolumn{2}{c}{$\begin{array}{c}\text { Rest of WECC and } \\
\text { percentage change from historical }\end{array}$} \\
\hline Coal & 50,492 & $-10.0 \%$ & 174,829 & $0.2 \%$ \\
Natural gas & 42,418 & $5.6 \%$ & 275,444 & $1.1 \%$ \\
Nuclear & 31,371 & $0.0 \%$ & 26,412 & $0.0 \%$ \\
Hydro & 4,180 & $0.0 \%$ & 193,415 & $0.0 \%$ \\
Renewable & 22,899 & $0.0 \%$ & 168,476 & $0.0 \%$ \\
\hline
\end{tabular}

Table 4-8. Natural Gas Capacity Factors for Baseline, and Difference from Historical Operation

\begin{tabular}{lccrc}
\hline & $\begin{array}{c}\text { Focus area and } \\
\text { percentage point change } \\
\text { from historical }\end{array}$ & $\begin{array}{c}\text { Rest of WECC and } \\
\text { percentage point change } \\
\text { from historical }\end{array}$ \\
\hline Combined cycle & .283 & .015 & .506 & .005 \\
Combustion turbines & .061 & .004 & .132 & .003 \\
\hline
\end{tabular}

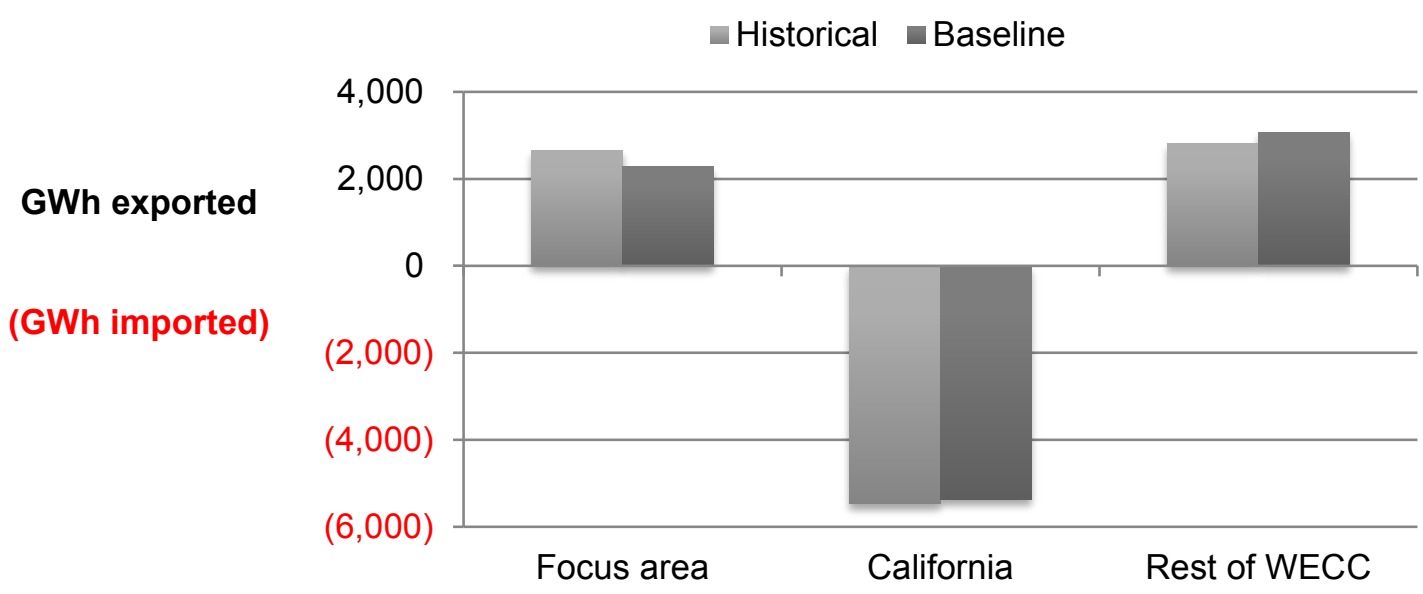

Figure 4-7. Change in imports and exports 


\subsubsection{2030 Shutdown}

One key point on the NGS timeline is 2030, the deadline for installing SCR controls on the remaining two operating units. This part of the PLEXOS analysis tests what might happen if the remaining two units are retired in 2030 rather than being upgraded with new emission controls and operated to 2044 as assumed in the baseline.

Recall that under baseline conditions, the amount of power exported from the focus area (in aggregate, generated from all sources) is already likely to fall by $14 \%$. A full retirement in 2030 would reduce exports even further: by about one-third from the baseline. Here, however, the response in the rest of WECC would largely be in California: that state would lean more on its in-state natural gas resources and import about 12\% less power than it would under baseline conditions. Net flows across the rest of WECC would remain largely unchanged (see Figure 4-9).

Table 4-9 shows that a 2030 shutdown would push total generation costs lower in the focus area, but the average cost of in-area generation would be about $2.7 \%$ higher than in the baseline. Average costs in the rest of WECC would move higher as well, traceable to the fact that, in this case, much of the additional generation would be in California where costs tend to be higher.

The use of natural gas generation would likely accelerate with a 2030 shutdown (Table 4-10 and Table 4-11). Utilization of combined cycle plants, as indicated by estimated capacity factor performance, would likely increase in the Southwest by 2.4 percentage points to more than $30 \%$. This would still be below the average combined cycle capacity factor average in the rest of WECC, however.

Table 4-10 also indicates greater use of renewables with full NGS retirement in 2030. The PLEXOS results show a shift from wind to solar, especially in the focus area.

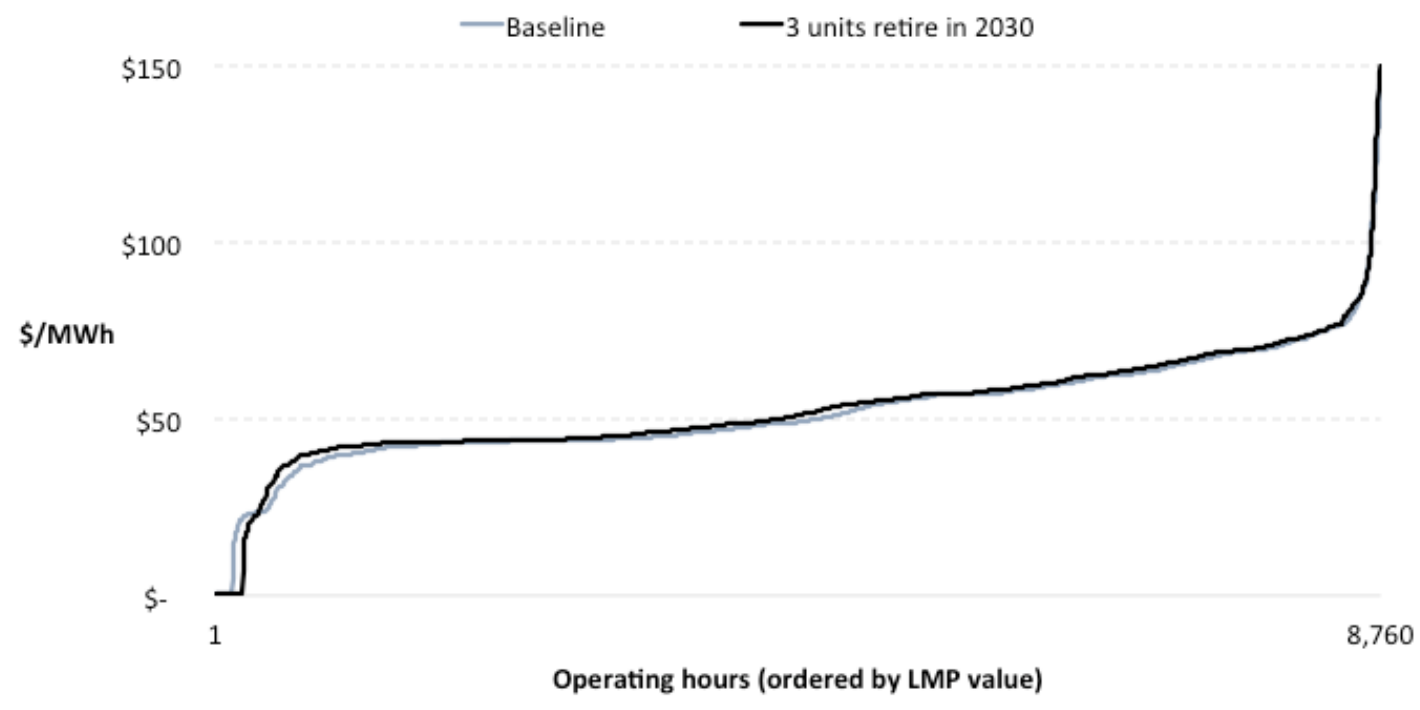

Figure 4-8. LMP duration curves for APS comparing full NGS retirement in 2030 
Table 4-9. Operational Results, 2030 Shutdown (Percentage Change from Baseline)

\begin{tabular}{lcccc}
\hline & \multicolumn{2}{c}{$\begin{array}{c}\text { Focus area and } \\
\text { percentage change from } \\
\text { baseline }\end{array}$} & \multicolumn{2}{c}{$\begin{array}{c}\text { Rest of WECC and } \\
\text { percentage change from } \\
\text { baseline }\end{array}$} \\
\hline Net generation (GWh) & 149,895 & $-4.3 \%$ & 912,122 & $0.7 \%$ \\
Cost of generation & $\$ 3,846$ & $-1.6 \%$ & $\$ 17,805$ & $2.0 \%$ \\
Average cost per MWh & $\$ 25.66$ & $2.7 \%$ & $\$ 19.52$ & $1.3 \%$ \\
\hline
\end{tabular}

Table 4-10. Net Generation by Fuel Type, 2030 Shutdown (Percentage Change from Baseline)

\begin{tabular}{lcrrr}
\hline & \multicolumn{2}{c}{$\begin{array}{c}\text { Focus area and percentage } \\
\text { change from baseline }\end{array}$} & \multicolumn{2}{c}{$\begin{array}{c}\text { Rest of WECC and percentage } \\
\text { change from baseline }\end{array}$} \\
\hline Coal & 39,239 & $-22.3 \%$ & 174,644 & $-0.1 \%$ \\
Natural gas & 46,150 & $8.8 \%$ & 282,316 & $2.5 \%$ \\
Nuclear & 31,338 & $-0.1 \%$ & 26,414 & $0.0 \%$ \\
Hydro & 4,182 & $0.0 \%$ & 193,448 & $0.0 \%$ \\
Renewable & 23,783 & $3.9 \%$ & 168,391 & $-0.1 \%$ \\
\hline
\end{tabular}

Table 4-11. Natural Gas Capacity Factors, 2030 Shutdown (Percentage Point Change from Baseline)

\begin{tabular}{lcccr}
\hline & $\begin{array}{c}\text { Focus area and percentage } \\
\text { point change from baseline }\end{array}$ & \multicolumn{2}{c}{$\begin{array}{c}\text { Rest of WECC and percentage } \\
\text { point change from baseline }\end{array}$} \\
\hline Combined cycle & $30.7 \%$ & 2.4 & $51.9 \%$ & 1.3 \\
Combustion turbines & $7.0 \%$ & 0.9 & $13.5 \%$ & 0.3 \\
\hline
\end{tabular}

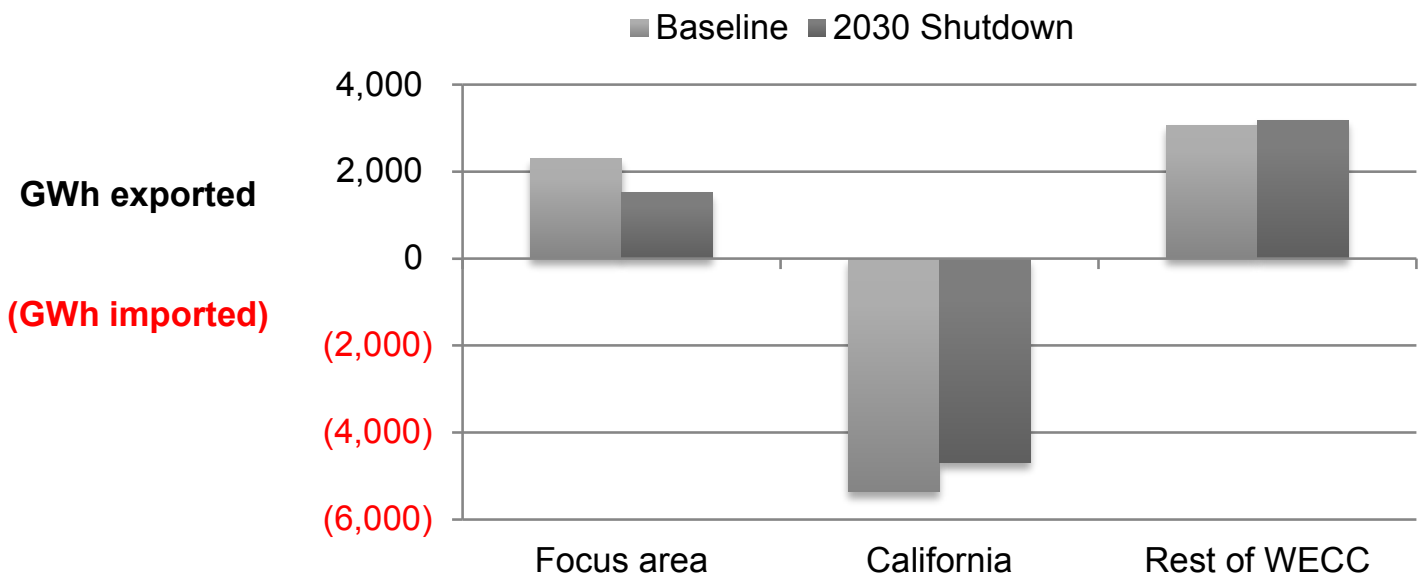

Figure 4-9. Change in imports and exports, 2030 shutdown 


\subsubsection{2020 Shutdown}

The PLEXOS runs in this part of the analysis test a more aggressive 2020 shutdown against the baseline. ${ }^{247}$ Effects of an accelerated retirement scenario would be comparable to the no-action alternative examined in the draft EIS.

With a complete shutdown, the focus area would still be a net exporter of power to the rest of WECC. The flows would be diminished significantly, however: from around $2 \mathrm{GWh}$ per year under baseline assumptions to about $1 \mathrm{GWh}$ per year. California would adjust by importing less; the rest of WECC would compensate by exporting more (Figure 4-11).

Within the Southwest, cost per megawatt-hour could increase by about $2.2 \%$ over the baseline. The rest of WECC would likely see an increase of only $1.2 \%$ (Table 4-12). Figure 4-10 suggests that the increase would tend to be for hours when average costs tend to be low.

Full retirement of NGS in 2020 tends to result in greater use of natural gas generation, more so than with a 2030 retirement (Table 4-13 and Table 4-14). Results show NGCC net generation increasing 9.7 TWh WECC-wide with about half of that generation in the Southwest. NGCT generation increases more modestly, most of it outside the Southwest. ${ }^{248}$

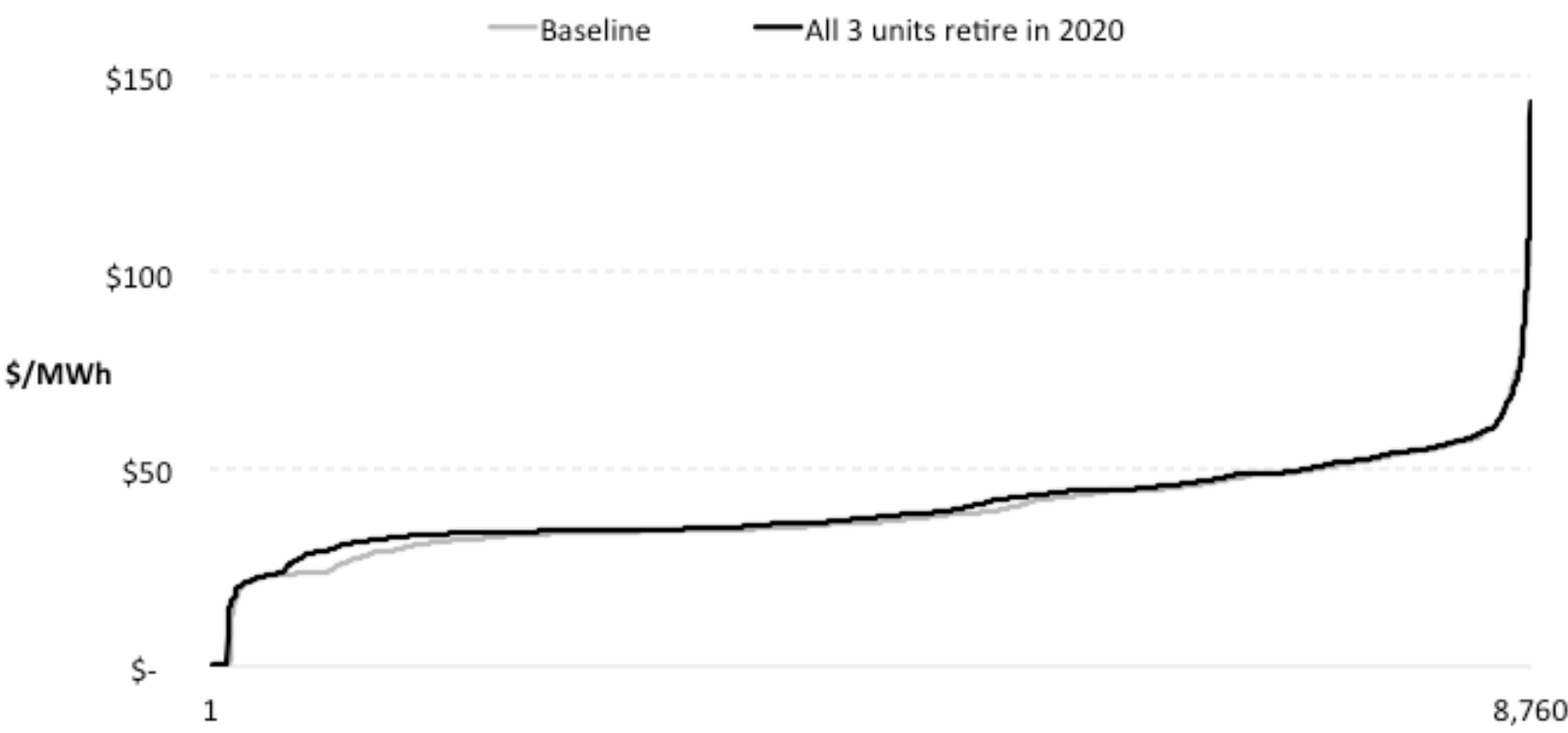

Operating hours (ordered by LMP value)

Figure 4-10. LMP duration curve for APS comparing full NGS retirement in 2020

\footnotetext{
247 The baseline scenario was re-run for this part of the analysis using conditions for 2020 rather than 2030.

248 Though there was similar variation in capacity factors related to other generation sources such as biomass, fixed hydroelectric, and solar PV, this variation did not correspond with significant differences in generation (greater than $.2 \mathrm{TWh}$ ) between the two scenarios. For subsequent cases, only those capacity factor changes that result in significant generation shifts (greater than $.2 \mathrm{TWh}$ ) are discussed in the text.
} 
Table 4-12. Operational Results, 2020 Shutdown (Percentage Change from Baseline)

\begin{tabular}{lcccc}
\hline & \multicolumn{2}{c}{$\begin{array}{c}\text { Focus area and } \\
\text { percentage change from } \\
\text { baseline }\end{array}$} & \multicolumn{2}{c}{$\begin{array}{c}\text { Rest of WECC and } \\
\text { percentage change from } \\
\text { baseline }\end{array}$} \\
\hline Net generation $(\mathrm{GWh})$ & 130,940 & $-4.9 \%$ & 865,420 & $0.8 \%$ \\
Cost of generation & $\$ 2,812$ & $-2.8 \%$ & $\$ 13,279$ & $2.0 \%$ \\
Average cost per MWh & $\$ 21.47$ & $2.2 \%$ & $\$ 15.34$ & $1.2 \%$ \\
\hline
\end{tabular}

Table 4-13. Net Generation by Fuel Type, 2020 Shutdown (Percentage Change from Baseline)

\begin{tabular}{lcrrr}
\hline & \multicolumn{2}{c}{$\begin{array}{c}\text { Focus area and percentage } \\
\text { change from baseline }\end{array}$} & \multicolumn{2}{c}{$\begin{array}{c}\text { Rest of WECC and percentage } \\
\text { change from baseline }\end{array}$} \\
\hline Coal & 39,061 & $-22.1 \%$ & 181,945 & $0.1 \%$ \\
Natural gas & 36,178 & $13.8 \%$ & 244,071 & $2.7 \%$ \\
Nuclear & 31,371 & $0.0 \%$ & 26,428 & $0.0 \%$ \\
Hydro & 4,180 & $0.0 \%$ & 192,663 & $0.0 \%$ \\
Renewable & 14,957 & $-0.2 \%$ & 157,553 & $0.0 \%$ \\
\hline
\end{tabular}

Table 4-14. Natural Gas Capacity Factors, 2020 Shutdown (Percentage Point Change from Baseline)

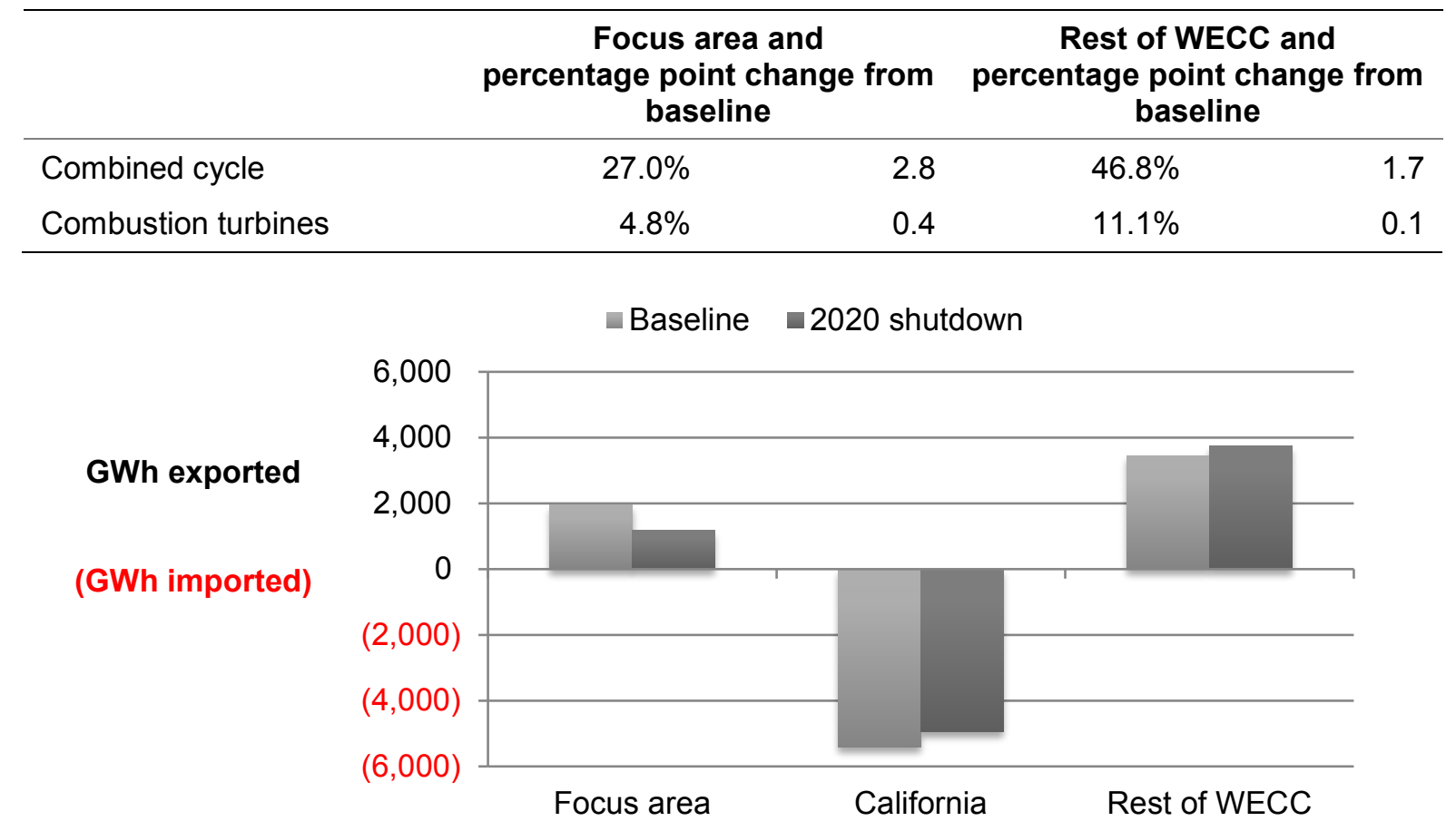

Figure 4-11. Change in imports and exports, 2020 shutdown 


\subsubsection{Potential Effect of High Natural Gas Prices}

The production cost analysis tested one other possibility: high natural gas prices. Though the impacts related to the TWG Agreement and the accelerated retirement scenario tend to move the market in similar directions, the impacts could change in a future with high gas prices. From this perspective, it is useful to compare the full retirement results with that of a full retirement in an environment of high gas prices to assess the unique impact of gas prices on the system.

This scenario resulted in the largest impact on system costs: a $\$ 4$ billion increase or $25 \%$ over that of the full retirement scenario. Regional and WECC-wide costs would also increase significantly - by 35\% (Table 4-15). The LMP duration curve in Figure 4-12 illustrates how the impact would be distributed across the entire year, using results for APS as an example.

Greater use of natural gas generation still accompanies the loss of coal generation, as shown in Table 4-16 and Table 4-17. High natural gas prices tend to shift the location of this generation from the focus area to other parts of WECC, as seen by contrasting these results with those shown earlier in Table 4-10 and Table 4-11. The Southwest stands to lose an additional $1 \mathrm{TWh}$ of generation over that of the full retirement scenario for a total net loss of $8 \mathrm{TWh}$ as compared to the TWG Agreement (Figure 4-13). In this case, all the BAs, outside of APS, stand to export less electricity, though SRP's share remains the highest.

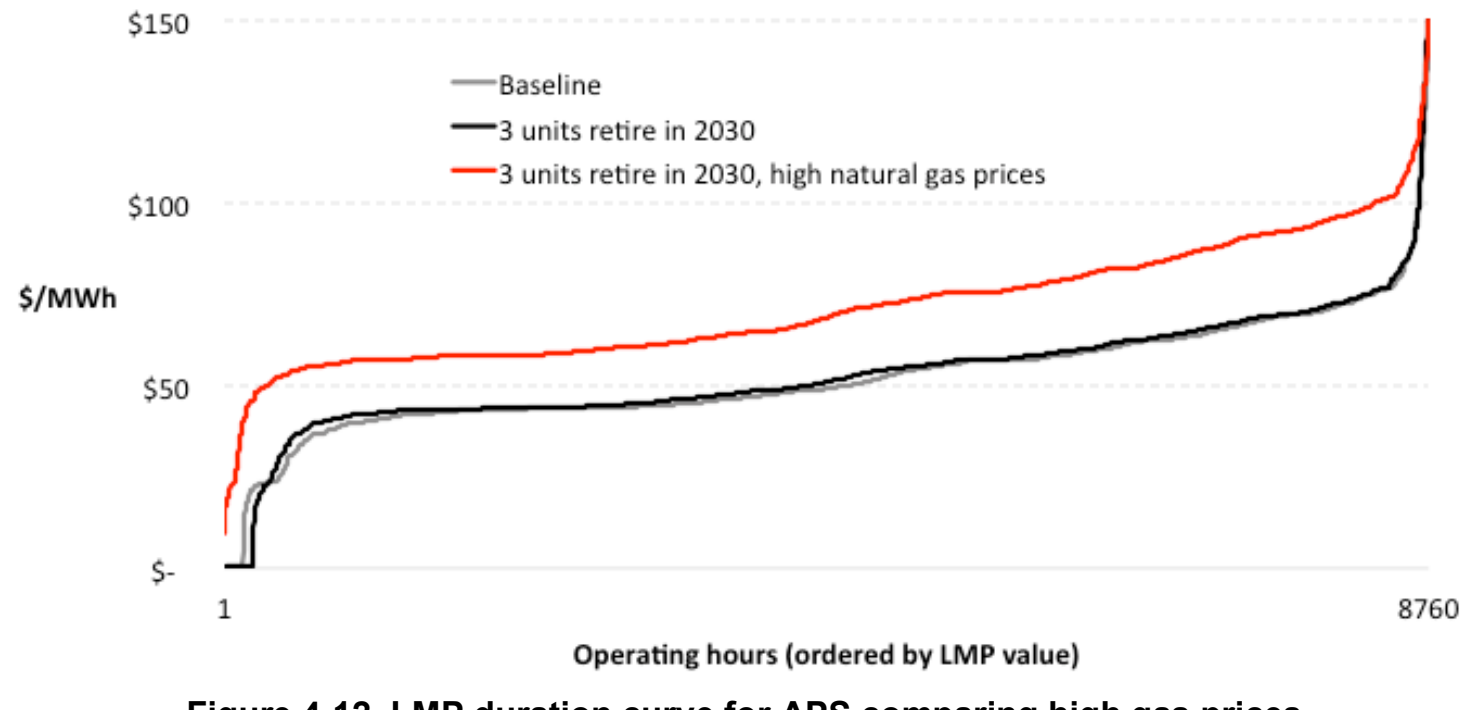

Figure 4-12. LMP duration curve for APS comparing high gas prices 
Table 4-15. Operational Results, 2030 Shutdown, High Gas Prices

\begin{tabular}{lcrrr}
\hline & \multicolumn{2}{c}{$\begin{array}{c}\text { Focus area and percentage } \\
\text { change from baseline }\end{array}$} & \multicolumn{2}{c}{$\begin{array}{c}\text { Rest of WECC and percentage } \\
\text { change from baseline }\end{array}$} \\
\hline Net generation (GWh) & 148,783 & $-5.0 \%$ & 913,129 & $0.8 \%$ \\
Cost of generation & $\$ 4,662$ & $19.3 \%$ & $\$ 22,456$ & $28.7 \%$ \\
Average cost per MWh & $\$ 31.34$ & $25.5 \%$ & $\$ 24.59$ & $27.6 \%$ \\
\hline
\end{tabular}

Table 4-16. Net Generation by Fuel Type, 2030 Shutdown, High Gas Prices

\begin{tabular}{lrrrr}
\hline & \multicolumn{2}{c}{$\begin{array}{c}\text { Focus area and percentage change } \\
\text { from baseline }\end{array}$} & \multicolumn{2}{c}{$\begin{array}{c}\text { Rest of WECC and percentage } \\
\text { change from baseline }\end{array}$} \\
\hline Coal & 39,267 & $-22.2 \%$ & 175,733 & $0.5 \%$ \\
Natural gas & 45,888 & $8.2 \%$ & 286,955 & $4.2 \%$ \\
Nuclear & 31,338 & $-0.1 \%$ & 26,418 & $0.0 \%$ \\
Hydro & 4,178 & $0.0 \%$ & 192,742 & $-0.3 \%$ \\
Renewable & 22,924 & $0.1 \%$ & 168,605 & $0.1 \%$ \\
\hline
\end{tabular}

Table 4-17. Natural Gas Capacity Factors, 2030 Shutdown, High Gas Prices

\begin{tabular}{lcccr}
\hline & \multicolumn{2}{c}{$\begin{array}{c}\text { Focus area and percentage } \\
\text { point change from baseline }\end{array}$} & \multicolumn{2}{c}{$\begin{array}{c}\text { Rest of WECC and percentage } \\
\text { point change from baseline }\end{array}$} \\
\hline Combined cycle & $30.5 \%$ & 2.2 & $53.0 \%$ & 2.4 \\
Combustion turbines & $6.9 \%$ & 0.9 & $14.2 \%$ & 1.0 \\
\hline
\end{tabular}

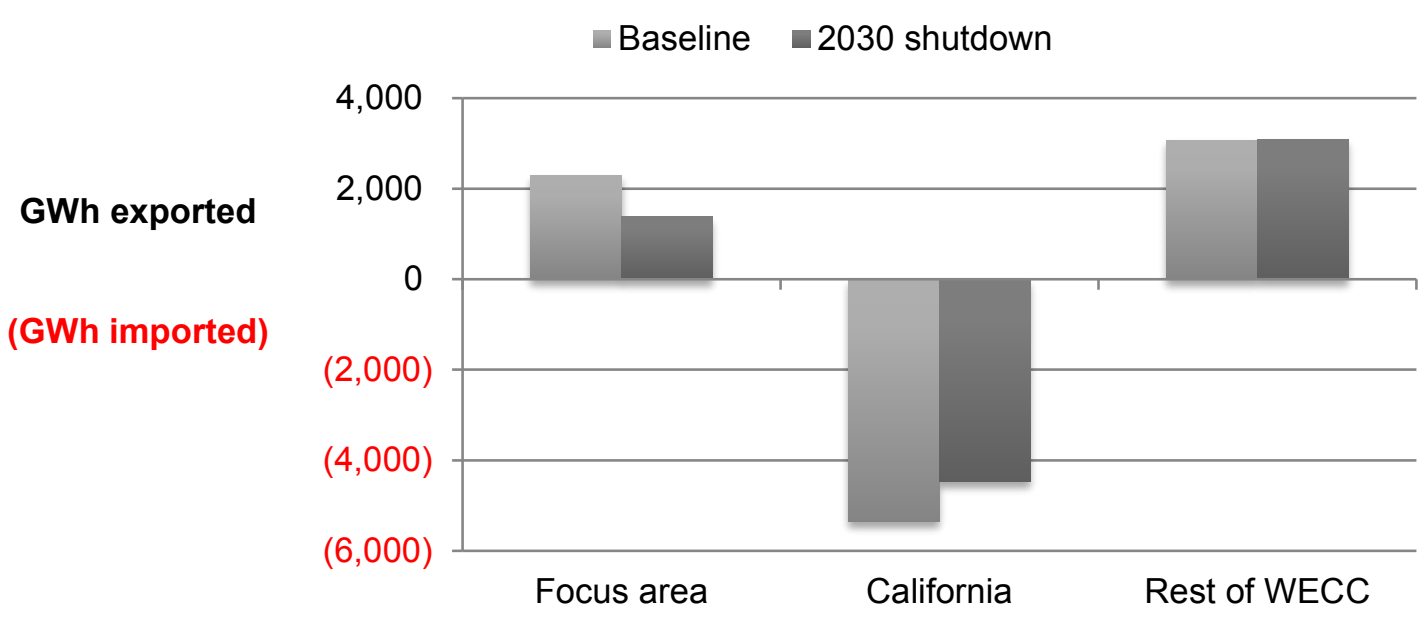

Figure 4-13. Change in imports and exports, 2030, high natural gas prices 


\subsubsection{Summary of Production Cost Results}

The cost impact of completely shutting down NGS tends to be overshadowed by the potential impact of higher natural gas prices. Production cost modeling results suggest that while a 2030 shutdown could increase the average per-megawatt-hour cost of producing electricity by $2.7 \%$ in the Southwest focus area, the cost increase would be 10 times greater if accompanied by high natural gas prices.

The average capacity factor of NGCCs in the Southwest focus region would likely increase under any retirement scenario, but would still remain below the average for all of the Western Interconnection. This is consistent with RPM capacity expansion modeling, which found that high reserve margins and low utilization of existing NGCC capacity dampens the need to build new generation to replace NGS.

One direct effect of reducing production at NGS is a reduction in exports from the Southwest focus region to California. This reduces the total cost of production (and, consequently, generator revenues) within the focus region. It does not, however, significantly change production staying within the region.

For the rest of the Western Interconnection, the change in net generation is consistent across all NGS retirement scenarios. One notable trend, however, is in the use of natural gas generation when fuel prices are high. The use of natural gas tends to shift slightly from the Southwest focus area to other parts of the Western Interconnection under high natural gas prices, possibly indicating that the West's most efficient NGCC plants reside outside the Southwest. ${ }^{249}$ Higher natural gas prices would tend to favor running the most efficient plants, all other conditions held unchanged.

\subsection{Glide Path Implications}

The modeling done here (RPM expansion modeling and PLEXOS production cost modeling) suggests that an NGS transitional glide path may benefit from a diverse portfolio of generation resources. Attempting a megawatt-for-megawatt replacement of NGS with another plant may constitute a path that would conflict with underlying market trends.

Natural gas generation will likely play some part in an NGS glide path strategy. What is uncertain is whether market conditions would support building a new NGCC rather than increasing the utilization of existing plants. Capacity expansion modeling suggests not. Production cost modeling suggests redispatching existing plants could accommodate the entire range of NGS scenarios, with increases in local per-megawatt-hour generation costs no greater than $2.7 \%$. This cost impact is an order of magnitude smaller than what high natural gas prices could cause by themselves, regardless of any NGS retirements.

The capacity expansion modeling also suggests that solar PV could be an important strategic element of an NGS glide path. Reducing the use of NGS seems to add weight to solar in the

\footnotetext{
${ }^{249}$ Ambient air temperature affects the operating efficiency of a thermal generator. Arizona's climate could be a factor that contributes to making thermal generators in the north somewhat more efficient during the Southwest's hot summer months.
} 
Southwest focus area, such that on a west-wide basis the demand for new renewables tends to shift from wind outside the Southwest and toward solar in the Southwest.

Solar (like wind and geothermal power) can also provide a hedge against high natural gas prices. Capacity expansion modeling suggests that high natural gas prices could increase the demand for renewables beyond what would otherwise be required by state RPS goals, especially in the event of full NGS retirement. Production cost modeling suggests that by shifting some of the local generation load from NGCCs, having more solar on the system could result in electricity cost savings for the Southwest in the event that future natural gas prices are high. 


\section{Modeling Economic Effects of 1-Unit Shutdown ${ }^{250}$}

This chapter examines the potential net economic impacts of shutting down one of three 750megawatt (MW) coal-fired generating units in the NGS. As discussed elsewhere in this report, this represents a business-as-usual scenario that can be used as a baseline to compare other options.

NGS purchases all of its coal from the nearby Kayenta mine. NGS is the sole customer of Kayenta, so in the absence of another customer, reducing coal demand by NGS would reduce the mine's level of output. This would economically affect several key regions. NGS itself is located on Navajo tribal land within Coconino County, and the Kayenta mine is located within Navajo County on land claimed by both the Navajo and Hopi Tribes. The shutdown would likely affect the overall state of Arizona as well, albeit to a much lesser extent.

For this analysis, we use several computable general equilibrium (CGE) models, which are commonly used to estimate economic and fiscal impacts. Each model is customized to represent a region: Coconino County; Navajo and Apache counties; and the rest of the State of Arizona. The data used in our analysis are drawn from a variety of sources. We chose 2013 as the base year because it is the most recent year that allows for a comprehensive and consistent baseline analysis.

Although Arizona's regional economy is fairly integrated, we differentiate the employment and income impacts on Native American and non-Native American households. Due to modeling limitations and data issues, however, we are not able to identify the unique fiscal impacts for each affected governmental unit (city, county, or tribe); instead we combine Hopi and Navajo Nations with Coconino and Navajo counties. When possible, however, we do identify unique impacts to individual governmental units.

\subsection{Regional Economic Characteristics}

Coconino and Navajo counties are located in north-central Arizona. In 2013, Coconino County was home to more than 136,000 residents, while population in the combined of Navajo and Apache counties was approximately 180,000 (Figure 5-1). From 1969 to 2013, annual population growth has averaged $2.4 \%$ in Coconino County and $1.8 \%$ in the Navajo/Apache region. By comparison, Arizona overall has averaged nearly 4\% annual population growth over this period. The "Great Recession" (December 2007-June 2009) had an important adverse impact on the region, and the slow recovery is reflected in halting population growth. Since 2009, annual population growth rates for Coconino and Navajo/Apache counties have averaged $0.7 \%$ and $0.2 \%$, respectively. ${ }^{251}$

\footnotetext{
250 This chapter was prepared by Harvey Cutler, professor of economics at Colorado State University.

${ }^{251}$ National Bureau of Economic Research, untitled press release, September 20, 2010. Using gross domestic product and other data, NBER's Business Cycle Dating Committee identified December 2007 as the beginning of the recession and June 2009 as beginning of the recovery period. http://www.nber.org/cycles/sept2010.pdf.
} 


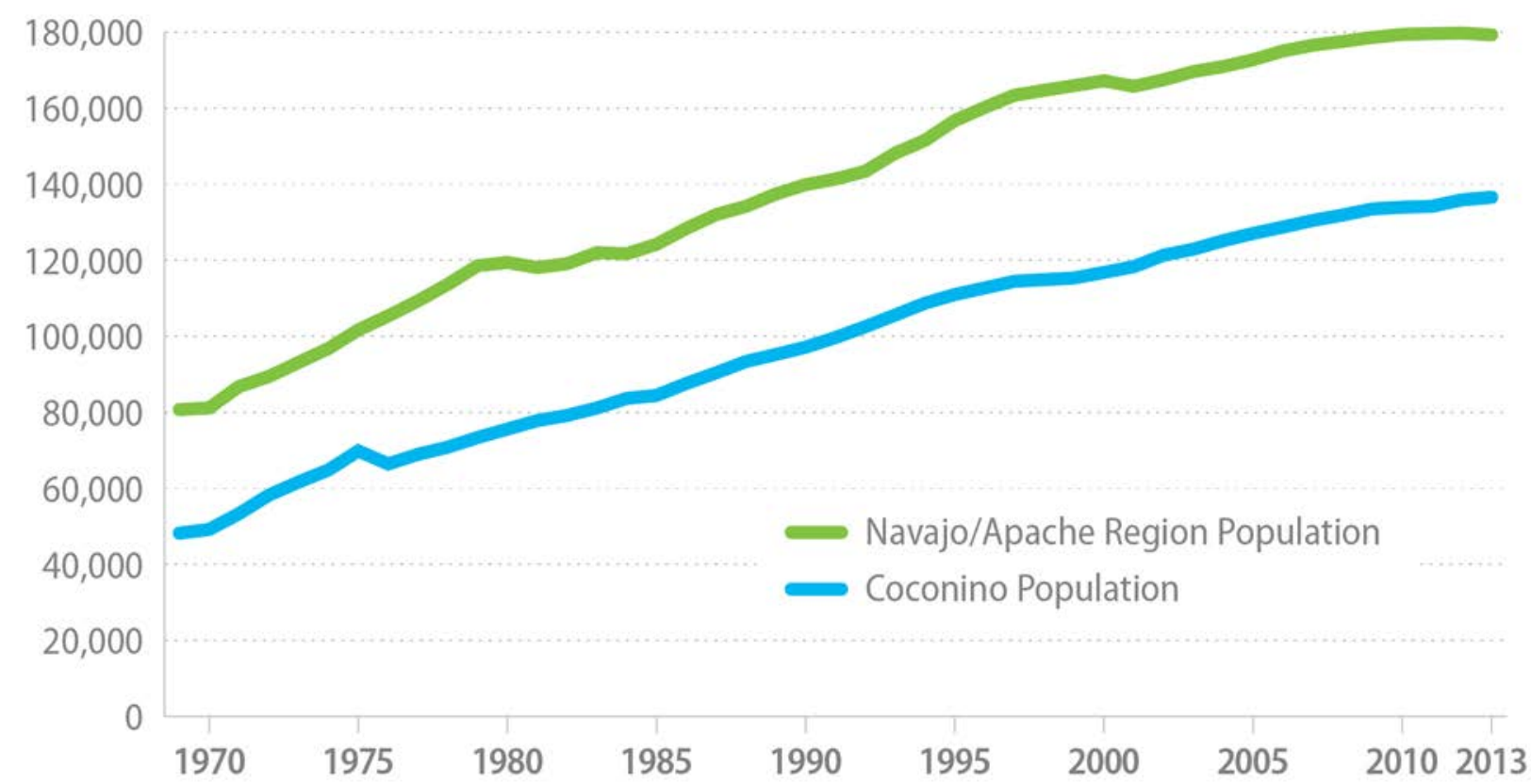

Figure 5-1. Population for Coconino and Apache/Navajo counties ${ }^{252}$

Employment and population are closely related, and this can be seen in Coconino County and the Navajo/Apache region. Figure 5-2 shows annual total employment in each county from 1969 to 2013 . Over this period, annual employment growth has averaged $2.9 \%$ for Coconino and $1.8 \%$ for Apache/Navajo region. However, since the end of the recession, annual job growth has averaged only $0.1 \%$ in Coconino County, while the rate has been $-0.3 \%$ in Navajo/Apache region. Reflecting slower growth, August 2014 unemployment rates in Coconino (6.4\%) and Apache and Navajo (10.6\%) were higher than the state overall (6.1\%).

252 Bureau of Economic Analysis (BEA), Local Area Personal Income Accounts (various tables), http://www.bea.gov/regional/downloadzip.cfm, accessed 2015. 


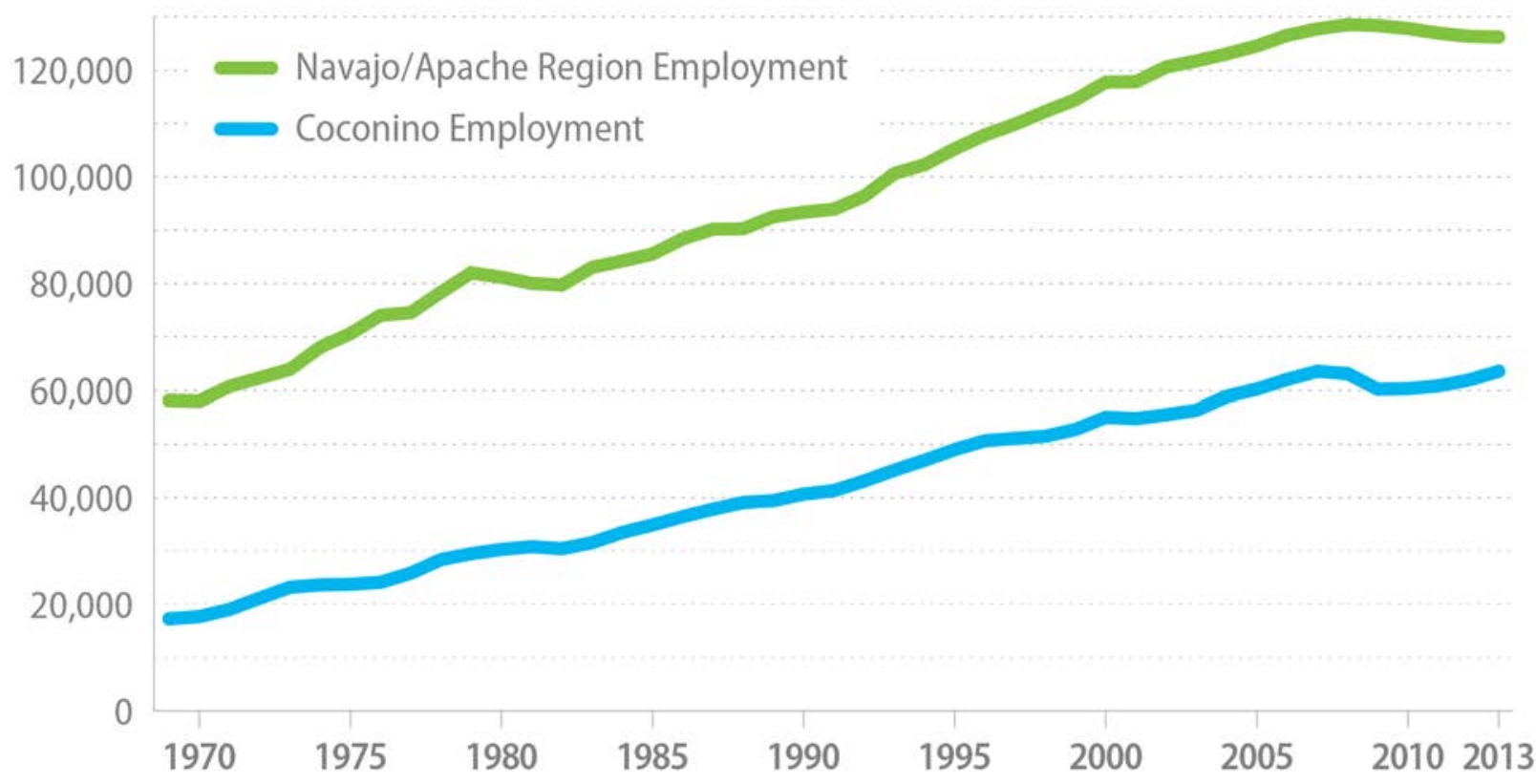

Figure 5-2. Employment for Coconino and Apache/Navajo counties ${ }^{253}$

A relatively large share of the population resides in lower income households. Table 5-1 through Table 5-4 describes the basic household income distribution for the two regions across two different population categories in 2013: Native Americans and non-Native Americans. These tables also individually delineate the regions between working and nonworking households. Working households are defined as households where at least one member is employed, whereas no members are employed in nonworking households.

Table 5-1 shows the level and distribution of household income outcomes of Native American households in Coconino County. As an example, 2,010 Native American households in the county $-19.6 \%$ of the county's Native American households - earn $\$ 10,000$ or less annually. Further, $33.8 \%$ of Native American households with incomes from $\$ 10,001$ to $\$ 15,000$ are classified as nonworking.

Table 5-2 presents a similar breakdown for non-Native American households in the county.

${ }^{253}$ Ibid. 
Table 5-1. Coconino Native American Households, $2013^{254}$

\begin{tabular}{lrrrrr}
\hline Household Income & $\begin{array}{r}\text { Total } \\
\text { Households }\end{array}$ & $\begin{array}{r}\text { Percent } \\
\text { of Total }\end{array}$ & $\begin{array}{r}\text { Working } \\
\text { Households }\end{array}$ & $\begin{array}{r}\text { Nonworking } \\
\text { Households }\end{array}$ & $\begin{array}{r}\text { Percent } \\
\text { Nonworking }\end{array}$ \\
\hline $\mathbf{S} \mathbf{\$ 1 0 , 0 0 0}$ & 2,010 & $19.6 \%$ & 618 & 1,392 & $69.3 \%$ \\
\hline $\mathbf{\$ 1 0 , 0 0 1}$ to $\$ \mathbf{1 5 , 0 0 0}$ & 916 & $8.9 \%$ & 606 & 310 & $33.8 \%$ \\
\hline $\mathbf{\$ 1 5 , 0 0 0}$ to $\$ \mathbf{2 5 , 0 0 0}$ & 1,356 & $13.2 \%$ & 995 & 361 & $26.6 \%$ \\
\hline $\mathbf{\$ 2 5 , 0 0 0}$ to $\$ \mathbf{3 5 , 0 0 0}$ & 1,350 & $13.1 \%$ & 1,174 & 176 & $13.0 \%$ \\
\hline $\mathbf{\$ 5 , 0 0 0}$ to $\$ \mathbf{5 0 , 0 0 0}$ & 1,936 & $18.8 \%$ & 1,751 & 185 & $9.6 \%$ \\
\hline $\mathbf{\$ 5 0 , 0 0 0}$ to $\$ \mathbf{7 5 , 0 0 0}$ & 1,280 & $12.5 \%$ & 1,162 & 118 & $9.2 \%$ \\
\hline $\mathbf{\$ 7 5 , 0 0 0}$ to $\$ \mathbf{9 2 , 0 0 0}$ & 920 & $8.9 \%$ & 919 & 1 & $0.1 \%$ \\
\hline $\mathbf{\$ 9 2 , 0 0 0}$ to $\$ \mathbf{\$ 1 4 5 , 0 0 0}$ & 443 & $4.3 \%$ & 442 & 1 & $0.2 \%$ \\
\hline $\mathbf{\$ 1 4 5 , 0 0 0}$ & 70 & $0.7 \%$ & 69 & 1 & $1.4 \%$ \\
\hline Total & 10,281 & & 7,736 & 2,545 & $24.8 \%$ \\
\hline
\end{tabular}

Table 5-2. Coconino Non-Native American Households, $2013^{255}$

\begin{tabular}{lrrrrr}
\hline Household Income & $\begin{array}{r}\text { Total } \\
\text { Households }\end{array}$ & $\begin{array}{r}\text { Percent } \\
\text { of Total }\end{array}$ & $\begin{array}{r}\text { Working } \\
\text { Households }\end{array}$ & $\begin{array}{r}\text { Nonworking } \\
\text { Households }\end{array}$ & $\begin{array}{r}\text { Percent } \\
\text { Nonworking }\end{array}$ \\
\hline$\leq \$ 10,000$ & 3,576 & $10.1 \%$ & 1,683 & 1,893 & $52.9 \%$ \\
\hline$\$ 10,001$ to $\$ 15,000$ & 2,619 & $7.4 \%$ & 1,467 & 1,152 & $44.0 \%$ \\
\hline$\$ 15,000$ to $\$ 25,000$ & 3,775 & $10.7 \%$ & 2,611 & 1,164 & $30.8 \%$ \\
\hline$\$ 25,000$ to $\$ 35,000$ & 3,540 & $10.0 \%$ & 2,945 & 595 & $16.8 \%$ \\
\hline$\$ 35,000$ to $\$ 50,000$ & 4,755 & $13.4 \%$ & 3,964 & 791 & $16.6 \%$ \\
\hline$\$ 50,000$ to $\$ 75,000$ & 6,743 & $19.0 \%$ & 6,073 & 670 & $9.9 \%$ \\
\hline$\$ 75,000$ to $\$ 92,000$ & 4,303 & $12.1 \%$ & 3,948 & 355 & $8.3 \%$ \\
\hline$\$ 92,000$ to $\$ 145,000$ & 4,093 & $11.5 \%$ & 3,805 & 288 & $7.0 \%$ \\
\hline$>\$ 145,000$ & 2,035 & $5.7 \%$ & 1,689 & 346 & $17.0 \%$ \\
\hline Total & $\mathbf{3 5 , 4 3 9}$ & & $\mathbf{2 8 , 1 8 5}$ & $\mathbf{7 , 2 5 4}$ & $\mathbf{2 0 . 5 \%}$ \\
\hline
\end{tabular}

There are several interesting comparisons across the two groups. Native American households make up a little less than $20 \%$ of total households in the county. Approximately $42 \%$ of Native American households earn no more than $\$ 25,000$. Among the rest of the population, only $28 \%$ of households earn less than this amount. The share of nonworking households is about 4.3 percentage points higher for Native American households. Both of these findings suggest that Native American households face more difficulties in the Coconino County labor market.

${ }^{254}$ U.S. Census Bureau, "2013 5 Year American Community Survey Public Use Microdata Sample,” accessed May 2015, http://www2.census.gov/acs2013 5yr/pums/.

${ }^{255}$ U.S. Census Bureau, "2013 5 Year American Community Survey Public Use Microdata Sample." 
The NGS employs approximately 548 workers, with Native Americans making up about $81 \%$ of these. ${ }^{256}$ Overall, NGS accounts for slightly less than $1 \%$ of total employment in Coconino County. The Kayenta coal mine-located in Navajo County - is a major part of the NGS supply chain and employs 422 workers, with Native Americans making up approximately $90 \%$ of the workers in the mine. Kayenta workers make up less than $1 \%$ of the workforce in the combined Navajo/Apache region.

Table 5-3 and Table 5-4 present companion descriptions for the two household groups for the Apache/Navajo region. While the general differences between Native American and nonNative American households are similar to Coconino County, Native Americans are a much larger share of the population, comprising slightly more than $50 \%$ of total households in the region. Although Native American households are more likely to be nonworking than nonNative American households (just like in Coconino County), the most notable issue here is that households in both groups are nearly as likely to be nonworking as working.

Table 5-3. Navajo/Apache Native American Households, $2013^{257}$

\begin{tabular}{llllll}
\hline Household Income & $\begin{array}{l}\text { Total } \\
\text { Households }\end{array}$ & $\begin{array}{l}\text { Percent } \\
\text { of Total }\end{array}$ & $\begin{array}{l}\text { Working } \\
\text { Households }\end{array}$ & $\begin{array}{l}\text { Nonworking } \\
\text { Households }\end{array}$ & $\begin{array}{l}\text { Percent } \\
\text { Nonworking }\end{array}$ \\
\hline$\leq \$ 10,000$ & 8,137 & $28.6 \%$ & 1,384 & 6,753 & $83.0 \%$ \\
\hline$\$ 10,001$ to $\$ 15,000$ & 2,814 & $9.9 \%$ & 1,148 & 1,666 & $59.2 \%$ \\
\hline$\$ 15,000$ to $\$ 25,000$ & 4,385 & $15.4 \%$ & 2,723 & 1,662 & $37.9 \%$ \\
\hline$\$ 25,000$ to $\$ 35,000$ & 2,987 & $10.5 \%$ & 2,312 & 675 & $22.6 \%$ \\
\hline$\$ 35,000$ to $\$ 50,000$ & 3,728 & $13.1 \%$ & 3,336 & 392 & $10.5 \%$ \\
\hline$\$ 50,000$ to $\$ 75,000$ & 3,777 & $13.3 \%$ & 3,491 & 286 & $7.6 \%$ \\
\hline$\$ 75,000$ to $\$ 92,000$ & 1,525 & $5.4 \%$ & 1,522 & 3 & $0.2 \%$ \\
\hline$\$ 92,000$ to $\$ 145,000$ & 775 & $2.7 \%$ & 729 & 46 & $5.9 \%$ \\
\hline$>145,000$ & 340 & $1.2 \%$ & 333 & 7 & $2.1 \%$ \\
\hline Total & $\mathbf{2 8 , 4 6 8}$ & & $\mathbf{1 6 , 9 7 8}$ & $\mathbf{1 1 , 4 9 0}$ & $\mathbf{4 0 . 4 \%}$ \\
\hline
\end{tabular}

Source: U.S. Census Bureau

${ }^{256}$ U.S. Bureau of Reclamation, NGS-Kayenta Mine Complex Project Draft EIS.

${ }^{257}$ U.S. Census Bureau, "2013 5 Year American Community Survey Public Use Microdata Sample." 
Table 5-4. Navajo/Apache Non-Native American Households, $2013^{258}$

\begin{tabular}{lrrrrr}
\hline Household Income & $\begin{array}{r}\text { Total } \\
\text { Households }\end{array}$ & $\begin{array}{r}\text { Percent } \\
\text { of Total }\end{array}$ & $\begin{array}{r}\text { Working } \\
\text { Households }\end{array}$ & $\begin{array}{r}\text { Nonworking } \\
\text { Households }\end{array}$ & $\begin{array}{r}\text { Percent } \\
\text { Nonworking }\end{array}$ \\
\hline$\leq \$ 10,000$ & 6,460 & $25.9 \%$ & 1,326 & 5,134 & $79.5 \%$ \\
\hline$\$ 10,001$ to $\$ 15,000$ & 2,040 & $8.2 \%$ & 701 & 1,339 & $65.6 \%$ \\
\hline$\$ 15,000$ to $\$ 25,000$ & 3,208 & $12.9 \%$ & 1,518 & 1,690 & $52.7 \%$ \\
\hline$\$ 25,000$ to $\$ 35,000$ & 2,489 & $10.0 \%$ & 1,496 & 993 & $39.9 \%$ \\
\hline$\$ 35,000$ to $\$ 50,000$ & 3,215 & $12.9 \%$ & 2,263 & 952 & $29.6 \%$ \\
\hline$\$ 50,000$ to $\$ 75,000$ & 3,744 & $15.0 \%$ & 2,970 & 774 & $20.7 \%$ \\
\hline$\$ 75,000$ to $\$ 92,000$ & 1,246 & $5.0 \%$ & 1,044 & 202 & $16.2 \%$ \\
\hline$\$ 92,000$ to $\$ 145,000$ & 2,053 & $8.2 \%$ & 1,910 & 143 & $7.0 \%$ \\
\hline$>\$ 145,000$ & 476 & $1.9 \%$ & 395 & 81 & $17.0 \%$ \\
\hline Total & $\mathbf{2 4 , 9 3 1}$ & & $\mathbf{1 3 , 6 2 3}$ & $\mathbf{1 1 , 3 0 8}$ & $\mathbf{4 5 . 4 \%}$ \\
\hline
\end{tabular}

Table 5-5 and Table 5-6 present similar descriptions of households for the rest of Arizona.

Table 5-5. Rest of Arizona Native American Households, $2013^{259}$

\begin{tabular}{lrrrrr}
\hline Household Income & $\begin{array}{r}\text { Total } \\
\text { Households }\end{array}$ & $\begin{array}{r}\text { Percent } \\
\text { of Total }\end{array}$ & $\begin{array}{r}\text { Working } \\
\text { Households }\end{array}$ & $\begin{array}{r}\text { Nonworking } \\
\text { Households }\end{array}$ & $\begin{array}{r}\text { Percent } \\
\text { Nonworking }\end{array}$ \\
\hline$\leq \$ 10,000$ & $27,175.00$ & $28.7 \%$ & $6,780.00$ & 20,395 & $75.1 \%$ \\
\hline$\$ 10,001$ to $\$ 15,000$ & $7,907.00$ & $8.4 \%$ & $3,955.00$ & 3,952 & $50.0 \%$ \\
\hline$\$ 15,000$ to $\$ 25,000$ & $13,350.00$ & $14.1 \%$ & $9,329.00$ & 4,021 & $30.1 \%$ \\
\hline$\$ 25,000$ to $\$ 35,000$ & $11,626.00$ & $12.3 \%$ & $9,338.00$ & 2,288 & $19.7 \%$ \\
\hline$\$ 35,000$ to $\$ 50,000$ & $13,335.00$ & $14.1 \%$ & $11,941.00$ & 1,394 & $10.5 \%$ \\
\hline$\$ 50,000$ to $\$ 75,000$ & $11,623.00$ & $12.3 \%$ & $10,593.00$ & 1,030 & $8.9 \%$ \\
\hline$\$ 75,000$ to $\$ 92,000$ & $4,625.00$ & $4.9 \%$ & $4,304.00$ & 321 & $6.9 \%$ \\
\hline$\$ 92,000$ to $\$ 145,000$ & $3,412.00$ & $3.6 \%$ & $3,303.00$ & 109 & $3.2 \%$ \\
\hline$>\$ 145,000$ & $1,485.00$ & $1.6 \%$ & $1,251.00$ & 234 & $15.8 \%$ \\
\hline Total & $\mathbf{9 4 , 5 3 8 . 0 0}$ & & $\mathbf{6 0 , 7 9 4 . 0 0}$ & $\mathbf{3 3 , 7 4 4}$ & $\mathbf{3 5 . 7 \%}$ \\
\hline
\end{tabular}

258 Ibid.

259 Ibid. 
Table 5-6. Rest of Arizona Other Households, $2013^{260}$

\begin{tabular}{lrrrrr}
\hline Household Income & $\begin{array}{r}\text { Total } \\
\text { Households }\end{array}$ & $\begin{array}{r}\text { Percent } \\
\text { of Total }\end{array}$ & $\begin{array}{r}\text { Working } \\
\text { Households }\end{array}$ & $\begin{array}{r}\text { Nonworking } \\
\text { Households }\end{array}$ & $\begin{array}{r}\text { Percent } \\
\text { Nonworking }\end{array}$ \\
\hline$\leq \$ 10,000$ & 250,386 & $11.5 \%$ & 74,690 & 175,696 & $70.2 \%$ \\
\hline$\$ 10,001$ to $\$ 15,000$ & 124,672 & $5.7 \%$ & 56,820 & 67852 & $54.4 \%$ \\
\hline$\$ 15,000$ to $\$ 25,000$ & 250,130 & $11.5 \%$ & 145,636 & 104,494 & $41.8 \%$ \\
\hline$\$ 25,000$ to $\$ 35,000$ & 238,388 & $11.0 \%$ & 164,182 & 74,206 & $31.1 \%$ \\
\hline$\$ 35,000$ to $\$ 50,000$ & 317,424 & $14.6 \%$ & 241,628 & 75,796 & $23.9 \%$ \\
\hline$\$ 50,000$ to $\$ 75,000$ & 388,292 & $17.8 \%$ & 320,481 & 67,811 & $17.5 \%$ \\
\hline$\$ 75,000$ to $\$ 92,000$ & 2361,04 & $10.8 \%$ & 207936 & 28,168 & $11.9 \%$ \\
\hline$\$ 92,000$ to $\$ 145,000$ & 230,288 & $10.6 \%$ & 209,912 & 20,376 & $8.8 \%$ \\
\hline$>\$ 145,000$ & 140,951 & $6.5 \%$ & 124,696 & 16,255 & $11.5 \%$ \\
\hline Total & $\mathbf{2 1 7 6 , 6 3 5}$ & & $\mathbf{1 , 5 4 5 , 9 8 1}$ & $\mathbf{6 3 0 , 6 5 4}$ & $\mathbf{2 9 . 0 \%}$ \\
\hline
\end{tabular}

\subsection{CGE Model Description}

Because they are grounded in theory yet provide a high level of detail, CGE models are often used for conducting economic impact analysis. ${ }^{261}$ These models are built on a family of equations that describe interactions among defined economic sectors. Each model used in this analysis contains more than 1,000 equations, the general forms of which are presented in the Appendix. The model is calibrated when the equations exactly reproduce the baseline data (i.e., the current state of the economy). ${ }^{262}$

Figure 5-3 presents a schematic of the CGE models used in this analysis, illustrating the interaction between households, industries (or firms), regional government, and outside economies. Arrows represent the flow of value.

There are three basic actors in a CGE model. Profit-maximizing firms produce goods and services using capital, intermediate goods, labor, and land as inputs. A series of equations is used to represent the flow of wages and income from capital investments and the production of goods. ${ }^{263}$

Households provide labor to firms in exchange for wages, which they use to purchase final goods and services from firms. Households are defined as all individuals or groups who occupy a housing unit in the region. These units include either single residential homes or multiple-unit

\footnotetext{
${ }^{260}$ Ibid.

${ }^{261}$ Mark Partridge and Dan Rickman, "Computable General Equilibrium (CGE) Modeling for Regional Economic Development Analysis," Regional Studies 44:10 (2010): 1311-1328.

${ }^{262}$ Input-output (I-O) analysis is often used to conduct economic impact studies, but CGE models are more flexible and account for a larger set of economic activity, such as how consumers or producers react to changing prices.

${ }^{263}$ Income from capital investments is also known as "gross operating surplus." Some reports and models also refer to it as "property type income."
} 
dwellings. This framework for dividing the population contains multiple household groups differentiated by income.

The local supply of labor comes directly from these household groups and is determined by elasticities of labor supply for each household. Labor supply can also change by households migrating into or out of the region depending on changes in relative economic conditions. ${ }^{264}$

Both firms and households pay a variety of taxes (e.g., sales, property, and income) to government, which uses revenue to pay for public goods and services, such as transportation, education, and welfare. Models assume a balanced government budget, so these expenditures are constrained by the tax revenues received.

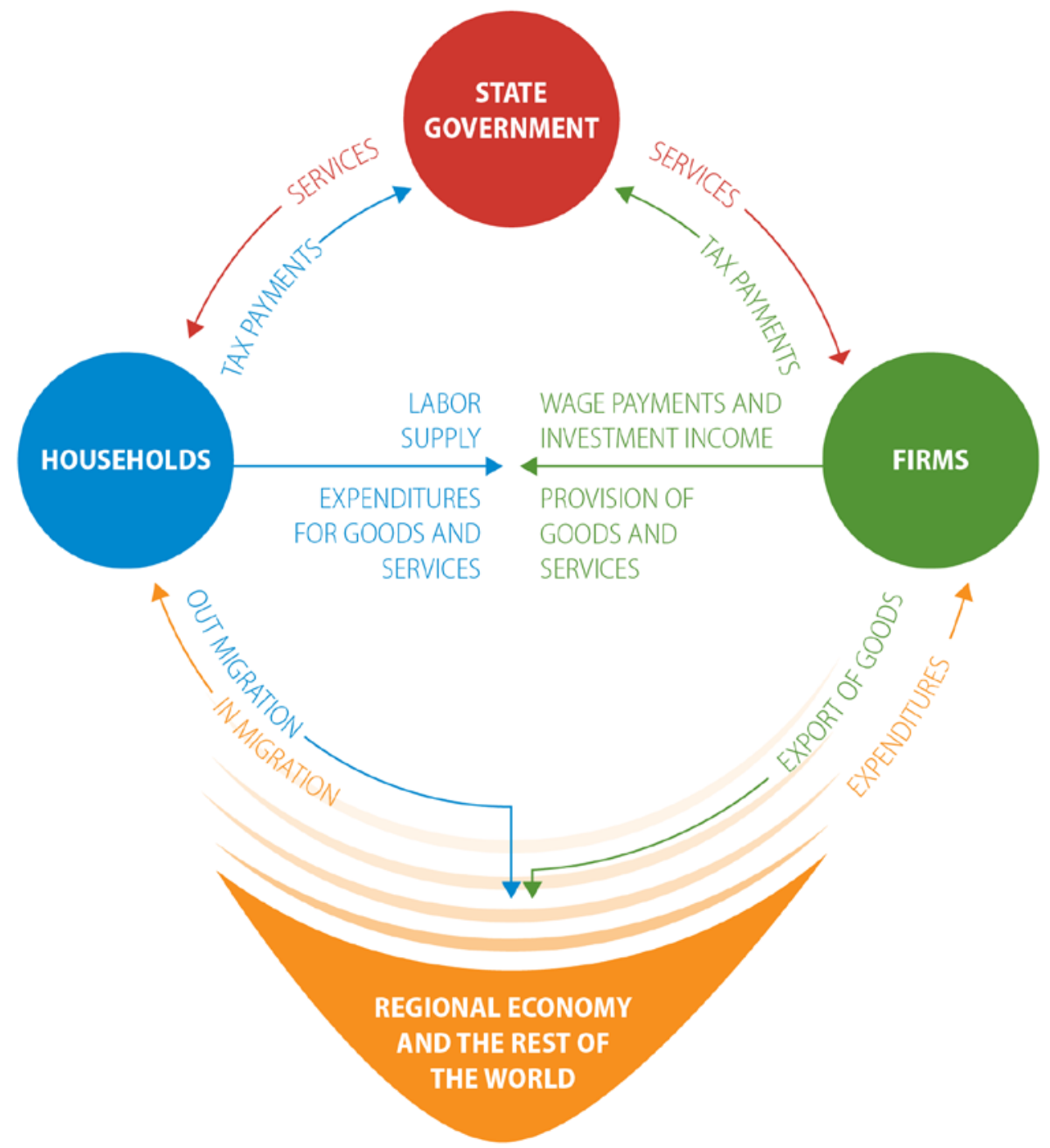

Figure 5-3. Circular flow diagram of a regional economy

\footnotetext{
${ }^{264}$ When quantifying the impact of changes in wages and employment, the model is flexible enough to take into account unemployment in the economy. The base data we have collected identifies the households that have at least one household member that is working and households that do not have a member that is employed. As an example, if NGS lays off one-third of its workforce, unemployment in the county will increase.
} 
The relative responsiveness of sectors to initial changes in the economy has important effects on the total economic impact. Elasticities represent how sensitive sectors are to changes such as prices and wages. For example, if consumer demand for electricity doesn't change much as a result of rate increases, then electricity demand is inelastic. If demand changes substantially, then electricity demand is elastic. Labor supply elasticity is how sensitive workers are (in terms of how much they work or how likely they are to enter the labor market) to changes in wages.

\subsection{Description of Data}

The primary data sources used are the U.S. Census Bureau's American Community Survey Public Use Microdata Sample (ACS-PUMS), the Bureau of Economic Analysis (BEA), and comprehensive annual financial reports (CAFR) from regional governments. ${ }^{265}$ Other data were imported from IMPLAN, a commercial input-output economic impacts model. For consistency checks, we used information provided by Hurlbut et al. (2012). ${ }^{266}$

The ACS-PUMS data are based on a household survey and describes the distribution of household income and wages paid by various economic sectors. These data also provide information on household size, occupation, and other demographic data. We use these data to quantify the number of households, number of workers within households, and both worker and household income. Data for households and workers are divided by income level. Because this analysis focuses heavily on impacts within tribal land, households are also divided into Native American and non-Native American (Table 5-1 through Table 5-6).

The BEA data provide sector employment, population, and other variables at the county or state level. County-level IMPLAN social accounting data is used to model industry transactions, capital purchases, and household expenditures. Transactions data show the flow of money between businesses through sales and purchases. Capital income (or gross operating surplus) represents industry-level returns on investment, including profits, corporate income, and property income. Household expenditures, also known as personal consumption expenditures, show how much consumers buy from each industry in the model. Included in these data are the transfers that the state makes to various levels of education as well as other sectors in the state economy.

These data are also used to construct the level and distribution of workers for each sector in the economy. Table 5-7 shows the distribution by commercial industry. We have divided sectors

\footnotetext{
${ }^{265}$ See Apache County, Arizona, Annual Adopted Budget Fiscal Year 2013 (St. Johns, AZ: Apache County Board of Supervisors, 2012, http://www.co.apache.az.us/wp-content/uploads/2015/08/2013-GFOA-Submitted-Bdgt.pdf; Coconino County, Arizona, Comprehensive Annual Financial Report Fiscal Year Ended June 30, 2013 (Flagstaff: Coconino County Manager's Office, 2014), http://www.azauditor.gov/sites/default/files/Coconino_County 06_30 13_CAFR.pdf; Navajo County, Arizona, Comprehensive Annual Financial Report Fiscal Year Ended June 30, 2013 (Holbrook, AZ: Navajo County Finance Office, 2014), http://www.navajocountyaz.gov/Portals/0/Departments/Finance/Documents/CAFRReports/2013CAFRFinal.pdf; State of Arizona, Comprehensive Annual Financial Report for the Fiscal Year Ended June 30, 2013 (Phoenix: Arizona Department of Administration General Accounting Office, 2014), http://www.azauditor.gov/sites/default/files/State_Of_Arizona_June30,2013_CAFR.pdf.

${ }^{266}$ Hurlbut et al., Navajo Generating Station and Air Visibility Regulations.
} 
into services, retail, construction, etc. in order to represent the sectoral composition of the economy. Wages paid to workers are grouped into five wage categories, shown in Table 5-8.

Table 5-7. Commercial Industries Included in the Models

\begin{tabular}{|l|l|}
\hline \multicolumn{2}{|c|}{ Commercial Industries } \\
\hline Services & Manufacturing \\
\hline Agriculture & Ambulatory Health Services \\
\hline Forestry and Fisheries & Hospitals \\
\hline Navajo Generating Station & Nursing Homes \\
\hline Utilities (Excluding NGS, Wind, and Solar) & Education and Social Assistance \\
\hline Water & Mining \\
\hline Retail & Wind \\
\hline Construction & Solar \\
\hline Wholesale and Trade & Accommodation and Food Services \\
\hline
\end{tabular}

Table 5-8. Income Groups Included in the Models

\begin{tabular}{|c|}
\hline Labor $(\mathrm{L})$ Wage and Income Groups \\
\hline $\mathrm{L} 1 \leq \$ 10,000$ \\
\hline$\$ 20,000<\mathrm{L} 2 \leq \$ 45,000$ \\
\hline$\$ 45,000<\mathrm{L} 3 \leq \$ 70,000$ \\
\hline$\$ 70,000<\mathrm{L} 4 \leq \$ 100,000$ \\
\hline$\$ 100,000<\mathrm{L} 5$ \\
\hline
\end{tabular}

Table 5-9. Local Government Functions Included in the Models

\begin{tabular}{|l|l|}
\hline \multicolumn{2}{|c|}{ Local Government } \\
\hline Services (Education, Health, Administration) & Local Taxes (Sales, Property, Other) \\
\hline
\end{tabular}

Table 5-9 shows the local government functions represented in the models. State and county government revenue for taxes (sales, income, property, other) and expenditures come from CAFRs for the State of Arizona, Coconino County, and Navajo County. Apache County data were obtained from its Fiscal Year 2013 budget. Additional financial data for Navajo and Hopi Nations were compiled from a variety of internet sources (see list of references for this chapter). These documents provide information about employment and wages, nonlabor expenditures for different government services (education, health, and administration). 


\subsection{Setting Up the Simulations}

In this analysis we simulated the impacts of shutting down one of three 750-MW generators at NGS. To approximate this, we initially reduced NGS employment by one-third (182 workers). The Navajo Nation government would also lose approximately one-third of the lease payments and other transfers from NGS. Lease payments and other transfers total approximately $\$ 43$ million annually, $\$ 12.9$ million of which is assumed to be lost due to reduced NGS operation.

To initiate our simulation we did two things. First, to examine the impacts of lowering facility needs, we reduced the available capital stock for NGS (KS0 in equation 20 in the Appendix). Second, to simulate the loss in revenue due to reduced electricity production, we reduced the amount of exports sold by NGS (PW0 in equation 13 in the Appendix) by one-third. These adjustments to KS0 and PW0 replicate a 182 worker decline at NGS. ${ }^{267}$

Because maintenance is an important aspect of ongoing NGS operations, we also model the impacts of reducing these needs. Typically, each unit is on a six-year cycle for minor and major maintenance operations, scheduled so that in any given year only one unit has an outage due to maintenance. Table 5-10 presents the duration, number of workers, and associated expenses of each type of maintenance.

Table 5-10. Maintenance Costs for NGS ${ }^{268}$

\begin{tabular}{|l|c|c|}
\hline & $\begin{array}{c}\text { Minor } \\
\text { Maintenance }\end{array}$ & Major Maintenance \\
\hline Duration & $\sim 4$ wks & $\sim 8$ wks \\
\hline Workers & & \\
\hline Contractor + NGS Temp & 756 & 724 \\
\hline Expenses & & \\
\hline Contractor Services \& Payroll & $\$ 9,291,000$ & $\$ 24,471,000$ \\
\hline $\begin{array}{l}\text { Purchases Equipment \& } \\
\text { Materials }\end{array}$ & $\$ 3,374,000$ & $\$ 8,925,000$ \\
\hline Other & $\$ 2,873,000$ & $\$ 6,197,000$ \\
\hline \hline Total Cost & $\$ 15,538,000$ & $\$ \mathbf{3 9 , 5 9 3 , 0 0 0}$ \\
\hline
\end{tabular}

${ }^{267}$ The reasoning behind reducing both the capital stock and exports is as follows: When an export sector experiences a reduction in capacity, the economy is impacted from two different perspectives. In the case of NGS, eliminating one of the three 750-MW coal-fired generating units reduces the amount of productive capital in the county economy. This results in a loss of capital income, which impacts household income in the county. A second factor is that there is a reduction in electricity sales (exports), resulting in less income flowing into Coconino County. Both of the capital and export effects are propagated through the economy in different ways, and it is important to model both factors to obtain a realistic description of the effects on the economy. ${ }^{268}$ U.S. Bureau of Reclamation, NGS-Kayenta Mine Complex Project Draft EIS. 
Deriving maintenance impacts involves a series of assumptions. First, we assume that maintenance costs are evenly spread across the three generators. To estimate the impacts of shutting down one, we begin by multiplying each of the lines in the table by one-third.

In practice, NGS maintenance operations are typically performed by a contracting national company. Accordingly, many of the workers and associated purchases are based outside of Arizona, so estimating the economic impacts of maintenance operations needs to account for substantial worker remittances and other leakages.

Labor is the dominant expenditure item in maintenance operations. Following estimates used in the draft EIS for NGS, we assume that $15 \%$ of the labor force is locally based. ${ }^{269}$ For these workers, all wages earned by performing maintenance at NGS are assumed to stay in the local community spent according to the "typical" spending patterns of households with similar income levels. The remaining workers are assumed to permanently live outside of Coconino County and spend much of their money somewhere else (e.g., housing, car payments, insurance). Building on survey data collected for other itinerant workers, we assume that $30 \%$ of the income earned by the migrant workforce is spent locally, and $70 \%$ is spent outside the region. We allocate the local expenditures such that $70 \%$ is spent on accommodations and $30 \%$ is spent on retail (including food). Therefore, with the retirement of one-third of NGS, the loss in expenditures for accommodations is $\$ 994,000$ and for retail is $\$ 426,000$.

The simulation for the Navajo/Apache region further reflects a one-third reduction in Kayenta Mine production, which would result in a loss of 142 related jobs. Similar to the Coconino case, the Navajo/Apache region receives approximately $\$ 51$ million annually from lease payments and other transfers related to Kayenta Mine. Navajo Nation receives \$37 million and Hopi receives $\$ 14$ million of the $\$ 51$ million. Therefore, it is assumed that these payments would be reduced by a third. Similar to Coconino County, the values for KS0 and PW0 are reduced for Kayenta Mine so that 142 jobs are lost.

The third simulation computes the economic impact on the rest of Arizona. In the base data, Coconino and Apache/Navajo counties import goods and services from the rest of Arizona. As these counties contract due to the partial closure of NGS, the imports from the rest of Arizona are reduced. From the state's perspective, these are viewed as exports to the three counties. The simulations for Coconino and Apache/Navajo counties estimate the reduction in imports (equation 15 in the Appendix) and these values are used as the reduction in exports (equation 13 in the Appendix) for the rest of Arizona.

Because the reduction in electricity production would reduce statewide supply, it is important to examine the effects of higher electricity prices. The production cost analysis presented in Chapter 4 indicates that the average per-megawatt-hour cost of electricity generation in Arizona could increase 2\% after shutting down one NGS unit. Assuming wholesale power costs contribute about one-quarter of the total cost represented in retail electricity rates, the

${ }^{269}$ Ibid. 
reduction at NGS could translate into a $0.5 \%$ increase in retail rates across Arizona. This is assumption is added in the CGE models for Arizona. ${ }^{270}$

\subsection{Model Results}

Table 5-11 presents estimated impacts on employment, migration, and tax revenue. Table 5-12 and Table 5-13 show detailed distributional household income impacts for Native American and non-Native American households, respectively. In all regions, reducing NGS generation results in a lower employment, household income, and government revenue. In addition, results show a slightly more out-migration than in-migration for both Native American and non-Native American households.

Modeled migration figures do not indicate a destination; rather, they show the number of households leaving a geographical area of origin. Households leaving Coconino, for example, could relocate elsewhere within Arizona or Navajo/Apache counties.

Table 5-11. Employment, Migration, and State and County Tax Revenue Impacts

\begin{tabular}{|c|c|c|c|c|c|c|}
\hline & \multicolumn{2}{|c|}{ Coconino } & \multicolumn{2}{|c|}{ Navajo/Apache } & \multicolumn{2}{|c|}{ Rest of Arizona } \\
\hline & $\begin{array}{l}\text { Absolute } \\
\text { Change }\end{array}$ & $\begin{array}{l}\text { Percent } \\
\text { Change }\end{array}$ & $\begin{array}{l}\text { Absolute } \\
\text { Change }\end{array}$ & $\begin{array}{l}\text { Percent } \\
\text { Change }\end{array}$ & $\begin{array}{l}\text { Absolute } \\
\text { Change }\end{array}$ & $\begin{array}{l}\text { Percent } \\
\text { Change }\end{array}$ \\
\hline NGS/Kayenta Employment & -182 & $-33.17 \%$ & $-1,412$ & $-33.62 \%$ & & \\
\hline Total Employment & -620 & $-0.77 \%$ & -814 & $-1.18 \%$ & $-2,023$ & $-0.06 \%$ \\
\hline $\begin{array}{l}\text { Total Household Migration } \\
\text { (Native American) }\end{array}$ & -79 & $-0.76 \%$ & -144 & $-0.51 \%$ & -28 & $-0.03 \%$ \\
\hline $\begin{array}{l}\text { Total Household Migration } \\
\text { (Non-Native American) }\end{array}$ & -83 & $-0.03 \%$ & -45 & $-0.18 \%$ & -511 & $-0.02 \%$ \\
\hline $\begin{array}{l}\text { Annual County Tax Revenue } \\
\text { (millions of \$) }\end{array}$ & -1.08 & $-0.56 \%$ & -1.57 & $-1.49 \%$ & & \\
\hline $\begin{array}{l}\text { Annual State Tax Revenue } \\
\text { (millions of \$) }\end{array}$ & -0.72 & $-0.87 \%$ & -9.70 & $-9.89 \%$ & -15.52 & $-0.06 \%$ \\
\hline
\end{tabular}

\footnotetext{
${ }^{270}$ This increase in retail rates is not included for the county CGE models for two reasons. First, a large number of Navajo and Hopi households do not have electricity service and therefore would not be affected by increases in retail electric rates. Second, the utilities that do serve customers in these areas receive most of their power from federal hydropower facilities and not NGS. Average retail rates in Arizona were 10.4 $\varnothing / \mathrm{kWh}$ in 2015. Production cost modeling for scenarios assuming no NGS shutdown indicate average production costs in Arizona are around $2.4 \notin / \mathrm{kWh}$, or about $23 \%$ of retail rates. Increasing $23 \%$ of rates by $2 \%$ results in a total rate impact of about $0.5 \%$.
} 
Table 5-12. Changes in Real Household Income (\$ Millions) for Native Americans

\begin{tabular}{lrrrrrrr}
\hline & \multicolumn{2}{c}{ Coconino } & \multicolumn{2}{c}{ Navajo/Apache } & \multicolumn{2}{c}{ Rest of Arizona } \\
\hline Household Income & $\begin{array}{l}\text { Absolute } \\
\text { Change }\end{array}$ & $\begin{array}{l}\text { Percent } \\
\text { Change }\end{array}$ & $\begin{array}{l}\text { Absolute } \\
\text { Change }\end{array}$ & $\begin{array}{l}\text { Percent } \\
\text { Change }\end{array}$ & $\begin{array}{l}\text { Absolute } \\
\text { Change }\end{array}$ & $\begin{array}{l}\text { Percent } \\
\text { Change }\end{array}$ \\
\hline$\leq \$ 10,000$ & -0.04 & $-0.41 \%$ & -0.22 & $-1.08 \%$ & -0.08 & $-0.09 \%$ \\
$\$ 10,001$ to $\$ 15,000$ & -0.05 & $-0.48 \%$ & -0.15 & $-1.09 \%$ & -0.11 & $-0.09 \%$ \\
$\$ 15,000$ to $\$ 25,000$ & -0.11 & $-0.39 \%$ & -0.93 & $-1.07 \%$ & -0.38 & $-0.09 \%$ \\
$\$ 25,000$ to $\$ 35,000$ & -0.34 & $-0.49 \%$ & -0.82 & $-1.15 \%$ & -0.39 & $-0.09 \%$ \\
$\$ 35,000$ to $\$ 50,000$ & -0.40 & $-0.35 \%$ & -2.09 & $-1.19 \%$ & -0.81 & $-0.10 \%$ \\
$\$ 50,000$ to $\$ 75,000$ & -0.91 & $-0.92 \%$ & -5.22 & $-2.14 \%$ & -0.77 & $-0.10 \%$ \\
$\$ 75,000$ to $\$ 92,000$ & -5.82 & $-5.65 \%$ & -7.48 & $-6.38 \%$ & -0.64 & $-0.11 \%$ \\
$\$ 92,000$ to $\$ 145,000$ & -1.96 & $-4.52 \%$ & -2.18 & $-2.45 \%$ & -0.88 & $-0.17 \%$ \\
$>\$ 145,000$ & -0.14 & $-2.35 \%$ & -2.51 & $-3.57 \%$ & -0.10 & $-0.06 \%$ \\
\hline Total & -9.78 & $-\mathbf{2 . 0 1} \%$ & -21.60 & $-2.43 \%$ & -4.18 & $-\mathbf{0 . 1 1 \%}$ \\
\hline
\end{tabular}

Table 5-13. Changes in Real Household Income (\$ Millions) for Non-Native Americans

\begin{tabular}{lcccc|ccc}
\hline & \multicolumn{2}{c}{ Coconino } & \multicolumn{2}{c}{ Navajo/Apache } & \multicolumn{2}{c}{ Rest of Arizona } \\
\hline Household Income & $\begin{array}{l}\text { Absolute } \\
\text { Change }\end{array}$ & $\begin{array}{l}\text { Percent } \\
\text { Change }\end{array}$ & $\begin{array}{l}\text { Absolute } \\
\text { Change }\end{array}$ & $\begin{array}{l}\text { Percent } \\
\text { Change }\end{array}$ & $\begin{array}{l}\text { Absolute } \\
\text { Change }\end{array}$ & $\begin{array}{l}\text { Percent } \\
\text { Change }\end{array}$ \\
\hline$\leq \$ 10,000$ & -0.04 & $-0.15 \%$ & -0.19 & $-1.25 \%$ & -1.11 & $-0.07 \%$ \\
$\$ 10,001$ to $\$ 15,000$ & -0.09 & $-0.13 \%$ & -0.13 & $-1.15 \%$ & -1.68 & $-0.08 \%$ \\
$\$ 15,000$ to $\$ 25,000$ & -0.15 & $-0.17 \%$ & -0.60 & $-1.14 \%$ & -6.07 & $-0.08 \%$ \\
$\$ 25,000$ to $\$ 35,000$ & -0.28 & $-0.26 \%$ & -0.65 & $-1.09 \%$ & -6.58 & $-0.09 \%$ \\
$\$ 35,000$ to $\$ 50,000$ & -0.51 & $-0.22 \%$ & -1.79 & $-1.05 \%$ & -21.90 & $-0.09 \%$ \\
$\$ 50,000$ to $\$ 75,000$ & -1.66 & $-0.36 \%$ & -3.42 & $-1.10 \%$ & -27.53 & $-0.09 \%$ \\
$\$ 75,000$ to $\$ 92,000$ & -3.10 & $-0.57 \%$ & -1.12 & $-0.68 \%$ & -24.63 & $-0.10 \%$ \\
$\$ 92,000$ to $\$ 145,000$ & -4.04 & $-0.67 \%$ & -3.89 & $-1.11 \%$ & -28.04 & $-0.10 \%$ \\
$>\$ 145,000$ & -1.26 & $-0.46 \%$ & -0.19 & $-0.14 \%$ & -18.45 & $-0.08 \%$ \\
\hline Total & -11.12 & $-\mathbf{0 . 4 6} \%$ & -11.97 & $-\mathbf{0 . 9 5 \%}$ & $-\mathbf{- 1 3 5 . 9 9}$ & $-\mathbf{0 . 0 9 \%}$ \\
\hline
\end{tabular}

\subsubsection{Coconino County}

Modeled employment at NGS eliminates 182 high-wage jobs with a one-unit shutdown. Due to reductions in intermediate input purchases and household income, the modeled results show employment within Coconino County declining by an additional 440 workers.

Overall, the employment losses lead to annual real household income reductions of $\$ 9.78$ million for Native American households and \$11.12 million for non-Native Americans. Reflecting the loss of high-paying jobs at NGS, the largest reductions occur in the groups with 
household income between $\$ 75,000$ and $\$ 145,000$. The decreases in this group, however, are far more significant for Native Americans, reflecting the demographics of those who work at NGS.

Due to the loss of employment opportunities in the county, some households migrate out of the county to find other employment opportunities. Table 5-11 reports that 79 Native American households $(0.76 \%)$ and 83 Other households $(0.03 \%)$ migrate out of Coconino County, or 166 Native American and 185 Other workers. This shows the relatively large impact on Native American households.

Overall, county-level tax revenue decreases by $\$ 1.08$ million and state tax revenue decreases by $\$ 0.72$ million annually. Because of data and modeling limitations, Navajo and Hopi Nation government data are combined in county government information. However, we are able to perform some additional calculations to determine the impact on tribal government revenue. We calculated the ratio of Native American tax revenue collected to real Native American household income and then multiplied that ratio on the losses in real household income reported in Table 5-11. We estimate that the combined Navajo and Hopi governments will lose $\$ 348,198$, which is included in the $\$ 1.08$ million loss for the combined county governments.

\subsubsection{Navajo/Apache Counties}

Model results show the largest employment and income decreases in Navajo and Apache counties. The Kayenta Mine reduces its labor needs by 142 workers, and nearly 700 other jobs are eliminated. Because all mine employees are Native American, all direct losses accrue to this population.

Real annual household income in Navajo and Apache counties drops $\$ 12$ million for nonNative Americans and \$22 million for Native Americans, with incomes between \$75,000 and $\$ 145,000$ losing the largest percentage of income. As with jobs, these income brackets show the largest reductions because incomes of Kayenta Mine employees fall within these brackets.

Navajo and Apache counties stand to lose \$1.6 million in local tax revenue annually while revenue decreases by $\$ 9.7$ million for the State of Arizona. Similar to the Coconino County analysis, the combined Navajo and Hopi governments are expected to lose $\$ 769,026$ - almost half the loss of the combined Navajo and Apache county governments.

\subsubsection{Rest of the State of Arizona}

Economic activity in the State of Arizona (excluding Navajo, Apache, and Coconino counties) declines for two reasons. First, lower economic activity in Coconino, Apache, and Navajo counties reduces the amount of goods and services that people and businesses in these counties purchase from the rest of the state. Second, because state-level electricity prices are estimated to increase $0.05 \%$, households and businesses have less money available to purchase other goods and services.

These two factors result in 2,023 fewer jobs ( $0.06 \%$ of state total). State tax revenue falls by a similar percentage $(0.06 \%)$, or $\$ 15.5$ million annually. Non-Native American household income is estimated to fall by $\$ 136$ million $(0.09 \%)$, while Native American household income falls by $\$ 4.18$ million $(0.11 \%)$. 


\subsection{Summary}

CGE analysis shows shutting down one generating unit at the NGS station results in decreases in employment, household income, and government revenue in all regions. The size of the Arizona economy and labor force makes these changes small at the state level. These impacts, however, are notable at the county level.

Household income decreases are most significant in relatively high-income Native American households. The loses in these three groups are five to ten times larger than for the other household groups in Navajo, Apache, and Coconino counties. This reflects the loss of relatively high-paying jobs at the NGS facility and Kayenta Mine that are held by Native Americans. In Coconino County the decline in household income for all Native American households is just under $2 \%$; it is nearly $2.5 \%$ in Navajo and Apache counties. This is a decrease of nearly $\$ 10$ million and \$22 million, respectively. 


\section{Potential Impact of Extreme Drought on Southwest Power Operations ${ }^{271}$}

One common use of power system modeling is to assess the grid's resilience in the face of extreme contingencies that, while improbable, are not impossible. For example, an often-used standard for loss-of-load expectations is whether the scenario being tested might lead to violating reliability standards one day in ten years. ${ }^{272}$ In a similar manner, this chapter examines the effects of extreme hydrological conditions that are improbable but not impossible. The aim is to set a baseline for evaluating how an NGS transitional glide path might respond in a worst-case climate change scenario.

The Colorado River is one of the most important natural resources in the Southwest. Some 27 million people rely on the river for drinking water and to irrigate 3.5 million acres of farmland in the Basin. ${ }^{273}$ The river's hydroelectric dams typically provide around $10 \mathrm{TWh}$ of electricity annually, with three-quarters coming from Hoover Dam and Glen Canyon Dam.

Climate change and the potential for extended drought in the West could affect future flows of the Colorado River, thereby affecting hydroelectric production at Hoover Dam and Glen Canyon Dam. This in turn could affect power system operations throughout the Southwest. Accounting for extended drought contingencies is therefore an important aspect of evaluating the efficacy of NGS glide paths. The analysis in this chapter models the potential effect of extreme drought on power system operations, then tests three potential NGS glide path models to measure the extent to which those options might mitigate some of the impacts.

Drought and above-average temperatures will have several effects on electricity production, not all of which are modeled here. Water shortages will likely increase the economic competition for water from all sources, which could increase the cost of cooling a thermal plant. High ambient temperatures that often accompany drought can also degrade the operational efficiency of thermal plants. To simplify the analysis, we assume that these two effects would not change dispatch patterns as significantly as reduced hydroelectric production would.

Representing hydroelectric facilities in power system modeling is difficult. Managing a reservoir requires meeting water-related requirements that do not easily translate into inputs for modeling the production of electricity. Consequently, assuming that a hydroelectric dam's dispatch can be optimized every hour for the entire year like conventional thermal generators (taking into account nothing but generator costs, electric load, line constraints, and marginal costs on the electric grid) often results in modeled results that do not match actual production.

${ }^{271}$ This chapter was prepared by Dominique Bain, doctoral candidate in Earth Sciences and Environmental Sustainability at Northern Arizona University (NAU), and Tom Acker, professor of Mechanical Engineering at NAU. Ignacio Losada Carreno and Roberto Puente Aranda, NAU undergraduate students in Mechanical Engineering, assisted with mapping and data visualization. The authors are grateful to the U.S. Bureau of Reclamation and its Colorado River Basin hydrologists for their comments on this chapter.

${ }^{272}$ North American Electric Reliability Corporation (NERC), Methods to Model and Calculate Capacity Contributions of Variable Generation for Resource Adequacy Planning (Princeton, N.J.: NERC, 2011).

${ }^{273}$ Bureau of Reclamation, Colorado River Interim Guidelines for Lower Basin Shortages and the Coordinated Operations for Lake Powell and Lake Mead (Washington, D.C.: U.S. Bureau of Reclamation, December 2007). 
While modeling is never perfect, its results can often be made more useful. The analysis reported in this chapter represents a rigorous attempt to model hydroelectric generation in the Colorado River Basin with detailed attention to basin hydrology and water management rules. It begins with hydrological modeling conducted by the U.S. Bureau of Reclamation, which manages federal water resources. The aim is to understand what different climatological conditions might mean for in-stream flows into Lake Powell and Lake Mead, and to translate water availability into electric generation capability. The chapter focuses on scenarios that represent normal hydrological conditions, historical drought, and extreme drought.

Next, the analysis applies the adjusted hydroelectric operating profiles to standard production cost modeling for the Western Electric Coordinating Council (WECC) planning area, which includes the entire Western Interconnection. Modeling assumptions are identical to those used by WECC's Transmission Expansion Planning and Policy Committee (TEPPC). The purpose of this part of the analysis is to establish a baseline: measure the magnitude of drought's potential impact on power system operations if nothing else were to change.

The last part of the chapter constructs three potential NGS glide paths for testing. Each glide path is a conceptual bundle of new generation capacity that could be added to replace some of the electricity currently provided by NGS. The analysis tests each glide path against the baseline (results from the baseline used by TEPPC in its modeling of the western grid) to determine whether a particular glide path provides any additional cushion against the potential impact of extended drought in the Southwest.

\subsection{River Management}

The Colorado River Basin covers portions of seven states: California, Arizona, Nevada, Wyoming, Colorado, New Mexico, and Utah, as shown in Figure 6-1. The U.S. Bureau of Reclamation is responsible for managing Colorado River flow and reservoir storage. The Bureau of Reclamation divides the Basin into two administrative zones: the Upper Basin and the Lower Basin. On the river, the two basins are separated at Lee Ferry in northern Arizona.

Inflow to Lake Powell was below average in 12 of the last 15 water years from 2000 through $2014 .^{274}$ This was the driest 15-year period for the region in over 100 years of record-keeping. The inflows for Lake Powell and the storage and percent capacity for Lakes Powell and Mead are shown in Figure 6-2.

\footnotetext{
${ }^{274}$ Bureau of Reclamation, Colorado River Basin: System Status Update (presented at Colorado River Citizens Forum, El Centro, CA, December 17, 2014), http://www.ibwc.gov/Files/CF_CO_Reclamation_Basin_Update_121714.pdf. Water years run from October 1 through September 30.
} 


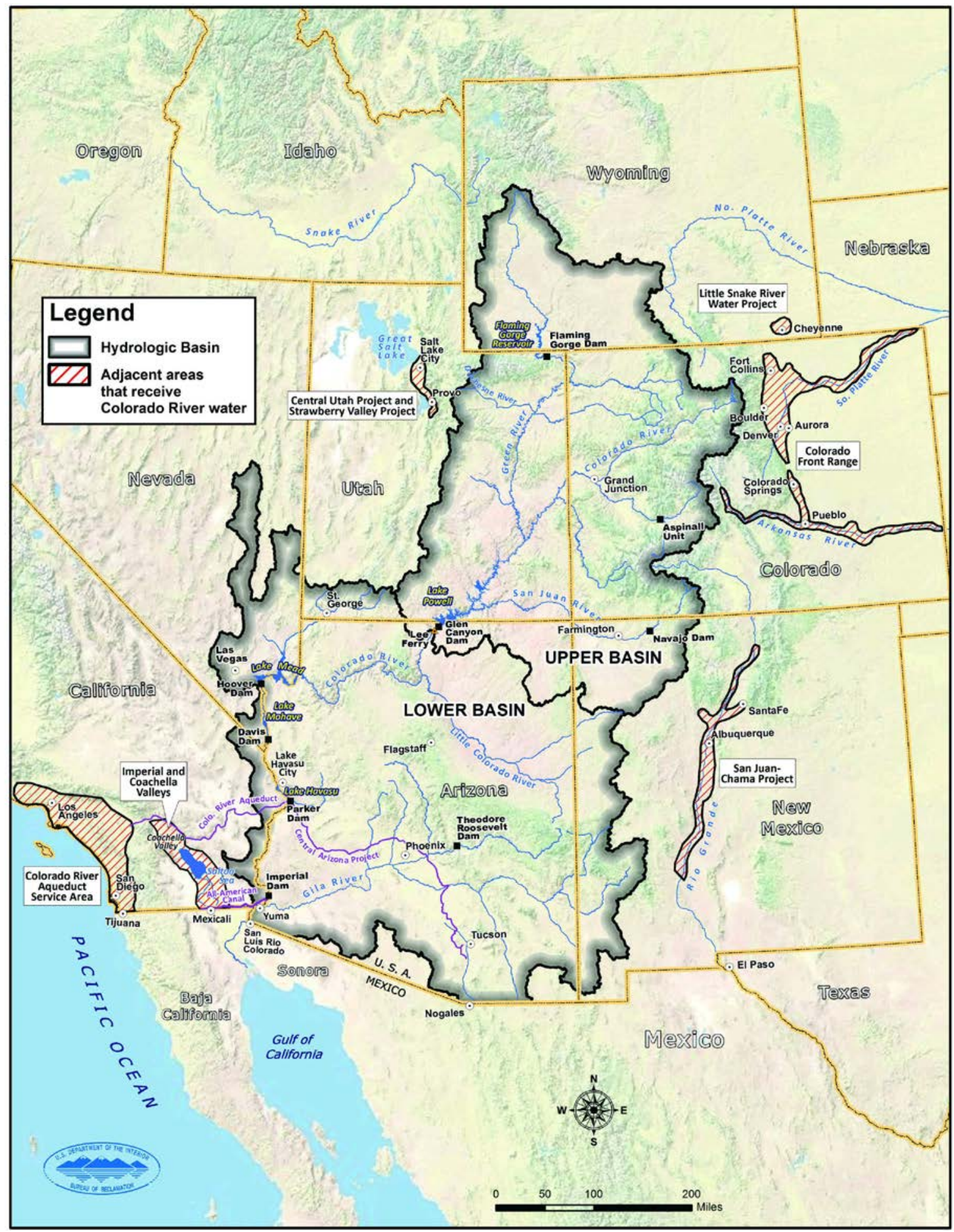

Figure 6-1. The Colorado River Basin, major dams in the river basin, and major projects ${ }^{275}$

${ }^{275}$ Ibid. 


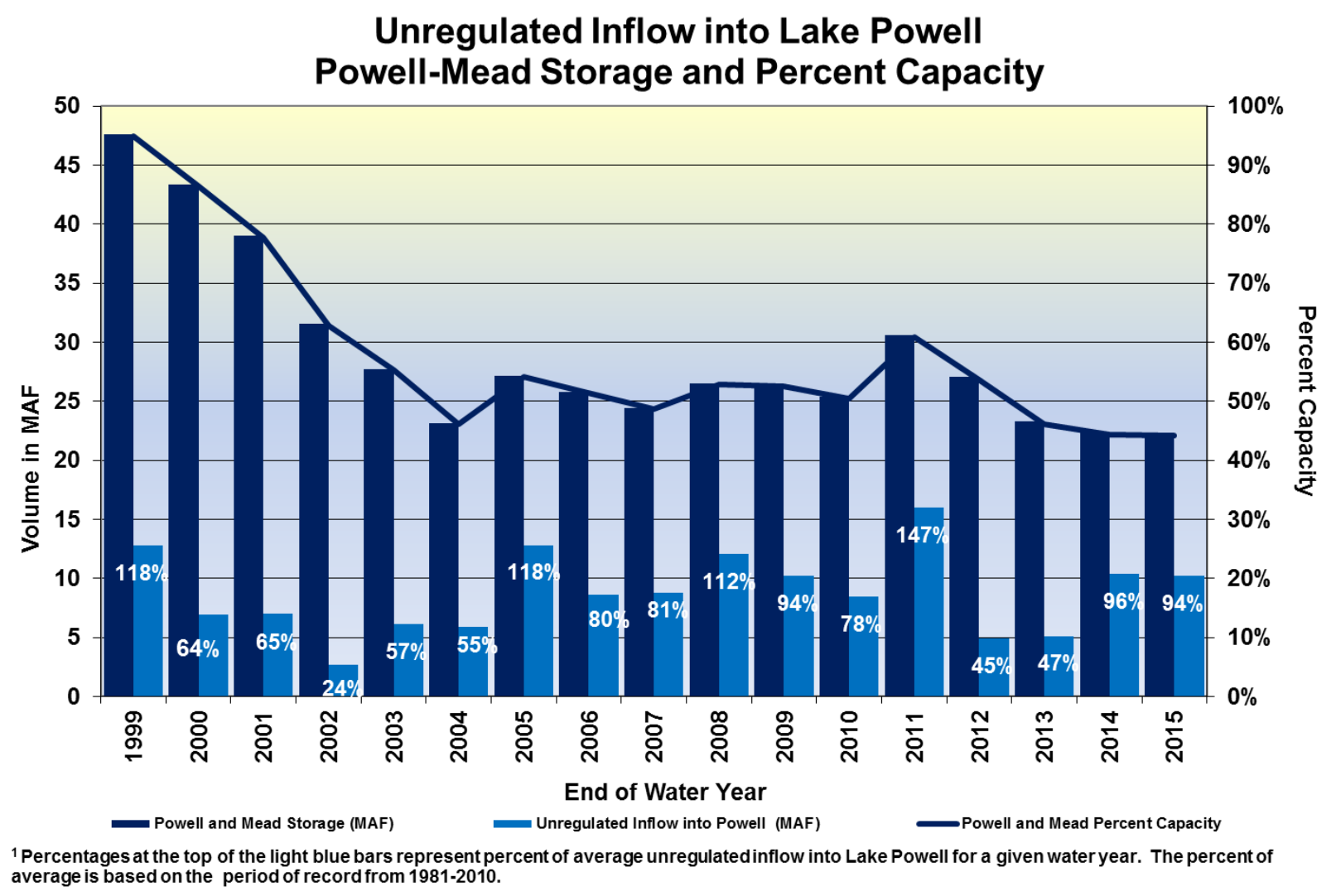

Figure 6-2. Unregulated inflow into Lake Powell, Powell-Mead storage, and percent capacity 276

In 2005, the Department of the Interior started a public process to develop additional operational guidelines and tools to meet the challenges of the first five years of the drought in the Basin. ${ }^{277}$ The new guidelines categorize water supply as normal, surplus, or shortage. The normal condition occurs when "sufficient mainstream water is available to satisfy 7.5 million acre-feet (maf) of annual consumptive use in the Lower Division states." The surplus condition exists when there is water in excess of 7.5 maf annually. A shortage condition exists when "the Secretary determines that insufficient mainstream water is available to satisfy 7.5 maf of annual consumptive use in the Lower Division States." 278 To date, flow conditions have not necessitated determination of a shortage condition. However, drought conditions have decreased the reservoir storage behind dams in the Colorado River Basin from 55.8 maf to 32.1 maf between October 1, 1999 and September 30, 2007.

"Coordinated operations" refer to releases from Lake Powell, which depend primarily on Lake Powell elevation, and secondarily on Lake Mead elevation during balancing release scenarios. Coordination of water releases from Lake Powell primarily depends on the elevation of Lake Powell, but also the elevation of Lake Mead. Table 6-1 outlines the elevation of Lake Powell and the releases based on Lake Mead's elevation. It also identifies the live storage of Lake

\footnotetext{
276 Ibid.

${ }^{277}$ Bureau of Reclamation, Colorado River Interim Guidelines, 5.

278 Ibid.
} 
Powell at different elevations. Live storage, or active storage, refers to the water that can be released through the dam without a pump. In contrast, dead storage, or inactive storage, refers to the water that cannot be drained by gravity. Table 6-2 outlines the elevations of Lake Mead, how those corresponded to water deliveries by state, and the live storage associated with that elevation. The determination of a normal, surplus, or shortage condition in the Lower Basin (and the resulting releases from Lake Mead) depends exclusively on Lake Mead elevation.

Table 6-1. Operations for Lake Powell under Interim Guidelines ${ }^{279}$

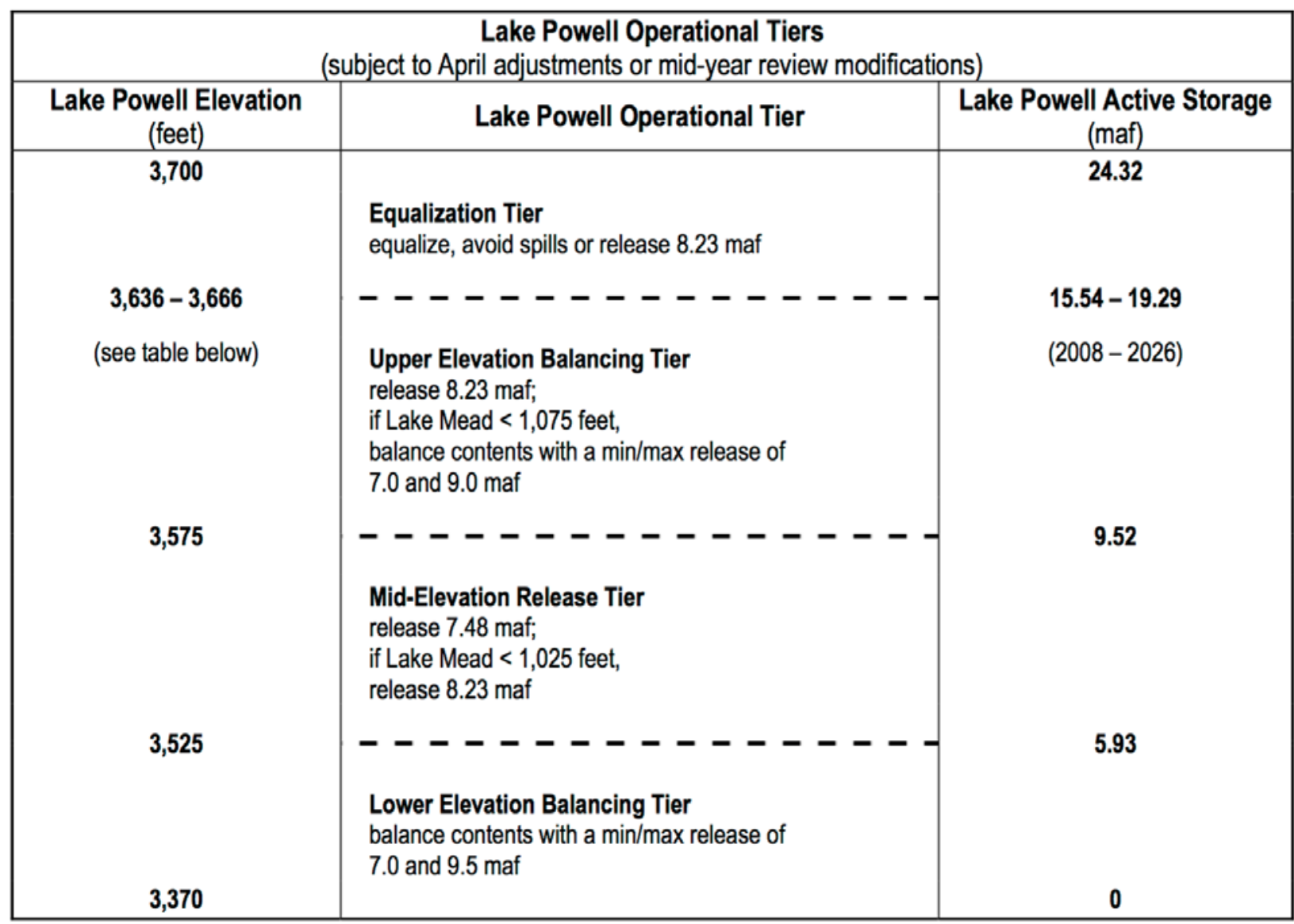

${ }^{279}$ Ibid, 50. 
Table 6-2. Lake Mead under Interim Guidelines ${ }^{280}$

\begin{tabular}{|c|c|}
\hline Elevation (ft) & Condition and Operation According to the Interim Guidelines \\
\hline At or above 1,145 & Domestic Surplus \\
\hline \multirow[t]{2}{*}{1,075 to 1,145} & Normal Conditions \\
\hline & Shortage Conditions \\
\hline 1,075 to 1,050 & $\begin{array}{l}\text { Deliver } 7.167 \text { maf } \\
\text { ( } 2.48 \text { maf to Arizona, } 0.287 \text { maf to Nevada, } 4.4 \text { maf to California) }\end{array}$ \\
\hline 1,050 to 1,025 & $\begin{array}{l}\text { Deliver } 7.083 \text { maf } \\
\text { (2.4 maf to Arizona, } 0.283 \text { to Nevada, } 4.4 \text { maf to California) }\end{array}$ \\
\hline below 1,025 & $\begin{array}{l}\text { Deliver } 7.0 \text { maf } \\
\text { ( } 2.32 \text { maf to Arizona, } 0.28 \text { to Nevada, } 4.4 \text { maf to California) } \\
\text { Further measures may be undertaken in consultation with Basin States }\end{array}$ \\
\hline
\end{tabular}

Based on the projections of January 1, 2016 system conditions in the August 2015 24-Month Study, Lake Powell operated in the Upper Elevation Balancing Tier in water year 2016 and Lake Mead operated in the Normal/ICS Condition in calendar year $2016 .{ }^{281}$ These operational tier determinations are described and memorialized in the 2016 Annual Operating Plan for Colorado River Reservoirs (AOP)." 282

\subsection{Future Water Supplies}

For this study, U.S. Bureau of Reclamation hydrologists provided modeling results used by the agency for Colorado River Basin water management and long-term planning. ${ }^{283}$ The Bureau of Reclamation uses the Colorado River Simulation System (CRSS) as its primary long-term water-planning tool. CRSS is a computer program that simulates the operation of the major reservoirs on the Colorado River, providing information about the projected future state of the system. ${ }^{284}$

As part of its output, CRSS produces multiple scenarios of future hydrologic and operational conditions which include projected hydropower generation at major dams such as Glen Canyon

\footnotetext{
280 Ibid.

${ }^{281}$ Operational study conducted by the U.S. Bureau of Reclamation to project future reservoir operations. "ICS" is intentionally created surplus. Study available online at www.usbr.gov/lc/region/g4000/24mo/index.html.

282 The AOP is available at http://www.usbr.gov/lc/region/g4000/aop/AOP16.pdf.

${ }^{283}$ Rick Clayton, Bureau of Reclamation hydrologist, various personal communications. The authors are grateful for his invaluable assistance throughout this study.

${ }^{284}$ More information about CRSS is available at

http://www.usbr.gov/lc/region/programs/strategies/FEIS/AppA.pdf.
} 
and Hoover power plants. Each scenario represents a monthly time-series of possible future water conditions from 2012 through 2060, an example of which is shown in Figure 6-3.

\subsubsection{Hydro Data}

The CRSS model provided about 100 scenarios (or "traces") for a set of constraints. The inputs include water supply assumptions and guidelines for dam operations. The CRSS model results captured two sets of water supply assumptions: Direct Natural Flow and Variable Infiltration Capacity. The first assumption set is based on natural flow, representing the flow that would have occurred at the location had depletions and reservoir regulation not been present upstream of that location. ${ }^{285}$ The Variable Infiltration Capacity (VIC) Macroscale Hydrologic Model takes climate change into account. ${ }^{286}$ For both water supply assumptions, the operational criteria described in the 2007 Interim Guidelines developed were applied throughout the period modeled. ${ }^{287}$ The outputs covered the years 2016-2050, although this study focused on the year 2030. This is consistent with the modeling time periods used elsewhere in this report.

The first step in selecting indicative hydrology scenarios was to rank all the traces by inflow into Lake Powell, which we assume to be a reasonable proxy for overall water supply in the Colorado River Basin. The ranks of interest were those close to the $10^{\text {th }}$ and $50^{\text {th }}$ percentiles. The next step was to look at the projected elevations of Lake Mead and Lake Powell in the clusters of traces around these two levels of inflow. The goal was to select three scenarios from among these clusters that matched the red circles in Figure 6-3 reasonably well. Each circle focuses on one particular result from a trace: Lake Mead elevation behind Hoover Dam. The uppermost of these three circles encloses a cluster of traces in which the Lake Mead elevation ranges from normal operation to a Tier 1 shortage condition. The middle circle corresponds to a Tier 2 shortage condition (Mead elevation between 1,025 ft and 1,050 ft). The lowest of the three circles indicate a Mead elevation between 900 and $920 \mathrm{ft}$. This level is below the Tier 3 shortage condition - $1,025 \mathrm{ft}$ - indicated by the black dashed line. Looking forward in time from the lowest circle shows that the Lake Mead elevation does not continue to decrease much through 2060, so this case can appropriately represent an extreme drought scenario.

\footnotetext{
${ }^{285}$ Reclamation's natural flow dataset is available at http://www.usbr.gov/lc/region/g4000/NaturalFlow/index.html.

${ }^{286}$ Information on the VIC model is at http://www.hydro.washington.edu/Lettenmaier/Models/VIC/Overview/ModelOverview.shtml.

${ }^{287}$ Bureau of Reclamation, Colorado River Interim Guidelines.
} 


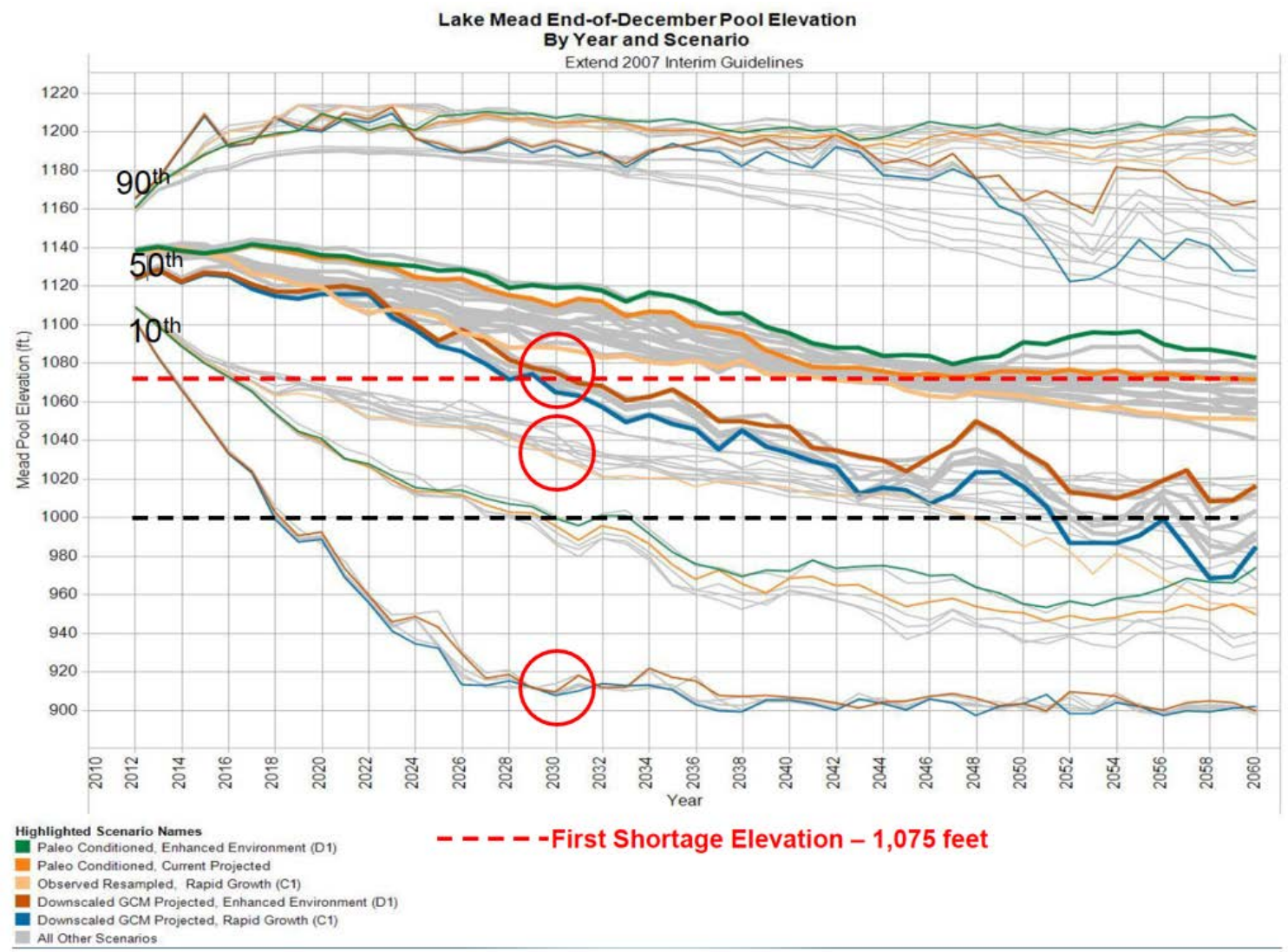

Figure 6-3. CRSS projections of Lake Mead future pool elevations

Table 6-3 and Table 6-4 show the traces ranked close to the $10^{\text {th }}$ and $50^{\text {th }}$ percentiles for the Variable Infiltration Capacity assumption and Direct Natural Flow assumption runs in CRSS. The tables also show Lake Powell and Lake Mead pool elevations. The runs highlighted in the tables are the scenarios selected to provide detailed inputs for modeling extreme drought, moderate drought, and historical conditions in the PLEXOS production cost model. The selected scenarios are assumed to be reasonably representative of the conditions that this modeling aims to test.

Many of the traces shown in Figure 6-3 indicate a continued decline in Lake Mead elevation after 2030. The trends captured in these other scenarios are beyond the scope of the power system impacts that this analysis aims to model. The goal here is not to predict whether or when an extended drought will occur. Rather, the objective is to ascertain extreme contingency conditions in 2030 that are reasonably representative of extreme contingency conditions that could occur in later years instead. Focusing on 2030 provides consistency with the nonhydrological assumptions - such as generator retirements, load growth, and the addition of new generating capacity - used in the power sector modeling described in detail in Chapter 4. 
Table 6-3. Variable Infiltration Capacity CRSS Runs

\begin{tabular}{|c|c|c|c|c|}
\hline Run Number & $\begin{array}{l}\text { Percentage } \\
\text { Rank of Run }\end{array}$ & $\begin{array}{l}\text { Lake Powell } \\
\text { Pool Elevation } \\
\text { (feet) }\end{array}$ & $\begin{array}{l}\text { Lake Mead Pool } \\
\text { Elevation (feet) }\end{array}$ & PLEXOS scenario \\
\hline Run 24 & $8.93 \%$ & 3409.08 & 895.25 & Extreme Drought \\
\hline Run 46 & $9.82 \%$ & 3650.22 & 1163.90 & \\
\hline Run 60 & $10.71 \%$ & 3582.06 & 1051.21 & \\
\hline Run 26 & $49.11 \%$ & 3515.15 & 1030.61 & \\
\hline Run 79 & $50.00 \%$ & 3494.31 & 954.52 & \\
\hline Run 51 & $50.89 \%$ & 3636.81 & 1125.50 & \\
\hline
\end{tabular}

The variable infiltration capacity assumption accounts for climate change.

Table 6-4. Direct Natural Flow CRSS Runs

\begin{tabular}{|c|c|c|c|c|}
\hline Run Number & $\begin{array}{l}\text { Percentage } \\
\text { Rank of Run }\end{array}$ & $\begin{array}{l}\text { Lake Powell } \\
\text { Pool Elevation } \\
\text { (feet) }\end{array}$ & $\begin{array}{l}\text { Lake Mead Pool } \\
\text { Elevation (feet) }\end{array}$ & PLEXOS scenario \\
\hline Run 39 & $9.35 \%$ & $3,588.45$ & $1,053.58$ & Moderate Drought \\
\hline Run 69 & $10.28 \%$ & $3,664.88$ & $1,191.19$ & \\
\hline Run 44 & $11.21 \%$ & $3,444.96$ & $1,009.33$ & \\
\hline Run 10 & $49.53 \%$ & $3,684.25$ & $1,212.29$ & \\
\hline Run 16 & $50.47 \%$ & $3,570.84$ & $1,103.96$ & Historical Hydro \\
\hline Run 95 & $51.40 \%$ & $3,643.13$ & $1,050.13$ & \\
\hline
\end{tabular}

The direct natural flow consumption is based on historical natural flow data.

\subsection{Baseline Production Cost Modeling in PLEXOS}

The selected hydrological traces, highlighted in yellow in Table 6-3 and Table 6-4, were then input into PLEXOS to set up different scenarios. All scenarios were based on TEPPC's 2024 database of production cost modeling input assumptions. They also all had aggregated transmission in BAs throughout the Western Interconnect, with the exception of those in Arizona and surrounding areas (AZPS, SRP, IID, WALC, PNM). See Chapter 4 for a more detailed discussion of the PLEXOS model. 


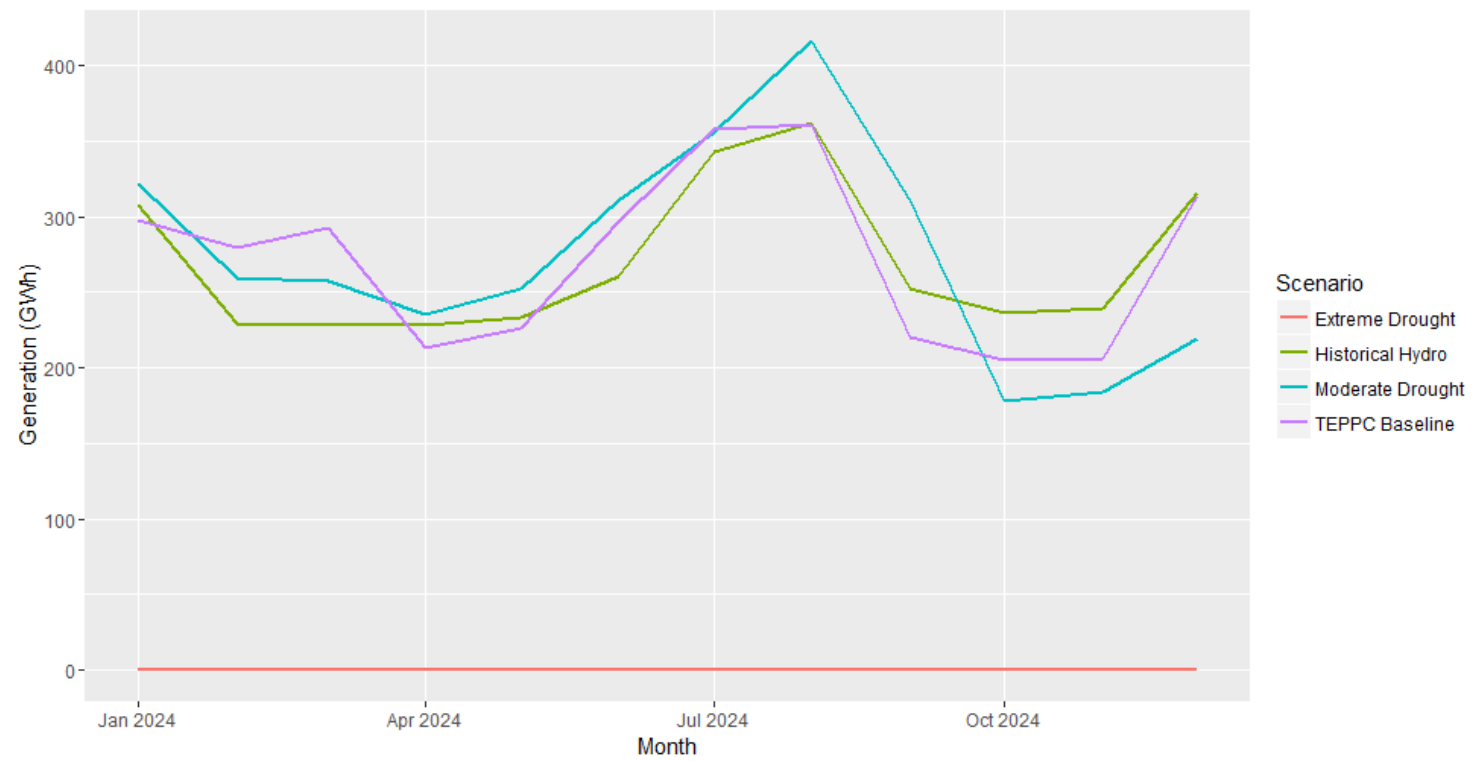

Figure 6-4. Electricity production at Glen Canyon Dam based on selected hydrological scenarios

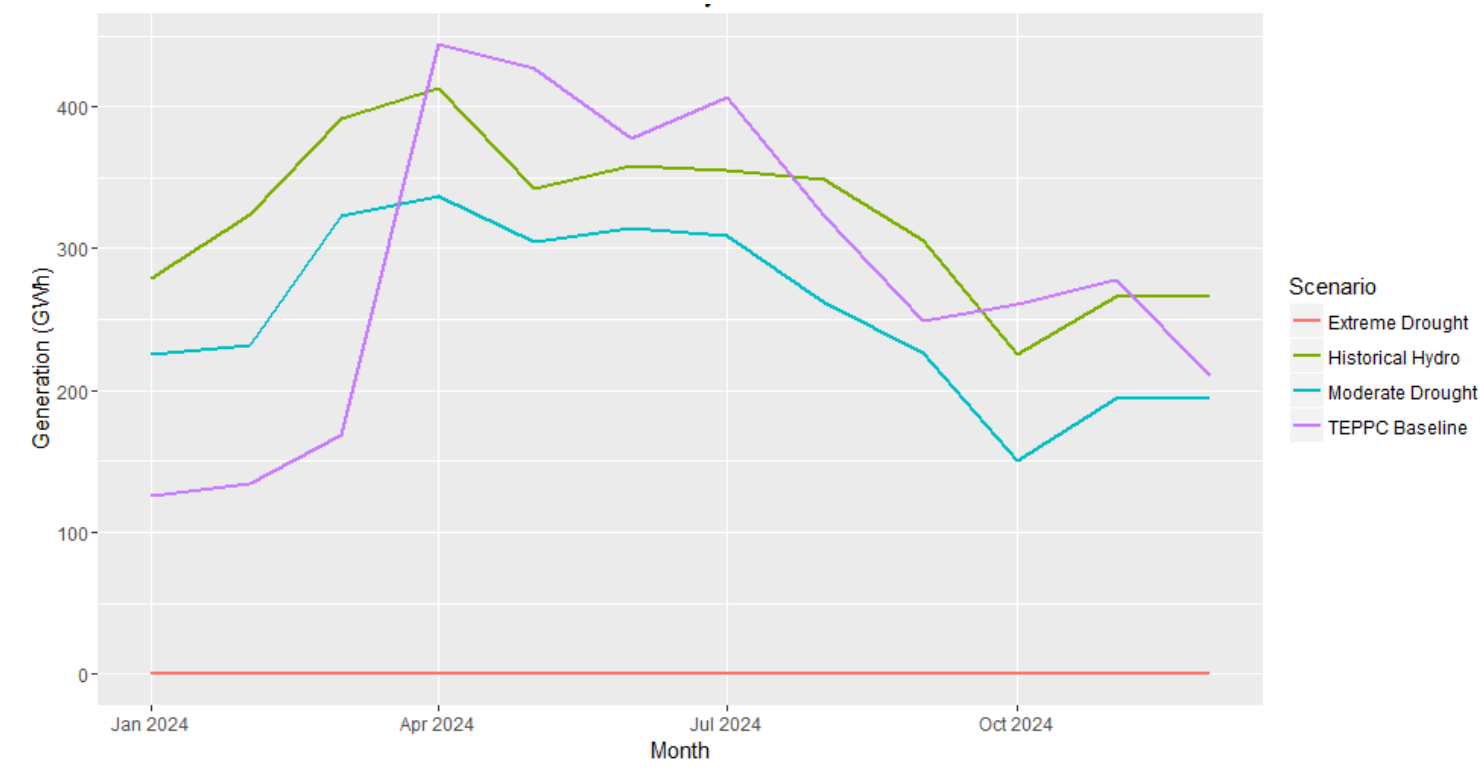

Figure 6-5. Electricity production at Hoover Dam based on selected hydrological scenarios

\subsubsection{Adjustments to Hydropower Production}

The output from the CRSS model includes power generation per month. This information was used in PLEXOS to create the hydro scenarios. For the seven hydroelectric dams on the Colorado River besides Hoover and Glen Canyon, the maximum monthly capacity was changed from their values in the TEPPC database to the $\mathrm{GWh} / \mathrm{month}$ indicated by the CRSS model runs for each dam. ${ }^{288}$

288 The upper basin dams include Blue Mesa, Morrow Point, Crystal, Flaming Gorge, and Fontenelle. The lower basin dams include Parker and Davis. 
Figure 6-4 and Figure 6-5 show the monthly production of hydropower for Glen Canyon Dam and Hoover Dam under the representative traces selected for detailed PLEXOS analysis. The four scenarios have different hydropower production profiles, but the most striking scenario is the one representing extreme drought. Under these hydrological conditions, the CRSS model suggests that reservoir levels at both Lake Mead and Lake Powell would be too low for any electricity production. If this were to happen, Lake Powell and Lake Mead would still release water for water users downstream, but it would not be possible to use the water for electricity generation. Thus, in the Extreme Drought Scenario, the operational ratings for Hoover and Glen Canyon Dams were changed to zero. For the other hydro scenarios, capacity was adjusted in the same manner used for other dams on the river.

\subsubsection{Results}

The results were analyzed using the statistical programing language $\mathrm{R}$. The $\mathrm{R}$ package, rplexos, was utilized first to convert PLEXOS output zip files to SQLite Databases and also used to query the results. The results presented here focus on total generation cost, LMP in Arizona, price duration curves, and capacity factors.

\subsubsection{Total Cost}

Table 6-5 shows the total generation cost for the model run and the percent change when compared to the TEPPC Baseline. The Historical Hydro Scenario has a lower total generation cost than the TEPPC Baseline, presumably because there is more hydropower available in that scenario. The Moderate Drought Scenario has a higher total generation cost compared to the TEPPC Baseline, while the Extreme Drought Scenario with the lowest amount of available hydropower has the highest total generation cost of all the scenarios.

Table 6-5. Total Production Cost for Four Scenarios (all of WECC)

\begin{tabular}{lll}
\hline & $\begin{array}{l}\text { Total Production Cost } \\
\text { (\$ Billions) }\end{array}$ & $\begin{array}{l}\text { Percent Change } \\
\text { Compared to TEPPC }\end{array}$ \\
\hline TEPPC Baseline & 22.24 & \\
\hline Historical Hydro & 22.20 & $-0.2 \%$ \\
\hline Moderate Drought & 22.25 & $0.0 \%$ \\
\hline Extreme Drought & 22.53 & $1.3 \%$ \\
\hline
\end{tabular}

Figure 6-6 shows the TEPPC map for BAs. Table 6-6 shows the production cost by BA for both the TEPPC Baseline Scenario and the Extreme Drought Scenario. It also shows the difference between the two costs and the percent difference in cost. (BAs with less than a 1\% difference in cost are not shown.) While there is a difference in cost between the TEPPC Baseline and the Extreme Drought Scenarios, the costs are spread out over many different BAs across different states including California, Arizona, Nevada, Idaho, and New Mexico. Total cost changes for specific BAs generally reflect two phenomena: changes in the amount of electricity generated inside the BA (that is, generation shifted elsewhere due to system-wide redispatch) and changes in the need to use the BA's more expensive generation resources. The changes can also include the cost of starting units that otherwise would not be used if Hoover and Glen Canyon Dams were available. 


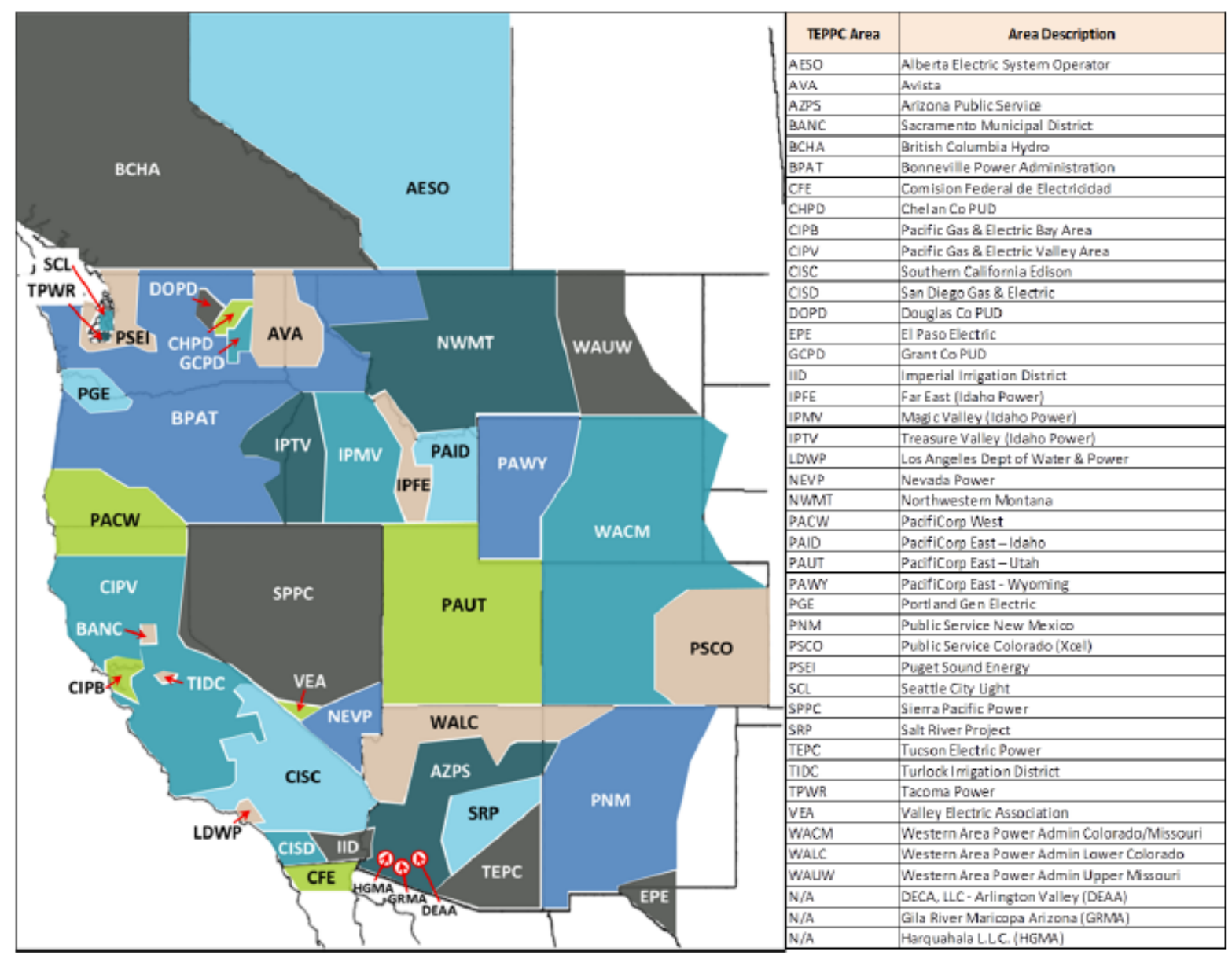

Figure 6-6. TEPPC map for BAs 
Table 6-6. Total Production Cost Differences by BA

\begin{tabular}{lcccc}
\hline $\begin{array}{c}\text { Balancing } \\
\text { Area }\end{array}$ & $\begin{array}{c}\text { TEPPC Baseline } \\
\mathbf{( \$ 0 0 0 )}\end{array}$ & $\begin{array}{c}\text { Extreme Drought } \\
\mathbf{( \$ 0 0 0 )}\end{array}$ & $\begin{array}{c}\text { Difference } \\
\mathbf{( \$ 0 0 0 )}\end{array}$ & $\begin{array}{c}\text { Difference } \\
\mathbf{( \% )}\end{array}$ \\
\hline CISC & $2,274,378$ & $2,298,930$ & 24,552 & $1.1 \%$ \\
\hline CIPV & $2,154,868$ & $2,198,006$ & 43,137 & $2.0 \%$ \\
\hline CIPB & $1,368,080$ & $1,387,886$ & 19,806 & $1.5 \%$ \\
\hline AZPS & $1,293,527$ & $1,308,353$ & 14,826 & $1.1 \%$ \\
\hline SRP & $1,083,499$ & $1,101,792$ & 18,293 & $1.7 \%$ \\
\hline NEVP & 898,692 & 926,023 & 27,331 & $3.0 \%$ \\
\hline CISD & 633,152 & 640,582 & 7,430 & $1.2 \%$ \\
\hline TEPC & 434,117 & 462,445 & 28,328 & $6.5 \%$ \\
\hline PNM & 365,655 & 370,280 & 4,625 & $1.3 \%$ \\
\hline WALC & 351,626 & 366,463 & 14,838 & $4.2 \%$ \\
\hline PGE & 317,436 & 325,272 & 7,836 & $2.5 \%$ \\
\hline EPE & 147,220 & 156,654 & 9,434 & $6.4 \%$ \\
\hline PSEI & 90,834 & 94,864 & 4,030 & $4.4 \%$ \\
\hline AVA & 63,677 & 64,585 & 907 & $1.4 \%$ \\
\hline TIDC & 32,259 & 32,845 & 587 & $1.8 \%$ \\
\hline IPTV & 24,448 & 24,778 & 330 & $1.4 \%$ \\
\hline TPWR & 4,142 & 4,211 & 69 & $1.7 \%$ \\
\hline IPMV & 1,390 & 1,764 & 374 & $26.9 \%$ \\
\hline
\end{tabular}

Note: BAs with less than a $1 \%$ difference in cost are not shown.

\subsubsection{Locational Marginal Prices}

Table 6-7 shows the median and mean LMPs throughout the Western Interconnection. There is little change over the three scenarios except for the Extreme Drought Scenario. Similar to the change in total costs for all of WECC, the percentage difference in average prices from the TEPPC scenario is $1.4 \%$; the median price is $0.9 \%$ higher.

Table 6-7. LMPs for Western Interconnection

\begin{tabular}{lll}
\hline & Median (\$/MWh) & $\begin{array}{l}\text { Mean } \\
\text { (\$/MWh) }\end{array}$ \\
\hline TEPPC & 34.47 & 36.21 \\
\hline Historical Hydro & 34.45 & 36.24 \\
Moderate Drought & 34.48 & 36.37 \\
Extreme Drought & 34.78 & 36.73 \\
\hline
\end{tabular}

Table 6-8 shows the minimum, median, mean, and maximum node prices for Arizona BAs. There is little change over the three scenarios, although as with results for all of WECC, the prices for the Extreme Drought Scenario are slightly higher. Average LMPs in the state 
increase by about $2.1 \%$, and the median price increases by about $1.7 \%$ rate. This suggests that losing Hoover and Glen Canyon Dams affects Arizona differently throughout the year, compared to how the rest of WECC is affected.

Table 6-8. LMPs for Arizona

\begin{tabular}{lll}
\hline & Median & Mean \\
\hline TEPPC & 31.82 & 33.24 \\
Historical Hydro & 31.80 & 33.16 \\
Moderate Drought & 31.83 & 33.32 \\
\hline Extreme Drought & 32.36 & 33.93 \\
\hline
\end{tabular}

The price duration curve for LMPs throughout the 2030 modeling year provides a closer look at how extreme drought might affect Arizona. Figure 6-7 shows the price duration curves for each of the four scenarios. Each curve arranges hourly average LMPs for the year in order of magnitude, without respect to time. To show the main trends more clearly, the handful of hours when LMPs are higher than $\$ 60 / \mathrm{MWh}$ are not shown. ${ }^{289}$ The price duration curves suggest that extreme drought would tend to make already-high prices slightly higher, but would tend to have a negligible effect on low-price hours (generally off-peak demand times).

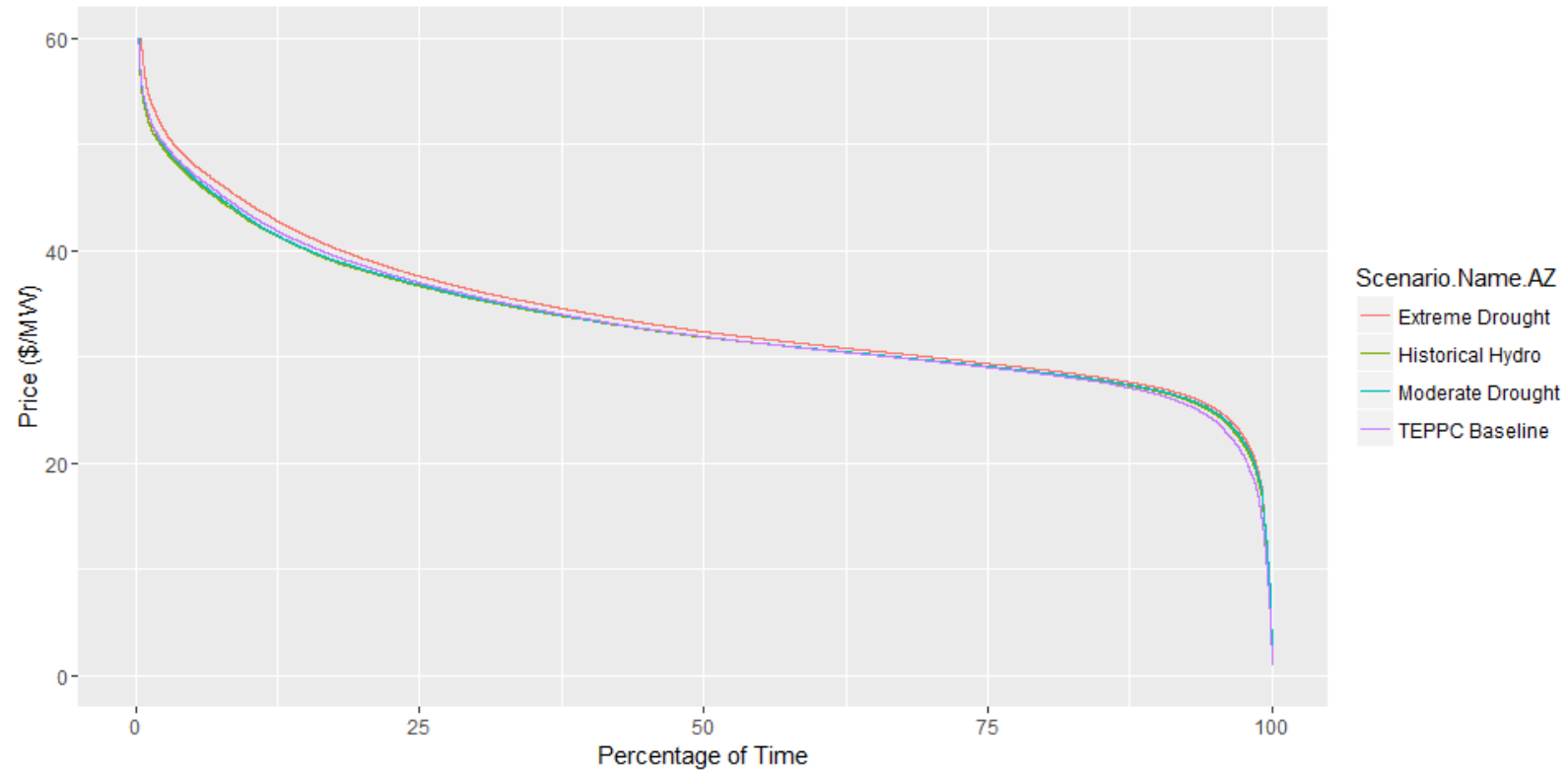

Figure 6-7. Price duration curve for Arizona BAs, excluding hours higher than $\$ 60 / \mathrm{MWh}$

\subsubsection{Capacity Factors}

Table 6-9 shows the capacity factors for NGCC plants, coal plants, and NGCT plants for the three major BAs in Arizona: APS, SRP, and TEP. Capacity factors were calculated by summing all of the generation by category for the year and dividing by the maximum possible

${ }^{289}$ Hours with prices higher than $\$ 60 / \mathrm{MWh}$ made up about $0.3 \%$ of all hours during the year. 
production. The results suggest a tendency to rely more on coal and NGCC generation if Hoover and Glen Canyon Dams were unavailable due to extreme drought. This tendency is especially apparent for TEP. ${ }^{290}$ Recall that in this stage of PLEXOS modeling, no new generation capacity of any kind has been added to the system.

Table 6-9. Capacity Factors by Generation Type

\begin{tabular}{lllll}
\hline Balancing & Coal & NGCC & NGCT \\
\hline \multirow{4}{*}{ APS } & Scenario & & $49 \%$ & $\mathbf{0} \%$ \\
& Extreme Drought & $62 \%$ & $48 \%$ & $0 \%$ \\
& Moderate Drought & $60 \%$ & $48 \%$ & $0 \%$ \\
& Historical Hydro & $60 \%$ & $49 \%$ & $0 \%$ \\
\cline { 2 - 2 } & TEPPC Baseline & $61 \%$ & $44 \%$ & $1 \%$ \\
& Extreme Drought & $68 \%$ & $43 \%$ & $1 \%$ \\
& Moderate Drought & $67 \%$ & $43 \%$ & $1 \%$ \\
& Historical Hydro & $67 \%$ & $44 \%$ & $1 \%$ \\
& TEPPC Baseline & $67 \%$ & $39 \%$ & $2 \%$ \\
\multirow{2}{*}{ TEP } & Extreme Drought & $65 \%$ & $37 \%$ & $2 \%$ \\
& Moderate Drought & $62 \%$ & $37 \%$ & $2 \%$ \\
& Historical Hydro & $61 \%$ & $37 \%$ & $2 \%$ \\
\hline
\end{tabular}

\subsubsection{Drought's Impact on Grid Operations}

PLEXOS results in this section suggest that an extended drought severe enough to eliminate power generation at Hoover and Glen Canyon Dams could increase the cost of producing electricity by $1.3 \%$ to $2.0 \%$ across the West. This is larger than the impact of historical or hydrologically moderate drought, scenarios that differ little in cost from the TEPPC Baseline.

The Extreme Drought Scenario tends to promote greater reliance on Arizona's coal (apart from NGS) and NGCC generators. This is not surprising in this stage of the analysis, when the loss of generation from Hoover and Glen Canyon Dams is not counterbalanced with any new capacity added to the system. This is a key point of comparison between the results in this section and those in the next, which models the effects of glide path scenarios for added capacity in 2030.

\footnotetext{
${ }^{290}$ It would be incorrect to infer from these results that TEP itself loses—or even has—a large direct entitlement from Hoover Dam or Glen Canyon Dam. A production cost model generally does not account for contractual constraints, only physical and reliability constraints. Thus, the higher utilization of coal by TEP under extreme drought is indicative of the replacement power TEP could contribute to aggregated system demand (not necessarily its own demand separately) if Hoover Dam and Glen Canyon Dam were not available. Whether contractual arrangements can or do adjust commensurately is outside the bounds of what PLEXOS has modeled here.
} 


\subsection{NGS Glide Path Scenarios}

The glide path scenarios modeled for drought sensitivity are based on NREL's Resource Planning Model (RPM), described in Chapter 4. RPM is a capacity expansion model customized for a regional power system. It models the need for new generation capacity at 5year intervals based on various assumptions about initial and future grid conditions. Consistent with other analyses in the NGS Phase 2 study, RPM modeling focuses particularly on modeled outcomes for 2030 .

\subsubsection{Selecting Indicative Glide Paths}

NREL performed special simulations with RPM for the purposes of this analysis of extreme drought. The central scenario is consistent with the federal implementation plan for controlling $\mathrm{NO}_{\mathrm{x}}$ emissions at NGS, as described in Chapter 1: one NGS unit retires in 2020. ${ }^{291}$ An accelerated NGS retirement scenario modeled all three units retiring in 2020. A number of conditions were varied in the model to represent possible planning futures, with the purpose of identifying distinct capacity expansion configurations to include in PLEXOS modeling for 2030 .

Table 6-10 provides an overview of the scenarios ultimately modeled in PLEXOS for 2030. RPM added no new capacity for 2030 under the central scenario with no drought, making those conditions essentially unchanged from the TEPPC Baseline scenario. When drought conditions were added, RPM added $700 \mathrm{MW}$ of solar PV. An RPM run with the accelerated retirement scenario, high natural gas prices, and high carbon prices also added $700 \mathrm{MW}$ of solar, as well as 1,500 MW of wind and $250 \mathrm{MW}$ of NGCT capacity. Throughout the various RPM scenarios modeled, high gas and carbon prices favored renewable energy to natural gas.

One scenario was added without RPM modeling. Because NGS plays an important role in the economies of the Navajo Nation and the Hopi Tribe, the analysis includes a special scenario with $750 \mathrm{MW}$ of NGCC capacity, $500 \mathrm{MW}$ of wind, and $500 \mathrm{MW}$ of solar PV located near the $500-\mathrm{kV}$ Moenkopi substation. This scenario is plausible based on site-specific circumstances: proximity to an existing natural gas pipeline, wind resources that are above average for Arizona, and solar resources comparable to the rest of the state's high potential.

291 The federal implementation plan also anticipates installing new $\mathrm{NO}_{\mathrm{x}}$ controls on the remaining two NGS units in 2030, but this is not expected to change the units' operating characteristics as represented in PLEXOS. 
Table 6-10. Four Glide Path Scenarios for Capacity Expansion

\begin{tabular}{|c|c|c|c|c|c|c|c|}
\hline & \multirow{2}{*}{$\begin{array}{l}\text { Retirement } \\
\text { Scenario }\end{array}$} & \multirow{2}{*}{ Price $^{b}$} & \multirow{2}{*}{$\begin{array}{l}\text { Drought } \\
\text { Scenario }\end{array}$} & \multicolumn{4}{|c|}{ Additional Generation (MW) } \\
\hline & & & & Gas & Wind & PV & Total \\
\hline \multirow{2}{*}{$\begin{array}{l}\text { No } \\
\text { additions }\end{array}$} & \multirow{2}{*}{ Central } & \multirow{2}{*}{ Mid } & None & 0 & 0 & 0 & 0 \\
\hline & & & Extreme & 0 & 0 & 0 & 0 \\
\hline \multirow{4}{*}{ Solar ${ }^{\mathrm{a}}$} & \multirow{2}{*}{ Central } & \multirow{2}{*}{ Mid } & None & 0 & 0 & 700 & 700 \\
\hline & & & Extreme & 0 & 0 & 700 & 700 \\
\hline & \multirow{2}{*}{ Accelerated } & \multirow{2}{*}{ Mid } & None & 0 & 0 & 700 & 700 \\
\hline & & & Extreme & 0 & 0 & 700 & 700 \\
\hline \multirow{2}{*}{$\begin{array}{l}\text { Expanded } \\
\text { Wind }^{\mathrm{a}}\end{array}$} & \multirow{2}{*}{ Accelerated } & \multirow{2}{*}{ High } & None & $250^{c}$ & 1,500 & 700 & 2,450 \\
\hline & & & Extreme & $250^{c}$ & 1,500 & 700 & 2,450 \\
\hline \multirow{2}{*}{ Moenkopi } & \multirow{2}{*}{ Accelerated } & \multirow{2}{*}{ Mid } & None & $750^{d}$ & 500 & 500 & 1,750 \\
\hline & & & Extreme & $750^{d}$ & 500 & 500 & 1,750 \\
\hline
\end{tabular}

a Modeled in RPM

b High natural gas prices based on EIA forecasts

${ }^{c}$ Combustion turbine

${ }^{\mathrm{d}}$ Combined cycle

The next step was to select plausible points on the Southwest grid where this new capacity could be located and added to the TEPPC Baseline scenario for modeling. Figure 6-8 shows a map of the major high-voltage transmission in Arizona and some of New Mexico. The points marked with letters (A, B, C, D, and E) are possible connection points for replacement generation. Transmission point A is near Page where Glen Canyon Dam and NGS are located. Transmission point B is near the Moenkopi substation (close to Cameron, Arizona) and located on the Navajo Reservation. Transmission point $\mathrm{C}$ is in the Phoenix metro area, with transmission point $\mathrm{D}$ close to Tucson. Finally, transmission point $\mathrm{E}$ is located in central New Mexico in the heart of a wind-rich resource area. The blue transmission line shown running from point E to the Phoenix metro area is the proposed SunZia transmission line. ${ }^{292}$

Table 6-11 outlines the transmission connections selected for modeling the new generation. Recall that RPM added $700 \mathrm{MW}$ of solar PV when drought conditions were modeled. For PLEXOS modeling, this result is represented by spreading the new generation throughout Arizona. For the Expanded Wind Scenario, a significant amount of the generation is injected at the Moenkopi node (point B), some solar PV in Phoenix and Tucson, and wind in New Mexico. In general, New Mexico has a better wind resource than Arizona, as shown in Figure 6-9. Because the goal of the Moenkopi NGS Replacement Scenario is to keep generation on the Navajo Reservation, all of the replacement generation is added at transmission point B.

${ }^{292}$ See http://www.sunzia.net/. 


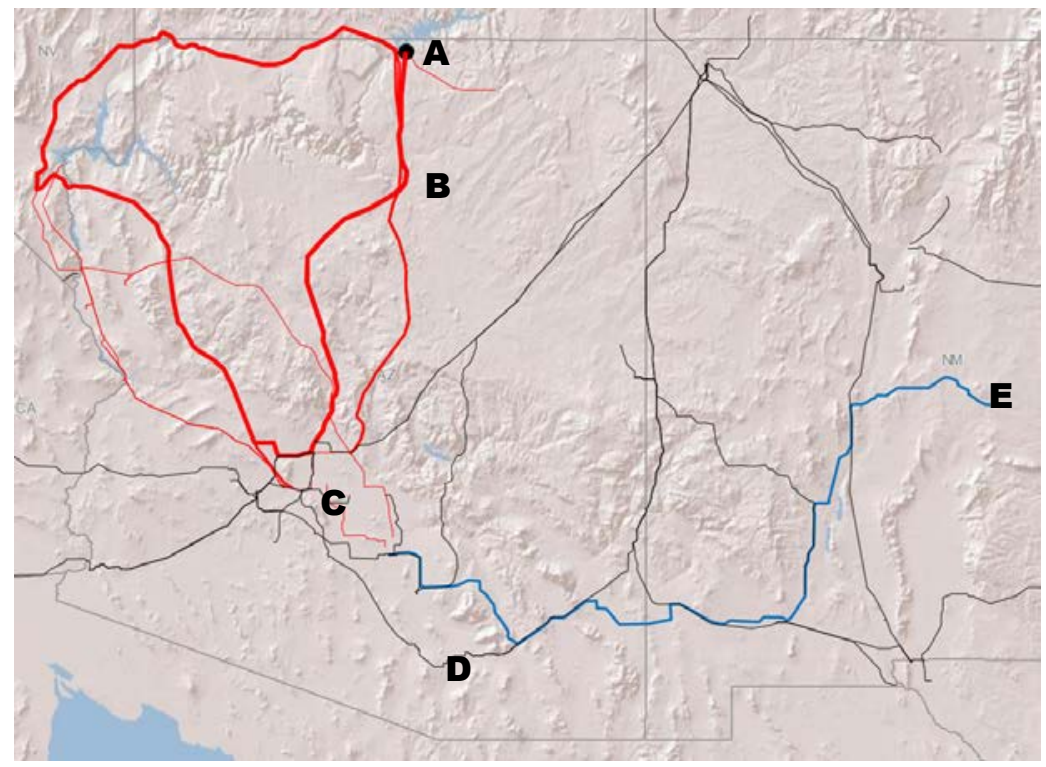

\section{Solar glide path}

700 MW of utility-scale PV spread among points $A, B, C$, and $D$

\section{Expanded wind glide path}

$1,000 \mathrm{MW}$ of wind at point E, 500 MW of wind at point $B$

$700 \mathrm{MW}$ of utility-scale PV spread among points $B, C$, and $D$

$250 \mathrm{MW}$ of natural gas at $\mathrm{B}$

\section{Moenkopi glide path (point B)}

$500 \mathrm{MW}$ of wind

$500 \mathrm{MW}$ of $\mathrm{PV}$

$750 \mathrm{MW}$ of natural gas

Figure 6-8. Transmission map showing proposed transmission connections for replacement generation in the glide path scenarios

Map data: SNL Energy, ESRI. Red lines indicate transmission associated with NGS. Blue line indicates the proposed SunZia transmission project. Black lines indicate all other major transmission.

Table 6-11. The Amount and Type of Replacement Generation Connected at Different Transmission Points Under Three Glide Path Scenarios

\begin{tabular}{llllll}
\hline & Point A & Point B & Point C & Point D & Point E \\
\hline Solar & $250 \mathrm{MW} \mathrm{PV}$ & $250 \mathrm{MW}$ of PV & $100 \mathrm{MW} \mathrm{PV}$ & $100 \mathrm{MW}$ PV & \\
Expanded & $500 \mathrm{MW}$ Wind & & \\
Wind & $500 \mathrm{MW}$ PV & \multirow{2}{*}{$100 \mathrm{MW}$ PV } & \multirow{2}{*}{$100 \mathrm{MW}$ PV } & $\begin{array}{l}1,000 \mathrm{MW} \\
\text { wind }\end{array}$ \\
& $250 \mathrm{MW}$ & & \\
& Natural Gas & & \\
Moenkopi & $500 \mathrm{MW}$ Wind & & \\
& $500 \mathrm{MW}$ PV & & \\
& $750 \mathrm{MW}$ & & \\
& Natural Gas & & \\
\hline
\end{tabular}

\subsubsection{Wind Data}

Wind data were selected for two sites: near Cameron, Arizona, representing the Moenkopi glide path; and the eastern terminus of the SunZia line southeast of Albuquerque, New Mexico, representing the expanded wind glide path.

The wind data for the selected sites was taken from the 2005 database created by 3 TIER for the Western Wind and Solar Integration Study. This set of modeled data was designed to capture intra-hour variations in wind production across the West at a high geospatial resolution - one 
arc-minute by one arc-minute, or in Arizona roughly $1.9 \mathrm{~km}$ by $1.9 \mathrm{~km}$. This large of an area could typically accommodate ten $3-\mathrm{MW}$ wind turbines, or about $30 \mathrm{MW}$ of capacity. ${ }^{293}$

Seventeen cells provided test data for $510 \mathrm{MW}$ near Cameron, Arizona; 34 cells in New Mexico provided data for 1,020 MW. Figure 6-10 and Figure 6-11 show the maps for the selected wind sites in Arizona and New Mexico. In each case, the cells selected for this modeling are similar other nearby cells with respect to their operating characteristics for wind power. If actual development were to occur on other nearby tracts rather than the ones selected for this analysis, the modeling results would be substantially the same.

Figure 6-12 and Figure 6-13 show the generation production profiles for the Arizona and New Mexico wind sites. For the Arizona site, wind capacity is highest during the day (between 9 a.m. and 3 p.m.) in the spring, when production can reach as much as $50 \%$ of rated capacity. Production tends to be lowest overnight in July and August.

For New Mexico, the capacity factor can reach $60 \%$ to $65 \%$ in the winter and spring months, with the most consistent period occurring between 7 a.m. and 5 p.m. in November, December and January, and from 9 a.m. to 3 p.m. in March.
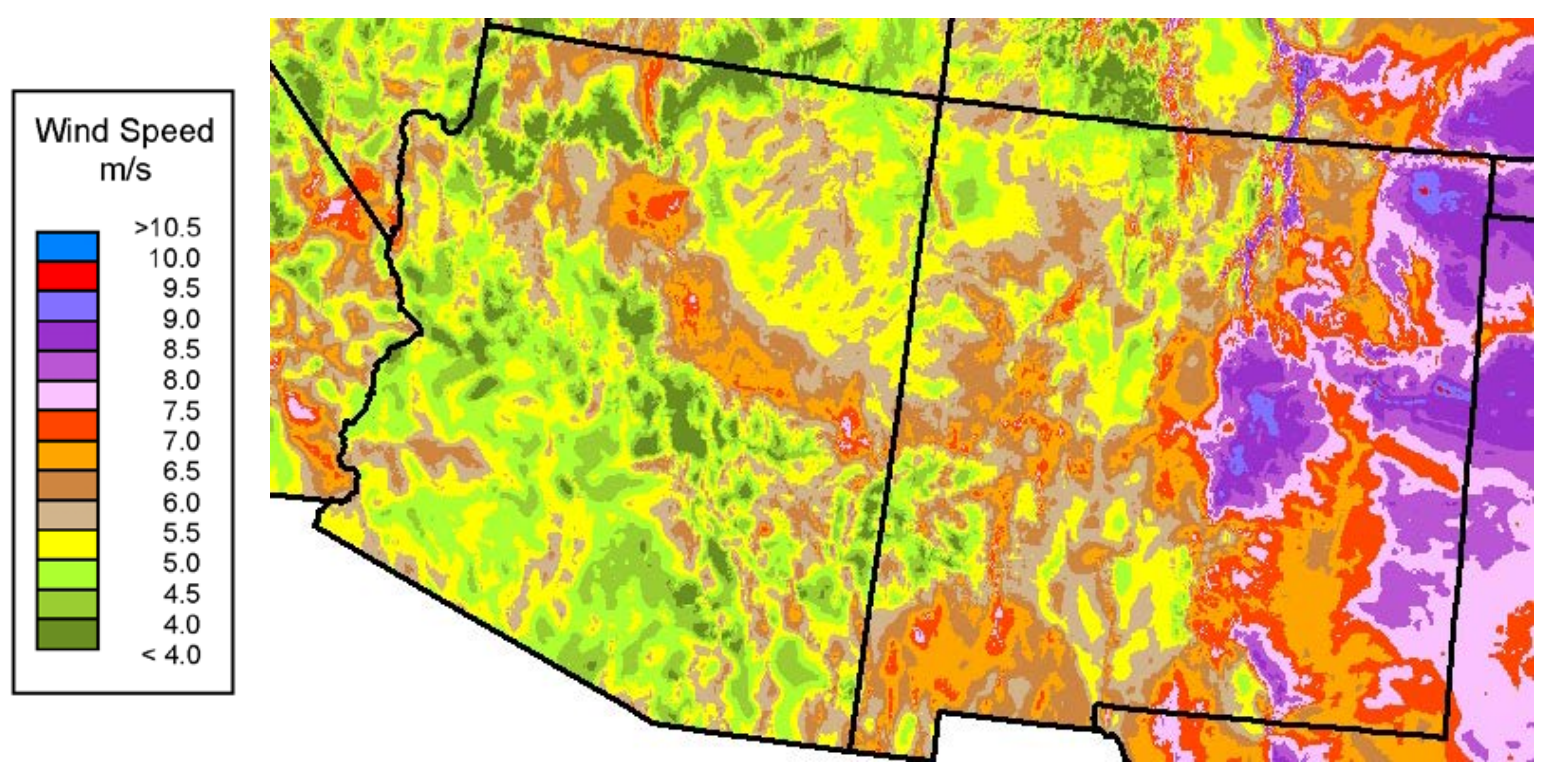

Figure 6-9. Wind Resources at 100m Hub Height for Arizona and New Mexico

Wind resource estimates developed by AWS Truepower 294

\footnotetext{
${ }^{293}$ GE Energy, Western Wind and Solar Integration Study; 3Tier, Western Wind Data Set, https://maps.nrel.gov/wind-prospector.

${ }^{294}$ See www.awstruepower.com.
} 


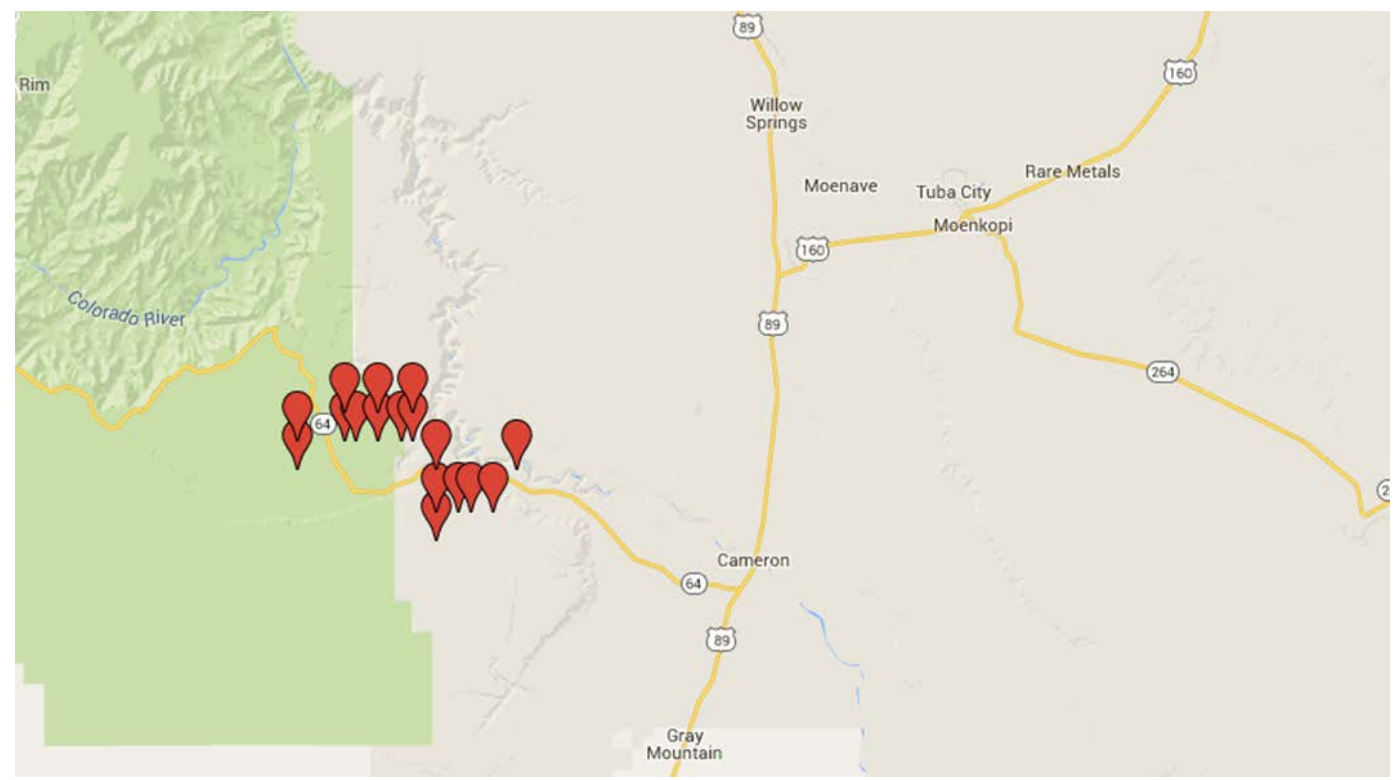

Figure 6-10. Locations of modeled wind sites near the Moenkopi substation Map data: Google, 3Tier

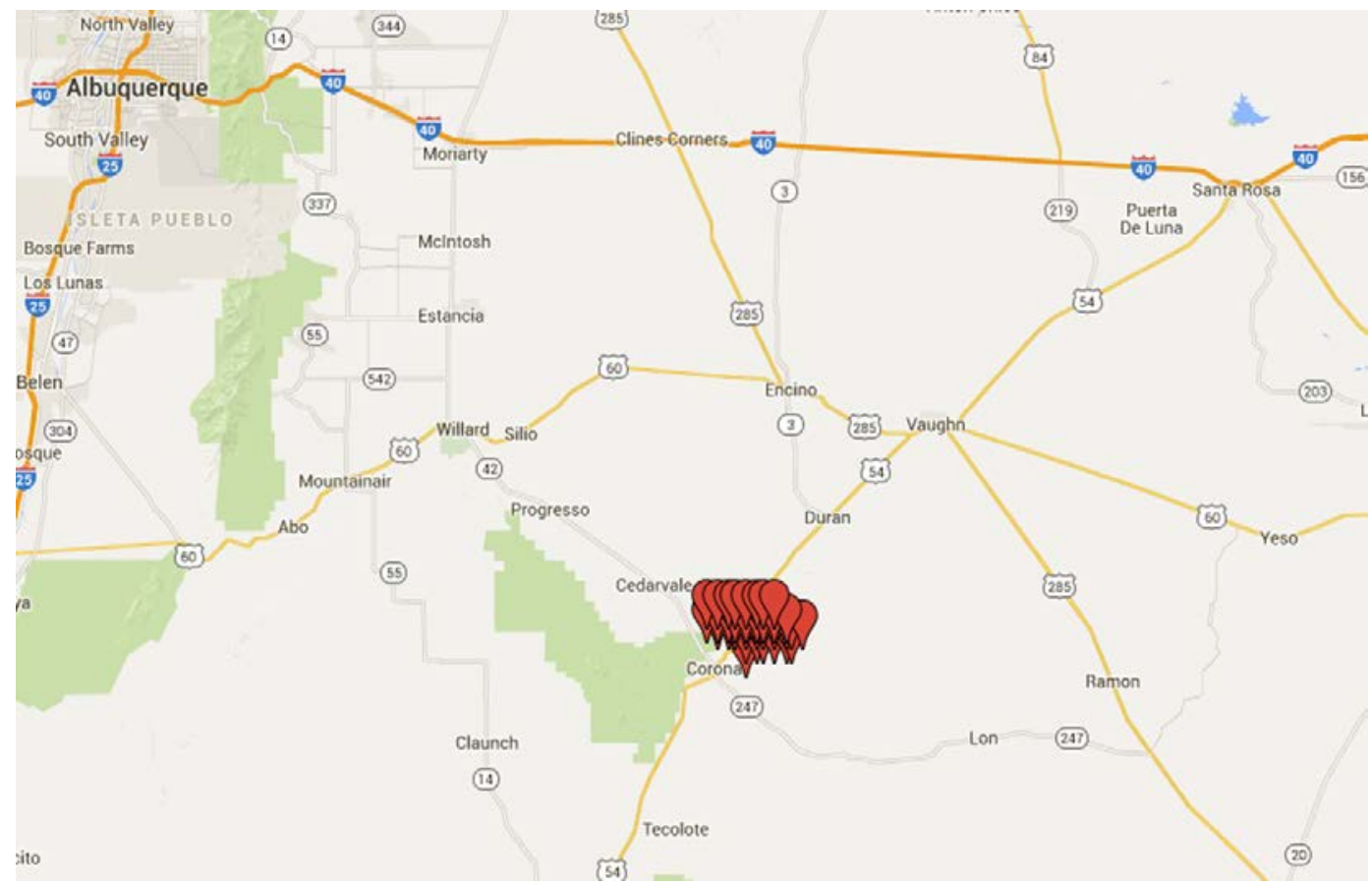

Figure 6-11. Map showing the location of modeled wind sites at the terminus of the SunZia line Map data: Google, 3Tier 

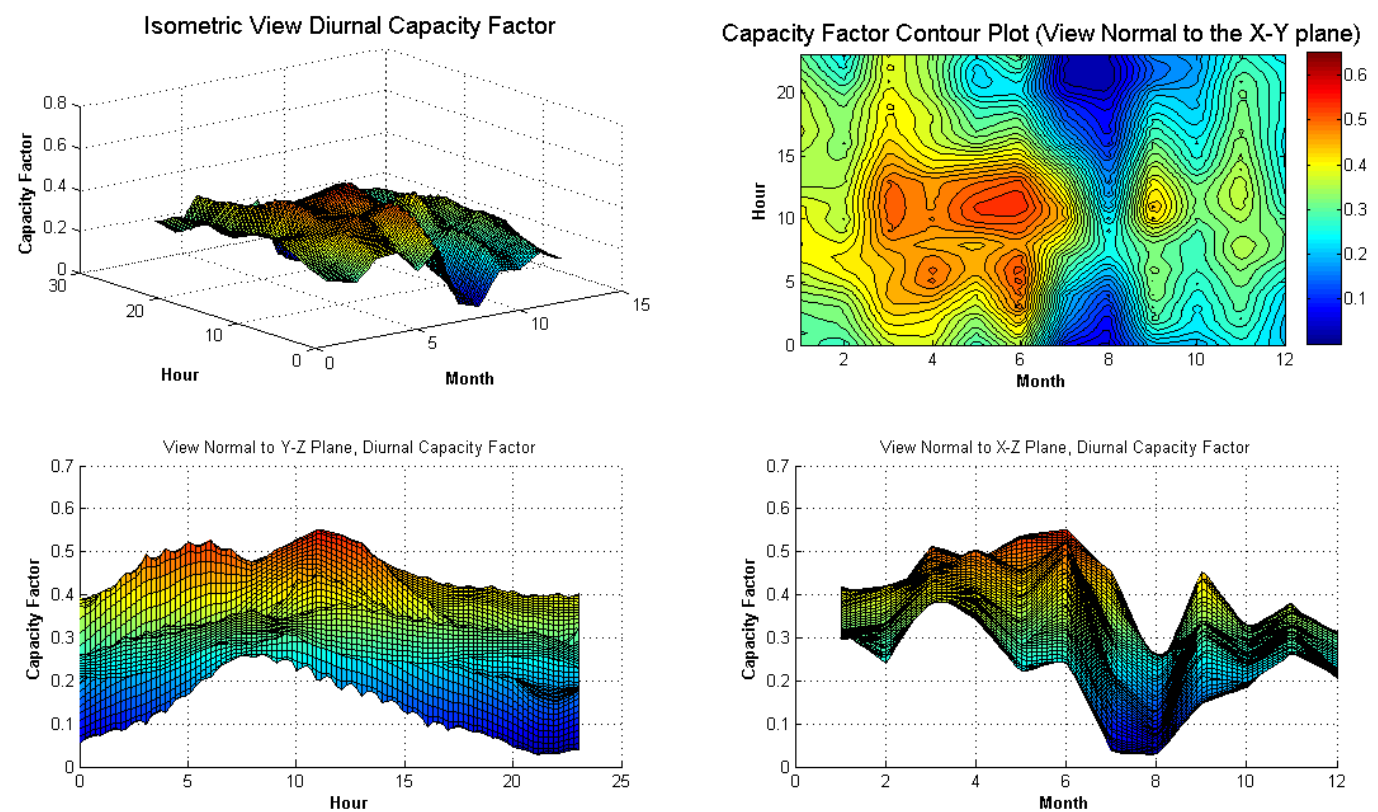

Figure 6-12. Seasonal and hourly capacity factors for Arizona wind generation
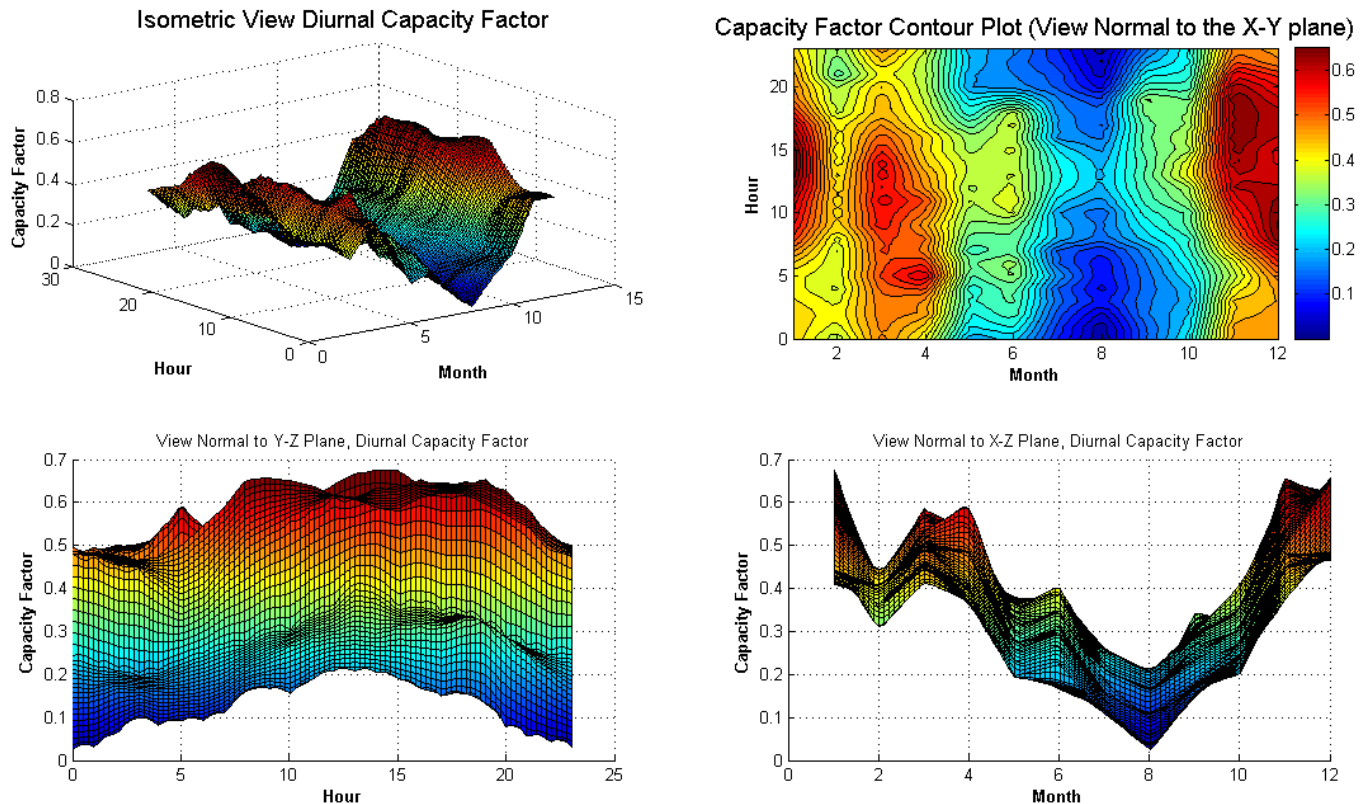

Figure 6-13. Seasonal and hourly capacity factors for New Mexico wind generation

\subsubsection{Solar Data}

Solar data were generated using the System Advisor Model (SAM). ${ }^{295}$ SAM uses the weather files from the NREL National Solar Radiation Database and can detail generation profiles for a particular site. Because weather and load are correlated and the load in the TEPPC database is

${ }^{295}$ See Nate Blair, Aron P. Dobos, Janine Freeman, Ty Neises, Michael Wagner, Tom Ferguson, Paul Gilman, and Steven Janzou, System Advisor Model, SAM 2014.1.14: General Description, NREL/TP-6A20-61019 (Golden, CO: National Renewable Energy Laboratory, 2014), http://www.nrel.gov/docs/fy14osti/61019.pdf. 
based on 2005 demand, solar data were based on the 2005 solar database. There is a correlation between solar and load because more sun and higher temperatures tend to increase airconditioning use.

The standard system selected for modeling was a single-axis tracking array, with a 33-degree tilt and 180-degree azimuth. The system was configured with a direct current-to-alternating current (DC-to-AC) efficiency of about $90 \%$ (that is, $100 \mathrm{MW}_{\mathrm{DC}}$ provides $90 \mathrm{MW}_{\mathrm{AC}}$ to the grid).

Figure 6-14 shows a map of the selected solar sites. The heat maps in Figure 6-15 through Figure 6-18 show the electricity production by month and hour of the day. Similar patterns can be seen across the four solar sites-high solar electricity output in the spring, specifically April, and a dip in electricity production in July and August. In Arizona, spring tends to be very clear while monsoon season, which peaks in July and August, brings rain and clouds over Arizona, especially in northern Arizona and especially in the afternoons. The solar electricity output reflects this weather pattern. Solar panels are also more efficient at cooler temperatures, favoring more efficiency in the spring season.

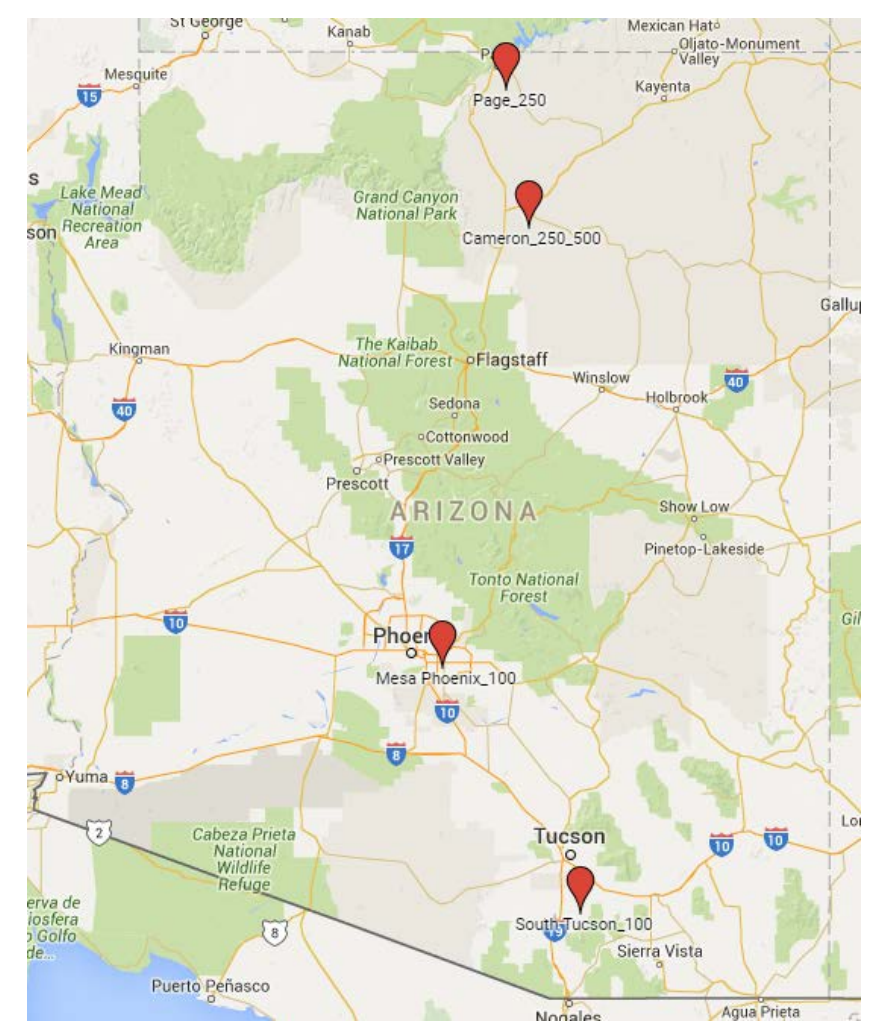

Figure 6-14. Locations of solar PV power plants in Arizona

Map data: Google, 3Tier 


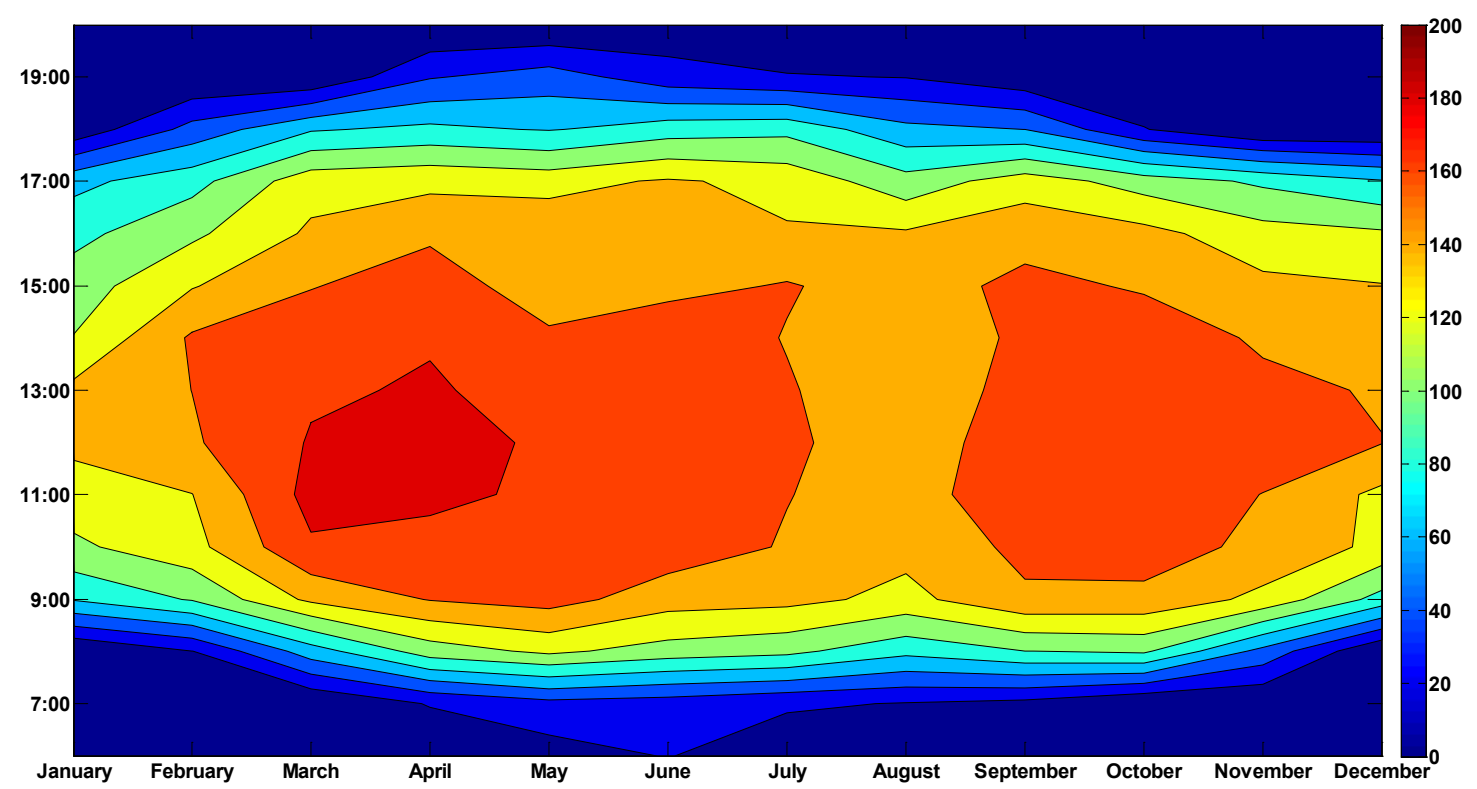

Figure 6-15. PV production profile for Page (average MW, hour of the day by month)

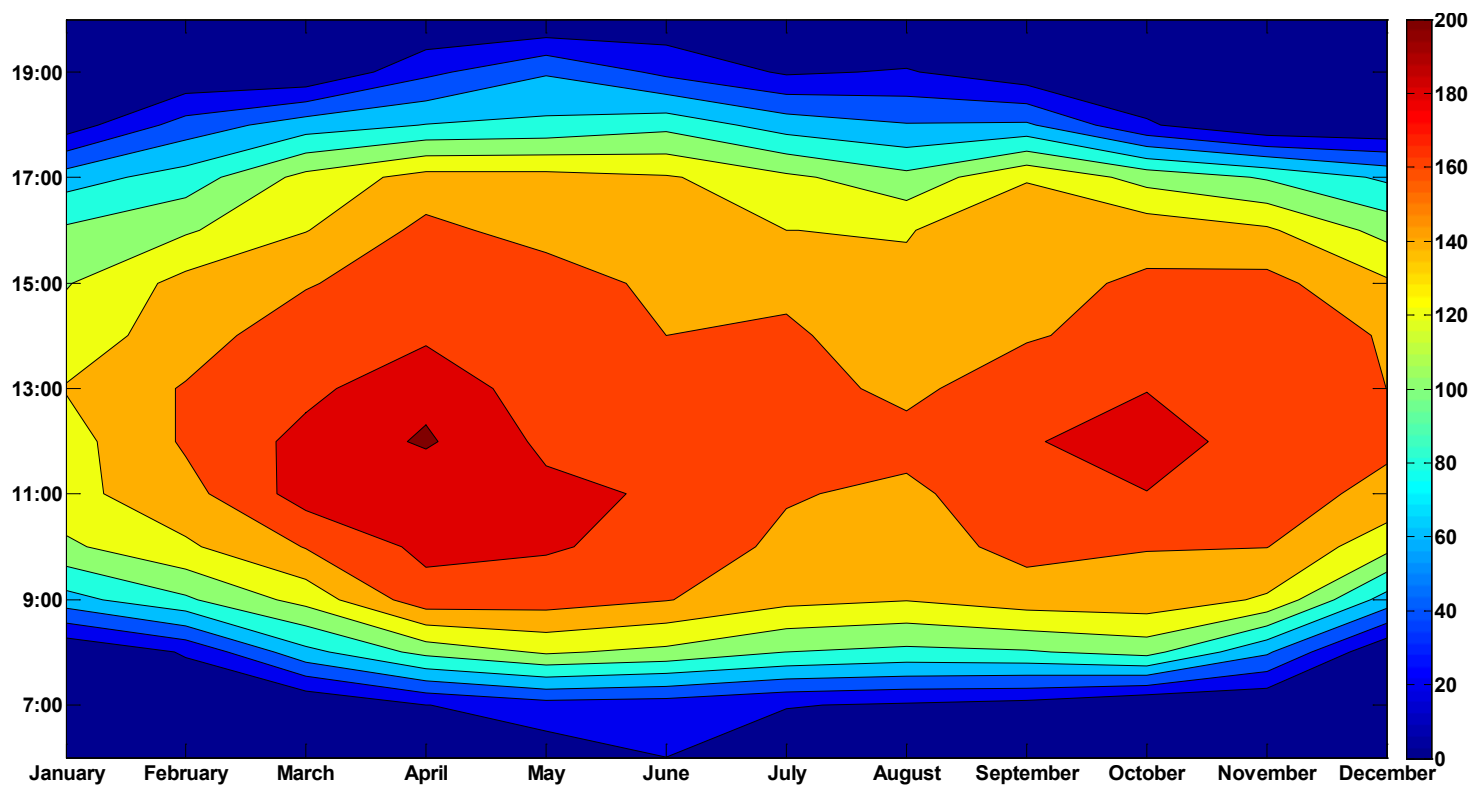

Figure 6-16. PV production profile for Cameron (average MW, hour of the day by month) 


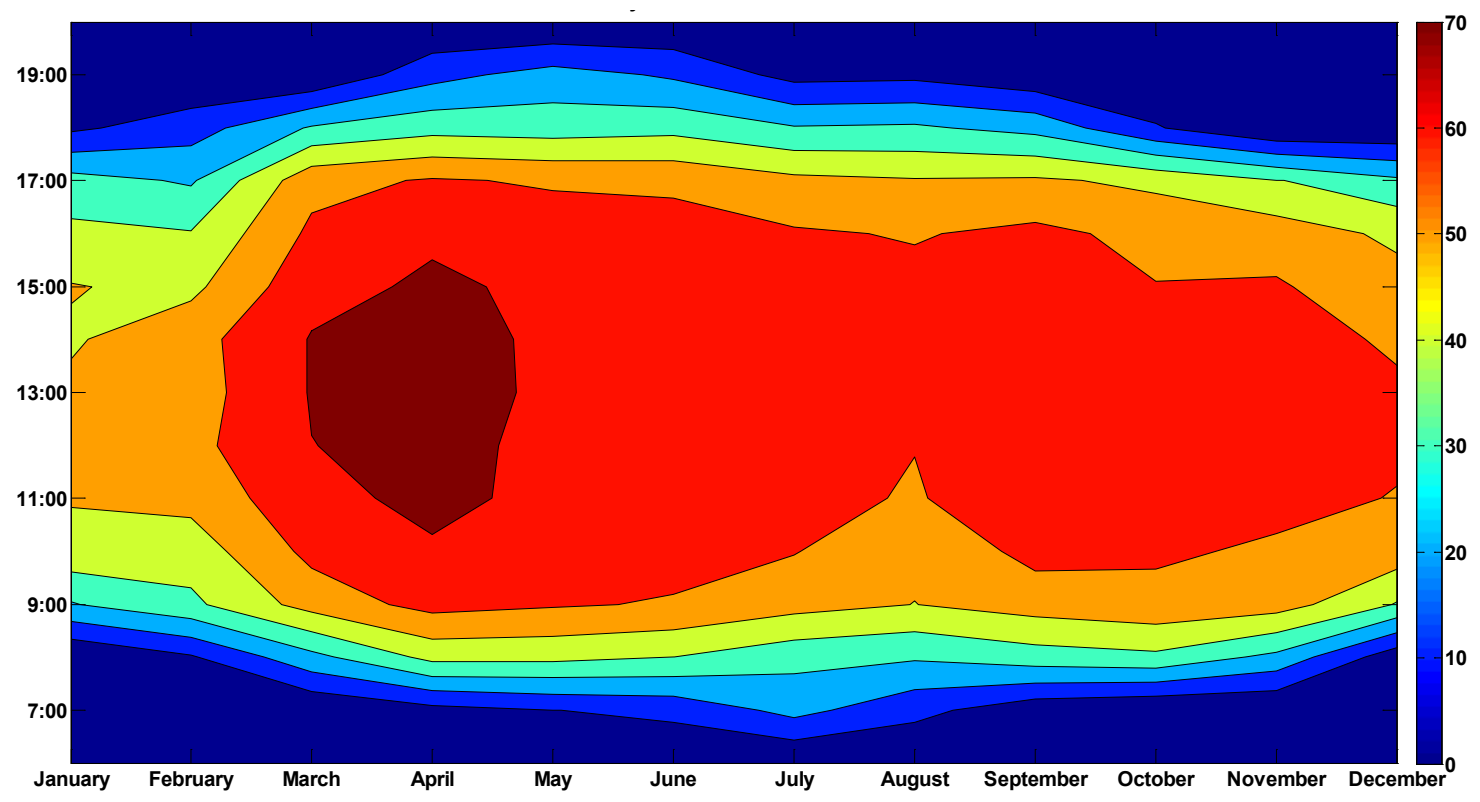

Figure 6-17. PV production profile for Mesa (average MW, hour of the day by month)

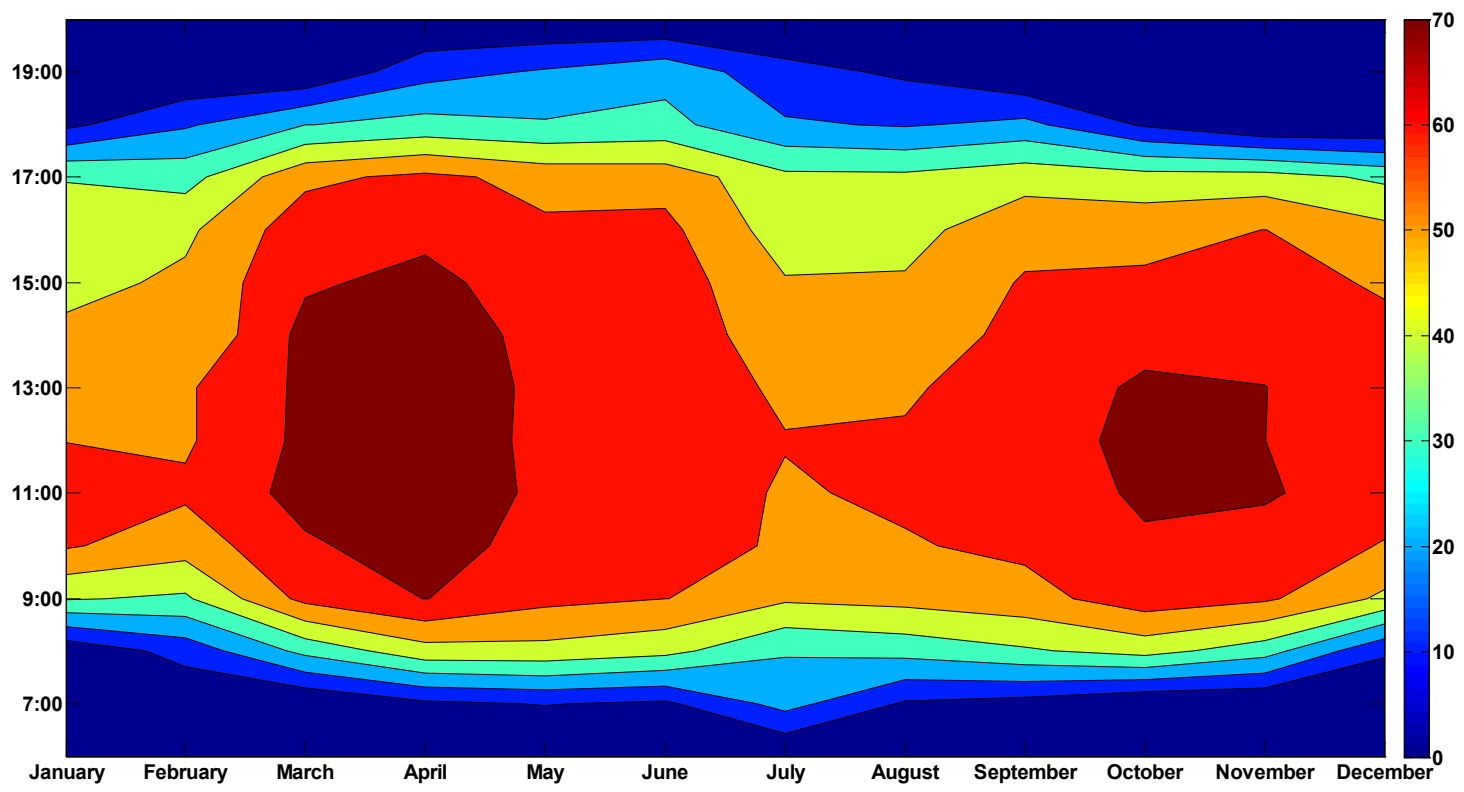

Figure 6-18. PV production profile for Tucson (average MW, hour of the day by month)

\subsubsection{Results}

This study produced a large amount of results. For ease of comparison, the results are presented by pairing initial scenarios (normal conditions with no drought) with their companion extreme drought scenarios, holding all other modeling assumptions the same. Each coupling of results focuses on how the results might change as a result of extreme drought only. 
To narrow down the field of presented results even further to a more digestible quantity, we conducted a general prescreening of results to determine whether some system-wide conditions tended to make drought-related impacts more visible. These parameters were the same as those used in the modeling described in Chapter 4: NGS retirement (the central one-unit retirement scenario versus the accelerated full retirement scenario); and future natural gas prices.

\subsubsection{Prescreening Outcomes}

As shown in Table 6-12, there was little difference between NGS retirement scenarios alone with respect to the impact of extreme drought across all of WECC. Combining the accelerated retirement assumption with high natural gas prices, however, somewhat magnified the drought impact.

Table 6-12. Impact of Extreme Drought on Total Generation Cost

\begin{tabular}{llcc}
\hline $\begin{array}{l}\text { NGS Retirement } \\
\text { Scenario }\end{array}$ & $\begin{array}{l}\text { Extreme } \\
\text { Drought }\end{array}$ & $\begin{array}{l}\text { Total Generation } \\
\text { Cost } \text { (\$ Billions) }\end{array}$ & $\begin{array}{l}\text { Drought Impact } \\
\text { (\% Increase) }\end{array}$ \\
\hline $\begin{array}{l}\text { Central } \\
\begin{array}{l}1 \text { unit retired in } \\
\text { 2030) }\end{array}\end{array}$ & no & 22.24 & 1.30 \\
$\begin{array}{l}\text { Accelerated } \\
\text { (all units retired } \\
\text { before 2030) }\end{array}$ & no & 22.53 & \\
$\begin{array}{l}\text { Accelerated, } \\
\text { with high natural } \\
\text { gas prices }\end{array}$ & no & 22.37 & 1.30 \\
\hline
\end{tabular}

Table 6-13 shows the median and mean LMPs for WECC for the different retirement scenarios. Simulations for the Central Retirement Scenario indicate an extended drought impact of between $0.9 \%$ and $1.4 \%$ (based on changes in the median and mean LMPs systemwide). The Accelerated Retirement Scenario, on the other hand, suggests a more moderated drought impact as indicated by mean LMPs. This could be due to overlapping price effects. That is, full retirement of NGS could instigate redispatch across the West that would tend to increase prices in a similar manner as would extended drought, thus "stealing" some of drought's impact on LMPs.

Table 6-13. Median and Mean LMPs for WECC: No Drought and Extreme Drought Assumptions

\begin{tabular}{|c|c|c|c|c|c|}
\hline \multirow{2}{*}{$\begin{array}{l}\text { NGS Retirement } \\
\text { Scenario }\end{array}$} & \multirow{2}{*}{$\begin{array}{l}\text { Extreme } \\
\text { Drought }\end{array}$} & \multirow{2}{*}{$\begin{array}{l}\text { Median } \\
\text { (\$/MWh) }\end{array}$} & \multirow{2}{*}{$\begin{array}{l}\text { Mean } \\
(\$ / M W h)\end{array}$} & \multicolumn{2}{|c|}{$\%$ Change with Drought } \\
\hline & & & & Median & Mean \\
\hline \multirow{2}{*}{ Central } & no & 34.47 & 36.21 & & \\
\hline & yes & 34.78 & 36.73 & $0.9 \%$ & $1.4 \%$ \\
\hline \multirow{2}{*}{ Accelerated } & no & 34.83 & 36.60 & & \\
\hline & yes & 35.12 & 37.00 & $0.8 \%$ & $1.1 \%$ \\
\hline \multirow{2}{*}{$\begin{array}{l}\text { Accelerated (modified, } \\
\text { with high natural gas } \\
\text { prices) }\end{array}$} & no & 42.35 & 43.42 & & \\
\hline & yes & 42.74 & 44.05 & $0.9 \%$ & $1.5 \%$ \\
\hline
\end{tabular}


Table 6-14 shows median and mean LMPs for Arizona BAs (APS, SRP, TEP, and WALC). On average, LPMs in Arizona are lower than WECC LMPs, in the \$32/MWh range for median and the $\$ 34 / \mathrm{MWh}$ range for mean for regular gas prices. High natural gas prices brought the median up to about $\$ 39 / \mathrm{MWh}$ and the mean up to about $\$ 40 / \mathrm{MWh}$. Table 6-14 also highlights the drought impacts. For Arizona, drought's impact on prices is slightly stronger with accelerated NGS retirement, and even stronger when high natural gas prices are included in the model.

Table 6-14. The Median and Mean LMPs for Arizona BAs and Percent Difference Between the No Drought Case and the Extreme Drought Case for the Couplets

\begin{tabular}{|c|c|c|c|c|c|}
\hline \multirow{2}{*}{$\begin{array}{l}\text { NGS Retirement } \\
\text { Scenario }\end{array}$} & \multirow{2}{*}{$\begin{array}{l}\text { Extreme } \\
\text { Drought }\end{array}$} & \multirow{2}{*}{$\begin{array}{l}\text { Median } \\
\text { (\$/MWh) }\end{array}$} & \multirow{2}{*}{$\begin{array}{l}\text { Mean } \\
(\$ / M W h)\end{array}$} & \multicolumn{2}{|c|}{$\%$ Change with Drought } \\
\hline & & & & Median & Mean \\
\hline \multirow{2}{*}{ Central } & no & 31.90 & 33.44 & & \\
\hline & yes & 32.36 & 34.07 & $1.4 \%$ & $1.9 \%$ \\
\hline \multirow{2}{*}{ Accelerated } & no & 32.43 & 33.98 & & \\
\hline & yes & 32.94 & 34.72 & $1.6 \%$ & $2.2 \%$ \\
\hline \multirow{2}{*}{ Accelerated (modified) } & no & 39.01 & 39.88 & & \\
\hline & yes & 39.66 & 40.95 & $1.7 \%$ & $2.7 \%$ \\
\hline
\end{tabular}

Figure 6-19 compares the price duration curves for Arizona (excluding LMPs higher than \$70/MWh). Natural gas prices push the curves higher for the Modified Accelerated Retirement Scenario with high natural gas prices, but more important for the present purpose is that the gap between the drought and no-drought scenarios extends across nearly all of the supply curve paths, suggesting a more systematically consistent impact.

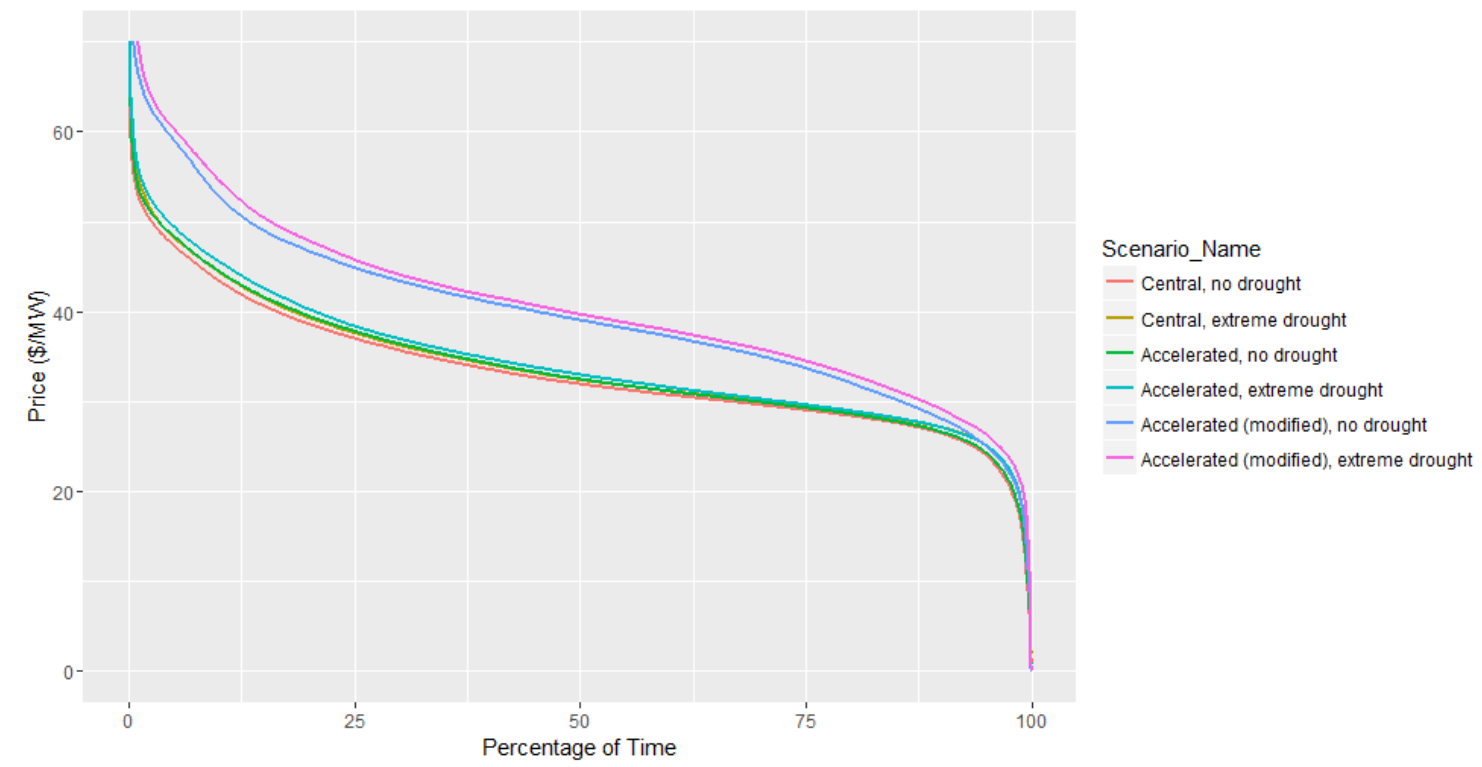

Figure 6-19. Price duration curve with high prices excluded for Arizona BAs for the NGS retirement and natural gas price scenarios

Note: The "Accelerated (modified)" scenarios (blue and purple lines) include high natural gas prices. 
For every coupling of Baseline and Extreme Drought Scenarios, the capacity factors for coal plants (Figure 6-20) and NGCC plants (Figure 6-21) are higher for the drought scenario. One particularly interesting result, however, is that while the scenario with high gas prices results in greater use of coal generally, drought itself appears to have little additional impact. The coal capacity factor for each Arizona BA increases about the same amount when extreme drought is added to the accelerated retirement scenario, regardless of natural gas prices.

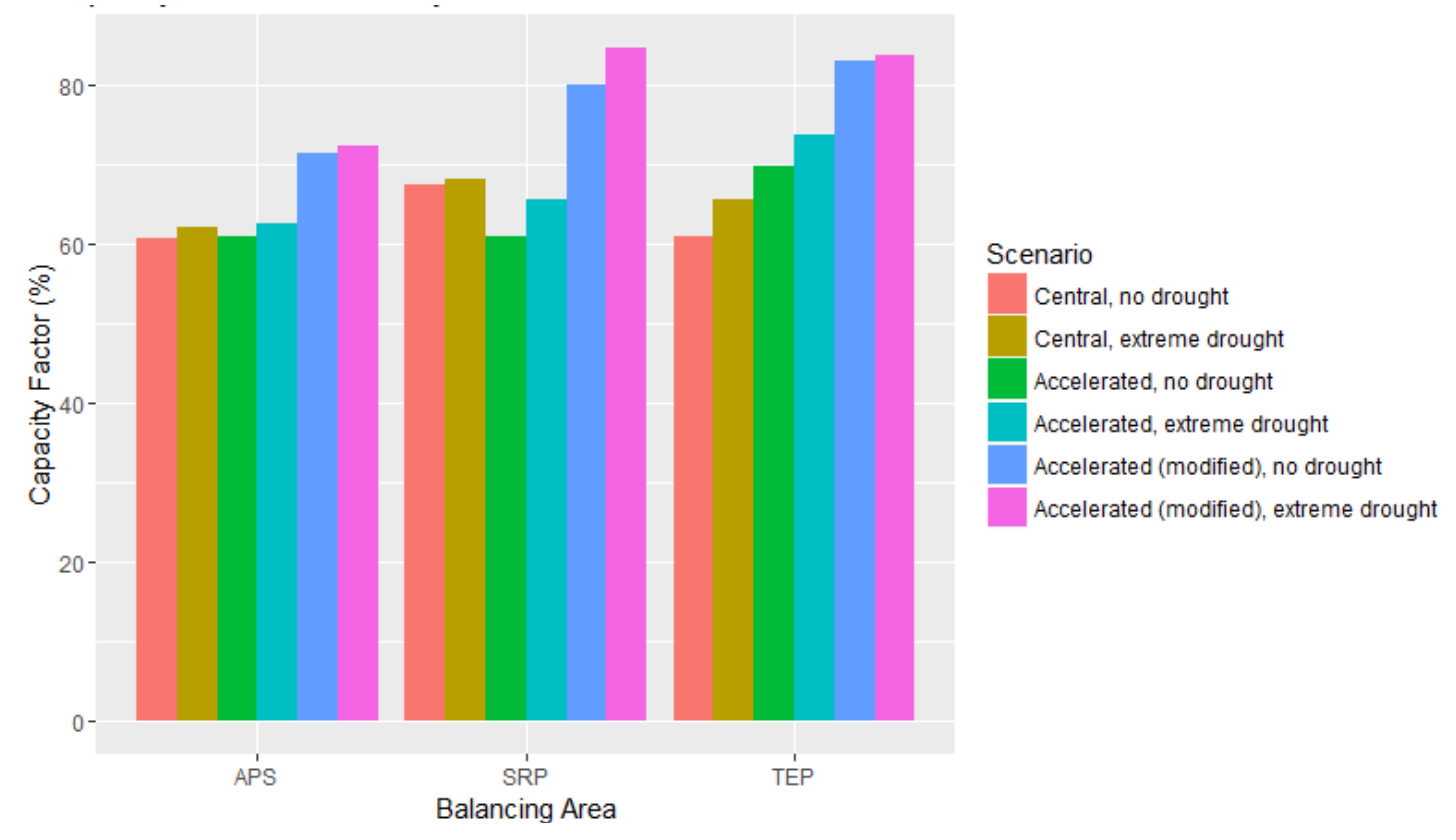

Figure 6-20. Capacity factors for coal plants in Arizona BAs for NGS retirement and natural gas prices scenarios

Note: The "Accelerated (modified)" scenarios include high natural gas prices.

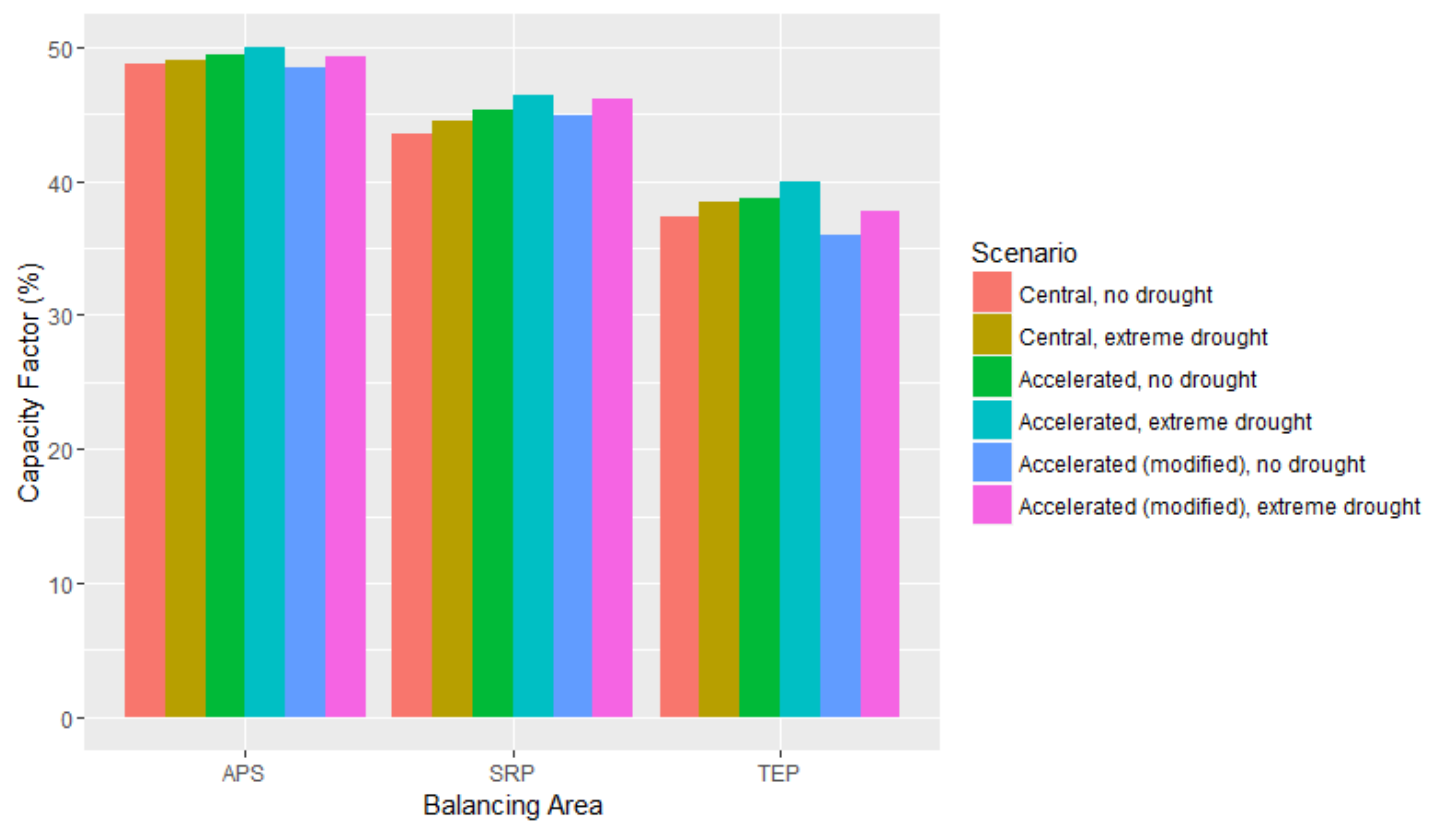

Figure 6-21. Capacity factors for NGCC plants in Arizona BAs for the NGS retirement and natural gas prices scenarios

Note: The "Accelerated (modified)" scenarios include high natural gas prices. 
The last step in the screening process was to examine changes in net imports for Arizona. Figure 6-22 shows these changes. Extreme drought tends to reduce net imports across the board for Arizona BAs. There appears to be little appreciable difference in the magnitude of these normal-to-drought reductions. Therefore, any change in Arizona net imports provides little basis for reducing the number of scenarios presented.

Two obvious phenomena are evident: the loss of production from Hoover and Glen Canyon Dams implicit in the extreme drought scenarios, which is apparent in the results for WALC; and absence of NGS in the accelerated retirement scenarios, which is apparent in the results for SRP. A significant share of these resources normally flows outside their originating BA as exports, so their effects would not be extraordinary.

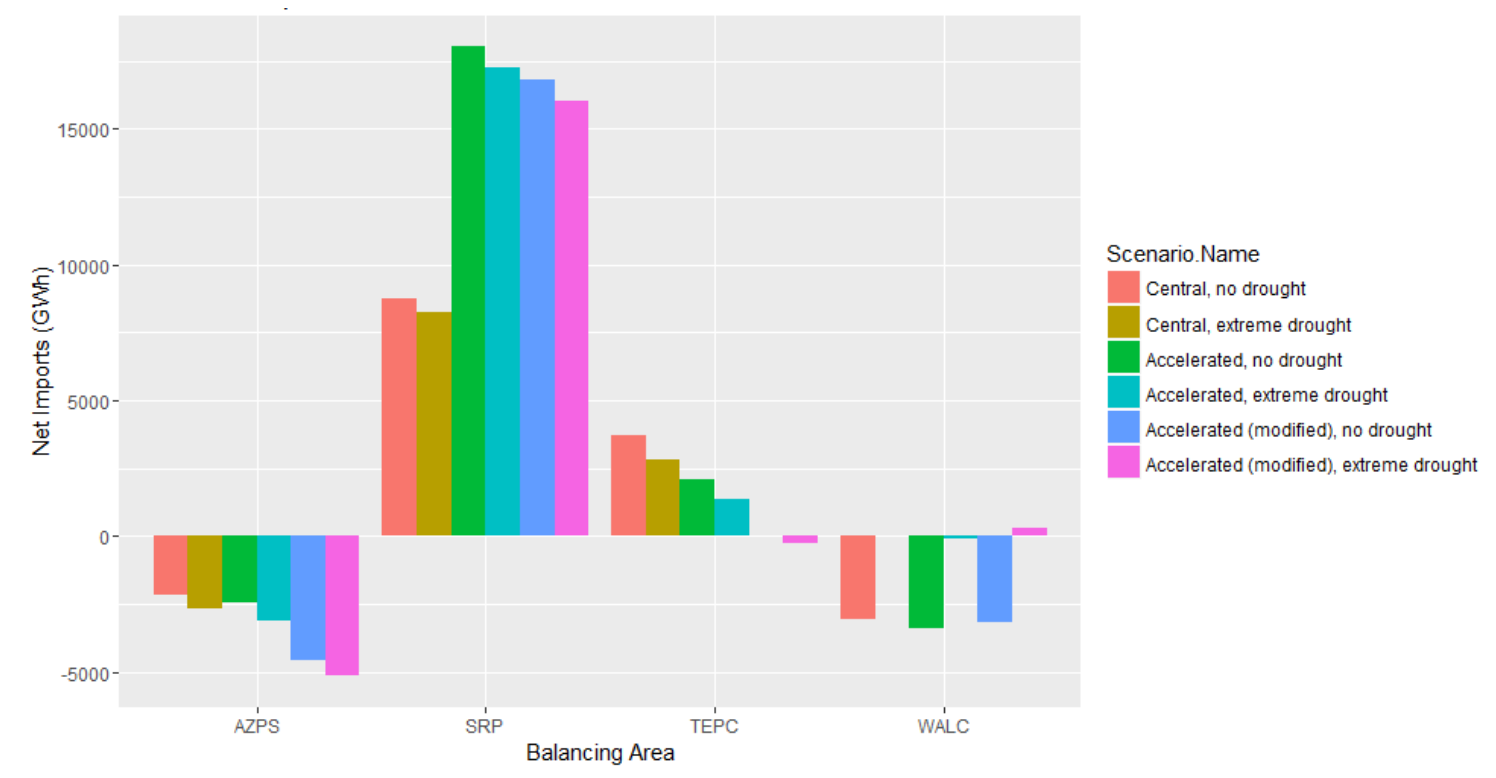

Figure 6-22. Net imports for NGS retirement and natural gas prices scenarios

Note: The "Accelerated (modified)" scenarios (blue and purple lines) include high natural gas prices.

The scenarios assuming early NGS retirement appear to show the possible impact of extreme drought with the greatest clarity. We therefore selected this set of scenarios to represent upperbound conditions of a range of plausible outcomes. This remainder of this chapter presents results comparing the three glide paths and their characteristics for mitigating the impact of a future extreme drought. All scenarios in this group are based on the accelerated retirement of NGS.

\subsubsection{Total Generation Cost}

Table 6-15 presents the total generation cost (in billions of dollars) across WECC for the capacity expansion scenarios. The percent difference for each couplet is presented to show the additional cost due to drought conditions, shown in the fourth column. Extreme drought increases total generation costs by $1.3 \%$ for the TEPPC Baseline (in which no new capacity is added). Adding capacity by 2030 , as in the three glide path scenarios, would tend to mitigate this impact by reducing the increase to between $1.25 \%$ and $1.26 \%$. 
Table 6-15. Total Generation Cost for Capacity Expansion Strategies

\begin{tabular}{lcccc}
\hline Glide Path & $\begin{array}{c}\text { Extreme } \\
\text { Drought }\end{array}$ & $\begin{array}{c}\text { Total } \\
\text { Generation Cost } \\
\text { (\$ Billions) }\end{array}$ & $\begin{array}{c}\text { \% Change } \\
\text { with Drought }\end{array}$ & $\begin{array}{c}\text { Drought Impact } \\
\text { More or Less than in } \\
\text { TEPPC Baseline? }\end{array}$ \\
\hline $\begin{array}{l}\text { TEPPC } \\
\text { (no new capacity) }\end{array}$ & no & 22.37 & $1.30 \%$ & less \\
Solar & no & 22.66 & $1.25 \%$ & less \\
Wind & yes & 22.32 & & \\
& no & 22.60 & $1.26 \%$ & less \\
\hline
\end{tabular}

All scenarios represented in the table are based on accelerated retirement of NGS.

\subsubsection{LMPs}

Table 6-16 shows how the median and mean LMPs for WECC change under the capacity expansion scenarios. Extreme drought tends to increase LMPs by as much as $1.1 \%$, representing the system-wide effect of losing generation from Hoover and Glen Canyon Dams (if NGS were fully retired). Holding all other conditions the same and adding capacity under the solar glide path, the average LMP increases by only $0.5 \%$ system-wide under extreme drought, less than half the drought impact likely to occur without the glide path.

The wind glide path appears to have less of a drought-mitigating effect that the solar glide path. This could be due to greater coincidence between hours of maximum solar generation and hours when system LMPs tend to be high. Solar-to-price coincidence would mean that the marginal value of a megawatt-hour offset by solar would tend to be more than the marginal value of a megawatt-hour offset by wind.

Results for the Moenkopi glide path actually suggest greater sensitivity to drought, with both the mean and median LMP increasing slightly more due to drought. This too could be attributable to the marginal value of generation during the hours when new resources added in this glide path would replace other generation on the system. 
Table 6-16. Median and Mean LMPs for WECC Under Capacity Expansion Glide Paths

\begin{tabular}{|c|c|c|c|c|c|c|}
\hline \multirow{2}{*}{$\begin{array}{l}\text { Glide } \\
\text { Path }\end{array}$} & \multirow{2}{*}{$\begin{array}{l}\text { Extreme } \\
\text { Drought }\end{array}$} & \multirow{2}{*}{$\begin{array}{l}\text { Median } \\
\text { (\$/MWh) }\end{array}$} & \multirow{2}{*}{$\begin{array}{c}\text { Mean } \\
\text { (\$/MWh) }\end{array}$} & \multicolumn{2}{|c|}{$\begin{array}{c}\% \text { Change with } \\
\text { Drought }\end{array}$} & \multirow{2}{*}{$\begin{array}{c}\text { Drought Impact More } \\
\text { or Less than in } \\
\text { TEPPC Baseline? }\end{array}$} \\
\hline & & & & Median & Mean & \\
\hline \multirow{2}{*}{ TEPPC } & no & 34.83 & 36.60 & & & \\
\hline & yes & 35.12 & 37.00 & $0.8 \%$ & $1.1 \%$ & \\
\hline \multirow{2}{*}{ Solar } & no & 34.77 & 36.67 & & & \\
\hline & yes & 35.02 & 36.84 & $0.7 \%$ & $0.5 \%$ & less \\
\hline \multirow{2}{*}{ Wind } & no & 34.61 & 36.38 & & & \\
\hline & yes & 34.88 & 36.69 & $0.8 \%$ & $0.9 \%$ & somewhat less \\
\hline \multirow{2}{*}{ Moenkopi } & no & 34.52 & 36.35 & & & \\
\hline & yes & 34.85 & 36.83 & $1.0 \%$ & $1.3 \%$ & more \\
\hline
\end{tabular}

All scenarios represented in the table are based on accelerated retirement of NGS.

Table 6-17 shows the median and mean for LMPs for Arizona BAs. While the Arizona LMPs are all lower than the WECC LMPs, they are more sensitive to extreme drought due to the proximity of Hoover and Glen Canyon Dams. In this more localized context, the solar glide path still provides some cushion to the price impact of extreme drought even in an environment with relatively low prices overall.

Table 6-17. Median and Mean LMPs for Arizona Under Capacity Expansion Glide Paths

\begin{tabular}{|c|c|c|c|c|c|c|}
\hline \multirow[t]{2}{*}{ Glide Path } & \multirow{2}{*}{$\begin{array}{l}\text { Extreme } \\
\text { Drought }\end{array}$} & \multirow{2}{*}{$\begin{array}{l}\text { Median } \\
\text { (\$/MWh) }\end{array}$} & \multirow{2}{*}{$\begin{array}{c}\text { Mean } \\
(\$ / M W h)\end{array}$} & \multicolumn{2}{|c|}{$\begin{array}{c}\% \text { Change with } \\
\text { Drought }\end{array}$} & \multirow{2}{*}{$\begin{array}{c}\text { Drought Impact More } \\
\text { or Less than in } \\
\text { TEPPC Baseline? }\end{array}$} \\
\hline & & & & Median & Mean & \\
\hline \multirow{2}{*}{ TEPPC } & no & 32.43 & 33.98 & & & \\
\hline & yes & 32.94 & 34.72 & $1.6 \%$ & $2.2 \%$ & \\
\hline \multirow{2}{*}{ Solar } & no & 32.33 & 33.93 & & & \\
\hline & yes & 32.76 & 34.51 & $1.3 \%$ & $1.7 \%$ & less \\
\hline \multirow{2}{*}{ Wind } & no & 32.06 & 33.27 & & & \\
\hline & yes & 32.52 & 34.02 & $1.4 \%$ & $2.3 \%$ & uncertain \\
\hline \multirow{2}{*}{ Moenkopi } & no & 31.87 & 33.08 & & & \\
\hline & yes & 32.28 & 33.84 & $1.3 \%$ & $2.3 \%$ & uncertain \\
\hline
\end{tabular}

All scenarios represented in the table are based on accelerated retirement of NGS.

On their own and in the absence of extreme drought, each of the glide paths tends to reduce both the average and the median LMP for Arizona (and for WECC as a whole). The Moenkopi glide path, for example, has an average LMP for Arizona that is nearly $\$ 1 / \mathrm{MWh}$ lower than what is modeled without the glide path's new capacity. This could account for the uncertain price effect when testing the impact of extreme drought by itself. The average LMP under the solar glide path differs little from the TEPPC Baseline with no drought, but provides some price mitigation value if extreme drought were to occur. The wind and Moenkopi glide path 
scenarios respond to extreme drought about the same as the TEPPC Baseline does, but a certain degree of cost reduction is achieved before the drought.

\subsubsection{Utilization of Coal, Natural Gas Combined Cycle}

Figure 6-23 and Figure 6-24 show the capacity factors for NGCC and coal generation under the glide path scenarios. For both types of resources in all three BAs under all glide path scenarios, the capacity factor tends to increase in drought years compared to nondrought years. This suggests that even with the addition of glide path resources, managing extreme drought could also involve leaning more heavily on the coal resources remaining on the system in 2030, as well as the existing NGCC capacity.

One caveat to these particular results is that drought could entail other operational impacts that were not modeled here. For example, drought accompanied by high ambient temperatures could degrade the operational efficiency of thermal units, which in turn would tend to reduce the capacity factor. In addition, scarce water resources could result in competition from consumptive uses outside the electricity sector, such as municipal water supplies and irrigation. Higher costs due to higher water prices are not factored into the analysis.

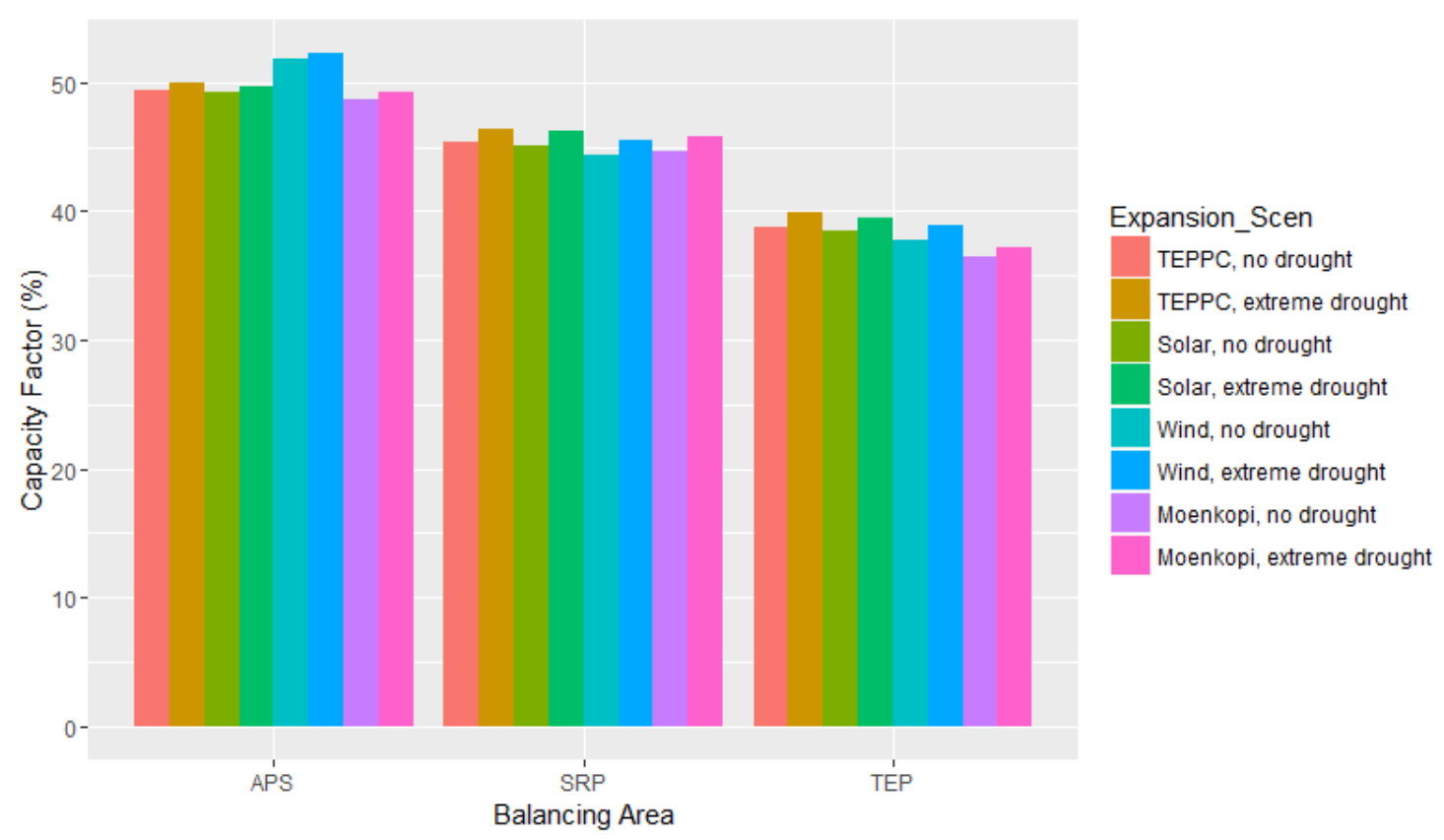

Figure 6-23. Capacity factors for NGCC plants in Arizona BAs for capacity expansion strategies 


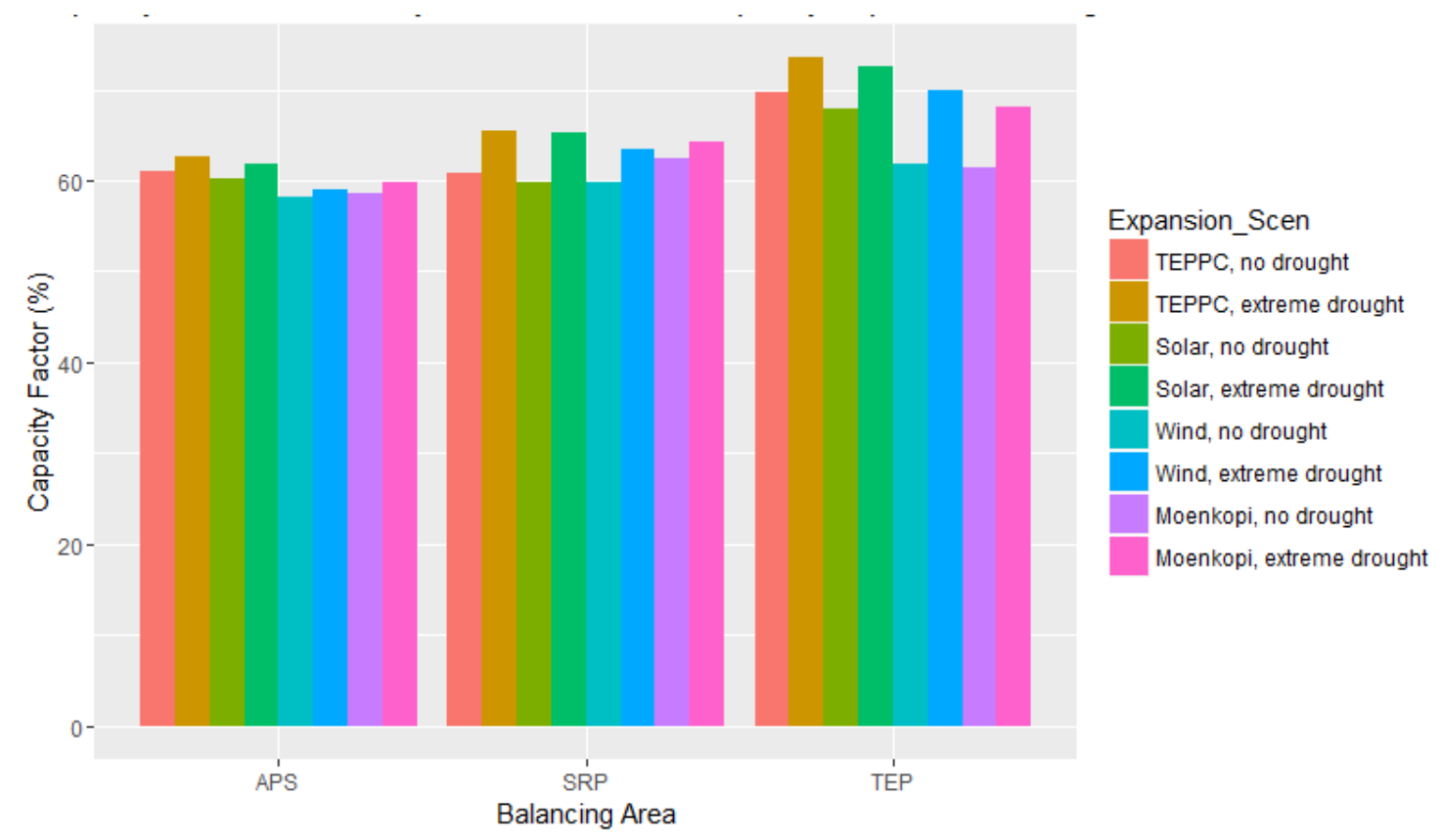

Figure 6-24. Capacity factors for coal in Arizona BAs for capacity expansion strategies

\subsection{Summary}

Hydrological modeling suggests that an extreme drought severe enough to eliminate electricity generation at Hoover and Glen Canyon Dams, while unlikely, is plausible by 2030. PLEXOS results in this chapter suggest that such an event could increase the cost of producing electricity by $1.3 \%$ to $2.0 \%$ across the West, all other factors held constant.

If no other resources are added to the system, the Extreme Drought Scenario tends to promote greater reliance on Arizona's remaining coal and NGCC generators. The increase in coal utilization due to drought appears to be unchanged by high natural gas prices, however. The results suggest that while existing coal resources could be a hedge against high natural gas prices generally, their potential for mitigating the effects of extreme drought is unaffected whether natural gas prices are high or low.

All three glide path models tested here appear to have some capacity to mitigate the impact of extreme drought. The solar glide path $(700 \mathrm{MW}$ of additional utility-scale PV spread across four theoretical locations in Arizona) could curb drought's impact on the cost of generation in Arizona more than the other two tested glide paths. However, both of the other glide paths would tend to reduce LMPs in Arizona under normal nondrought conditions, from an average of $\$ 33.98 / \mathrm{MWh}$ under the TEPPC Baseline to as low as $\$ 33.08 / \mathrm{MWh}$ for the Moenkopi glide path (a 2.6\% reduction). While the additional reduction specific to drought impact mitigation might be small, Arizona LMPs in these drought scenarios still tend to be lower than LMPs under the solar glide path.

Even with the addition of glide path resources, managing extreme drought could involve leaning more heavily on the coal resources remaining on the system in 2030, as well as on the existing NGCC capacity. For both types of resources in all three BAs under all glide path scenarios, the capacity factor tends to increase in drought years compared to nondrought years under the same glide path scenario. 


\section{Conclusion}

The public interests that depend on the federal government's $24.3 \%$ share of NGS are different from the traditional interests of the plant's utility co-owners, but ultimately they are affected by the same market forces that are evident throughout the electricity sector. This report tracks the relevant sectoral trends for the purpose of informing federal policies that might protect these unique public interests against a variety of plausible NGS contingencies. Models for possible federal actions are examined in Volume 2 of this study.

Electricity produced at NGS is currently more expensive than electricity purchased on the wholesale spot market. Price trends examined in this analysis suggest a turnaround might be years away, especially if natural gas prices remain low. These trends mean that the ability to sell surplus power from the federal share of NGS on the wholesale market is uncertain and will likely remain so for a period of time that will be determined by natural gas prices. The loss of revenue from surplus NGS power sales could harm key federal interests, particularly low-cost water delivery and economic development for Arizona Indian tribes.

The same market conditions that cast uncertainty over the ability to sell NGS surplus power also add to the economic risk of building a new NGCC generator. This analysis calculates that a new, highly efficient NGCC operating at a 70\% capacity factor would need to clear $\$ 24 / \mathrm{MWh}$ in net revenues to recover its capital costs. In recent years, however, the margin between wholesale power prices and variable operating costs has not been that large. Several existing NGCC plants in the Southwest appear to have capacity that has been underutilized historically but that might be able provide additional generation without the need for new capital investment.

At the same time, the costs of utility-scale solar and wind power have continued to decline. Arizona has some of the most productive solar resource potential in the United States, which significantly improves the amount of energy generated for every dollar of capital investment. Nevertheless, while well-sited utility-scale solar and wind are trending toward a general cost balance with new NGCC, the cost of producing electricity at existing natural gas generators is at this time economically superior to new capacity of any type, as indicated by low wholesale power prices. State renewable energy requirements still seem to push new development of solar, wind, and geothermal generation, and these resources could be part of an NGS transition strategy.

The Southwest relies less on coal and more on natural gas and renewables for generating electricity than it did two decades ago. While low natural gas prices since 2015 might have accelerated the shift in recent months, the transition has in fact been persistent since 2001. This trend is also occurring throughout the Western Interconnection as a whole and nationwide.

In 2000, more than half of all electric generation in the Southwest came from plants that were larger than $2 \mathrm{GW}$ in capacity. The share of generation coming from plants larger than $2 \mathrm{GW}$ has fallen to around $30 \%$ today. Even when excluding renewables (which by their nature tend to be smaller and more dispersed), Arizona's electric generation picture is less concentrated and more dispersed today than it was in 2001 . When new supply is needed, a very large central station plant like NGS is less likely to be the choice. 
Not only is the West's generation fleet becoming less concentrated and more dispersed, it is also becoming more coordinated operationally. Two major utilities outside Californiaincluding NV Energy, which owns a share of NGS - have joined an energy imbalance market (EIM) operated by CAISO. Five more utilities - including APS, which also owns a share of NGS - have studied membership and have announced plans to join in the near future. For federal decisions related to NGS, an expanded EIM and other movements toward more regional coordination could:

- Reduce the ability to sell surplus power from NGS, because noncoal alternatives such as renewables and natural gas generation are likely to become more cost competitive and easier to manage

- Favor long-term NGS transition strategies that provide operational flexibility

- Increase the feasibility and the advantages of a multiresource strategy for procuring CAP pumping power (in contrast to relying on a single resource such as NGS).

The modeling conducted for this report suggests that an NGS transitional glide path may benefit from a diverse portfolio of generation resources - including NGS operated in a way that would reduce the short-term economic impact of the transition to cleaner energy sources. Attempting a megawatt-for-megawatt replacement of NGS with one new plant could run counter to the underlying cost trends and structural trends. Modeling indicates that natural gas generation could play some part in an NGS glide path strategy. What is uncertain is whether market conditions would support building a new NGCC plant rather than increasing the utilization of existing plants. Modeling done for this study suggests not; redispatching existing plants could accommodate a variety of NGS scenarios with local per-megawatt-hour generation cost increases no greater than $2.7 \%$.

The modeling suggests that solar PV could be an important strategic element of an NGS glide path. Reducing the use of NGS seems to increase the relative cost effectiveness of solar in the Southwest. New renewables tend to shift on a West-wide basis, with wind outside the Southwest losing market momentum and solar in the Southwest gaining market momentum.

Climate change and the potential for extended drought in the West could affect future flows of the Colorado River, which in turn could affect hydroelectric production at Hoover Dam and Glen Canyon Dam. Reservoir levels that are too low for power generation at either facility, while improbable, are plausible based on current hydrological modeling. Planning for remote contingencies is common in power system modeling, and a drought this extreme could affect federal decisions related to NGS in at least two ways. First, the loss of federal hydropower could create an additional need for replacement electricity supplies, a contingency that could be included in the federal government's NGS-related decisions. Second, it suggests the need to examine NGS strategic options with respect to their ability to cushion the system-wide impact of extreme drought.

A drought severe enough to eliminate Hoover Dam and Glen Canyon Dam from the region's electric generation fleet could increase the cost of generating electricity for the entire Western Interconnection. The effect would likely be more pronounced in Arizona, where modeling 
results suggested a reduction in electricity exports and higher average cost of generation. If no other resources are added to the system, extreme drought would tend to promote greater reliance on Arizona's remaining coal and NGCC generators. This study tested three approaches (or "glide paths") for replacing electricity from the federal share of NGS with electricity produced from new solar, wind, and natural gas facilities. All three appear to have some capacity to mitigate the impact of extreme drought. A solar glide path (700 MW of additional utility-scale PV spread across Arizona) would reduce the increases in generation costs attributable to an extended drought. The two multiresource glide paths would not significantly moderate the cost impact of an extreme drought when it occurs, but they would tend to reduce the cost of generation overall under normal nondrought conditions.

One caveat to the modeling results for drought is the other potential operational impacts that were not represented. For example, drought accompanied by high ambient temperatures could degrade the operational efficiency of thermal units. In addition, scarce water resources could result in competition from consumptive uses outside the electricity sector, such as municipal water supplies and irrigation. Higher generation costs due to higher prices for cooling water are not factored into the analysis.

While the federal government faces an imminent decision about whether or not to allow NGS to operate after 2019, it need not wait until then to begin assessing its long-term options if it decides continued operation is justified. The question of whether NGS continues to operate overlaps with the question of how it should operate after 2019. Both questions are influenced by the availability of reasonable alternatives, which in turn are influenced by how the sector is evolving more broadly. 


\section{Appendix: Computable General Equilibrium Modeling}

This appendix describes the equations used in the CGE models, described in Chapter 5. Equations (1)-(5) in this appendix describe the behavior of the seven household groups, which differ by income level, as shown in Table 1. Equation (2) shows that household income comes from labor $\left(\mathrm{Y}_{\mathrm{L}}\right)$, land $\left(\mathrm{Y}_{\mathrm{LA}}\right)$ and capital income $\left(\mathrm{Y}_{\mathrm{K}}\right)$. The parameters $\mathrm{A}_{\mathrm{H}, \mathrm{L}}, \mathrm{A}_{\mathrm{H}, \mathrm{LA}}$, and $\mathrm{A}_{\mathrm{H}, \mathrm{K}}$ allocate the various sources of income to the different household groups. Labor, land, and capital taxes are represented by TAUFL T,L $_{\text {, TAUFL }}$ TAA, and TAUFL $_{\mathrm{G}, \mathrm{K}}$, respectively. LNFOR $_{L A}$ and $\mathrm{KPFOR}_{K}$ represent outflows of land and capital income determined by the percentage of firms that are owned by entities outside the state.

Equation (3) presents disposable income $\left(\mathrm{YD}_{\mathrm{H}}\right)$ as calculated by adding retirement flows and remittances $\left(\right.$ PRIVRET $_{H}$ ) to labor income and subtracting state and federal personal income taxes $\left(\mathrm{PITO}_{\mathrm{H}}\right)$. Consumption demand is derived in equation (4) from a Cobb-Douglas utility function, which is affected by real disposable income $\left(\mathrm{YD}_{\mathrm{H}}\right)$ and price movements relative to a base price $\left(\mathrm{PJ}_{\mathrm{J}} / \mathrm{P} \mathrm{J}_{\mathrm{J}}\right)$. Two other equations solve for household savings, $\mathrm{S}_{\mathrm{H}}$ (equation (5)), and the overall price level faced by each household group, $\mathrm{CPI}_{\mathrm{H}}$ (equation (1)).

Producer behavior and factor supply. Firms are grouped into 23 productive sectors that demand inputs from five labor groups $\left(\mathrm{FD}_{\mathrm{L}}\right)$, capital $\left(\mathrm{FD}_{\mathrm{K}}\right)$, and land $\left(\mathrm{FD}_{\mathrm{LA}}\right)$. The labor groups are differentiated by wage rates $\left(\mathrm{RA}_{\mathrm{L}}\right)$. Equations (6)-(12) describe the output of producers $\left(\mathrm{DS}_{\mathrm{I}}\right)$, and their factor demand, while equations (21)-(24) model factor supply. Equations (7) and (8) present a CES production function and the associated first order conditions, where $\mathrm{DS}_{\mathrm{i}}$ represents output produced by each sector and $\mathrm{FD}_{\mathrm{F}, \mathrm{I}}$ is factor demand for the labor groups, capital, and land. $\mathrm{RA}_{\mathrm{L}}$ is the wage rate for each labor group. These equations guarantee that the private sector will maximize profits by choosing optimal levels of all factors, subject to standard production function relationships. The producing sectors further demand intermediate inputs in fixed proportions (AD $\mathrm{IJ}$ ), as shown in equation (9). Equations (10)-(12) simply calculate the income received by each factor as a function of its quantity demanded and factor price.

Local labor supply comes directly from the seven household groups described earlier and from migration. In equation (21), the proportion of local households that are working $\left(\mathrm{HW}_{\mathrm{H}} / \mathrm{HH}_{\mathrm{H}}\right)$ is determined as a function of real wages internal to the state $\left(\mathrm{RA}_{\mathrm{L}} / \mathrm{CPI} \mathrm{I}_{\mathrm{H}}\right)$, transfer payments (TP), and responses to income tax rates (PIT0). Related to local labor supply is the migration of households described in equation (23). Total household count, calculated in equation (23), is determined by the base number of households in the state $\left(\mathrm{HHOH}_{\mathrm{H}}\right)$ times the natural rate of population growth $\left(\mathrm{NRPG}_{\mathrm{H}}\right)$ and by migration induced by changes in real household income $\left(\mathrm{YD}_{\mathrm{H}} / \mathrm{CPI}_{\mathrm{H}}\right)$. Moreover, households are inversely related to the relative size of nonworking to total households in the economy $\left(\mathrm{HN}_{\mathrm{H}} / \mathrm{HH}_{\mathrm{H}}\right)$. In essence, the differences between the solution for households in a simulation and the base level reflect net migration and population growth for the state. The parameters ETAYD and ETAU are elasticities.

In equation (20) capital stock $\left(\mathrm{KS}_{\mathrm{K}, \mathrm{IG}}\right)$ is a function of the base stock less depreciation plus investment $\left(\mathrm{N}_{\mathrm{K}, \mathrm{I}}\right)$. Linking investment and capital provides a long-run perspective for our simulation results. Because this is a regional model, state savings does not determine state investment. Equation (22) specifies land supply as a function of LAS0, the base land area in 
the state and the returns to land relative to the base values $\left(\mathrm{R}_{\mathrm{LA}, \mathrm{I}} / \mathrm{R} 0_{\mathrm{LA}, \mathrm{I}}\right)$. The ratio of domestic supply relative to its base $\left(\mathrm{DS}_{\mathrm{I}} / \mathrm{DS}_{\mathrm{I}}\right)$ is also a factor, since increased economic activity in a sector can cause sector capital growth. The parameter ETAL is the elasticity describing the responsiveness of land supply to rates of return on land and domestic output.

Equation (18) describes the new capital supply, which is also net investment by firms, as a function of the base value of investment $\left(\mathrm{N}_{\mathrm{K}, \mathrm{I}}\right)$, and relative returns to capital $\left(\mathrm{R}_{\mathrm{K}, \mathrm{I}} / \mathrm{R} 0_{\mathrm{K}, \mathrm{I}}\right)$. As with the land supply equation, the ratio of domestic output relative to its base is included to represent the impact of economic activity on capital acquisition. The elasticity of net investment is described by ETAIX. The variable $\mathrm{CN}_{\mathrm{I}}$ is the resulting investment demand by sector, which is determined in equation (19) as a function of new capital supply.

Trade relations. Regional economies are usually relatively small and open, and highly dependent on both imports and exports. Accordingly, relative changes in external and internal prices can have a large effect on simulation outcomes. Equation (13) describes exports (CXI) as a function of its base value $\left(\mathrm{CX}_{\mathrm{I}}\right)$ and the local domestic price $\left(\mathrm{PD}_{\mathrm{I}}\right)$ of a product relative to its exported world price $\left(\mathrm{PWO}_{\mathrm{I}}\right)$. The elasticity of export demand is described by ETAEI. Imports are described through equations (14) and (15). Equation (14) calculates the proportion of domestic demand that is supplied locally ( $\mathrm{D}_{\mathrm{I}}$ ), which, similar to the export equation, is described by a base value, relative domestic prices compared to import prices, and an elasticity that describes its responsiveness (ETAD $\left.{ }_{\mathrm{I}}\right)$. Imports are calculated in equation (15) as the portion of domestic demand $\left(\mathrm{DD}_{\mathrm{I}}\right)$ that is not supplied locally. In equation (16), the price of goods in the domestic market is calculated as a weighted average of the domestic producer price and the world price of imports.

Finally, the financial side of the trade balance is calculated in equation (17). Since Coconino, Apache, and Navajo counties as well as Arizona are small open economies, savings can easily flow out of or into the state to help finance new investment or net exports. Clearly, it is not accurate to constrain investment by local savings, given that the economy draws resources from many different parts of the country via branch banking. Net foreign savings is available, as an unconstrained variable, reflecting the difference between returns to foreign ownership of labor and capital (LNFOR and KPFOR), net exports, remittances (PRIVRET $\mathrm{H}$ ), government transfers $\left(\mathrm{GVFOR}_{\mathrm{G}}\right)$, and net wages from commuters.

State and local governments. Government revenue is described in equation (25), which shows it as the sum of a wide range of taxes related to local production, exports, imports, factor payments, and household income. Equations (26) and (27) describe the state's demand for intermediate inputs and factor demand, respectively. The variable $\mathrm{CG}_{\mathrm{I}, \mathrm{GN}}$ in equation (26) is local real government consumption of inputs required in the course of their provision of services, while $A G$ allocates tax revenue $\left(\mathrm{Y}_{\mathrm{GN}}\right)$ and government transfers $\left(\mathrm{GVFOR}_{\mathrm{GN}}\right)$ into expenditures according to the fixed proportions found in $\mathrm{AG}_{\mathrm{I}, \mathrm{GN}}$. Equation (27) describes the state's demand for factors $\left(\mathrm{FD}_{\mathrm{F}, \mathrm{GN}}\right)$ and is structured similarly to the government consumption equation.

Model closure equations. Each factor and product market has a set of closure equations that provide insight into the equilibrium behavior of the model. Equation (28) closes the labor market by setting total labor supply equal to total demand. Supply consists of laborers coming 
from resident working households. The parameter JOBCOR $\mathrm{H}_{\mathrm{H}, \mathrm{L}}$ transforms working households into workers. This is set equal to the sum of local factor demand. There is one equation for each labor category, which determines the wage rate for that labor group. Capital and land have equations specified for each product and factor. In equation (29), capital stock must equal the factor demand for capital in each of the 23 productive sectors. Thus, separate returns to capital, by sector, are created through these closure equations. The land closure equation in equation (30) works the same way. Equation (31) is an identity that ties all sources and uses of a sector's production together. Total local demand for each product $\left(\mathrm{DD}_{\mathrm{I}}\right)$ is calculated in equation (32).

\section{Households}

$$
\begin{aligned}
& \mathrm{CPIH}=\Sigma \text { IPI }(1+\Sigma \text { GS TAUC GS,I }) \text { CHI,H } / \Sigma \text { I }(\text { P0I }(1+\Sigma \text { GS TAUQGS,I })) \\
& \text { CHI,H }
\end{aligned}
$$

$$
\begin{aligned}
& \left.\mathrm{Y}_{\mathrm{H}}=\Sigma_{\mathrm{L}} \mathrm{A}_{\mathrm{H}, \mathrm{L}} \mathrm{HW}_{\mathrm{H}} / \Sigma_{\mathrm{H} 1} \mathrm{~A}_{\mathrm{H} 1, \mathrm{~L}} \mathrm{HW}_{\mathrm{H} 1}\left(\mathrm{Y}_{\mathrm{L}}\right)\left(1-\Sigma_{\mathrm{G}} \mathrm{TAUFL}_{\mathrm{G}, \mathrm{L}}\right)\right)+\Sigma_{\mathrm{LA}} \mathrm{A}_{\mathrm{H}, \mathrm{LA}} \\
& \left.\mathrm{HW}_{\mathrm{H}} / \Sigma_{\mathrm{H} 1} \mathrm{~A}_{\mathrm{H} 1, \mathrm{LA}} \mathrm{HW}_{\mathrm{H} 1}\left(\mathrm{Y}_{\mathrm{LA}}+\mathrm{LNFOR}_{\mathrm{LA}}\right)\left(1-\Sigma_{\mathrm{G}} \mathrm{TAUFLA}_{\mathrm{G}, \mathrm{LA}}\right)\right)+\Sigma_{\mathrm{K}} \mathrm{A}_{\mathrm{H}, \mathrm{K}} \\
& \mathrm{HW}_{\mathrm{H}} / \Sigma_{\mathrm{H} 1} \mathrm{~A}_{\mathrm{H} 1, \mathrm{~K}} \mathrm{HW}_{\mathrm{H} 1}\left(\mathrm{Y}_{\mathrm{K}}+\mathrm{KPFOR}_{\mathrm{K}}\right)\left(1-\Sigma_{\mathrm{G}} \mathrm{TAUFK}_{\mathrm{G}, \mathrm{K}}\right) \\
& \mathrm{YD}_{\mathrm{H}}=\mathrm{Y}_{\mathrm{H}}+\mathrm{PRIVRET}_{\mathrm{H}} \mathrm{HH}_{\mathrm{H}}+\Sigma_{\mathrm{G}} \mathrm{TP}_{\mathrm{H}, \mathrm{G}} \mathrm{HH}_{\mathrm{H}}-\Sigma_{\mathrm{GI}} \mathrm{PIT0}_{\mathrm{GI}, \mathrm{H}} \mathrm{Y}_{\mathrm{H}}-\Sigma_{\mathrm{G}} \mathrm{TAUH}_{\mathrm{G}, \mathrm{H}} \\
& \mathrm{HH}_{\mathrm{H}}
\end{aligned}
$$

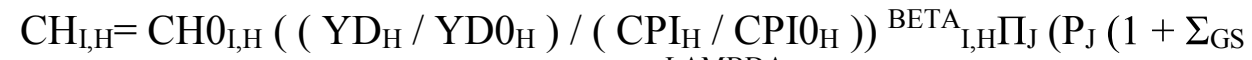

$$
\begin{aligned}
& \text { TAUC } \left._{G S, J}\right) /\left(\mathrm{PO}_{\mathrm{J}}\left(1+\Sigma_{\mathrm{GS}} \text { TAUQ GS,J }\right)^{\text {LAMBDA }_{\mathrm{J}, \mathrm{I}}}\right. \\
& \mathrm{S}_{\mathrm{H}}=\mathrm{YD}_{\mathrm{H}}-\Sigma_{\mathrm{I}} \mathrm{P}_{\mathrm{I}} \mathrm{CH}_{\mathrm{I}, \mathrm{H}}\left(1+\Sigma_{\mathrm{GS}} \mathrm{TAUC}_{\mathrm{GS}, \mathrm{I}}\right)
\end{aligned}
$$

\section{Producers}

\section{Trade}

$$
\begin{aligned}
& \mathrm{PVA}_{\mathrm{I}}=\mathrm{PD}_{\mathrm{I}}-\Sigma_{\mathrm{J}} \mathrm{AD}_{\mathrm{J}, \mathrm{I}} \mathrm{P}_{\mathrm{J}}\left(1+\Sigma_{\mathrm{GS}} \mathrm{TAUV}_{\mathrm{GS}, \mathrm{J}}\right) \\
& \mathrm{DS}(\mathrm{I})=\gamma_{\mathrm{I}} \Sigma_{\mathrm{F}}\left(\mathrm{ALPHA}_{\mathrm{F}, \mathrm{I}} \mathrm{FD}_{\mathrm{F}, \mathrm{I}}\right)^{(-\mathrm{RHO}(\mathrm{I}))(-1 / \mathrm{RHO}(\mathrm{I}))} \\
& \mathrm{R}_{\mathrm{F}, \mathrm{I}} \mathrm{RA}_{\mathrm{F}}\left(1+\Sigma_{\mathrm{GF}} \mathrm{TAUFX}_{\mathrm{GF}, \mathrm{F}, \mathrm{I}}\right) \mathrm{FD}_{\mathrm{F}, \mathrm{I}}=\mathrm{PVA}_{\mathrm{I}} \mathrm{DS}_{\mathrm{I}} \mathrm{ALPHA}_{\mathrm{F}, \mathrm{I}} \\
& \mathrm{V}_{\mathrm{I}}=\Sigma_{\mathrm{J}} \mathrm{AD}_{\mathrm{I}, \mathrm{J}} \mathrm{DS}_{\mathrm{J}} \\
& \mathrm{Y}_{\mathrm{L}}=\Sigma_{\mathrm{IG}}\left(\mathrm{R}_{\mathrm{L}, \mathrm{IG}} \mathrm{RA}_{\mathrm{L}} \mathrm{FD}_{\mathrm{L}, \mathrm{IG}}\right) \\
& \mathrm{Y}_{\mathrm{K}}=\Sigma_{\mathrm{IG}}\left(\mathrm{R}_{\mathrm{K}, \mathrm{IG}} \mathrm{RA}_{\mathrm{K}} \mathrm{FD}_{\mathrm{K}, \mathrm{IG}}\right) \\
& \mathrm{Y}_{\mathrm{LA}}=\Sigma_{\mathrm{IG}}\left(\mathrm{R}_{\mathrm{LA}, \mathrm{IG}} \mathrm{RA}_{\mathrm{LA}} \mathrm{FD}_{\mathrm{LA}, \mathrm{IG}}\right)
\end{aligned}
$$

$$
\begin{aligned}
& \mathrm{CX}_{\mathrm{I}}=\mathrm{CX}_{\mathrm{I}}\left(\mathrm{PD}_{\mathrm{I}}\left(1+\Sigma_{\mathrm{GK}} \text { TAUX }_{\mathrm{GK}, \mathrm{I}}\right)\right) /\left(\mathrm{PW}_{\mathrm{I}}\left(1+\Sigma_{\mathrm{GK}} \text { TAUQ }_{\mathrm{GK}, \mathrm{I}}\right)^{\text {ETAE }}\right. \\
& \mathrm{D}_{\mathrm{I}}=\mathrm{D}_{\mathrm{I}} \mathrm{PD}_{\mathrm{I}} / \mathrm{PWM}_{\mathrm{I}}\left(1+\Sigma_{\mathrm{GK}} \mathrm{TAUM}_{\mathrm{GK}, \mathrm{I}}\right) \\
& \mathrm{M}_{\mathrm{I}}=\left(1-\mathrm{D}_{\mathrm{I}}\right) \mathrm{DD}_{\mathrm{i}} \\
& \mathrm{P}_{\mathrm{I}}=\mathrm{D}_{\mathrm{I}} \mathrm{PD}_{\mathrm{I}}+\left(1-\mathrm{D}_{\mathrm{I}}\right) \mathrm{PWM}_{\mathrm{I}}\left(1+\Sigma_{\mathrm{K}} \mathrm{TAUM}_{\mathrm{GK}, \mathrm{I}}\right)
\end{aligned}
$$


$\left.\left.\mathrm{NKI}=\Sigma_{\mathrm{I}} \mathrm{M}_{\mathrm{I}} \mathrm{PWM}_{\mathrm{I}}-\Sigma_{\mathrm{I}} \mathrm{CX}_{\mathrm{I}} * \mathrm{PD}_{\mathrm{I}}\right)-\Sigma_{\mathrm{H}} \mathrm{PRIVRET}_{\mathrm{H}} * \mathrm{HH}_{\mathrm{H}}\right)-\Sigma_{\mathrm{LA}} \mathrm{LNFOR}_{\mathrm{LA}}-$ $\Sigma_{\mathrm{K}} \mathrm{KPFOR}_{\mathrm{K}}-\Sigma_{\mathrm{G}} \mathrm{GVFOR}_{\mathrm{G}}$

Investment

$$
\begin{aligned}
& \left.\mathrm{N}_{\mathrm{K}, \mathrm{I}}=\mathrm{N} 0_{\mathrm{K}, \mathrm{I}}\left(\mathrm{R}_{\mathrm{K}, \mathrm{I}} / \mathrm{R}_{\mathrm{K}, \mathrm{I}}\right){ }^{\mathrm{ETAIX}} \mathrm{K}, \mathrm{I}_{(\mathrm{DS}} / \mathrm{DS}_{\mathrm{I}}\right)^{\mathrm{ETAIX}}{ }_{\mathrm{K}, \mathrm{I}} \\
& \mathrm{P}_{\mathrm{I}} *\left(1+\Sigma_{\mathrm{GS}} \mathrm{TAUN}_{\mathrm{GS}, \mathrm{I}}\right) \mathrm{CN}_{\mathrm{I}}=\Sigma_{\mathrm{IG}} \mathrm{B}_{\mathrm{I}, \mathrm{IG}}\left(\Sigma_{\mathrm{K}}, \mathrm{N}_{\mathrm{K}, \mathrm{IG}}\right) \\
& \left.\mathrm{KS}_{\mathrm{K}, \mathrm{IG}}=\mathrm{KS}_{\mathrm{K}, \mathrm{IG}}(1-\mathrm{DEPR})+\mathrm{N}_{\mathrm{K}, \mathrm{IG}}\right) \text { ) }
\end{aligned}
$$

\section{Factor Supply}

$\left.\left.\mathrm{HW}_{\mathrm{H}} / \mathrm{HH}_{\mathrm{H}}=\mathrm{HW}_{\mathrm{H}} / \mathrm{HH}_{\mathrm{H}}\left(\left(\left(\Sigma_{\mathrm{L}}, \mathrm{RA}_{\mathrm{L}}\right) / \mathrm{RA}_{\mathrm{L}}\right)\right) / 5\right) /\left(\mathrm{CPI}_{\mathrm{H}}\right) / \mathrm{CPI}_{\mathrm{H}}\right)^{\text {ETARA }_{\mathrm{H}}}$ * $\left(\Sigma_{\mathrm{G}} \mathrm{TP}_{\mathrm{H}, \mathrm{G}} / \mathrm{CPI}_{\mathrm{H}}\right) /\left(\Sigma_{\mathrm{G}} \mathrm{TP}_{\mathrm{H}, \mathrm{G}} / \mathrm{CPI} 0_{\mathrm{H}}\right){ }^{\mathrm{ETAPT}_{\mathrm{H}}} *\left(\left(\Sigma_{\mathrm{GI}} \mathrm{PIT}_{\mathrm{GI}, \mathrm{H}} \mathrm{HH}_{\mathrm{H}}+\Sigma_{\mathrm{G}} \mathrm{TAUH} 0\right.\right.$ $\left.\left.\mathrm{HH}_{\mathrm{H}}\right) /\left(\Sigma_{\mathrm{GI}} \mathrm{PIT}_{\mathrm{GI}, \mathrm{H}} \mathrm{HH}_{\mathrm{H}}+\Sigma_{\mathrm{G}} \mathrm{TAUH}_{\mathrm{G}, \mathrm{H}} \mathrm{HH}_{\mathrm{H}}\right)\right)^{\mathrm{ETAPIT}_{\mathrm{H}}}$

\section{Government}

$$
\left.\mathrm{LAS}_{\mathrm{LA}, \mathrm{I}}=\mathrm{LAS0}_{\mathrm{LA}, \mathrm{I}}\left(\mathrm{R}_{\mathrm{LA}, \mathrm{I}}\right) / \mathrm{R}_{\mathrm{LA}, \mathrm{I}}\right)^{\mathrm{ETAL}} \mathrm{LA}, \mathrm{I}_{(}\left(\mathrm{DS}_{\mathrm{I}} / \mathrm{DS}_{\mathrm{I}}\right)^{\mathrm{ETAL} 1}{ }_{\mathrm{LA}, \mathrm{I}}
$$

$\mathrm{HH}_{\mathrm{H}}=\mathrm{HHOH}_{\mathrm{H}} \mathrm{NRPG}_{\mathrm{H}}+\mathrm{MIOH}_{\mathrm{H}}\left(\mathrm{YD}_{\mathrm{H}} / \mathrm{HH}_{\mathrm{H}} /\left(\mathrm{YDO}_{\mathrm{H}} / \mathrm{HHO}_{\mathrm{H}}\right) /\left(\mathrm{CPI}_{\mathrm{H}} / \mathrm{CPI} 0_{\mathrm{H}}\right)\right)$ $\operatorname{ETAYD}_{\mathrm{H}}\left(\mathrm{HN}_{\mathrm{H}} / \mathrm{HH}_{\mathrm{H}} /\left(\mathrm{HNO}_{\mathrm{H}} / \mathrm{HHO}_{\mathrm{H}}\right) \mathrm{ETAU}_{\mathrm{H}}-\mathrm{MOO}_{\mathrm{H}}\left(\mathrm{YDO}_{\mathrm{H}} / \mathrm{HHO} \mathrm{H}_{\mathrm{H}}\right) /\left(\mathrm{YD}_{\mathrm{H}} / \mathrm{HH}_{\mathrm{H}}\right) /\right.$ $\left.\left(\mathrm{CPI} 0_{\mathrm{H}} / \mathrm{CPI}_{\mathrm{H}}\right)\right)^{\mathrm{ETAYD}}\left(\mathrm{HNO}_{\mathrm{H}} / \mathrm{HHO}_{\mathrm{H}}\right) /\left(\mathrm{HN}_{\mathrm{H}} / \mathrm{HH}_{\mathrm{H}}\right)^{\mathrm{ETAU}_{\mathrm{H}}}$

$$
\mathrm{HN}_{\mathrm{H}}=\mathrm{HH}_{\mathrm{H}}-\mathrm{HW}_{\mathrm{H}}
$$

$$
\begin{aligned}
& \mathrm{Y}_{\mathrm{GX}}=\Sigma_{\mathrm{I}} \mathrm{TAUV}_{\mathrm{GX}, \mathrm{I}} \mathrm{V}(\mathrm{I}) \mathrm{P}_{\mathrm{I}}+\Sigma_{\mathrm{I}} \mathrm{TAUX}_{\mathrm{GX}, \mathrm{I}} \mathrm{CX}_{\mathrm{I}} \mathrm{PD}_{\mathrm{I}}+\Sigma_{\mathrm{I}} \mathrm{TAUM}_{\mathrm{GX}, \mathrm{I}} * \mathrm{M}_{\mathrm{I}} \\
& \mathrm{PWM}_{\mathrm{I}}+\Sigma_{\mathrm{H}, \mathrm{I}} \mathrm{TAUC}_{\mathrm{GX}, \mathrm{I}} \mathrm{CH}_{\mathrm{I}, \mathrm{H}} * \mathrm{P}_{\mathrm{I}}+\Sigma_{\mathrm{I}} \mathrm{TAUN} \mathrm{NXX}_{\mathrm{I}, \mathrm{I}} \mathrm{CN}_{\mathrm{I}} \mathrm{P}_{\mathrm{I}}+\Sigma_{\mathrm{GN}, \mathrm{I}} \mathrm{TAUG}_{\mathrm{GX}, \mathrm{I}} \\
& \mathrm{CG}_{\mathrm{I}, \mathrm{GN}} \mathrm{P}_{\mathrm{I}}+\Sigma_{\mathrm{F}, \mathrm{I}} \mathrm{TAUFX}_{\mathrm{GX}, \mathrm{F}, \mathrm{I}} \mathrm{RA}_{\mathrm{F}} \mathrm{R}_{\mathrm{F}, \mathrm{I}} \mathrm{FD}_{\mathrm{F}, \mathrm{I}}+\Sigma_{\mathrm{F}, \mathrm{GN}} \mathrm{TAUFX}_{\mathrm{GX}, \mathrm{F}, \mathrm{GN}} \mathrm{RA}_{\mathrm{F}} \mathrm{R}_{\mathrm{F}, \mathrm{GN}} \\
& \mathrm{FD}_{\mathrm{F}, \mathrm{GN}}+\Sigma_{\mathrm{L}} \mathrm{TAUFH}_{\mathrm{GX}, \mathrm{L}} \mathrm{Y}_{\mathrm{L}}+\Sigma_{\mathrm{K}} \mathrm{TAUFH}_{\mathrm{GX}, \mathrm{K}} \mathrm{Y}_{\mathrm{K}}+\Sigma_{\mathrm{LA}} \mathrm{TAUHH}_{\mathrm{GX}, \mathrm{LA}} \mathrm{Y}_{\mathrm{LA}}+\Sigma_{\mathrm{H}} \\
& \mathrm{PIT}_{\mathrm{GX}, \mathrm{H}} \mathrm{HH}_{\mathrm{H}}+\Sigma_{\mathrm{H}} \mathrm{TAUH}_{\mathrm{GX}, \mathrm{H}} \mathrm{HH}_{\mathrm{H}}+\Sigma_{\mathrm{GX} 1} \mathrm{IGT}_{\mathrm{GX}, \mathrm{GX} 1} \\
& \text { (26) } \quad \mathrm{P}_{\mathrm{I}}\left(1+\Sigma_{\mathrm{GS}} \mathrm{TAUG}_{\mathrm{GS}, \mathrm{I}}\right) \mathrm{CG}_{\mathrm{I}, \mathrm{GN}}=\mathrm{AG}_{\mathrm{I}, \mathrm{GN}}\left(\mathrm{Y}_{\mathrm{GN}}+\mathrm{GVFOR}_{\mathrm{GN}}\right)
\end{aligned}
$$

$$
\Sigma_{\mathrm{H}} \mathrm{HW}_{\mathrm{H}} \mathrm{JOBCOR}_{\mathrm{H}, \mathrm{L}}=\Sigma_{\mathrm{Z}} \mathrm{FD}_{\mathrm{L}, \mathrm{Z}}
$$

$$
\begin{aligned}
& \mathrm{KS}_{\mathrm{K}, \mathrm{IG}}=\mathrm{FD}_{\mathrm{K}, \mathrm{IG}} \\
& \mathrm{LAS}_{\mathrm{LA}, \mathrm{IG}}=\mathrm{FD}_{\mathrm{LA}, \mathrm{IG}} \\
& \mathrm{DS}_{\mathrm{I}}=\mathrm{DD}_{\mathrm{I}}+\mathrm{CX}_{\mathrm{I}}-\mathrm{M}_{\mathrm{I}} \\
& \mathrm{DD}_{\mathrm{I}}=\mathrm{V}_{\mathrm{I}}+\Sigma_{\mathrm{H}} \mathrm{CH}_{\mathrm{I}, \mathrm{H}}+\Sigma_{\mathrm{G}} \mathrm{CG}_{\mathrm{I}, \mathrm{G}}+\mathrm{CN}_{\mathrm{I}}
\end{aligned}
$$




\section{Indices}

\begin{tabular}{|c|c|}
\hline I & private sector \\
\hline IG & private sectors and local government services \\
\hline $\mathrm{F}$ & factors (L1, L2, L3, L4, and L5 KAP and Land) \\
\hline $\mathrm{L}$ & $\mathrm{L} 1, \mathrm{~L} 2, \mathrm{~L} 3, \mathrm{~L} 4$, and $\mathrm{L} 5$ \\
\hline $\mathrm{H}$ & HH1, HH2, HH3, HH4, НH5, HH6, and HH7 \\
\hline G & all governments \\
\hline GN, GS, GX & different tax combinations \\
\hline \multicolumn{2}{|c|}{ Variable Descriptions } \\
\hline $\mathrm{CG}_{\mathrm{I}, \mathrm{G}}$ & local government consumption \\
\hline $\mathrm{CH}_{\mathrm{I}, \mathrm{H}}$ & household consumption \\
\hline $\mathrm{CN}_{\mathrm{I}}$ & investment by sector of source \\
\hline $\mathrm{CPI}_{\mathrm{H}}$ & consumer price index across households \\
\hline $\mathrm{CX}_{\mathrm{I}}$ & export demand \\
\hline $\mathrm{D}_{\mathrm{I}}$ & domestic supply share of domestic demand \\
\hline $\mathrm{DD}_{\mathrm{I}}$ & domestic demand \\
\hline $\mathrm{DS}_{\mathrm{I}}$ & domestic supply \\
\hline $\mathrm{FD}_{\mathrm{F}, \mathrm{Z}}$ & factor demand \\
\hline $\mathrm{IGT}_{\mathrm{G}, \mathrm{GX}}$ & intergovernmental transfers \\
\hline $\mathrm{KS}_{\mathrm{K}, \mathrm{IG}}$ & capital stock \\
\hline $\mathrm{LAS}_{\mathrm{LA}, \mathrm{IG}}$ & stock of land in acres \\
\hline $\mathrm{HH}_{\mathrm{H}}$ & total number of households \\
\hline $\mathrm{HN}_{\mathrm{H}}$ & number of nonworking households \\
\hline $\mathrm{HW}_{\mathrm{H}}$ & number of working households \\
\hline $\mathrm{M}_{\mathrm{I}}$ & imports \\
\hline $\mathrm{N}_{\mathrm{K}, I \mathrm{I}}$ & gross investment by sector \\
\hline NKI & nominal net capital outflow \\
\hline $\mathrm{KPFOR}_{\mathrm{K}}$ & nominal capital outflow \\
\hline $\mathrm{LNFOR0}_{\mathrm{LA}}$ & nominal land outflow \\
\hline GVFOR $0_{\mathrm{G}}$ & nominal government outflow \\
\hline $\mathrm{P}_{\mathrm{IG}}$ & aggregate prices paid by sectors \\
\hline $\mathrm{PD}_{\mathrm{I}}$ & domestic prices \\
\hline $\mathrm{PVA}_{\mathrm{I}}$ & value added prices \\
\hline $\mathrm{PWO}_{\mathrm{I}}$ & export prices (demand shifter for export demand) \\
\hline PWM0I & import prices \\
\hline $\mathrm{R}_{\mathrm{F}, \mathrm{Z}}$ & initial sector rental rate for factors \\
\hline $\mathrm{RA}_{\mathrm{F}}$ & average rental rate for factors \\
\hline $\mathrm{S}_{\mathrm{H}}$ & savings \\
\hline SPI & total personal income \\
\hline $\mathrm{V}_{\mathrm{I}}$ & intermediate demand \\
\hline $\mathrm{TP}_{\mathrm{H}, \mathrm{G}}$ & social security payments \\
\hline $\mathrm{YD}_{\mathrm{H}}$ & disposable household income \\
\hline $\mathrm{Y}_{\mathrm{H}}$ & gross household income \\
\hline \multicolumn{2}{|l|}{ Tax Rates } \\
\hline TAUQ $_{\mathrm{GS}, \mathrm{I}}$ & all tax rates \\
\hline
\end{tabular}


TAUC $_{\mathrm{GS}, \mathrm{I}}$

TAUM $_{\mathrm{GS}, \mathrm{I}}$

TAUX $_{\mathrm{GS}, \mathrm{I}}$

TAUFX $_{\mathrm{GF}, \mathrm{F}, \mathrm{Z}}$

TAUFH ${ }_{G X, L A}$

TAUFH $_{\mathrm{GX}, \mathrm{K}}$

TAUH $_{\mathrm{GX}, \mathrm{H}}$

TAUV $_{\mathrm{GS}, \mathrm{I}}$

TAUN $_{\mathrm{GS}, I}$

TAUG $_{\mathrm{GS}, \mathrm{I}}$

\section{Parameters}

BETA $_{\mathrm{I}, \mathrm{H}}$

LAMBDA $_{J, I}$

DELTA $_{\mathrm{I}}$

ALPHA $_{F, I}$

ETAE I $_{I}$

ETADI $_{\text {I }}$

ETAIX $_{K, I}$

ETAIX1K,I

ETARA $_{H}$

ETAPT $_{\mathrm{H}}$

ECOMOL $_{L}$

ECOMI $_{\mathrm{L}}$

ETAL $_{\text {LA,I }}$

ETAL1 LA,I

ETAYD $_{H}$

ETAU $_{H}$

$\mathrm{MIOH}_{\mathrm{H}}$

$\mathrm{MOO}_{\mathrm{H}}$

$\mathrm{NRPG}_{\mathrm{H}}$ sales tax rates and other local tax rates

use tax rates

export taxes

labor taxes

taxes on land

taxes on capital

personal income tax rates

taxes on intermediate goods

taxes on investment goods

federal taxes

income elasticity for demand

price elasticity

scale parameter for the production functions

relative share of factors

elasticity for export demand

import supply elasticity

price for investment

domestic supply elasticities for investment

labor supply elasticities for households

elasticity of labor supply with respect to households

elasticity of commuting out with respect to relative wages - set equal to zero

elasticity of commuting in with respect to relative wages- set equal to

zero

elasticity of land supply with respect to rates of return

elasticity of land supply with respect to domestic supply

elasticity of migration with respect to real household income

elasticity of migration with respect to the ratio of nonworking household to total households

rate of in-migration

rate of out-migration

natural rate of population growth 